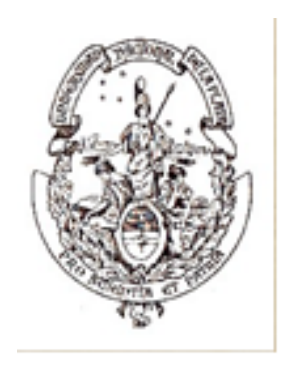

Universidad Nacional de La Plata

Facultad de Humanidades y CienCias de la EduCaCión

SeCretaría de Posgrado

\title{
Representaciones en torno a los marginales durante el Siglo de Oro Español
}

Tesis para optar por el grado de Doctora en Historia

Doctoranda: Prof. Ana Inés Rodríguez Giles

Directora: Dra. María Inés Carzolio

Codirector: Dr. Carlos Alberto Astarita

La Plata, 27 de septiembre de 2013 


\section{Resumen:}

La presente tesis tiene como objetivo analizar las representaciones sobre la marginalidad durante el Siglo de Oro Español, comparando los textos literarios y normativos. Nos referimos a la marginalidad que vivieron los hombres que eran subproductores y subconsumidores y no tenían vínculos estables con las redes que encuadraban a los actores sociales. Estas personas fueron criminalizadas progresivamente a partir del siglo XIV. Desde el siglo XVI la novela picaresca se ocupó centralmente de su existencia, mientras se discutía también acerca de sus derechos, conflicto que encontramos en los debates teológicos. Examinaremos cuáles fueron las fronteras de la marginalidad, atendiendo a la diferencia entre el sector de los vagabundos y otros grupos más o menos segregados; rastrearemos cómo fue la percepción sobre los marginales expuesta en los textos normativos que tenían como fin la penalización y, paralelamente, analizaremos la descripción literaria, que presenta diversos grados de condena ética acerca de ellos; indagaremos sobre las prácticas de la microsociedad marginal, representadas en la literatura $\mathrm{y}$, por último, observaremos sus relaciones con la sociedad mayoritaria, detectables en diversos documentos. Esta investigación permitirá apreciar el alcance de la literatura como documento social, ver las causas de la criminalidad según la mirada de los contemporáneos y relevar la capacidad de adaptación y conductas de los marginales.

Palabras Clave: Marginalidad - Picaresca - Representación - España - Siglo de Oro 


\section{ÍNDICE}

INTRODUCCIÓN

$\begin{array}{ll}\text { CAPÍTULO } 1 & 13\end{array}$

$\begin{array}{ll}\text { INTRODUCCIÓN } & 14\end{array}$

$\begin{array}{ll}\text { LOS MARGINALES EN LA EUROPA MODERNA } & 15\end{array}$

$\begin{array}{ll}\text { EL ENCUADRAMIENTO DEL MARGEN SOCIAL } & 27\end{array}$

\begin{tabular}{ll}
\hline LA SANCIÓN DE LA MARGINALIDAD & 34
\end{tabular}

\begin{tabular}{ll}
\hline CONCLUSIÓN & 38
\end{tabular}

$\begin{array}{ll}\text { CAPÍTULO } 2 & 40\end{array}$

INTRODUCCIÓN

LA ELECCIÓN DE LAS FUENTES

$\begin{array}{ll}\text { A-LA PICARESCA } & 47\end{array}$

\begin{tabular}{ll} 
A-1. LOS PÍCAROS & 47 \\
\hline$A-2$. EL GENERO & 52
\end{tabular}

A-2. EL GÉNERO

A-3. EL CONTEXTO

\begin{tabular}{ll} 
A-4. LOS AUTORES & 62 \\
\hline A-5. ELPUBELCO & 68
\end{tabular}

$\begin{array}{ll}\text { A }-5 . \text { EL PÚBLICO } & 68\end{array}$

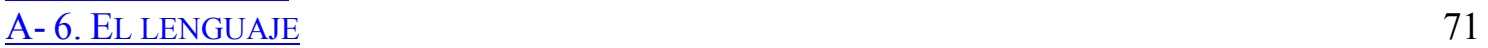

B - LAS CORTES

B-1. LAS PETICIONES EN TORNO A LOS HOMBRES BALDÍOS EN SU CONTEXTO

B-2. LAS CORTES, EL REY, LAS CIUDADES Y LOS PROCURADORES

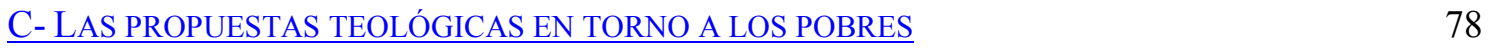

CONCLUSIÓN 83

CAPÍTULO 3

$\begin{array}{ll}\text { INTRODUCCIÓN } & 87\end{array}$

IDENTIFICACIÓN DEL HOMBRE BALDÍO

$\begin{array}{lr}\text { LAS PENAS } & 95\end{array}$

MOVILIDADES Y REPRESENTACIONES 103

$\begin{array}{ll}\text { EL DESORDEN Y LA PROPAGACIÓN } & 117\end{array}$

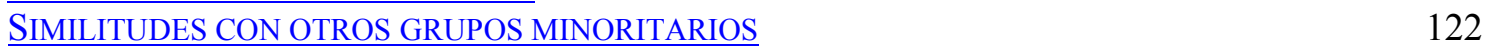

\begin{tabular}{ll}
\hline CONCLUSIÓN & 124
\end{tabular}

$\begin{array}{lr}\text { CAPÍTULO } 4 & 128\end{array}$

$\begin{array}{lr}\text { INTRODUCCIÓN } & 129\end{array}$

$\begin{array}{lr}\text { LA POSESIÓN DE CRIADOS COMO CAPITAL SOCIAL } & 130\end{array}$

\begin{tabular}{ll}
\hline LA CONTRATACIÓN & 137
\end{tabular}

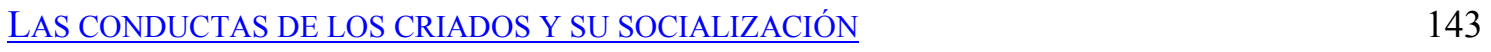

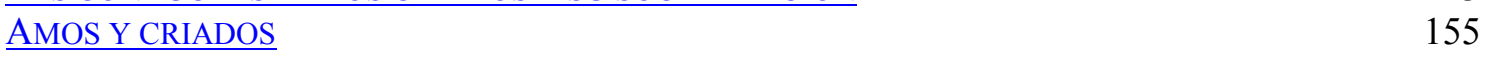

\begin{tabular}{lr}
\hline EL FINAL DEL SERVICIO & 171
\end{tabular}

\begin{tabular}{ll}
\hline CONCLUSIÓN & 174
\end{tabular}

$\begin{array}{ll}\text { CAPÍTULO 5 } & 177\end{array}$ 
$\begin{array}{lr}\text { INTRODUCCIÓN } & 178\end{array}$

$\begin{array}{lr}\text { EL TEATRO DEL MENDIGO } & 180\end{array}$

$\begin{array}{lc}\text { LA INCAPACIDAD FÍSICA COMO PREMISA } & 184\end{array}$

$\begin{array}{lr}\text { EL PORDIOSEO Y LA CREENCIA CRISTIANA } & 188\end{array}$

$\begin{array}{ll}\text { EL MENDIGO, EL DELINCUENTE } & 197\end{array}$

LA PROPAGACIÓN DE LOS MENDIGOS Y SU SOCIABILIDAD 200

LA PERSECUCIÓN Y EL CASTIGO 205

\begin{tabular}{ll}
\hline LAS PÍCARAS Y LA MENDICIDAD & 208 \\
\hline
\end{tabular}

$\begin{array}{lr}\text { CONCLUSIÓN } & 210\end{array}$

$\begin{array}{ll}\text { CAPÍTULO 6 } & 213\end{array}$

$\begin{array}{lr}\text { INTRODUCCIÓN } & 214\end{array}$

\begin{tabular}{ll}
\hline EL LENGUAJE & 214
\end{tabular}

\begin{tabular}{ll}
\hline LAMOVILIDAD & 221
\end{tabular}

$\begin{array}{ll}\text { LOS VÍNCULOS Y LA REPRODUCCIÓN DEL SECTOR MARGINAL } & 237\end{array}$

LACONSTRUCCIÓN DEL VAGABUNDO 248

CONCLUSIÓN 256

$\begin{array}{ll}\text { CONCLUSIONES GENERALES } & 258\end{array}$

$\begin{array}{ll}\text { BIBLIOGRAFÍA } & 266\end{array}$ 


\section{INTRODUCCIÓN}

La observación de problemas del presente nos conduce a indagar sobre conflictos semejantes en el pasado con la aspiración de comprender y explicar, pesquisa a la cual el oficio de historiadores nos convoca y obliga. Problemas referentes a la diversidad social, a los límites a las aspiraciones de masas de hombres y a la intolerancia que se desprenden de la desigualdad, han guiado esta tesis, en la cual hemos trabajado durante los últimos cinco años con la financiación de dos becas de Posgrado del CONICET. Nuestra mirada parte de una región que presenta numerosas problemáticas en torno a la segregación social, para cuestionarnos acerca de aquellos sujetos que históricamente han sido considerados como una anomalía, culpabilizados de variados problemas por quienes sí están plenamente integrados en el sistema social. Sin embargo, los marginales son producto de -y funcionales a- la dinámica socioeconómica.

En el presente, la marginalidad es un fantasma amenazador para las clases medias, que en su posición de inseguridad como tales, siempre temen caer de su estado, el cual defienden a partir de valores compartidos por personas que pertenecen a la misma clase y que reivindican esta posición, además del orden en el que se inscribe. Los segregados por la sociedad funcionan entonces como un espejo donde los miembros de aquel sector no quieren verse reflejados. De esta manera, los primeros aparecen como culpables paradigmáticos de los males que amenazan a los últimos. La marginalidad es considerada a veces con morbosidad: las páginas policiales y la prensa amarilla -que en los últimos años se ha propagado también en la televisión- están plagadas de historias que muestran, con risa y horror, un abanico compuesto por personas malformadas, enfermas o adictas, prostitutas, locos, ladrones o mendigos. Este tipo de figuras no son una novedad, sino que podemos encontrarlas en la imaginación colectiva a lo largo de los siglos.

Una pequeña parte de este tipo de imágenes constituye el tema de nuestra tesis, que pretende contribuir a la reflexión acerca de los retratos que los hombres integrados socialmente hacen, con hostilidad y temor, acerca de aquellos que no compartieron su suerte. Esta investigación indaga sobre las representaciones de los marginales en España durante la Baja Edad Media y temprana modernidad: se analizarán las diversas concepciones sociales acerca de los hombres que se encontraban fuera de las estructuras regulares de reproducción de la sociedad entre los siglos XIV y XVII, mostrando las distintas ópticas que, desde la literatura, los debates teológico-filosóficos y la 
normativa, describen la dinámica de la representación de este sector, en correspondencia con los cambios sociales e ideológicos.

Indagaremos acerca del devenir de la marginalización social desde la segunda mitad del siglo XIV, cuando comenzó un fuerte movimiento de penalización de los hombres que quedaban fuera de las redes sociales, hasta la primera mitad del siglo XVII, cuando se publicaron las piezas fundamentales de la novela picaresca española, género literario que, a través de las ficciones autobiográficas de sujetos marginales, ilustra varios aspectos de la existencia de su grupo cultural ${ }^{1}$. El período a estudiar está enmarcado por la emisión de discursos legislativos, literarios y teóricos que tuvo lugar a partir de la observación del proceso de criminalización aludido, frente al cual se plantearon diferentes modos de considerarlo.

Abordaremos las representaciones de la marginalidad a partir de la comparación de diversas clases de fuentes. Consideramos necesario estudiar la caracterización realizada en la novela picaresca -género literario paradigmático del contexto que analizamos-, desde una nueva óptica que retome los problemas teóricos sobre el encuadramiento de los marginales a partir de las categorías aportadas por la sociología y la antropología. De este modo, no sólo contribuiremos al estudio de la historia cultural a partir del análisis de las formas de representación, sino que pretendemos que nuestro trabajo colabore al esclarecimiento del concepto de marginalidad con el objeto de incidir sobre su operatividad. Conflictos teóricos y prácticos en torno a la caracterización del fenómeno de la marginación en el pasado y en el presente demuestran que este tema merece especial atención.

El objeto de nuestro estudio se enmarca en el contexto europeo de la temprana modernidad. En este período encontramos el inicio de una política explícita de criminalización y persecución de los marginales, dinámica que podemos explicar por la necesidad de someter a quienes habían sido desplazados de los sistemas tradicionales de dominación o que se resistían a ser encuadrados en ellos. El tratamiento del problema que generaba la existencia de marginales, a través de los dos polos de la asistencia y la represión marca los posibles modelos puestos en práctica en adelante -de manera conjunta o alternativamente-, para darle solución.

\footnotetext{
${ }^{1}$ El recorte temporal de esta tesis se basa en los postulados de J. Le Goff, quien sostiene la vigencia de una larga Edad Media que se extiende hasta el fin del Antiguo Régimen. Jacques Le Goff, Una larga edad media. Barcelona, Paidós, 2008.
} 
La modernidad temprana resulta de especial interés para el estudio de este conflicto, debido a la posibilidad de analizar, a través de fuentes cualitativamente distintas que fueron producidas entonces, los ensayos realizados para la erradicación de los sujetos no ordenados en el marco de la sociedad antiguorregimental. En este período, la urbanización y la consiguiente aparición de hombres desarraigados en las ciudades -quienes eran observados como una anomalía del sistema que en realidad los producía como parte de su propia dinámica- generaron turbulencias en el aparato teórico.

Las representaciones acerca de los marginales informan sobre su relación con el cuerpo social y la actitud de este último frente a aquéllos. Por otra parte, el análisis de la picaresca nos permite examinar también cuestiones que no se hacen explícitas en las fuentes cuyo discurso tenía como objetivo la regulación, como así también observar contradicciones entre diversas clases de escritos.

El marco social de la temprana modernidad hispánica dio lugar al surgimiento del pícaro, personaje literario paradigmático durante este período. Se trataba de un estereotipo, a los ojos de los literatos y su público, generado a partir de la observación de diferentes individuos provenientes de un sector marginal. Estudiaremos a este personaje tomando como eje vertebrador del análisis la noción de su marginalidad y cotejaremos los caracteres de su representación en el aparato normativo y en la novela picaresca.

Nuestra tesis cuenta con hipótesis que dan lugar al despliegue de otros problemas enmarcados en ellas y que, analizados conjuntamente, contribuirán a su demostración. Estos conflictos serán examinados separadamente en capítulos que abordarán los contenidos de las fuentes de manera comparada. Los interrogantes que guían este estudio son los siguientes:

¿Qué denominamos con la categoría de marginalidad? ¿Quiénes son los marginales, según las diversas representaciones?

En primer lugar nos encontramos con la necesidad de definir la marginalidad, problema central que resolveremos antes de avanzar sobre su representación. En este marco debemos precisar sus fronteras, dificultad que obstaculiza y a la vez constituye su categorización, ya que ella misma es un margen. Esta noción refiere a un fenómeno difundido a lo largo de la historia y, en tanto homogeneiza diversos sectores más o menos segregados, convoca una discusión siempre abierta y actual para los historiadores y especialistas en ciencias sociales. El estudio del concepto cobró relevancia a lo largo 
de los últimos cincuenta años, a lo largo de los cuales su empleo e interpretación sufrieron un proceso de ampliación que ha llevado a la necesidad de revisarlo, pero fundamentalmente de precisarlo.

Debemos tener en cuenta que se trata de un fenómeno multicausal, multidimensional y procesual y contemplar los mecanismos por los que ciertas personas o determinados colectivos quedan al margen de la participación plena en la vida social. Todas las sociedades generan marginados de una $\mathrm{u}$ otra manera. Nosotros nos concentraremos en la temprana modernidad europea, cuando diversos y numerosos sujetos fueron más intensamente segregados que en los siglos anteriores por distintos motivos (religiosos, étnicos, socio-económicos, etc.). Este fenómeno ha generado un problema a los historiadores, quienes muchas veces lo han abordado de manera conjunta, confundiendo categorías que hoy implican marginalidad, pero que entonces no lo hacían necesariamente, pues este último concepto es más amplio que todos aquéllos con los cuales se asocia. Estos problemas teóricos e historiográficos en torno a la noción de marginalidad serán revisados en el capítulo primero.

Propondremos como primera hipótesis considerar a los marginales en el contexto que estudiamos, como producto de la dinámica social que los necesita tanto como los rechaza, y que se materializa en estos agentes como resultado de la conjunción de diversos factores: su marginalidad está determinada por una inserción intermitente en el mercado laboral así como en su participación inestable en el consumo, pero a eso se suma que son itinerantes y sus prácticas rechazan muchas de las normas éticas por las cuales se rige la sociedad. Esta imagen se puede sintetizar en la del vagabundo, que sólo temporalmente puede insertarse socialmente o domiciliarse en un lugar. Consideramos a los marginales de este modo, ya que no se trata de minorías religiosas ni étnicas, ni su persecución es esencialmente política o consecuencia de conductas condenadas, sino que en su marginalidad es central el conflicto socioeconómico, al cual los socialmente integrados pueden agregar muchos otros para concluir con su condena.

Una vez delimitado el problema de la definición de la marginalidad, podemos avanzar sobre otras hipótesis de nuestro trabajo. La forma en que fueron representados los marginales da cuenta del cambio de discursos de la élite, que acompañó la dinámica política en su búsqueda de apuntalar cuestiones sociales que escapaban al control del sistema económico. Intentaremos explicar por qué las manifestaciones de los literatos respecto a este fenómeno se intensifican durante el siglo XVI, paralelamente al cambio de objetivos en las normativas que, además de postular la obligación de los hombres a 
trabajar, regulan la asistencia. Examinaremos este conflicto a partir de la comparación entre los discursos sobre esta problemática mediante la vinculación de textos normativos, concepciones teóricas y, especialmente, escritos de ficción teniendo en cuenta que todas son formas de representación, en nuestro caso, de la marginalidad.

Si bien estos problemas serán abordados en varios apartados, el capítulo segundo versará específicamente sobre la representación de la realidad social en la literatura picaresca y las condiciones de su emergencia. En este contexto evaluaremos cuáles fueron las formas de representar a los mendigos por parte de algunos autores, considerando asimismo a qué tipo de público se dirigían estas novelas, las limitaciones impuestas por el género y la adscripción social del literato, la cual condiciona su percepción del problema. Así podremos comparar el ideario que se atribuye al pícaro o marginal con lo que pretende prohibirles la normativa, en un trabajo que otorga relevancia a las fuentes literarias que, si no dan cuenta taxativamente de la realidad, sí pueden testimoniar acerca de su representación $\mathrm{y}$, por consiguiente, del conjunto de nociones socialmente compartido, pues se trata de textos que suponen la introducción de factores externos para generar sentido.

La literatura posee su propia imagen de la inserción de los marginales en la dinámica social. Esto resulta un desafío para el tratamiento particular y complejo de este tipo de fuentes. En nuestro estudio examinaremos este discurso como una vía de acercamiento al sector marginal que causaba temores por su modo de vida y que era criminalizado dentro de una sociedad que se imaginaba a sí misma como estática, aunque atravesaba un período de intenso cambio económico y social. Los estudiosos de la narrativa se han detenido extensamente sobre los conflictos representados en la novela picaresca, pero se limitaron a examinar los problemas internos de su disciplina y, subsidiariamente, indagaron sobre las cuestiones socioculturales que, si bien cobraron relevancia durante la década de 1980, fueron luego abandonadas, postergando la necesidad de un análisis histórico que la crítica literaria realizó en forma deficiente. En tanto se trata de representaciones de la sociedad producidas por diversos literatos, no consideraremos lo que es planteado en las novelas como un reflejo de la dinámica social del período sino como propuestas de interpretación verosímiles o concebibles para y por los contemporáneos. Compararemos las condiciones de producción de la picaresca con las que dieron lugar a la normativa emanada de las Cortes, antes de adentrarnos en el análisis de este tipo de fuentes. Por último, en el segundo capítulo veremos problemas referentes a los debates teológico-filosóficos en torno a los pobres que tuvieron lugar 
durante el siglo XVI, considerándolos como parte del condicionamiento ideológico en la producción picaresca.

En el capítulo tercero evaluaremos la estigmatización de los marginales a través de las peticiones y los ordenamientos de las Cortes, teniendo en cuenta también los siglos previos a la narrativa de pícaros, desde que se advirtió el problema del aumento del vagabundeo. En estos documentos podemos observar la penalización de las conductas de los marginales. El peligro que representaban cobró forma en el pensamiento político, pues en tanto que los mendigos no cumplieran con la obligación de comportarse como gobernados en las funciones sociales que se atribuían a los hombres en tanto miembros de distintos grupos que conformaban la sociedad, amenazarían su estabilidad. La normativa no se explaya sobre el modo de vida de estos individuos y debemos acercarnos a ellos leyendo las regulaciones acerca de diversas actividades en las cuales intervenían. Por otro lado, las acusaciones que caían sobre ellos estaban orientadas a regular su existencia en beneficio de los sectores económicos y sociales de los cuales partían dichas imputaciones -oligarquías urbanas, noblezas y monarquía-, tal como observaremos en el capítulo tercero. Las leyes de pobres constituyen importantes documentos que nos informan sobre el modo en que la élite social consideraba a los marginales, así como acerca de los argumentos que aquellos grupos esgrimían para justificar el rechazo hacia ellos. Finalmente, a partir de esta consideración, compararemos la forma que cobró la estigmatización de estos sujetos con las que recaían sobre otros grupos segregados, que no compartían, sin embargo, los mismos caracteres en la realidad.

Examinaremos, a través de la lectura de las distintas fuentes, cuál fue la incidencia de la participación de estos hombres en la estructura social. Las atribuciones que se les hacen en la documentación de Cortes serán contrastadas con las que encontramos en las novelas. En el capítulo cuarto analizaremos si, según los textos literarios, fueron rechazados sistemática y unánimemente o si al menos una parte de la sociedad les hallaba una funcionalidad para diversas labores subsidiarias que podrían realizar temporalmente e integrarlos de manera intermitente. Estudiaremos la representación literaria de las conductas y actividades de los marginales, así como las estrategias que ponían en práctica para sobrevivir, tal como fueron descriptas en las novelas picarescas, pero veremos asimismo cuáles eran los grupos que se relacionaban con los marginales, cómo lo hacían y cómo contribuían a la permanencia de estos hombres en su estado. 
Las últimas hipótesis que plantea esta tesis giran en torno a cómo era la sociabilidad de los marginales. Consideramos que la relación entre estos sujetos y otros miembros del cuerpo social resultaría necesaria para ambos sectores. Este lazo estaba teñido por la imposibilidad de aquéllos para generar vínculos sólidos y permanentes con los otros segmentos de la sociedad, cuyo excedente les permitía sobrevivir magramente.

Los lazos entre los marginales y la comunidad con la que conviven nos conducen a otros dos interrogantes que saldaremos con nuestro estudio. A partir del análisis de las obras literarias comprobaremos que la aspiración a erradicar a los marginales se vio frustrada fundamentalmente por dos motivos: su habilidad para evadir la ley hacía inocuas las normas basadas en la suposición de la estabilidad de las personas, pues la flexibilidad de estos hombres para cambiar de ambiente y adaptarse a diversas situaciones les facilitaba la continuidad en una vida que contrariaba las reglas sociales; en segundo término, la sociedad despreciaba a estos sujetos, que no vivían de acuerdo con sus reglas pero la tolerancia relativa hacia ellos les permitía subsistir, de la misma manera en que fecundaba los sentimientos de piedad y rechazo de forma simultánea y contradictoria.

De esta manera, es necesario analizar el vínculo entre los marginales y el entramado social, que aparece en la literatura en una relación ambigua, exponiendo una cercanía física alterada por las diferencias culturales de su microsociedad. Por otro lado, cuando analizamos la legislación, encontramos que, si las conductas de los marginales son condenadas, también lo es la complicidad con ellos de los hombres integrados socialmente -testificada por la literatura-, lo que podría avalar nuestra hipótesis sobre la fluidez de los contactos e intercambios entre los miembros de ambos sectores, que además resultan necesarios para la reproducción de los marginales. Veremos hasta qué punto los pícaros son rechazados por la sociedad mayoritaria, en tanto podemos observarlos sirviendo intermitentemente en la casa de un señor, enmarcándose en clientelas en las que se incluían periódicamente.

La imposibilidad de generar relaciones estables nos conduce a otra hipótesis: los marginales refractan entre ellos dicha forma de socialización, por ello no pueden mantener lazos permanentes entre pares, en contradicción con las sospechas por parte de variados discursos que suponían (y continúan haciéndolo) la asociación permanente de los marginales, generalmente con el objetivo de dañar de un modo u otro al cuerpo social. El análisis pormenorizado de las fuentes nos permitirá corroborar que, si bien los autores intentan exponer esta lógica, se desprende de sus propios escritos la relatividad 
de esta proposición. Se trata de marginales que aparecen como parte de la configuración de la sociedad tradicional y su sistema de representaciones.

Estos conflictos serán analizados a lo largo de tres capítulos. En el cuarto veremos cómo se insertan periódicamente en diversas actividades de servicio. Luego de examinar dichas ocupaciones, el capítulo quinto estará dedicado al estudio de la mendicidad, actividad preponderante en las diversas representaciones de estos sujetos. Allí prestaremos especial atención a su funcionamiento en el marco de una comunidad cristiana que ha interiorizado la lógica reciprocitaria inherente a la teología de la salvación eterna, semántica religiosa que es retomada por los pícaros y de la cual se sirven. Finalmente, en el capítulo sexto observaremos, reanudando lo examinado en los anteriores, la forma en que se representa la reproducción social de los marginales -en relación con su carácter itinerante, sus vínculos y la lengua en que se expresan-, ligando este retrato con la intención de criminalizarlos.

Esperamos responder a las preguntas que nos hemos hecho antes de comenzar nuestro análisis, cuyo objeto radica en un tema que abre las puertas para la reflexión sobre cuestiones más amplias que lo sobrepasan, demostrando que los márgenes constituyen un conflicto central en la historiografía, en tanto lo son para la sociedad. 
CAPÍTULO 1

PROBLEMAS EN TORNO A LA MARGINALIDAD EN LA EUROPA MODERNA 


\section{Introducción}

La marginalidad presenta problemas teóricos, propios de un concepto que pretende definir aquello que, en tanto se encuentra en una situación fronteriza, evade la precisión. Cuando hablamos de márgenes pensamos en lugares que no se encasillan de manera definida ni en uno ni en otro sitio, sino que se mueven en un espacio difícilmente encuadrable. Esta categoría presenta dificultades en tres aspectos. En primer lugar, la propiedad del margen de no estar ni en un lugar ni en otro hace que los sujetos que atraviesan esta condición, lo hagan de manera fluctuante, pasando alternativamente por etapas de integración y de exclusión. En segundo término, la clasificación se impone por parte de quienes la observan y sancionan, de modo que la marginación puede ser analizada como un producto del discurso que la determina. Este aspecto presenta sus propias dificultades, pues dicha consideración puede variar, además de ser imprecisa. Por último, la intervención del investigador, también un sujeto social que piensa desde sus propios parámetros qué es el margen y que, partiendo de sus referencias teóricas, introduce su cuota de subjetividad.

La marginalidad ha suscitado múltiples propuestas entre los especialistas en ciencias sociales, que serán repasadas en este capítulo. Haremos especial referencia a cómo se presenta esta problemática para la historiografía bajomedieval y tempranomoderna, antes de entrar en el examen particular de la representación de los marginales en la novela picaresca en el Siglo de Oro y en el discurso político desde la Baja Edad Media, tema que nos ocupará a lo largo de esta tesis.

El estudio de los sectores marginales fue difundido a partir de la segunda mitad del siglo XX, cuando autores de diversas áreas de las ciencias sociales y la filosofía comenzaron a interrogarse acerca de los segregados por la sociedad. Los movimientos contestatarios en los países desarrollados o las revoluciones tercermundistas estimularon la investigación acerca de los sectores marginales por parte de los especialistas de diversas áreas. El avance epistemológico llevó al cuestionamiento de los instrumentos de estudio disponibles entonces para dar respuesta a un problema anteriormente no atendido. En el marco de la historiografia, el surgimiento de la escuela de Annales, con los estudios de sectores sociales hasta entonces no atendidos, fue la piedra de toque para el inicio de este tipo de indagaciones ${ }^{1}$.

\footnotetext{
${ }^{1}$ Ver Jean Claude Schmitt, "L'histoire des marginaux", en Le Goff, Jacques (dir.). La nouvelle histoire.
} 
Desde el materialismo histórico, K. Marx apuntó en su capítulo acerca de la acumulación originaria del capital, el vínculo entre la usurpación de los terrenos de dominio público, el desplazamiento de los campesinos, la producción de manufacturas y la persecución de los vagabundos, que eran castigados por situaciones de las cuales ellos eran víctimas y entre quienes encuentra a los padres de la clase obrera ${ }^{2}$.

Los marginales son designados de esta manera en el marco de una sociedad con una mayoría integrada y, especialmente, por parte de un discurso hegemónico que los define como tales. Por lo tanto, podemos decir que un motivo disparador del estudio de estos actores es su propia estigmatización, pues para que su existencia se constituya como un objeto de análisis debió ser considerada como "anormal"3. Veamos el fenómeno en el contexto que nos ocupa.

\section{Los marginales en la Europa moderna}

La marginalidad fue inherente a la dinámica feudal, que producía, a través de su propio funcionamiento, el empobrecimiento de sus productores, quienes a partir de dicha situación podían perder su status tributario y de este modo, sus atributos como miembros de la comunidad en la cual se inscribían. Esta forma de marginación de una fracción de los pobres surgió durante la Edad Media y tuvo una dinámica que condujo a que sufriera variaciones hasta llegar a la plena modernidad, las cuales provocaron que fuera cambiando su consideración social y la gravedad que se atribuía al fenómeno que constituían, dando lugar a su persecución, que comenzó jurídicamente durante el siglo XIV.

Los hombres que no pudieran mantenerse mediante su trabajo serían aceptados en el marco de la comunidad como "pobres de la aldea", tratándose en su mayoría de viudas, niños o viejos ${ }^{4}$. Estos indigentes que vivían mediante trabajos temporales así como gracias a la caridad eran además necesarios desde el punto de vista ideológico para una religión de salvación eterna que postulaba que lo que el rico otorgaba como limosna al pobre en vida, le sería retribuido en el plano celestial, tal como estudiaremos

\footnotetext{
París, CEPL, 1978, pp 344-369.

${ }^{2}$ Karl Marx, El capital. México, Fondo de Cultura Económica, 1984, p 625. Allí, los nombra además como "pícaros".

${ }^{3}$ Juan Villarreal, La exclusión social. Buenos Aires, Editorial Norma, 1996, p 19.

${ }^{4}$ Michel Mollat, Pobres y miserables en la Edad Media. México, Fondo de Cultura Económica, 1988, p 11 .
} 
detenidamente en el capítulo quinto. Sin embargo, a partir de la Baja Edad Media, la pobreza mostraría rasgos diferentes respecto a lo valorado hasta entonces: ahora se trataba de masas de hombres desarraigados que alarmaban debido a su frecuencia en el mundo urbano y a la dificultad para domiciliarlos, para someterlos a una actividad laboral y para subordinarlos a un amo ${ }^{5}$.

La noción de marginalidad a la cual nos referimos está en relación con la postulada desde el materialismo histórico por C. Astarita, quien propone como marginales a los campesinos desclasados que debieron volcarse o bien a la industria doméstica ( $\mathrm{si}$ es que conservaban lo mínimo para continuar establecidos en la comunidad), o bien al vagabundeo, oscilando entre la integración en la comunidad mediante ocupaciones temporales y la exclusión, en tanto delincuentes ${ }^{6}$. Sin embargo, debemos reparar en que los que nos ocupan son los que mencionamos en último término, a quienes encontramos diferenciados de los primeros en tanto éstos continuaban subordinados al orden y su pobreza era integrada (pues de la misma manera que el pobre de la aldea no abandonaba su domicilio, tampoco lo hizo el campesino reducido a la industria doméstica, que seguía recibiendo la solidaridad de la comunidad, a pesar de su condición marginal en el plano económico), mientras los itinerantes no guardaban esa característica, situación que condujo a la producción de los discursos que estudiaremos en esta tesis.

Según lo postulado por Astarita, el sector marginal fue numeroso y una parte de él afectó profundamente la economía, ya que intervino directamente en el proceso que permitió la acumulación de capital por parte de los mercaderes. Desde el materialismo histórico, la persecución de los marginales se explica por motivos económicos ya que la política represiva para obligarlos a trabajar garantizaba la reserva de mano de obra para el nuevo sistema de acumulación ${ }^{7}$. En este contexto, las acusaciones que caían sobre ellos estaban orientadas a regular su existencia en beneficio de los sectores económicosociales representados políticamente: oligarquías urbanas, noblezas y monarquía. Sin

\footnotetext{
${ }^{5}$ Tal como sostienen H. Lis y C. Soly, “...viudas, enfermos, inválidos y mendigos que aceptaban su destino fueron considerados como elegidos de Dios, mientras que la pobreza de los obreros jornaleros mal pagados no se consideraba como tal. (...) La limosna no sólo garantizaba la salvación del alma del donante, también aseguraba la subsistencia del mercado de mano de obra y el mantenimiento del 'equilibrio social'". Hugo Lis y Catharina Soly, Pobreza y capitalismo en la Europa preindustrial (13501850). Madrid, Akal, 1985, pp 39 y 40.

${ }^{6}$ Carlos Astarita, -"Dinámica del sistema feudal, marginalidad y transición al capitalismo", en Carrillo, Santiago (et al.). Disidentes, heterodoxos y marginados en la Historia. Salamanca, Ediciones Universidad de Salamanca, 1998, pp 21-49, p 36.

${ }^{7}$ Karl Marx, op cit, p 627.
} 
embargo, este aspecto se relaciona con la preservación del orden, en tanto ello era fundamental para el mantenimiento de la relación económico-social. La permanencia de cada uno en su estado y el cumplimiento de las obligaciones inherentes a él aseguraban la perpetuación de las relaciones explotativas, que encontraban su fundamento en los postulados teológicos, filosóficos y políticos que propugnaban la desigualdad jurídica en favor de los sectores dominantes.

La pauperización progresiva del campedinado condujo a que este grupo no tuviera suficientes tierras de cultivo para garantizar su tributación, por lo que debió adaptarse a esa realidad a través de su inserción en nuevas relaciones económicas como el servicio, el trabajo a jornal, la producción de manufacturas destinadas al intercambio, la emigración, el ejército o la marina, entre otros. Este proceso de empobrecimiento dentro del propio sistema feudal se profundizó a partir del siglo XIV, como consecuencia de la pulverización de la propiedad campesina, ya fuera por los sucesivos fraccionamientos hereditarios, la adquisición de tierras por parte de residentes urbanos, la polarización social dentro de la clase productora, la limitación del uso de los predios comunales o la acumulación de tierras por parte de los señoríos, individual o conjuntamente $^{8}$. Por otra parte, hubo concentración de la población en villas medianas y abandono de las aldeas pequeñas, así como creación de cotos redondos por parte de algunos monasterios y aristócratas.

En la larga transición del feudalismo al capitalismo, el marginal que permaneció en la aldea con disposición de una pequeña porción de tierra fue fundamental para el surgimiento del nuevo modo de acumulación, ya que podía ser contratado como mano de obra asalariada en un proceso que prefigura la proletarización de los sectores desposeídos ${ }^{9}$. Pero otros, excluidos de las organizaciones que encuadraban a los actores sociales en el sistema feudal, podían emigrar a las ciudades (donde tenían más oportunidades para subsistir, empezando por la caridad pública y privada), cuya franja marginal de población se veía incrementada por el arribo de quienes abandonaban las zonas rurales. Dichas concentraciones urbanas, como las aldeas, tampoco admitían que los pobres extranjeros permaneciesen en ellas, lo que obligaba a los recién llegados a hallar una mínima inserción como mendigos legítimos o como asalariados.

\footnotetext{
${ }^{8}$ Corina Luchía, La dinámica de la propiedad comunal y las condiciones de desarrollo transicional del feudalismo al capitalismo en el área concejil de realengo castellana. Siglos XIV al XVI. Buenos aires, Universidad de Buenos Aires, 2008, mimeo, especialmente pp 322-323 y 338. La autora observa algunos de estos aspectos.

${ }^{9}$ Carlos Astarita, Dinámica del sistema feudal, marginalidad... op cit, pp 47 y 48.
} 
Una parte de los marginales cuestionaba el orden social al no inscribirse en relaciones sociales estables, vinculadas al trabajo y a la consiguiente fijación en el espacio, convirtiéndose en protagonistas de diversos problemas sociales y culturales. No podemos dejar de mencionar en este marco el clásico acápite de C. Hill "Los hombres sin amo" 10 , dedicado a estos actores sociales en Inglaterra ${ }^{11}$. Allí considera su existencia como una contradicción respecto al orden feudal y la concepción de que no podía haber tierras ni hombres sin señor, tornando en problemática su masividad en el siglo XVI, cuando la sociedad se iba haciendo móvil. El autor destaca la consideración que se tenía acerca de estos hombres: serían potenciales disolventes de la sociedad, aunque en realidad sólo presentaban un problema de seguridad, dado que su carencia de motivaciones ideológicas hacía imposible que ellos organizaran una rebelión. En el marco de su estudio, el historiador inglés piensa en la importancia de este sector para la experiencia puritana, que clamaba por la disciplina interior, una obediencia que implicaba que los hombres se consideraran como amos a sí mismos ${ }^{12}$.

Los marginales vivían al borde de la subsistencia, gracias a la combinación de estrategias de supervivencia en las que intercalaban el trabajo asalariado, la limosna y diversas actividades punibles, como el juego, la estafa, el robo o la prostitución. Su vida era considerada delictiva a priori, porque no trabajaban regularmente y no estaban domiciliados. La ruptura de los lazos que los unían a la comunidad imposibilitaba la socialización del grupo, impidiéndoles interiorizar los valores sociales que estructuraban la vida de los sujetos de una comunidad y que garantizaban la reproducción de la sociedad. Tal como sintetiza B. Geremek, estos agentes no participaban de manera constante en la producción, no tenían lazos sociales, corporación, familia ni domicilio fijo $^{13}$. Proponemos que los agentes que nos ocupan presentan una superposición de dos condiciones: se trata de marginales en el plano económico-social, pero además marginados por las políticas y representaciones acerca de ellos.

Desde el punto de vista económico, en el período que estudiamos, el capitalismo no estaba suficientemente evolucionado como para poder conminar a estos hombres a

\footnotetext{
${ }^{10}$ Christopher Hill, El mundo trastornado. El ideario popular extremista en la Revolución Inglesa del siglo XVII. Madrid, Siglo XXI de España, 1983, pp 28-46.

${ }^{11}$ Entre ellos distingue diversos tipos: los vagabundos que circulaban por el campo, los que lo hacían en las ciudades, los que se adscribieron a diversas sectas, los pobres sin tierras que ocupaban comunales y bosques y, por último, aquellos que se dedicaban al comercio itinerante (que, en tanto móviles, pudieron extender las ideas religiosas radicales). Ibidem, pp 29-34.

${ }^{12}$ Ibidem, p 37.

${ }^{13}$ Bronislaw Geremek, Les marginaux parisiens aux XIV et XV siècles. Saint Amand, Flammarion, 1990, p 361.
} 
trabajar mediante mecanismos económicos, lo que determinaba la necesidad de las "Leyes de pobres"; pero, avanzado el proceso de desarrollo de las relaciones capitalistas, aquéllos se presentan como mano de obra de reserva y ejercen presión sobre el monto de los salarios de los trabajadores, lo cual les otorga una funcionalidad económica diferente ${ }^{14}$. Estos marginales pueden ser definidos como "normales inútiles" o "supernumerarios", calificación que pone en juego la diferencia fundamental entre estos hombres y aquellos que no están activos por incapacidad física o los excluidos absolutos, cuya existencia no influye en el costo de la fuerza de trabajo. Este aspecto presenta una diferencia notoria entre la sociedad que estudiamos y la capitalista actual, ya que en aquélla, en la medida en que la mano de obra tenía niveles relativamente bajos de vinculación con el mercado, el marginal no cumplía las funciones que atañen en la actualidad al ejército de reserva de mano de obra, que presiona la remuneración hacia la baja, mientras su magnitud ejerce un freno en las demandas del trabajador (cuanto mayor es ese ejército de reserva, más defensivos se tornan los conflictos del proletariado), indicando que en cada sistema existen funcionalidades y lógicas diferentes para el sector marginal.

El pícaro representa un tipo de marginal específico que sólo reproduce su propia subsistencia. En caso de subordinarse temporalmente, construye el status de su amo, poniéndose al servicio de una nobleza menor o de sectores en ascenso, que lo utilizan como instrumento de ostentación para erigir la imagen de su poder, tal como veremos en el capítulo cuarto.

Durante el ocaso de la Edad Media vemos el crecimiento de las ciudades, espacio que resultaba, por diferentes motivos, un polo de atracción para los vagabundos, pues en la urbe se conjugaban diversos actores sociales y convivían sujetos provenientes de distintas clases y estamentos, es decir, en ella se encontraban reunidas la riqueza y la pobreza $^{16}$. Así, parte de los sujetos que perdían su antiguo modo de subsistencia se veían atraídos por la ciudad, donde el anonimato podía garantizarles una magra supervivencia a partir de la mendicidad, los trabajos temporales o los pequeños delitos. Allí la limosna callejera fue otra consecuencia de la emigración de parte de los pobres rurales. Aquellos que habían salido de las redes comunitarias -que los preservaban en su

\footnotetext{
${ }^{14}$ José Nun, Marginalidad y exclusión social. Buenos Aires, Fondo de Cultura Económica, 2003, pp 7577.

${ }^{15}$ Robert Castel, "Las trampas de la exclusión”, en CEIL (comp.). Pobres, pobreza y exclusión social. Buenos Aires, CEIL, 1995, pp 247-262, p 253.

${ }^{16}$ Michel Mollat, op cit, p 116.
} 
estado y daban sentido a su existencia social- se volvieron temibles al exhibir una situación existencial desordenada, en el marco de un colectivo atemorizado por la potencial subversión del orden social ${ }^{17}$.

Durante el siglo XVI, cuando se debatieron los derechos y libertades de los pobres, sobre todo entre los teólogos escolásticos, se intensificó la legislación sobre el problema y también surgió la picaresca. El incremento en la emisión de discursos acerca de los desposeídos (y la alarma respecto a su vertiente no integrada) sugiere la agudización del conflicto, pero fundamentalmente el temor de la élite social frente a él. Estas perspectivas en torno a esa marginalidad fueron plasmadas en el derecho, la escolástica y la literatura, dando lugar a la elaboración de discursos que pueden considerarse manifestaciones de aquella inquietud a través de diversas expresiones sociales $^{18}$.

Este período está signado en el plano político por el surgimiento y posterior consolidación de las monarquías modernas, eclosión que implicó la emergencia de adversarios externos, por un lado, y la construcción de los enemigos internos por el otro. Dentro de esta última dinámica podemos considerar a los distintos sectores excluidos o marginados en diversos grados (brujas, judíos, vagabundos, leprosos, etc.) como adversarios contra quienes el aparato político debía aplicar su fuerza coercitiva. En correspondencia con este proceso, la historia de las mentalidades da cuenta de que esta sociedad estuvo signada por el miedo a los diversos actores que pudieran perturbarla ${ }^{19}$.

Diversos autores, cuyas conclusiones más relevantes revisaremos más adelante, examinaron las representaciones de distintos tipos de marginales ${ }^{20}$. Nuestro interés

\footnotetext{
${ }_{17}^{17}$ Jean Delumeau, El miedo en Occidente. Madrid, Taurus, 1989, pp 296 y 297.

${ }^{18}$ Michel Mollat, op cit, pp 11, 12 y 15.

${ }^{19}$ Jean Delumeau, op cit, passim.

${ }^{20}$ Jean Claude Schmitt, L'histoire... op cit; Juan Carlos González Hernández, "Marginación y picaresca en el proceso de cambio de la sociedad tradicional", en AAVV, Homenaje a José Antonio Maravall 19111986. Valencia, Monografías del Consell de Valencia de Cultura, 1988, pp 151-165; Bernard Vincent, “Ciudades y marginalidad”, en Fortea Pérez, José Ignacio (ed.). Imágenes de la diversidad. El mundo urbano en la Corona de Castilla (Siglos XVI-XVIII). Cantabria, Universidad de Cantabria, 1997, pp 347361; Jacques Le Goff, "Los marginados en el Occidente Medieval", en Le Goff, Jacques. Lo maravilloso y lo cotidiano en el Occidente Medieval. Barcelona, Gedisa, 1985, Capítulo IX, pp 129-135; Bronislaw Geremek, La piedad y la horca. Historia de la miseria y la caridad en Europa. Madrid, Alianza, 1989; Les marginaux... op cit; La estirpe de Caín. Madrid, Mondadori, 1991; Antonio Serrano González, Como lobo entre ovejas. Soberanos y marginados en Bodin, Shakespeare, Vives. Madrid, Centro de Estudios Constitucionales, 1992; Pedro Carasa Soto, "La historia y los pobres: de las bienaventuranzas a la marginación", en Historia Social. № 13, Valencia, Universidad Nacional de Educación a Distancia, 1992, pp 77-99; Michel Cavillac, "Pícaros y pobreza en tiempos del Guzmán de Alfarache: Cristóbal Pérez de Herrera y Mateo Alemán (1594-1604)”, en Torre de los Lujanes. №51, Madrid, Real Sociedad Económica Matritense de Amigos del País, 2003, pp 15-30.
} 
radica en el estudio de aquellos que fueron tipificados por J. Le Goff como los marginados propiamente dichos: desclasados y mendigos ${ }^{21}$, amenazadores porque atentaban contra valores fundamentales de la ideología medieval, como la estabilidad del orden, por su nomadismo, y la realización material de aquél, en tanto que rechazaban la labor a la cual estaban adscriptos.

La sociedad precapitalista valoraba el trabajo desde el aspecto moral, independientemente de su rentabilidad ${ }^{22}$. Las actividades de servicio que realizaban los pícaros no eran necesariamente rentables sino que se asociaban al status o la vida doméstica de sus amos. Este tipo de ocupaciones resultaban de la obligación que tenían de subordinarse a un señor, dado que su vida itinerante dificultaba su control mediante la imposición de las normas a las que concernía regular su existencia y que propugnaban domiciliarlos para poder controlarlos.

La existencia de un sector marginal y su representación tuvieron diversas consecuencias, que serán aquí examinadas. Respecto a la imposibilidad de su control y el consiguiente temor por su peligrosidad, debemos hacer referencia al estudio de A. Serrano González. Dedicado a la epistemología jurídica, el autor postula, a partir del examen de la forma en que se representa la política monárquica y su relación con los marginales en varias obras modernas, que era imposible la dominación sobre aquellos que se encontraban fuera de las estructuras sociales ${ }^{23}$.

Geremek vincula la movilidad permanente de los marginales con el desprecio que producen en la sociedad ${ }^{24}$, aspecto que merece ser discutido. A través de nuestro análisis, observamos que el rechazo por parte de la sociedad debe ser matizado. En el discurso político estos marginales son presentados como sujetos peligrosos y asociales contra quienes la comunidad debe reaccionar; sin embargo, a través de la propia legislación se vislumbra que quienes eran compelidos a perseguirlos, no lo hacían. Entretanto, la picaresca sugiere que la animadversión hacia estos hombres no era unánime, pues los vemos convivir e interactuar asiduamente con otros miembros del cuerpo social.

\footnotetext{
${ }^{21}$ Jacques Le Goff, Los marginados... op cit, p 131.

${ }^{22}$ Según P. Bourdieu en este tipo de formaciones sociales: "Con el derecho de exigir de cada uno que se entregue a una ocupación, por improductiva que sea, el grupo debe asegurar a todos una ocupación, incluso puramente simbólica." Pierre Bourdieu, Argelia 60. Estructuras económicas y estructuras temporales. Avellaneda, Siglo XXI, 2006, p 59.

23 Antonio Serrano González, op cit, passim.

${ }^{24}$ Bronislaw Geremek, Les marginaux... op cit, p 361.
} 
Durante la temprana modernidad, la literatura presenta como protagonistas a algunos tipos de marginales, mientras retrata también diversas clases de sujetos segregados por no cumplir con las pautas sociales. Desde la semiótica cultural, I. Lotman encuentra la relevancia del goliardo, el lumpen o el bandido en tanto son excepcionales por su conducta. Estos personajes serían valorados positiva o negativamente (según distintos emisores de discursos), y ganarían, por su anomalía, el derecho a permanecer en la memoria colectiva ${ }^{25}$. También pueden ser considerados como un eje que sirve para cuestionar paródicamente ciertas pautas sociales que, vistas desde otra perspectiva, pueden ser puestas en tensión ${ }^{26}$. Otro personaje que encarna este fenómeno es el bufón de corte, quien personifica la ambivalencia de la marginalidad, mostrando su posibilidad de entrar y salir de ella a través de un personaje segregado pero instalado en el centro de poder, con la consiguiente pérdida de su condición anterior y conversión en parásito del $\operatorname{poder}^{27}$. Aquí podemos apuntar otro caso paradójico, el del ermitaño, un sujeto que decide aislarse, pero que no es considerado como marginal por su carácter ejemplar y la implicación religiosa de su conducta.

Los límites entre quien es marginado por no subordinarse a las reglas sociales y quien no corre esta suerte a pesar de no acatar a las normas son imprecisos, porque esto depende de qué posición ocupa el agente en la sociedad. Además es necesario tener en cuenta que los criterios propuestos por las élites acerca de qué es aceptado y qué no lo es (definiendo de esta manera el límite de la integración) también pueden ser fluctuantes. Del mismo modo, debemos considerar que los distintos sectores sociales podían tener, en ocasiones, evaluaciones diferentes sobre la violación de las normas.

A partir del estudio de diversas clases de transgresión, R. Córdoba de la Llave plantea una definición interesante para el análisis que nosotros proponemos. Según el autor, durante la Edad Media se consideraría marginado al que transgrediera "las normas, conductas y pautas de comportamiento establecidas", ya fuera por delitos o

\footnotetext{
${ }^{25}$ Iuri Lotman, La semiósfera. Semiótica de la cultura y del texto. Madrid, Cátedra, 1996, Tomo II, p 216.

26 "El marginado es el criado, el pícaro, el delincuente (...) en una serie indefinida de voces diferentes o en contrapunto a las de los personajes principales, que eran los receptáculos tradicionales de los valores asociados a los nobles, detentadores de la razón y el poder social. El marginado entra en la literatura como figura-marco que cumple funciones cómicas, paródicas y criticas, en un discurso de inversión, en un contraste efectuado a través de su aparición extemporánea que juega con su propia marginación y la utiliza". Jesús García Varela, "Factores constitutivos del discurso del marginado en la literatura del siglo de Oro", en Thesaurus. Tomo XLIX, N², Santafé de Bogotá, Instituto Caro y Cuervo de Colombia, 1994, pp 275-292, p 277.

${ }^{27}$ Ibidem, p 283.
} 
actitudes violentas, por asumir conductas sociales o comportamientos sexuales condenables, o por provocar el rechazo físico o moral de la comunidad ${ }^{28}$.

En torno a los discursos que sancionaron progresivamente la marginalidad durante la historia moderna, E. Nathan Bravo ejemplifica mediante el caso de la Reforma Protestante, las fluctuaciones que dan lugar a que un movimiento originalmente heterodoxo pase a constituir uno ortodoxo, demostrando que la distinción entre lo dominante y lo marginal no es una diferenciación entre absolutos, sino que depende de diversos factores relacionados con la acumulación de poder $^{29}$. La autora vincula la marginalidad con el sistema de valores de la sociedad: lo dominante determina qué es lo marginal, sosteniendo los proyectos de fracciones sociales particulares, pues detrás de los ideales hay grupos con mayor o menor autoridad, eso explica por qué una posición marginal puede dejar de serlo y viceversa ${ }^{30}$. De esta manera, no se trata de una situación objetiva sino de un juego de fuerzas entre distintos sectores, cuyo balance depende de cuál es la capacidad de cada grupo de dominar en la sociedad. Así, cuando un colectivo ocupa una posición hegemónica, sus ideales también lo hacen y se proyectan como compartidos y válidos para la humanidad.

E. Mitre Fernández vincula la marginalidad con el sistema de valores porque, sostiene, aquél fenómeno radica en la segregación de aquellas personas que conviven en el seno de una comunidad pero que no comparten los valores en los que ésta se asienta $^{31}$. Por lo tanto, el cambio en dicho régimen indicaría una variación correlativa de lo marginal ${ }^{32}$.

El análisis de los marginales en el contexto de la modernidad europea conlleva distinguirlos de los excluidos, los pobres y las minorías étnicas y religiosas, que generalmente son considerados globalmente, sin atender a la heterogeneidad en su

\footnotetext{
28 Ricardo Córdoba de la Llave, "Marginación social y criminalización de las conductas", en Medievalismo. Año 14, No 13-14, Murcia, Ediciones de la Universidad de Murcia, 2004, pp 293-322, p 294.

29 Elia Nathan Bravo, “Ordenes mendicantes: integración de elementos marginales a la Iglesia”, en Gónzález, Aurelio y Walde Moheno, Lilian von der (eds.), Edad Media: marginalidad y oficialidad. México, Universidad Nacional Autónoma de México, 1998, pp 183-205, p 187.

${ }^{30}$ Ibidem, p 194.

31 El autor parte de los estudios de la religiosidad y las mentalidades. Emilio Mitre Fernández, Fronterizos de Clio (marginados disidentes y desplazados en la Edad Media). Granada, Universidad de Granada, 2003, p 8.

${ }^{32}$ Por ejemplo, la brujería constituye una forma de marginalidad particular desde el siglo XII, cuando fue asimilada a la herejía y evaluada como una inadecuación a las prácticas religiosas, consecuentemente peligrosa $\mathrm{y}$, por lo tanto, perseguida, cuando antes era considerada sólo una expresión de paganismo precristiano. Bronislaw Geremek, Les marginaux... op cit, p 367.
} 
definición teórica y de su posicionamiento dentro de la sociedad. Este problema tiene su base en dos situaciones fundamentales y diferentes: en primer lugar, varias de estas categorías pueden superponerse en la experiencia de un solo agente; en segundo término, todos los grupos mencionados fueron segregados en mayor o menor medida.

Necesitamos separar la categoría de marginal de la de excluido, pues se trata de dos situaciones diferentes: si bien ambas se presentan como alteridad: mientras el primero convive con la sociedad, el segundo es separado de ella (pensemos, por ejemplo, en la diferencia entre los mendigos y los leprosos).

También distinguiremos al marginal del desviado; pues si bien ambos violan las normas sociales, el primero no tuvo la oportunidad de aprenderlas y el segundo, conociéndolas, las quiebra deliberadamente; en este caso hay una elección de ir en contra de las normas aprendidas ${ }^{33}$.

Hemos encontrado en la bibliografía consultada la confusión entre la condición del pobre y la del marginal. Desde la antropología y la sociología se han analizado estas categorías analíticas, pero en los estudios históricos permanece abierta la dificultad para diferenciarlas cuando se superponen en un mismo sector social ${ }^{34}$. Debemos tener en cuenta que a lo largo de la historia -y en la actualidad- una gran parte de la población fue -y es- indigente ${ }^{35}$, pero la medición y evaluación de dicho fenómeno varía según los distintos contextos sociales ${ }^{36}$. Numerosos estudios que abordan el problema de la

\footnotetext{
${ }^{33}$ Ver Juan Carlos González Hernández, op cit, p 151.

${ }^{34}$ Córdoba de la Llave vincula la pobreza y la marginalidad aduciendo que el pobre verdadero padece una marginalidad comprendida o integrada. Ricardo Córdoba de la Llave, op cit, p 294. Respecto a esto diremos que la marginalidad no puede exhibir las características mencionadas, ya que es inherente a ella no ser integrada ni comprendida. Los pobres que obedecen a las pautas sociales no son marginales sino, por el contrario, un ejemplo de integración por su sumisión. En la misma línea, R. Castel, quien ha desarrollado importantes estudios sobre la marginalidad en el contexto actual, sostiene que la pobreza está en la base de la marginalidad profunda, aunque admite que este factor no es exclusivamente determinante porque hay pobreza integrada. Robert Castel, "La dinámica de los procesos de Marginalización”, en Topía. Año I, No II, Buenos Aires, Editorial Topía, 1991, pp 18-27, pp 20 y 21.

35 Este problema merece un estudio con otros objetivos y no el que se basa en la marginalidad y sus representaciones.

${ }^{36}$ Así, S. Woolf generaliza, a partir de diversas estadísticas, el número de pobres, similar en España, Francia e Inglaterra durante la modernidad. "Los pobres 'estructurales', incapaces de ganarse la vida por razones de edad, enfermedad o incapacidad física $\mathrm{y}$, por lo tanto, totalmente dependientes de la beneficencia o la mendicidad, suponían entre un 4 y un 8 por 100 de la población de Salisbury, Norwich, Odense, Lyon, Toledo, Venecia, Florencia, Roma y algunas otras ciudades del norte y el centro de Italia desde el siglo XV hasta el siglo XVIII. Los pobres urbanos 'coyunturales' o 'de épocas de crisis' dependientes, en general, de los bajos salarios o del empleo ocasional, y por tanto afectados directamente por las fluctuaciones de los precios del pan, eran cerca de un 20 por 100 . Un tercer círculo concéntrico para usar la metáfora de Pullan- de artesanos, pequeños vendedores al detalle y funcionarios menores, que corresponderían a las unidades familiares gravadas con las mínimas tasas de impuestos, pudieron caer varias veces con facilidad por debajo del nivel de subsistencia por razones personales o como resultado del cese del empleo, engrosando así la proporción de los pobres urbanos que, en momentos de crisis,
} 
marginalidad complican este concepto con el pauperismo, que puede ser una cualidad de aquel fenómeno pero no su esencia. La pobreza puede constituir el detonante de la marginación de una persona que no se adapta a esa situación, pero debemos tener en cuenta que en el período que estudiamos, la gran mayoría de la población era pobre, aunque los hombres no eran marginados por tal motivo en tanto cumplieran con las expectativas que la sociedad tenía acerca de ellos. Inversamente, podemos observar cómo algunos individuos salían temporal o definitivamente de la miseria, sin abandonar por eso su condición de marginalidad, dado que sus conductas y actividades seguían siendo contrarias a las normas sociales. Podemos decir que la primera puede ser una característica importante de la segunda, pero no la única ni inherente: ni todos los pobres son marginales, ni todos los marginales son pobres, aunque en numerosas ocasiones se define a los últimos en relación a la indigencia y el desarraigo, porque constituyen factores desintegradores respecto a los grupos que participan de las normas sociales dominantes ${ }^{37}$.

Las minorías también suelen ser confundidas con los marginales, pues ambos grupos fueron estigmatizados y perseguidos. Desde la Edad Media, el orden cristiano, entendido en el plano jurídico, social y mental generó diversas formas de segregación respecto de distintos grupos como los extranjeros, sospechosos de heterodoxia, los leprosos y los judíos. Todos ellos son representados como una infrasociedad desconocida, que conformaría, tal como la denomina H. Martin, "otra edad media"38. Sin embargo, las minorías deben ser deslindadas de la marginación ya que su situación es consecuencia de la religión que profesan y las formas de vida que las hace diferentes al resto de la sociedad, que las engloba pero no las asimila. Los factores que pueden llevar a una mayor o menor tolerancia de manera periódica dependen del balance de poder o la necesidad que los sectores dominantes pueden tener respecto a los otros grupos, en correspondencia con la funcionalidad de la minoría para el resto del cuerpo

incluía desde el 50 al 70 por 100 del total de las unidades familiares." Stuart Woolf, Los pobres en la Europa moderna. Barcelona, Crítica, 1989, p 17.

${ }^{37}$ Así, los pobres y vagabundos conformarían el grupo "más cercano al del marginado integral, absoluto, suma de discapacidades laborales, reservas morales, prevención y persecución judicial, desarraigo social, etcétera". Enrique Villalba Pérez, "Delincuencia, marginación y control del orden público en el Madrid del siglo XVII", en Morán, Miguel y García, Bernardo. El Madrid de Velázquez y Calderón. Villa y Corte en el siglo XVII. Madrid, Ayuntamiento de Madrid, 2000, pp 169-180, p 169.

${ }^{38}$ Hervé Martin, Nouvelle Clio, L'histoire et ses problèmes. Mentalités Médiévales. XIe - Xve siècles. París, Presses Universitaires de France, 1996, Capítulo XIII “Les mentalités au négatif”, pp 405 y 439. 
social $^{39}$. El estudio de la marginalidad puede relacionarse con el de las minorías ya que, tal como sintetiza H. Martin, "un sistema de relaciones sociales tiene que integrar plena y establemente a la mayoría de los individuos para permanecer firme, en función de lo cual los grupos marginados serán siempre grupos minoritarios"

Debemos enmarcar este problema en la desconfianza que generaba todo aquel que era visto como otro. En este contexto variados grupos fueron sospechados de producir envenenamientos, incendios, rapto de niños o propagación intencionada de las enfermedades, incluso, se elucubra acerca de la alianza entre diversos grupos marginados por diferentes motivos, por ejemplo el rumor sobre el complot de judíos (segregados por su religión) y leprosos (excluidos como consecuencia de la enfermedad $)^{41}$. Se consideraba también el peligro de la contaminación de la sangre, por el contacto sexual, o por la leche de las nodrizas, que se estimaba conductora de factores congénitos. Pero en el caso de los vagabundos, la sospecha se fundaba en que dispersarían epidemias a través de su deambular. Este temor ganó impulso con los brotes de peste bubónica durante el siglo XIV, cuando, además, la sociedad se veía obligada a una existencia en ruptura con el sistema al que estaba habituada: la inseguridad no nacía solamente de la presencia de la enfermedad, sino también de una desestructuración de los elementos que integraban el entorno cotidiano. Antes de que apareciera el miedo a la peste negra, sobre todo después de las Cruzadas, se temía a los leprosos, quienes fueron temprana y fuertemente segregados a leprosarios -que se construyeron fuera de los límites de los recintos urbanos- y debían hacer conocer su cercanía mediante una campanilla, para permitir a los sanos mantenerse alejados de ellos ${ }^{42}$.

Ante una situación anormal producida por el peligro de la enfermedad, la población se sentía impulsada a expulsar a los mendigos, quienes además de ser considerados sembradores de la peste, eran bocas que alimentar, mientras el aparato represivo que debería controlarlos se había hundido ${ }^{43}$. Otra consecuencia de la peste

\footnotetext{
${ }^{39}$ Manuela García Pardo, "Marginados en el mundo medieval y moderno", Almería 5 a 7 de noviembre de 1998. Almería, Instituto de estudios almerienses, Diputación de Almería, 2000, pp 13-24, p 15.

${ }^{40}$ Ricardo Córdoba de la Llave, op cit, p 295.

${ }^{41}$ Ver Hervé Martin, op cit, p 426.

${ }^{42}$ Así, R. I. Moore describe el proceso de segregación que tuvo lugar a partir del siglo VII, su utilización con fines persecutorios, la construcción de los leprosarios, etc. El autor analiza la separación total de la comunidad, que implicaba la pérdida de protección y propiedad y la dimensión más temible de la enfermedad. Robert Ian Moore, La formación de una sociedad represora. Crítica, Barcelona, 1989, pp 62 y ss.

${ }^{43}$ Jean Delumeau, op cit, p 177.
} 
radicaba en que luego de sus embates, que desestructuraban la sociedad, aumentaba la cantidad de vagabundos ${ }^{44}$. Así, las diatribas contra los falsos pobres alcanzaron su cima durante la difusión de la peste bubónica, pues la epidemia conducía a la toma de conciencia del peligro que implicaba la aglomeración de pobres: con la adscripción del concepto de contagio (aunque esta idea no estaba muy clara todavía) al de pobreza, se le agregaba otra carga peyorativa ${ }^{45}$.

La existencia de los marginales se proyectaba como la causa de otros conflictos, convirtiéndolos en enemigos sociales respecto a quienes se debía sentir temor, justificando el ejercicio de la violencia contra ellos. Estos hombres encontraron su representación literaria en la figura del pícaro, a la cual nos dedicaremos en extenso en el próximo capítulo, pero por ahora diremos que retrataba una persona cuya marginalidad estaba signada por su permanente movilidad y la práctica de muy diversas actividades no especializadas para sobrevivir magramente en distintas urbes españolas durante el Siglo de Oro.

\section{El encuadramiento del margen social}

A lo largo del examen bibliográfico encontramos variadas formas de considerar la marginalidad, teniendo en cuenta diversas variables para su clasificación. Los volúmenes dedicados a este fenómeno reúnen estudios que versan sobre conflictos diferentes, demostrando la heterogeneidad y vastedad de los problemas que se engloban bajo la noción de marginalidad, amplitud que termina por convertirla en una idea difusa $^{46}$. Algunos autores se muestran escépticos en torno a este conflicto

\footnotetext{
${ }^{44}$ Los tres grandes brotes de peste en España tuvieron lugar en los períodos 1596-1602, 1648-1652 y 1677-1685. Ibídem, p 160. Durante sus embates, se hacía caso omiso del código moral establecido. Thomas Henry Hollingsworth, Demografía Histórica. Cómo utilizar las fuentes de la historia para construirla. México, Fondo de Cultura Económica, 1983, pp 305 y ss.

${ }^{45}$ Carmen López Alonso, La pobreza en la España Medieval. Estudio histórico social. Madrid, Ministerio de Trabajo y Seguridad Social, 1986, p 244 y José Luis Betrán Moya, "Pobreza y marginación en la Barcelona de los siglos XVI y XVII", en Historia Social. No 8, Valencia, Universidad Nacional de Educación a Distancia, 1990, pp 101-121, p 118.

${ }^{46} \mathrm{AAVV}$, Marginados y minorías sociales en la España Moderna. Y otros estudios sobre Extremadura. VI Jornadas de Historia en Llerena. Llerena, Sociedad Extremeña de Historia, 2005; Santiago Carrillo (et al.), Disidentes, heterodoxos y marginados en la Historia. Salamanca, Ediciones Universidad de Salamanca, 1998 y Francisco Durán Villa y Xavier Manuel Santos Solla (eds.), Semata $N^{o}$ 16, Marginados y Excluidos. Un enfoque interdisciplinar. Santiago de Compostela, Universidad de Santiago de Compostela, 2005 constituyen testimonios de la dificultad aludida.

F. Cortés sostiene que como se trata de una categoría descriptiva, no inserta en una teoría, no es posible identificar enunciados que la precedan, aunque sí derivar proposiciones consecuentes. Fernando Cortés,
} 
epistemológico, negando la posibilidad de encontrar una referencia claramente establecida para este concepto que, en tanto puede representar individuos, procesos o relaciones de trabajo, no admitiría la precisión. Otros optan por la elección de uno de estos aspectos como definitorio de la categorización para su utilización en un estudio, elección metodológica que compartimos.

En la bibliografía consultada encontramos que se denomina marginal desde el punto de vista sociológico a todo sujeto que, por diversos motivos, no está integrado plenamente en las redes sociales de su comunidad, sin atender a las diferencias en las causas de dicha segregación ni a los grados en que ésta pueda presentarse. En primer lugar, en tal caso no se tienen en cuenta los motivos por los cuales un sujeto puede ser estigmatizado, involucrando todos los factores que influirían en diversos casos, agrupando realidades diferentes que merecen ser atendidas de manera particular. En segundo término, los distintos grados que puede tener la segregación también son homogeneizados, llegando a confundir este fenómeno incluso con el de la separación de la comunidad, esto es, la exclusión. Así, se enredan marginados, minorías, excluidos e incluso pobres. Los autores se han inclinado por dos maneras de definir el concepto: o bien se han volcado a considerar todas las cualidades que la sociedad requiere de una persona para integrarla -y de las cuales los marginales carecen- o han categorizado como marginales a aquellos sectores que ellos pretenden estudiar como tales, sin atender a la definición teórica que puede enmarcarlos en -o separarlos de- otros grupos segregados.

Las definiciones amplias pueden considerar a la marginalidad como un medio de regulación general necesario para el funcionamiento social, en tanto que, en palabras de S. Paugam, la exclusión constituye un paradigma social, esto es “...un conjunto de representaciones del orden social suficientemente concordantes y estables en el tiempo para que se organice a escala de la sociedad entera una reflexión sobre sus fundamentos

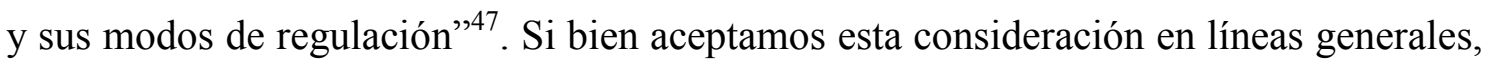
porque la marginalización funciona como forma de dominación ya que permite oponerla a la mayoría, que obedecerá las normas en pos de no caer en dicha condición, disentimos en tanto evaluamos necesaria la diferenciación entre diversos grupos que

"Consideraciones sobre la marginalidad. Marginalidad económica y exclusión social”, en Papeles de población. No 47, Toluca, Universidad Autónoma del Estado de México, 2006, pp 71-84, p 78.

${ }^{47}$ Serge Paugam, "La exclusión en la sociedad francesa: Usos sociales y aporte de la investigación", en Sociedad. No 16, Buenos Aires, Facultad de Ciencias Sociales (UBA), 2000, pp 29-48, p 37. 
podrían enmarcarse en ella (marginales, locos, perseguidos políticos y un largo etcétera).

Este problema conduce a diversas confusiones en los trabajos empíricos, en los cuales podemos encontrar variaciones en el uso del concepto que nos ocupa al interior de un mismo estudio, sin advertir que está siendo utilizado con distintos significados simultáneamente ${ }^{48}$.

En el marco de nuestra indagación es ineludible la mención de los estudios de R. Castel, debido a su relevancia en el ámbito de la sociología. Este autor sostiene que la exclusión se impuso como una palabra híbrida para etiquetar "todas las variedades de miseria en el mundo" ${ }^{49}$. El sociólogo considera el problema fundamental que presenta esta categoría para encuadrar a diversos actores sociales en ella: “... a fuerza de repetir la letanía de la falta, se oculta la necesidad de analizar positivamente cómo está constituida la misma [la marginalidad]. Y esto por una razón de fondo: los rasgos constitutivos y esenciales de las situaciones de "exclusión" no se encuentran en las situaciones mismas $" 50$. Si bien Castel pretende ser crítico respecto a la definición de la marginalidad a partir de la carencia, confunde las categorías de marginalidad y exclusión, que sólo pueden ser igualadas si se conceptualizan a partir de aquélla. Siempre que definamos a los marginales a partir de que les falta algún atributo para ser integrados, corremos el riesgo de confundirlos con los excluidos, en tanto ambos grupos comparten la ausencia mayor o menor de las condiciones necesarias para la plena inclusión social, pero acordamos con el autor en que los discursos de poder son dispositivos excluyentes y en su definición de la marginalidad como "efecto de un proceso que atraviesa el conjunto de la sociedad y que se origina en el centro y no en la periferia de la vida social",51. Se trataría de una dinámica "alimentada por

\footnotetext{
${ }^{48}$ Entre los trabajos que repasamos en este análisis, hemos comprobado este problema. Por ejemplo, E. Nathan Bravo usa el término marginal a lo largo de algunas páginas de dos modos diferentes: para referirse al ideal apostólico de "predicación en la pobreza y, por otro lado, para aludir a los pobres, a quienes considera marginados por su falta de recursos económicos o políticos, incluyendo también a los enfermos o a quienes eran segregados por su incapacidad de vivir plenamente en la sociedad". Aquí no sólo encontramos la dualidad admitida por la autora, basada en un primer plano referido al mundo de las representaciones y un segundo que concierne a la realidad, sino que también es preciso señalar que intervienen en este último aspecto diversos factores uqe resultan homogeneizados, por la confusión entre pobreza y exclusión. Elia Nathan Bravo, op cit, pp 183-184.

${ }^{49}$ Robert Castel, Las trampas... op cit, p 247. V. Bennholdt-Thomsen sostiene que alude a condiciones de vida que están asociadas al hambre, la enfermedad y otras carencias, englobando un amplio conjunto de problemas y temas en los estudios que se hacen en torno a este concepto. Veronika Bennholdt-Thomsen, "Marginalidad en América Latina. Una crítica de la teoría", en Revista mexicana de sociología. Vol. 43, $\mathrm{N}^{\circ}$ 4, México, Universidad Nacional Autónoma de México, 1981, pp 1505-1545, p 1505.

${ }^{50}$ Robert Castel, Las trampas... op cit, p 249.

${ }^{51}$ Ibídem, p 250.
} 
desregulaciones que afectan también a individuos que no son precisamente marginales, sino que están en fenómenos de marginalidad y exclusión" ${ }^{, 52}$. Pensar que constituye un devenir y no una condición estática resulta fundamental para la comprensión de un proceso de este tipo, basado en la permeabilidad de las fronteras entre diversas situaciones sociales.

En el nivel de la representación literaria, según los relatos picarescos la marginalidad sería el resultado de situaciones desfavorables que se acumularían en la biografía de un personaje, y se extenderían a su entorno más cercano, como consecuencia de un primer infortunio que irrumpiría en su existencia.

La antropología aborda la marginalidad revelando inevitables intencionalidades políticas que vinculan su estudio con el conflicto social contemporáneo. Las opiniones de O. Lewis han tenido trascendencia en tanto fueron discutidas o apoyadas por diversos estudiosos, que se posicionaron ante la individualización del problema de la marginalidad y su propuesta acerca de la ineludible reproducción de dicha condición, fenómeno que el antropólogo analiza a partir del concepto de "subcultura de la pobreza" ${ }^{\natural 3}$. Según el autor, las personas que tienen mayores probabilidades de formar parte de este sector son las que pertenecen a los estratos inferiores de una sociedad que cambia velozmente y que se encuentran relativamente marginados en ella ${ }^{54}$. Sin embargo, esta categoría es discutida por otros antropólogos, que aducen que dicho concepto individualiza las causas de este fenómeno. De esta manera se subestima la funcionalidad de la existencia de un sector marginal en la estructura social y se culpabiliza al marginal, quien no podría salir de su situación debido a su incapacidad de adaptación a las normas sociales y la consecuente reproducción de su situación ${ }^{55}$.

Los historiadores consideran la categoría y la utilizan para el análisis en nuestra disciplina de múltiples maneras, pero también puede haber diversos criterios para clasificar de uno u otro modo; veamos algunas propuestas que pueden ser esclarecedoras. L. C. Álvarez Santaló (estudioso tanto de la historia social cuanto de las mentalidades) propone cuatro variables para la definición de lo marginal: a) economicista, que mide el grado de colaboración en el proceso productivo, segregando a

\footnotetext{
${ }^{52}$ Robert Castel, La dinámica... op cit, p 18.

${ }^{53}$ Oscar Lewis, "La cultura de la pobreza", en Vendrell Ferré, Joan (comp.). Teoría social e historia. La perspectiva de la antropología social. México, Instituto Mora, 2005, pp 321-337, p 335.

${ }_{55}^{54}$ Ibídem, p 324.

${ }^{55}$ Pilar Monreal Requena, “¿Sirve para algo el concepto de cultura de la pobreza?”, en Revista de Occidente. № 215, Madrid, Fundación Ortega y Gasset, 1999, pp 75-88.
} 
quienes tienen una baja y accidental colaboración; b) ideológico-religioso, de acuerdo al nivel de adhesión a los valores e instituciones hegemónicos, haciendo caso omiso de la disidencia; c) legal, que produce la exclusión del status; d) social, teniendo en cuenta los vínculos que los sujetos pueden establecer ${ }^{56}$. Consideramos que esta propuesta es pertinente para evaluar diversas formas de segregación, siempre que se delimiten los factores inherentes a dicho fenómeno en cada caso. Pero también creemos que varios de los atributos catalogados anteriormente pueden yuxtaponerse en un mismo agente, como en el caso que nos ocupa. Aquí, si bien el motivo de la marginalidad se corresponde con el primero de los cuatro grupos apuntados, los otros tres son inherentes a su criminalización.

Por su parte, J. C. Schmitt, quien enmarca sus estudios en la historia cultural y antropológica, clasifica tres tipos de marginalidad: la de aquellos que se autoexcluyen de la comunidad como una forma de protesta social o de evasión, identificable como una marginalidad consciente y contestataria ${ }^{57}$, la involuntaria, y una tercera en la cual ambos niveles están unidos ${ }^{58}$. Esta calificación parte del grado de conciencia que tienen los marginales respecto a su condición y resulta útil para indagar acerca de su interacción con el resto de la sociedad. En tanto apuntamos a la marginalidad como parte de la dinámica económica, sólo consideraremos las dos últimas propuestas del autor, que constataremos a lo largo de nuestro análisis.

Los estudios de Geremek resultan de especial relevancia para nosotros, en tanto analiza contextos históricos próximos a los que abordamos en esta tesis -por eso retomaremos varias de sus argumentaciones-, además de haber trabajado acerca de lo que la literatura nos puede mostrar al respecto. El autor define al marginal como aquel que no tiene status, no participa de manera constante en la producción, no tiene lazos, corporación, familia ni domicilio fijo, características que podemos rastrear en las representaciones que analizamos.

Por último, nos interesa observar un aspecto que presentan los sujetos que nos ocupan: su movilidad. La marginalidad no es un fenómeno que pueda estudiarse en un corte $^{\text {sincrónico }}{ }^{59}$, sino que implica la fluctuación que, tal como analizaremos en el

\footnotetext{
${ }^{56}$ León Carlos Álvarez Santaló, "Hagiografía y marginación: Una propuesta de prudencias de uso", en Carrillo, Santiago (et al.). Disidentes, heterodoxos y marginados en la Historia. Salamanca, Ediciones Universidad de Salamanca, 1998, pp 119-144, p 122.

${ }^{57}$ J. C. González Hernández lo califica como desviación, ya que sus protagonistas han aprendido las reglas sociales pero las violan deliberadamente. Juan Carlos González Hernández, op cit, p 152.

58 Jean Claude Schmitt, L'histoire... op cit, p 346.

${ }^{59}$ En palabras de G. A. Saraví: "El carácter multidimensional y procesual de la exclusión exige una
} 
último capítulo, se proyecta también en el plano espacial: si bien el nomadismo no es determinante, sí lo encontramos como una característica de los marginales en distintos contextos históricos anteriores al siglo XX. En algunos casos, ese carácter itinerante resulta un motivo importante de la estigmatización (como observamos en el caso de los gitanos), mientras en otros constituye una consecuencia de la segregación que ya experimentan, pues al no tener anclaje en la comunidad, los sujetos se mueven, aunque puedan establecerse temporalmente.

Antes de terminar este apartado, queremos revisar los aportes de la sociología latinoamericana en torno a este problema, por haber dado lugar a un intenso debate entre los estudiosos del subcontinente. En los países centrales, el problema de la marginalidad cobró interés para los científicos sociales en un contexto de prosperidad económica, por lo tanto se refirió a quienes estaban fuera del progreso y del reparto de beneficios, mostrando por un lado el desfasaje entre el bienestar de la sociedad y la situación de los subproletarios y, por otro lado, la crisis del lazo social ${ }^{60}$. Pero también surgieron respuestas respecto a la marginalidad por parte de los sociólogos latinoamericanos, algunas de cuyas conclusiones repasaremos. Nuestro interés en ellas reside en que son producto de las mismas problemáticas que nos rodean como investigadores.

En Latinoamérica, a partir de la década de 1960, la marginalidad comenzó a ser objeto de un debate que buscaba explicar los motivos por los cuales algunos sectores quedaban relegados del proceso de desarrollo capitalista y la inserción del subcontinente en su dinámica. En este sentido, muchas propuestas se dirigieron a observar el grado de inclusión de las personas en el sistema productivo. La discusión se intensificó durante última década del siglo pasado como consecuencia de la pauperización de amplios sectores de la sociedad mientras esta región del globo se encuadraba en el modelo neoliberal. Por eso, dichas propuestas tienen un gran interés por su enfoque económico y social, mientras que en Europa y -aún más- en Estados Unidos se otorgaba relevancia

perspectiva que permita trascender la instantaneidad característica de los estudios tradicionales sobre pobreza y deshilvanar la madeja de desventajas que se entretejen y retroalimentan en trayectorias biográficas." Gonzalo Saraví, "Nuevas realidades y nuevos enfoques: exclusión social en América Latina", En Saraví, Gonzalo (ed.). De la pobreza a la exclusión: continuidades y rupturas de la cuestión social en América Latina, México, CIESAS, 2007, Capítulo 1, pp 19-52, p 30.

${ }^{60}$ Serge Paugam, op cit, pp 30 y 40 . Mitre Fernández encuentra la categoría de marginalidad cercana a la de lumpenproletariado. Emilio Mitre Fernández, op cit, p 15. 
a otros puntos de vista dirigidos al análisis del fenómeno como un problema del individuo $^{61}$.

J. Nun, M. Murmis y J. C. Marín localizan tres tipos de marginalidad. El primero comprendería el vínculo que se ha mantenido con las formas de producción precapitalistas, abarcando a los propietarios de medios de producción, el segundo englobaría a quienes han perdido la relación con dichos medios y se trasladarían a la ciudad, donde tampoco conseguirían insertarse en el proceso productivo (o sólo lo lograrían de modo intermitente y en actividades que subutilizarían su capacitación previa) y el tercero incluiría a la fuerza de trabajo que ya estuvo integrada y luego correría la misma suerte que el segundo grupo. Entonces, la marginalidad puede también fundamentarse en el ámbito de la producción, como una forma particular de incorporación a la división social del trabajo. Esa condición resultaría parte de la dinámica de la formación de riquezas, ya que esta fuerza laboral contribuye a la valorización del capital y su acumulación ${ }^{62}$.

En estudios más recientes, E. Bogani sostiene que percibir a dichos individuos como fuera del sistema de clases sociales implica desconocer a la marginalidad como un proceso y una relación social, presentándola como un "insólito e inexplicable" factor emergente de la situación latinoamericana. El autor considera que se trata de un producto predecible de las relaciones económicas, dado que las fuerzas del capital marginalizan a los trabajadores ${ }^{63}$.

Por su parte, G. Saraví sostiene que el mercado, el trabajo y la ciudadanía son los tres aspectos concomitantes a la inclusión y que la progresiva salida de ella tiene lugar a través de un proceso de acumulación de desventajas que se entretejen y retroalimentan como consecuencia del desempleo y la precarización, producto de las transformaciones estructurales en los mercados de trabajo. El autor propone que, en las biografías marginales, los "accidentes o eventos aleatorios pueden constituirse o en desigualdades desencadenantes o en nuevos engranajes de procesos de acumulación de

\footnotetext{
${ }^{61}$ Para el caso Latinoamericano, el estudio del DESAL (Centro para el Desarrollo Económico y Social de América Latina) distingue cinco dimensiones del concepto de marginalidad, referidas a los individuos (ecológica, sociopolítica, sociocultural, económica, política), teniendo en cuenta a los sujetos que se encuentran en situaciones de marginalidad, a diferencia del económico, que atiende a su papel en las relaciones de producción. Fernando Cortés, op cit, pp 75- 77.

${ }^{62}$ Respecto a este debate, V. Bennholdt-Thomsen sostiene que no se trata de un fenómeno transitorio sino de un elemento estructural del capitalismo dependiente. La autora argumenta que aquellos que no tienen nada, siempre poseen su fuerza de trabajo y el hecho de que no puedan venderla, los transforma en marginales en todos los aspectos sociales. Veronika Bennholdt-Thomsen, op cit, p 1508.

${ }^{63}$ Esteban Bogani, "De marginales y desocupados", en Nueva Sociedad. № 197, Buenos Aires, Fundación Friedrich Ebert, 2005, pp 41-53, p 45.
} 
desventajas", en los que un inconveniente puede dar lugar a otros, resultando la exclusión el estadio final de la dinámica descripta ${ }^{64}$.

Todos estos estudios referentes a la marginalidad latinoamericana contemporánea constituyen un anclaje teórico para nuestro análisis, dado que, en acuerdo con ellos, consideramos que las explicaciones para este fenómeno se encuentran en la propia dinámica del sistema económico y que aquélla se acentúa a lo largo de la vida de una persona, aunque no necesariamente de manera lineal. Agregamos, sin embargo, que, una vez producido el surgimiento de sectores marginales, este fenómeno es retomado por los diversos discursos que, además, los transforman en chivos expiatorios de los distintos problemas que dicho sistema sea incapaz de controlar. Notamos, asimismo, que en el contexto que estudiamos debemos tener en cuenta también la desigualdad jurídica de los hombres, que era inherente al sistema de explotación.

En esta sección hemos revisado algunas propuestas que nos han resultado relevantes para la definición de la marginalidad, así como la variabilidad de las fronteras donde esta situación se ubica en cada sociedad y los cambios en las condiciones que presentan quienes se encuentran en este espacio. También observamos cómo, en muchos casos, esto se corrobora en el plano geográfico, con la amplia movilidad de los marginales. Sin embargo, este fenómeno mantiene un elemento permanente: hay una sanción por parte de los centros de poder (político, religioso y económico) sobre qué es lo integrado, lo marginal o lo excluido, cuestión que abordaremos en el próximo apartado.

\section{La sanción de la marginalidad}

En el contexto que nos ocupa, los marginales son considerados por el discurso hegemónico como el reverso de los integrados en la sociedad, consecuentemente, en tanto esto atañe a cuestiones morales fundamentales para el mantenimiento de la armonía y la paz, se los presenta como enemigos de la comunidad, tanto más peligrosos por no encontrarse separados espacialmente de ella, aunque se postula la antinomia marginalidad-integración.

\footnotetext{
${ }^{64}$ Gonzalo Saraví, Nuevas realidades... op cit, p 34 también pp 25, 27 y 35.
} 
Algunos autores sostienen que la marginalidad es definida por la sanción de la sociedad, que al marcar la frontera de la desviación subraya la normalidad ${ }^{65}$. En este marco, T. van Dijk, postula que hay principios ideológicos que se formulan en contextos de admisión, inclusión, socialización, iniciación, enseñanza, pero también en los de jurisprudencia, penalización, marginación y exclusión. Tal como veremos a partir del próximo capítulo, la finalidad de la construcción de las fuentes que nos ocupan consiste en deslegitimar a determinados grupos minoritarios, mediante la degradación de la pertenencia, de las acciones, de los objetivos, de las normas y valores, de la posición social y del acceso a los recursos sociales de quienes participan en ellos ${ }^{66}$. El lingüista holandés sostiene que es importante que los miembros de un grupo sean considerados como tales por los otros integrantes de la comunidad, pero para que un sujeto sea admitido en las diferentes formaciones sociales, la regla que se impone es la de que comparta con la mayoría de sus pares las creencias, costumbres y actuaciones. En el caso que nos ocupa, al ser corporativa la sociedad castellana temprano moderna, y al formar parte una persona simultáneamente en ella de varios de sus colectivos (castellano, vecino de la ciudad, miembro de determinado estamento o religión, etc.), su integración era directamente proporcional a la cantidad de entidades a las que adscribía $^{67}$. La comunidad de la aldea y las reglas para la adquisición de la vecindad requerían una inserción plena en el sistema de prácticas y representaciones compartidas por los demás, así como la vigilancia de la disidencia. Las transgresiones a las reglas, la desviación y la oposición abierta, eran sancionadas con la marginación, la exclusión o la eliminación, ya fuera física, económica, social o cultural. Todo esto se proyectaba más allá de las relaciones de producción, mientras el desarrollo del individualismo tenía que ver con una menor necesidad de integrarse en varios de los cuerpos que conformaban la sociedad.

\footnotetext{
${ }^{65}$ Ferrán García Olivier, "Elusiva cultura marginal”, en AAVV, Cultura y culturas en la historia. Salamanca, Ediciones Universidad de Salamanca, 1995, pp 19-38, p 29.

${ }^{66}$ Estas son las estrategias que postula Van Dijk y que nosotros podemos constatar en nuestras fuentes. Teun van Dijk, Ideología. Una aproximación multidisciplinaria. Barcelona, Gedisa, 1999, pp 192, 322 y 323.

${ }^{67}$ Tal como sostiene P. Rosanvallon, "En una sociedad de cuerpos, existen enormes desniveles políticos y sociales, pero al mismo tiempo hay continuidad y todos los seres están relacionados. Los cuerpos organizan y cubren a toda la sociedad, enlazando al príncipe y a sus súbditos, a los ricos y a los pobres, a los hombres y a las mujeres, los amos y los empleados, los adultos y los niños. Hay un lugar para cada quien, incluso si no todos están en el mismo lugar. Y las capacidades jurídicas son muy variables en este tipo de sistema: están ligadas a los bienes y a las estructuras sociales, antes que a los individuos considerados por sí mismos." Pierre Rosanvallon, La consagración del ciudadano: historia del sufragio universal en Francia. México, Instituto Mora, 1999, p 98.
} 
Desde otro ángulo, Castel sostiene que la exclusión es siempre el resultado de procedimientos oficiales de discriminación que obedecerían a estrictas reglas de construcción y que comprenderían la sanción y aislamiento de la sociedad, representando un verdadero status ${ }^{68}$. Sin embargo, consideramos que es necesario diferenciar marginalidad y exclusión, dado que en la primera no hay un proceso jurídico de separación de la comunidad, sino que se trata de una situación ambigua, pues el marginal viviría precariamente en los intersticios de la sociedad.

Los sectores segregados son invisibilizados dado que la sociedad no los observa en sí mismos, sino a la relación que mantiene con ellos ${ }^{69}$. H. Becker sostiene que la desviación no es una cualidad del acto cometido por una persona, sino consecuencia de la aplicación de normas y sanciones a un transgresor, por parte de la sociedad. De esta manera, el desviado es aquél a quien se etiqueta de este modo: la condena de la transgresión depende de que los otros la vean como problemática ${ }^{70}$. Becker, procedente de la Escuela de Chicago, instauró la teoría del etiquetamiento, que implicó un giro en la sociología de la desviación, en tanto localiza el origen del problema en la decisión de los sectores hegemónicos -luego replicada en diversas esferas- de dotar de una connotación negativa a las conductas o prácticas de determinados sujetos.

Teniendo en cuenta la noción de la marginalidad como una calificación impuesta por otros, observaremos cuáles pueden ser las causas para que los sectores hegemónicos realicen esta estimación respecto a determinados fragmentos de la sociedad. En este sentido, nos interesa la propuesta de Schmitt, quien encuentra la frontera que separa la integración de la exclusión en la utilidad social, que deriva del beneficio material que obtiene la colectividad de sus agentes sociales, así como la garantía de la seguridad de los bienes, las personas y el orden establecido ${ }^{71}$. Los discursos que construyen la segregación de algunos actores sociales tienen su fundamento en que se supone que su mera existencia atenta contra la estabilidad de la comunidad en la que conviven junto a quienes sí están integrados. Geremek sostiene, en relación con esta clase de postulados, que el marginado no comete un crimen, sino que su existencia misma lo es, desde la perspectiva de quienes lo consideran de tal modo ${ }^{72}$. Dicha evaluación depende, en

\footnotetext{
${ }^{68}$ Robert Castel, Las trampas... op cit, p 258. Como vemos, este sociólogo por momentos distingue exclusión y marginalidad, pero en otros confunde ambas categorías.

${ }^{69}$ Ferrán García Olivier, op cit, p 29.

${ }^{70}$ Howard Becker, Outsiders. Etudes de sociologie de la deviance. París, A.-M. Métailié, 1985, pp 33 y 35.

${ }^{71}$ Jean Claude Schmitt, L'histoire... op cit, p 367.

${ }^{72}$ Bronislaw Geremek, Les marginaux... op cit, $\mathrm{p} 18$.
} 
última instancia, de la sanción de los grupos dominantes, luego reproducida en diversas esferas sociales.

Sin embargo, el marginal es necesario para la sociedad como ejemplo de lo indebido, pero también para construir la idea de seguridad, que debe ser defendida frente a los agentes desestabilizadores. La situación de frontera en que se encuentran los marginales (ni integrados, ni excluidos) posibilita esta construcción ideológica, pues si estuvieran separados de la sociedad, su "peligro" sería inhibido ${ }^{73}$.

El discurso político delimita qué sujetos serán segregados de una sociedad. Esta calificación se reproduce en el imaginario de la población integrada, que debe compartirlo para ocupar esta posición ${ }^{74}$. Para que determinadas personas se perciban como distintas, tienen que ser consideradas de ese modo por otros, pues toda identidad requiere del reconocimiento de la comunidad para que exista social y públicamente ${ }^{75}$.

Para cada grupo que se estima que desafía a los sectores dominantes o al statu $q u o$, las principales categorías identificatorias que lo definen pueden ser descalificadoras. Las estrategias de deslegitimación generalmente presuponen normas, valores e ideologías que se presentan como universales o ampliamente aceptadas en la sociedad. Los grupos dominantes no se refieren abiertamente a sus propios intereses sino que utilizan argumentos que afirman que sus acciones o políticas son para el bien común o que tienen efectos positivos para los grupos dominados ${ }^{76}$. En los capítulos cuarto, quinto y sexto veremos el funcionamiento de estas cuestiones en la literatura picaresca.

\footnotetext{
${ }^{73}$ La idea de la importancia de la existencia de los marginales como un contrapunto del orden social está presente en varios autores: Juan Carlos González Hernández, op cit, pp 154 y 155; Emilio Mitre Fernández, op cit, $\mathrm{p} 49$.

74 Teniendo en cuenta las formas de clasificación social, L. C. Álvarez Santaló propone que la marginalidad puede definirse tanto por lo que se hace cuanto por lo que deja de hacerse. Así, existiría una marginalidad culpable, con la que se identificaría al enemigo de la comunidad. Estos marginales no serían sociedad sino "no-sociedad", comunidad especialmente temible por su carácter de extraña al orden, idealmente representado por el grupo que utiliza este criterio. Por otro lado estaría la marginalidad inocente, marcada por el "no hacer", sin embargo no cumplir con lo que la comunidad manda es igualmente culpable. Conformarían este grupo quienes no colaboran eficazmente en la tarea común, sin atacar de manera directa a los responsables, por eso, sostiene el autor, estos marginales sí pertenecerían a la sociedad. León Carlos Álvarez Santaló, Hagiografía ... op cit, pp 123 y 124.

${ }^{75}$ Gilberto Giménez, "Materiales para una teoría de las identidades sociales". México, Instituto de Investigaciones Sociales, UNAM, 1997, mimeo, p 3. F. García Olivier sostiene que el primer síntoma de la periferización social es el paso de los grupos marginales por las fuentes literarias, iconográficas y archivísticas. Ferrán García Oliver, "Elusiva cultura marginal", en AAVV, Cultura y culturas en la historia. Salamanca, Ediciones Universidad de Salamanca, 1995, pp 19-38, pp 27 y 28.

${ }^{76}$ Teun van Dijk, op cit, p 323.
} 


\section{Conclusión}

Dentro del campo de las ciencias sociales existen numerosos debates sobre quiénes son los marginales y cuáles son los parámetros para definirlos de este modo. Encontramos diversos puntos de vista, según se centren en las pautas socio-culturales, la lingüística o la economía, así como si versan sobre la formación social o los sujetos. Consideramos que estos análisis, de manera autónoma, no son suficientes para hallar solución al conflicto teórico. Además, todas estas esferas se relacionan empíricamente en los agentes que viven en condiciones de marginalidad, tal como aquí la entendemos.

Los discursos de los sectores dominantes definen y caracterizan en su particularidad a los sujetos a quienes quieren segregar para diferenciarlos de la sociedad a la cual se dirigen y los análisis realizados desde las ciencias sociales muchas veces aceptan esta forma de denominación sin considerar la posibilidad de evaluar de otra manera cómo y quiénes son dichos agentes.

Lo que caracteriza a los marginales que nos ocupan es su condición de vagabundos que sobreviven en los poros de una sociedad sedentaria, circunstancia ligada a todas las estructuras económicas, sociales y culturales. El origen de esta situación se encuentra en la imposibilidad de seguir garantizando la propia subsistencia en el marco de sociabilidad establecido, pero el hecho de ser itinerantes convierte a los hombres en sospechosos para una sociedad sedentaria y estamental, acentuando su carácter marginal e imposibilitándoles mantener un marco de sociabilidad normal. Esta condición territorial se encadena con dos aspectos fundamentales que definen a los subsiguientes: la inviabilidad de sociabilización estable (objetivamente) y la estigmatización de este grupo por parte de la sociedad (desde el plano subjetivo).

Respecto al primer problema, los marginales quedan fuera de las posibilidades de inserción en las redes sociales admitidas como normales. Su forma de vida resulta contraria a las normas habitualmente demandadas para la vinculación en el ámbito de una familia u otro tipo de institución. Además de que ellos sean vistos como temerarios, su propia vida parece riesgosa e inestable, cualidades que serían antagónicas con la posibilidad de participar en estas redes de contención. Los marginales mostrarían dos características a lo largo de diferentes situaciones históricas: la no concordancia con los valores éticos, morales o religiosos de su ambiente social y su condición nómade (ambas como causa o consecuencia de su marginalidad), mientras su inserción laboral es escasa e intermitente, acentuando (o determinando) su estado. 
Consideramos que es necesario especificar los motivos de la segregación de diversos conjuntos de la sociedad, para evitar la confusión cuando nos abocamos a su estudio. Así, no será lo mismo tratar acerca de los marginales económicos que de los perseguidos políticos, los herejes, las minorías étnicas o de los desviados. Por este motivo, a lo largo de esta tesis, nos referiremos a los marginales a partir de las pautas que hemos sentado en este capítulo, aunque admitimos que variadas formas de segregación se yuxtaponen en un mismo agente, motivo por el cual creemos aun más importante dicha precisión en el análisis.

En relación con el segundo aspecto, la criminalización del sector marginal implica ante todo la definición desde el lenguaje, ya que la idea que se tiene de este grupo se construye mediante el discurso. Por otro lado, debemos tener en cuenta que todas las sociedades albergan hablas particulares de los diversos sectores sociales que viven en su seno. El segmento marginal presentará la suya, que resultará una fuente de sospecha para el resto de la sociedad que no puede comprenderla y por eso le teme. Asimismo, el discurso contra este grupo encontrará su expresión de manera política mediante las diversas legislaciones y normativas (por parte de la monarquía o de la Iglesia, por ejemplo), que se abocan a su persecución.

Habiendo repasado el contexto de marginación que preludió la emergencia de la narrativa picaresca, en el próximo capítulo analizaremos los mecanismos mediante los cuales la literatura retomó la representación de los marginales a partir de la conformación de la figura del pícaro, que fue su expresión en el plano de la novela. Hemos visto hasta aquí las nociones de estigmatización de los sectores segregados de la sociedad y su inculpación de todo aquello que la perturbara, así como la imputación de diversas cualidades negativas y atemorizadoras. Analizaremos en adelante su práctica en el discurso literario y político. 
CAPÍTULO 2

LA PICARESCA EN SU CONTEXTO 


\section{Introducción}

El problema que significan socialmente los marginales ocupa a los historiadores, tal como observamos en el capítulo precedente, pero también a los artistas y comunicadores (hoy la industria cultural) que se encargan de representarlos a través de la pantalla o en el tabloide, donde podemos encontrar sus historias. Estos relatos dan cuenta de una preocupación respecto a quienes fueron segregados por el sistema social que no es nueva. En esta investigación rastrearemos el mundo de los marginales que fueron retratados por la literatura picaresca en el marco de los debates que generaba, entre diversos sectores de la élite española tempranomoderna, la presencia de dichos personajes sociales. Enmarcada en un proceso de criminalización de los vagabundos, quienes eran vistos como perturbadores del orden social, la picaresca se encargó de describirlos según la imagen que surgía de la observación por parte de algunos miembros de la élite - de la cual provenían los autores, en general, pero a la que también pertenecía el público lector al que estas obras se dirigían.

Esta narrativa se inicia en el contexto de la cultura renacentista, que postulaba la emergencia del sujeto y su individualidad. La libertad de los hombres pasaba a entenderse en tanto dejaban de ser pensados únicamente a partir de su vínculo jurídico con otro individuo, lo cual implicaba también sujetos más móviles. Sin embargo, este renacimiento no fue entendido de la misma manera por todos y algunos autores criticaron ciertas ideas acerca de la libertad y la individualidad, que resultaban, en tanto que revolucionarias, peligrosas para el orden existente, a cuya defensa acudían.

El humanismo, además, tuvo un carácter distintivo en España, aspecto que ha sido ampliamente debatido. La discusión se plantea en torno a si su cultura estuvo ideológicamente preparada para la transformación que implicó dicho movimiento y si ese cambio pudo pervivir luego de la Contrarreforma. En esta región habría tenido lugar un humanismo particular, diferente al del resto del continente, por ese motivo no debería ser analizado con los mismos parámetros que éste, pues la vertiente peninsular del movimiento fue más pedagógica, emocional y canalizada por la vía de la literatura ${ }^{1}$.

La narrativa picaresca muestra el problema del control social en el marco de la transición del feudalismo al capitalismo, para cuya comprensión debemos considerar

\footnotetext{
${ }^{1}$ Este debate es reseñado por J. García Gibert, cuyas conclusiones retomamos. Javier García Gibert. La humanitas hispana. Sobre el humanismo literario en los Siglos de Oro. Salamanca, Ediciones Universidad de Salamanca, 2010, pp 13 y 58.
} 
que las formas de dominación de este último comienzan a presentar diferencias respecto de las que encontramos en el sistema feudal. Si en éste existía la adscripción personal del siervo a su señor -que no era sólo contractual sino que, sancionada en la tradición y respaldada por la religión, era legítima-, en el capitalismo, por el contrario, el dominio de unos hombres sobre otros es abstracto, excediendo las relaciones personales. El período que estudiamos presenta como particularidad que el asalariado, dueño de sí mismo, sólo vendía su fuerza de trabajo de manera relativamente libre, pues si bien la contratación estaba condicionada por los municipios y sus oligarquías, las trabas impuestas por éstos podían ser sorteadas por los interesados gracias a la ineficiencia del control que eran capaces de ejercer, mientras la progresiva desintegración de los lazos inmediatos en que la relación de explotación siempre se había fundado, dio lugar lentamente a la formación de vínculos mediados por el dinero.

Las nuevas formas de entender al individuo, con la consiguiente necesidad de cambiar las estrategias para dominarlo, produjo la emisión de diversos discursos (guías, tratados, ordenanzas y legislación, novelas, poesía, teatro, crónicas), en los cuales se testimonian las representaciones de los tipos sociales según diversos puntos de vista que están relacionados con su autoría, la intención del texto y las reglas del género. Dado que hallamos un enorme caudal de fuentes de diversa índole, hemos tomado la decisión metodológica de orientar nuestra mirada fundamentalmente a dos tipos de discursos, las peticiones y respuestas de las $\operatorname{Cortes}^{2}$ y la novela picaresca, selección que hemos realizado teniendo en consideración cuáles son los aspectos que deseamos analizar acerca de los marginales.

La picaresca resulta una fuente adecuada a nuestros propósitos, pues si bien se trata de relatos de ficción, describe minuciosamente cuestiones que no han merecido la atención en otro tipo de escritos, como la precepción acerca de las formas en que se reproducía socialmente el sector marginal y su relación con el resto de la sociedad. En primer lugar, en tanto las formas de sociabilidad de dicho grupo no han sido descriptas por los propios protagonistas ${ }^{3}$, debemos indagar en lo que han escrito sobre ellas

\footnotetext{
${ }^{2}$ En esta tesis utilizaremos: Real Academia de la Historia. Cortes de los Antiguos Reinos de León y de Castilla. Madrid, Establecimiento Tipográfico "Sucesores de Rivadaneyra", 1863- 1903 y Congreso de los Diputados. Actas de las Cortes de Castilla. Madrid, Establecimiento Tipográfico "Sucesores de Rivadaneyra", 1887.

${ }^{3}$ Si bien J. Amelang en su minucioso estudio acerca de las biografías escritas por artesanos denomina a estos personajes sociales como marginales, en el capítulo precedente hemos expuesto una noción diferente de la suya en este aspecto, por tanto consideramos que dichas fuentes no provienen de los marginales a quienes aquí nos referimos. James S. Amelang, El vuelo de Ícaro. La autobiografía popular en la Europa moderna. Madrid, Siglo XXI, 2003.
} 
personas relativamente ajenas a su mundo. La narrativa que escogimos resulta suficientemente cercana al fenómeno, mientras su minuciosidad nos permite llegar a un análisis microsocial que otros documentos no nos habilitan. En segundo término, a partir de los textos que seleccionamos, podemos, además de vislumbrar las existencias marginales, estudiar la representación que se hacían de ellos los autores, lo cual nos brinda una valiosa información acerca de las concepciones sociales vigentes acerca de los pícaros.

Esta fuente contiene un retrato ficcional y literario, lo cual implica tener en cuenta ciertas precauciones para su análisis, considerando todos los factores que intervienen en su producción, que deforman y pueden alejar la realidad de su representación en este tipo de narrativa. En los siguientes apartados veremos qué cuestiones debemos ponderar para examinar la picaresca, considerando las reglas del género, la individualidad de cada uno de los autores, y quiénes eran sus destinatarios.

En la segunda parte de este capítulo nos dedicaremos a exponer los problemas particulares que presentan las peticiones y las respuestas de Cortes para el estudio que nos proponemos. Se trata de un discurso que tiene un fin normativo y a través del cual podemos vislumbrar algunas perspectivas de las existencias marginales y su vínculo con el resto de la sociedad. Estas fuentes, por oposición a las literarias, nos permiten observar un interés compartido por los procuradores y la monarquía, así como la dinámica del problema, cuestiones que aclararemos escuetamente en este capítulo y profundizaremos en el próximo.

Finalmente, antes de avanzar sobre el análisis de las actas de las Cortes y la literatura en los próximos capítulos, haremos referencia al debate que sostuvieron los escolásticos en el siglo XVI acerca de los pobres. Observaremos diversos aspectos comunes a las fuentes que nos ocuparán en adelante y los postulados esgrimidos en dicha controversia, en pos de comprender el marco ideológico de su producción. Los textos en los cuales los teólogos propusieron soluciones al problema de la pobreza durante el siglo XVI no serán considerados como la materia central de nuestro estudio, aunque nos referiremos a ellos cuando sea pertinente para nuestro análisis. 


\section{La elección de las fuentes}

Antes de proseguir, expondremos la selección que hemos hecho para nuestro estudio. El corpus de la picaresca cuenta con cerca de diecisiete volúmenes de importancia ${ }^{4}$, que fueron escritos por diversos autores en un lapso de aproximadamente un siglo, a partir de la publicación de La vida del Lazarillo de Tormes en 1554. Evidentemente se trata de un conjunto de textos no sólo muy diverso, sino también extenso. Además, debemos tener en cuenta que durante esos cien años se desarrollaron cambios políticos y sociales que produjeron nuevas inquietudes. Por otro lado, el sector social al cual pertenecían los autores, así como sus trayectorias, fueron muy heterogéneos, tal como detallaremos en el apartado pertinente. Debido a estas variables nos vemos obligados a seleccionar sólo un grupo de novelas para abordar en este estudio. A tal efecto, escogemos algunas obras que consideramos emblemáticas acerca de las problemáticas que presenta el género, pero para ello tendremos en cuenta, por un lado, el objeto de nuestro análisis -que abarca sólo un aspecto de todo aquello que puede ser observado en la picaresca-, y por el otro, su importancia dentro de este corpus. Hemos intentado elegir novelas que fueran además representativas en tanto que diferentes por las intenciones de sus autores y, en consecuencia, el retrato de la sociedad que eligieron hacer. Los demás volúmenes de esta narrativa serán considerados de manera secundaria e ilustrativa, sólo en los casos en que evaluemos pertinente hacer referencia acerca de ellos.

Teniendo en cuenta estas premisas, examinaremos las tres novelas estimadas como las más importantes de la picaresca (La vida del Lazarillo de Tormes, La vida del Buscón llamado Don Pablos y la primera parte de Guzmán de Alfarache ${ }^{5}$ ), debido a que, si bien han sido extensamente estudiadas por parte de la crítica literaria, no han merecido la misma suerte en cuanto a su atractivo para los historiadores. Algunas cuestiones de interés para nosotros referentes a estas novelas han sido exitosamente saldadas por parte del arduo trabajo de los críticos, cuyas conclusiones retomaremos.

\footnotetext{
${ }^{4}$ Decimos que esa cifra es aproximada porque los debates en torno al género y cuáles novelas pueden postularse como pertenecientes a él hacen que algunos autores incluyan ciertas obras que otros descartan. Consideramos la clásica edición de este corpus realizada por A. Valbuena y Prat, que luego sería cuestionada por los críticos a la hora de estimar si alguna de las obras contenidas en ella participa del género o no. Ángel Valbuena y Prat. La novela picaresca española. Madrid, Aguilar, 1956.

5 A partir de aquí nos referiremos a estas tres novelas como El Lazarillo, El Buscón y El Guzmán, respectivamente. También haremos oportunamente referencias a la segunda parte de la novela de Mateo Alemán.
} 
El Lazarillo es considerada la primera obra picaresca ${ }^{6}$ y a partir de su comparación con el resto de las novelas que componen el género podemos observar cómo varió la forma de representar a los marginales. En la primera, la óptica respecto al marginal es más favorable a éste (Lázaro), mientras carga las tintas contra los miembros de la Iglesia, quienes aparecen alejados de la caridad cristiana. Además, a diferencia de los otros pícaros, Lazarillo actúa en soledad, no tiene otro compañero como servidor (más que su esposa en el último tratado), ni cuando limosnea o se encuentra baldío. El anónimo autor parece, a diferencia de los demás, haber tenido la intención de retratar la existencia de una víctima campesina de las circunstancias económicas de su tiempo y su lucha para poder sobrevivir día a día. Por otra parte, nos resulta especialmente interesante la ilustración acerca de cómo una familia de origen rural, integrada en la comunidad local, puede caer en la marginalidad, desintegrándose.

Si bien algunos aspectos del El Guzmán que nos ocupan han sido estudiados con pericia y minuciosidad por parte de M. Cavillac, y varios interrogantes pertinentes a nuestro análisis en torno a esta novela ya han sido saldados por la tesis de ese crítico, veremos en los capítulos cuarto y quinto la representación de la socialización marginal y de la mendicidad, respectivamente. Observaremos en esta obra el estereotipo de la corporación de mendigos, que constituyó una noción muy extensa en el período que estudiamos. Asimismo examinaremos el funcionamiento del trabajo de servicio y la sociabilidad en este marco, aspecto también retratado en la novela. Sin embargo no nos detendremos en otras cuestiones como la narración de los delitos del protagonista (que en su mayoría tienen lugar en la segunda parte de la obra) fuera de estos contextos que hemos mencionado, ni en las representaciones de otras cuestiones como su origen, el significado de su derrotero y los vínculos con sus empleadores, aunque los tendremos en cuenta, dado que consideramos que han sido explicadas exhaustivamente por el especialista francés.

La incursión de F. de Quevedo en la novela picaresca nos ofrece una crítica exacerbada respecto a los marginales que en ella retrata y satiriza. A través de El Buscón, el autor pretende ilustrar la nocividad de dichos personajes sin encontrar en ellos más que un grupo asocial y peligroso. En esta obra particularmente casi no

\footnotetext{
${ }^{6}$ Debemos indicar que existen diversas consideraciones en torno a la función de El Lazarillo en el género. A. Parker la considera como una obra precursora del género, mientras que Francisco Ayala la eleva a prototipo. Por su parte, A. Castro ha visto en ella la prefiguración de la novela moderna, línea de interpretación que ha sido exitosa y es generalmente aceptada. Alan Francis, Picaresca, decadencia, historia. Madrid, Gredos, 1978, p 33.
} 
hallamos la inclusión del pícaro en el trabajo de servicio -ni en otro-, sino que sobrevive siempre a costa de la mendicidad o la estafa, mientras se atiende obsesivamente a la reproducción social de los marginales.

Además de las tres obras paradigmáticas del género elegimos otras dos que consideramos pertinentes para nuestro análisis. Hemos incluido Las aventuras del Bachiller Trapaza ${ }^{7}$ para observar cómo fueron variando estas representaciones en el ocaso de este género literario. En este texto veremos especialmente la forma en que se presenta la ocupación en el servicio por parte de este personaje. Esta novela cuenta con recursos característicos de la cortesana pero, a pesar de dar importancia a diversos eventos en la corte, su protagonista es un pícaro que se emplea también en otros ámbitos. Nuestro interés por esta obra radica en la posibilidad de indagar acerca del servicio doméstico y los vínculos que se tienden en este contexto.

Por último, incluimos La hija de Celestina porque nos interesa contrastar la representación de las mujeres marginales en las novelas en las cuales ellas tienen un rol secundario y este caso, en que su intervención es protagónica, pues en una y otra oportunidad las evaluaciones acerca de ellas son diferentes. Además, veremos que en esta obra, la crítica respecto a los marginales es más aguda que en las otras novelas examinadas. La pertenencia de esta novela a la picaresca es discutida desde dos aspectos: por un lado, gran parte del relato se construye como un discurso indirecto, por otro, su protagonista es una mujer. Sin embargo, aquellos que no la incluyen en el género la consideran como una obra con personajes picarescos. En adelante veremos además por qué esos dos aspectos no son necesariamente excluyentes para la crítica. Ésta es una novela de caminos, en cuyo recorrido podremos ver las relaciones entre marginales y la reproducción de sus vínculos, así como la construcción imaginaria de bandas delictivas en pos de incentivar la persecución y la prohibición de la circulación de los hombres sin amo.

Teniendo en cuenta que se trata de un conjunto de fuentes que informan también sobre la subjetividad de un individuo, el autor, creemos necesario contrastarlas con otras de naturaleza diferente que, si bien contienen una información menos minuciosa acerca de las prácticas, es colectiva y expresa la imposición de los intereses de un grupo para incidir sobre la realidad. Se trata de las Cortes de los Antiguos Reinos de Castilla y de León, que también presentan sus singularidades y dificultades. En este capítulo

\footnotetext{
${ }^{7}$ A partir de aquí El Bachiller Trapaza.
} 
observaremos sus problemas específicos, antes de proseguir con su estudio particular. Por lo pronto, adelantamos que hemos evaluado peticiones entre los años 1268 y 1628 , lapso extenso cuyo análisis nos permite estimar la evolución del fenómeno. Por otro lado, aclaramos nuevamente que hemos considerado las demandas referentes a los hombres baldíos, la regulación del trabajo y la circulación de los individuos, pero sólo pocas otras concernientes a cuestiones vinculadas con diversas minorías $\mathrm{u}$ otros conflictos relacionados de manera indirecta con nuestro objeto. Procuraremos no distraernos con los problemas referentes a otros sectores segregados (aunque los mencionaremos cuando resulte pertinente), contra quienes se elabora la normativa (moros, gitanos, prostitutas, etc.), que presenta en su enunciación características similares a la forma en que se menciona a los marginales que nos ocupan.

\section{A - La picaresca}

En las siguientes páginas veremos los problemas propios de la picaresca. Analizaremos en primer lugar cuestiones referentes al pícaro, observando las discusiones de los críticos en torno a esta controvertida figura, para adentrarnos luego en otros debates acerca de este género literario. En tanto esta narrativa nos importa como una representación social, veremos cuáles eran los intereses de los autores de las novelas que nos ocupan, así como el público al cual se dirigían.

\section{A- 1. Los pícaros}

Los pícaros fueron extensamente representados por esta narrativa, que se encontraba flanqueada por otros discursos que también trataban y censuraban la vida vagabunda ${ }^{8}$. La descripción de estos hombres se desarrolló mediante la ilustración de variados aspectos de su existencia: las actividades que desempeñaban, sus itinerarios, su forma de relacionarse (con el resto de la sociedad y dentro de la subcultura que conformaban), su apariencia y su lenguaje, particularidades que fueron estereotipadas, retroalimentándose su tipificación a través de diversas obras del género. En este sentido consideramos que, si bien la literatura debe leerse por el historiador con todos los

\footnotetext{
${ }^{8}$ Nos referimos aquí a los debates de los escolásticos que versaron acerca de los pobres y su derecho a la limosna, como parte de su preocupación intelectual y política. En este último aspecto se enmarcaban las diversas normativas que pretendían regular a los vagabundos.
} 
recaudos necesarios como fuente para analizar la realidad del período, nos informa acerca de la evaluación de dicho contexto por parte de los coetáneos.

La comprensión de la valoración de los contemporáneos contribuye al estudio de las mentalidades. Según P. Burke, las formas lingüísticas y sus variaciones y cambios informan acerca de "la naturaleza de la totalidad de las relaciones sociales en una determinada cultura" ${ }^{\text {. }}$. El estudio de la forma en que se designa a los marginales, así como la representación que hacen los autores del habla del grupo puede echar luz sobre diversos aspectos de la subcultura que conformaban y su vínculo con la sociedad ordenada.

En tanto la literatura permite la representación, la picaresca es el retrato de una subcultura (marginal) realizado por parte de un miembro de otro estamento social, cargado por sus propias ideas acerca de ese mundo que le resulta más o menos conocido. En este contexto, que se enmarca políticamente en un período de persecución del vagabundeo, la picaresca toma posición en la estigmatización de un conjunto de individuos. Dado que se trata de una producción intelectual individual, el escritor puede o no representar las ideas generales de su estamento respecto de los marginales ${ }^{10}$.

Existe una controversia sobre la etimología y significado de la palabra pícaro, que conduce lógicamente a otra en torno a las novelas que presentan este tipo de protagonistas; comencemos, entonces, por tratar de resolver este problema para poder esclarecer la pertenencia al prototipo y al género ${ }^{11}$. Coetáneamente a la producción de esta literatura, S. de Covarrubias lo define a través de su vínculo con el picaño, "El andrajoso y despedaçado, de la palabra pittacium, portio corii curti, quo muniuntur calcei, y de aquí se llamó picaño el remiendo que se echa al çapato" ${ }^{12}$. Sin embargo, del mismo modo que se puede relacionar con sus andrajos, que dan cuenta de su pobreza, también lo vincula con la ocupación temporal de los hombres libres, pues "Se pudo dezir de pica, que es el asta, porque en la guerra, hincándola en el suelo, los vendían had

\footnotetext{
${ }^{9}$ Peter Burke, Hablar y callar: funciones sociales del lenguaje a través de la historia. Barcelona, Gedisa, 1996, p 34.

${ }^{10}$ Sobre la individualidad del autor que representa su única visión del mundo, ver la intervención de S. de Beauvoir en el debate “¿Para qué sirve la literatura?”, publicado en Jean Paul Sartre y Simone de Beauvoir (coord.), ¿Para qué sirve la literatura? Buenos Aires, Proteo, 1970, especialmente, pp 71 y ss. 11 K. Meyer-Minnemann reseña este debate. Klaus Meyer-Minnemann, "El género de la novela picaresca", en Meyer-Minnemann, Klaus y Schlickers, Sabine (eds.). La novela picaresca. Concepto genérico y evolución del género (siglos XVI y XVII). Madrid, Iberoamericana Verbuert, 2008, pp 13-40, p 24. En el marco del propio género, la palabra pícaro no aparece hasta El Guzmán.

${ }^{12}$ Sebastián de Covarrubias, Tesoro de la lengua castellana o española. Barcelona, Horta, 1943, p 869.
} 
hastam por esclavos. Y aunque los pícaros no lo son en particular de nadie, sonlo de la República, para todos los que los quieren alquilar, ocupándolos en cosas viles" "13. Aquí confirmamos la relación entre el pícaro y el hombre baldío, pobre y libre. Pero Covarrubias añade aun más cuestiones, pues también vincula a estos personajes con los extranjeros desheredados en busca de mejor suerte, pues "Picardía es una provincia de Francia, y pudo ser que en algún tiempo alguna gente pobre della viniesse a España con necessidad y nos truxessen el nombre" ${ }^{14}$. En este fragmento se añade, además, la figura del migrante pobre, característico entre los protagonistas de las novelas que analizamos. Tal como indica T. Altenberg, los diferentes usos del nombre pícaro (al lado de otros como bellaco, ganapán, tacaño) en El Buscón, sugieren que el nacimiento en la pobreza y la conducta despreciable se implican mutuamente y dan cuenta de la concepción estática y jerárquicamente estratificada de la sociedad que tenía Quevedo ${ }^{15}$, aunque a través de las líneas de la novela podemos vislumbrar la posibilidad de una sociedad mucho más móvil de la que el literato concebía.

F. Lázaro Carreter encuentra en el pícaro un individuo sin oficio, "disponible siempre para trabajos subalternos, que mueve a aprensión por su miseria $\mathrm{y}$, dada su falta de principios, sospechoso de delinquir"16. Según esta interpretación, se trata de marginales pasibles de ser contratados (en tanto libres y sin ocupación), pero rechazados socialmente. Sin embargo, el crítico estructuralista les atribuye determinadas prácticas ("Como actividades básicas unas veces, y complementarias otras, practicaba el hurto, el juego y la mendicidad" ${ }^{17}$ ) que, si bien se presentan en la mayoría de los protagonistas del género, no consideramos esenciales a la definición, dado que partimos de la noción del marginal, cuyas estrategias de supervivencia pueden ser las mencionadas $\mathrm{u}$ otras, $\mathrm{y}$ por ausencia de las cuales algunos pícaros (entre ellos el Lazarillo) no pueden ser estimados como tales para el autor ${ }^{18}$. El crítico español considera como estereotipo del pícaro al Guzmán y aduce que el ángulo que lo homologa con el Lazarillo es el moral ${ }^{19}$.

\footnotetext{
${ }^{13}$ Ibídem, p 869.

${ }^{14}$ Ibidem, p 869.

${ }^{15}$ Tilmann Altenberg, "Francisco de Quevedo, Historia de la vida del Buscón”, en Meyer-Minnemann, Klaus y Schlickers, Sabine (eds.). La novela picaresca. Concepto genérico y evolución del género (siglos XVI y XVII). Madrid, Iberoamericana Verbuert, 2008, pp 353-390, p 373.

${ }^{16}$ Fernando Lázaro Carreter, Lazarillo de Tormes en la picaresca. Barcelona, Ariel, 1972, p 219.

${ }^{17}$ Ibidem, p 219.

18 "Nunca obró así Lázaro (...) que se aplicó exclusivamente a servir, y que se reconcilió con la vida cuando obtuvo el oficio real". Ibídem, p 219.

19 Según Lázaro Carreter, el pícaro sería "... un desarrollo de Lázaro a la altura de 1599, es decir, inducido por otra realidad; pero allí están visibles muchas articulaciones básicas de su complexión moral". Ibídem, p 221.
} 
Debemos disentir nuevamente, porque esta característica es la más fluctuante en esta clase de personajes literarios, según la necesidad de cada autor de condenar a su criatura. La marginalidad es constitutiva de la figura literaria del pícaro, sin embrago, no es similar la manera en que los literatos representan su desviación, variable según la cual los agentes retratados resultan más o menos condenables (pensemos, por ejemplo, en las diferencias entre Pablos y Lazarillo). Por otro lado, consideramos que el mozo del ciego se enmarca entre los pícaros, no sólo porque su dedicación como servidor no es exclusiva (pues también mendiga temporalmente), sino debido a que su servicio es parte de una improvisación permanente en pos de sobrevivir en la marginalidad, de la cual no consigue salir.

Este género irrumpe con una novedad al otorgarle un rol central a un paria, pues si bien podemos encontrar este tipo de personajes a lo largo de la historia literaria con su primera aparición en la comedia romana y su pervivencia en la tradición oral y escrita durante la Edad Media ${ }^{20}$, la importancia que cobró en la modernidad como protagonista está pautada por las preocupaciones de la sociedad que enmarcaba a los autores, así como por las nuevas inquietudes en el sistema de ideas derivadas de su visibilidad, que conducían a pensar en estos sujetos como autónomos. En el marco de la cultura renacentista, la emergencia del marginal como protagonista tiene su piedra de toque en La Celestina, donde el personaje literario del marginado se individualiza y cobra profundidad psicológica. Pero también se trata de una provocación al lector, mediante la presentación de un protagonista en discordia con las actitudes normativas tradicionalmente adscritas a sus pares nobles. El estereotipo ${ }^{21}$ del marginal se reprodujo a medida que se desarrolló el género, estableciendo las características que correspondían a su representación.

Algunos críticos establecen una relación directa entre el marginal real y su figura literaria, mientras otros postulan una mayor independencia entre ambos, incluso

\footnotetext{
${ }^{20}$ Jesús García Varela, op cit, p 276.

${ }^{21}$ Dado el uso que haremos de este concepto, esclarecemos su definición desde la sociología. "Vinculado estrechamente con el concepto de prejuicio, el estereotipo consiste en una idea o visión -extendida y arraigada- no crítica respecto de un fenómeno, categoría social, grupo o institución social. El estereotipo dificulta una comunicación auténtica entre individuos pertenecientes a grupos disímiles al generar expectativas de conducta generalmente negativas respecto del alter.

El estereotipo se vincula estrechamente con la respuesta social dada a las conductas desviadas y a la cuestión racial y religiosa. Dígase otro tanto respecto de las conductas esperadas en relación con los sexos -identidad de género-.

Íntimamente vinculado a la tendencia del hombre a clasificar a los demás jerárquicamente (y a sí mismo respecto de los demás), el estereotipo está presente en toda sociedad o comunidad, cualquiera que sea el sistema de estratificación social imperante." Enrique del Acebo Ibáñez y Roberto Brie, Diccionario de sociología. Buenos Aires, Claridad, 2001, p 144.
} 
asumiendo que la intervención en la narrativa de dicho personaje social (cuyo principal exponente en la novelística sería el pícaro) resultaría independiente del contexto social $^{22}$. K. Meyer-Minnemann sostiene que las características del pícaro no deben deducirse de los datos de la realidad social, sino que el crítico otorga un sentido particular a esta figura, que cobró vida a partir del siglo XVI español, pero que tendría un derrotero propio ${ }^{23}$.

Además de marginal, este personaje es presentado como un transgresor, característica que se considera inherente a su condición social e incluso como causa de ella y que lo conduce a una contradicción permanente con su entorno, lo cual habilita la afirmación de su individualidad, que se despliega a lo largo de una existencia en cuyo transcurso se construye a sí mismo.

Los marginados en la literatura surgen dentro de un contexto de cambio de cosmovisión durante el renacimiento, cuando estos nuevos protagonistas desafían a los viejos personajes didácticos (los santos o los nobles) y ponen en tela de juicio los ejes rectores de la sociedad ${ }^{24}$. También pueden resultar agentes cómicos (tal como veremos en El Bachiller Trapaza) que emergieron a medida que el carnaval se extinguía junto con su función equilibradora y su marco social integrador. En este contexto, constituían un esquema paródico que era parte de las cosmovisiones manifiestas en dichas festividades.

Cavillac sostiene que el pícaro es el emblema de todos los desclasamientos y desviaciones ideológicas. En su análisis de El Guzmán como un libro burgués, sostiene que la figura del pícaro tiene como fin subrayar la homología entre el ocio aristocrático y el de los pícaros ${ }^{25}$. Pero Cavillac observa también cómo Guzmán fluctúa entre la inclusión y la exclusión, y asume las aspiraciones conflictivas propias de los desclasados. En tanto este protagonista ofrece la posibilidad de establecer un doble registro, reprimido y represivo ${ }^{26}$, permite mostrar una mirada desde un ángulo que un personaje integrado no podría encarnar. Este punto de vista habilita la censura, por parte de esta figura, no sólo acerca del accionar de los marginales, sino también respecto a los

\footnotetext{
${ }^{22}$ Jesús García Varela, op cit, p 276.

${ }^{23}$ Klaus Meyer-Minnemann, El género... op cit, p 26.

${ }^{24}$ Jesús García Varela, op cit, p 291.

${ }^{25}$ Este crítico observa a Guzmán, "abocado, en parte por su culpa, a vivir trampeando", como encarnación y arquetipo socioeconómico de los problemas que acarreaba España. Michel Cavillac, Pícaros y mercaderes en el Guzmán de Alfarache. Granada, Universidad de Granada, 1994, pp 324 y 360.

${ }^{26}$ Ibidem, pp 433 y 418.
} 
sujetos socialmente integrados, recurso que también posibilitaba la crítica social por parte de los literatos.

A lo largo de nuestro análisis veremos que a pesar de que se intentaba demostrar que los pícaros eran sujetos antisociales y peligrosos, la relativa aceptación por parte de quienes estaban integrados les permitía la supervivencia, además de haber habilitado que los escritores tuvieran contacto con los marginales a quienes representaron en las novelas.

En el marco de nuestra investigación, hallamos que lo que caracteriza a los pícaros es la debilidad de sus lazos sociales, lo que a su vez es constitutivo de su libertad. Se trata de sujetos en disponibilidad que, separados de los posibles recursos para la subsistencia, y en tanto no se habían desarrollado aún los mecanismos para volver a subordinarlos a la producción, se convierten en una población supernumeraria que debe ser domesticada. En el período que analizamos se maduran las herramientas sistémicas para realizar tal empresa, a través de diversas normativas que emplean distintos instrumentos para hacerlo, cuyo fracaso muestran las novelas. Por otra parte, en el marco de una sociedad sedentaria, la movilidad del pícaro dificulta su subordinación, pero también su sociabilidad de acuerdo con los parámetros normales. Por último, diremos que si la noción no excluye la capacidad de establecer vínculos sólidos $^{27}$, su existencia muestra la débil posibilidad de sostener una relación estable.

Concluimos, entonces, que el pícaro es el personaje cuya pertenencia social es la de un marginal que subsiste más o menos magramente a través de ocupaciones temporales, lícitas e ilícitas, alternativamente. Además, resulta un sujeto móvil, condición necesaria por las prácticas que utiliza para sobrevivir, pero que anula la posibilidad de que entable lazos sólidos y estables. La trama de las novelas picarescas depende estrechamente de la presencia de las características mencionadas en sus protagonistas, que dan lugar a la sucesión episódica de sus movimientos y vínculos efímeros. Por último, la calificación moral de estos personajes es en general negativa, pero este aspecto se encuentra sujeto a la evaluación que el autor tenga sobre su criatura.

\section{A- 2. El género}

\footnotetext{
${ }^{27}$ Katharina Niemeyer y Klaus Meyer-Minnemann, “Cervantes y la picaresca”, en Meyer-Minnemann, Klaus y Schlickers, Sabine (eds.). La novela picaresca. Concepto genérico y evolución del género (siglos XVI y XVII). Madrid, Iberoamericana Verbuert, 2008, op cit, p 223-262, p 244.
} 
Diversos aspectos de este corpus literario -los significados, estructura, realismo, protagonistas y facetas religiosas- han sido parte de un intenso debate. La primera cuestión gira en torno a la definición del género y qué novelas lo conforman ${ }^{28}$. La principal singularidad de dichas obras será la de contar con un pícaro como un protagonista, cuya caracterización hemos tratado de delinear en el apartado anterior.

Las novelas que conforman este corpus son muchas y de diversos autores, de manera que cada obra presenta particularidades que deben ser consideradas a la luz del género, lo que ha dado lugar a numerosas controversias ${ }^{29}$. A partir de esta consideración, tendremos en cuenta las discusiones que incumben a nuestro análisis, por lo tanto consideraremos en primer lugar la relación de la narrativa que nos ocupa con la realidad social del período en el que fue producida.

Si el vínculo entre el marginal literario y el real es objeto de debate, éste también se extiende sobre si la picaresca constituye o no un retrato de la sociedad en la cual determinados escritores se abocaron a este género. Recientemente, los estudios literarios tienden a observarlo como un relato con bastante autonomía respecto a la realidad que lo rodea, considerando que la trayectoria de un pícaro literario no está sujeta a la de un hombre al que fuera atribuible este calificativo en el marco social, lo que conduce a su evaluación como una construcción artística en la cual se expresa un escritor con su propia intencionalidad ${ }^{30}$.

La vida del pícaro es obra de la invención autoral (y no dominada por el azar), allí los sucesos tienen lugar con una determinada finalidad, que está en consonancia con el género y la mencionada voluntad del escritor. Sin embargo, el mundo de la picaresca está constituido según las exigencias de la verosimilitud, que remiten a la visión compartida por autores y lectores ${ }^{31}$. Algunos personajes o estructuras presentes en el género constituyen parte de esquemas del cuento popular que el lector coetáneo podía esperar en ese contexto ${ }^{32}$.

\footnotetext{
${ }^{28}$ F. Cabo Aseguinolaza reseña dicho debate en Fernando Cabo Aseguinolaza, El concepto de género y la literatura picaresca. Santiago de Compostela, Universidad de Santiago de Compostela, 1992, pp 13-44.

${ }_{29}$ Algunas de las novelas ejemplares de M. de Cervantes son analizadas a partir de los elementos picarescos que pueden contener, sin embargo no son incluidas en el marco del género. Elizabeth Campuzano, "Ciertos aspectos de la novela picaresca", en Hispania. Vol. 32, №2, Madrid, Consejo Superior de Investigaciones Científicas, 1949, pp 190-197, p 195.

${ }^{30}$ Klaus Meyer-Minnemann, El género... op cit, p 27.

${ }^{31}$ Ibídem, pp 26 y 27.

${ }^{32}$ Katharina Niemeyer, ““... El ser de un pícaro el sujeto deste libro’. La Primera parte de Guzmán de Alfarache (Madrid, 1599)", en Meyer-Minnemann, Klaus y Schlickers, Sabine (eds.). La novela picaresca. Concepto genérico y evolución del género (siglos XVI y XVII). Madrid, Iberoamericana Verbuert, 2008, pp 77-116, pp 102 y 103.
} 
El carácter autobiográfico y ficcional de la picaresca es un punto compartido por muchos críticos ${ }^{33}$, para quienes estos dos aspectos son necesarios en la estructura de las novelas del género. Sin embargo, la característica de ser una pseudoautobiografía excluye a algunas obras que gran parte de la crítica no duda en incluir en el género entre ellas La hija de Celestina y El Bachiller Trapaza, que nosotros analizamos-, en tanto siguen siendo textos cuyos protagonistas son pícaros ${ }^{34}$.

J. Amelang ha estudiado las autobiografías populares y su relación con el contexto social de la modernidad. El autor encuentra en el relato picaresco "unas memorias en primera persona contadas por un narrador de baja extracción social, cuyas experiencias (penosas en general) le llevaban a aumentar su conocimiento de sí mismo" 35 . Discute la neta separación entre lo real y lo imaginario "en la autobiografía y en otras formas de escritura en primera persona surgidas en las márgenes de la sociedad"36.

Es cierto que la pseudoautobiografía marginal abre la posibilidad de realizar críticas sociales que no serían factibles o verosímiles si provinieran de un personaje integrado. Sin embargo, éstas pueden ser incluidas aunque el relato se realice en tercera persona a través de todas las intervenciones del protagonista, en tanto el género admitiría estas variables, pero conservando como protagonista al pícaro y su circulación. Por otro lado, por cuanto se trata de biografías ficcionales, el autor es diferente del marginal representado y puede expresar su propia visión del mundo a través de su criatura mientras muestra también el pensamiento que él supone e imputa al sujeto que representa. Dicha representación de las ideas del pícaro incluye las nociones que dicho personaje podría tener respecto al sector social al cual pertenece el escritor que lo describe.

F. Cabo Aseguinolaza propone que la situación del protagonista de la narración constituiría "un agente inserto en un tercer nivel de los relatos" ${ }^{37}$ picarescos en primera persona, lo cual es fundamental en varias novelas, puesto que la narración se desprende del presente del personaje, que despliega su biografía según la demanda de otro. La

\footnotetext{
${ }^{33}$ Tal como sostiene Meyer-Minnemann. Klaus Meyer-Minnemann, El género... op cit, p 29.

${ }^{34}$ Fernando Cabo Aseguinolaza, op cit, $\mathrm{p} 46$.

${ }^{35}$ James S. Amelang, op cit, p 29.

${ }^{36}$ Ibidem, p29. Esto sucede, por ejemplo, con Vida y hechos de Estebanillo González, que también quedaría en una situación dudosa, dado que su identidad pudo ser rastreada. Jesús-Antonio Cid, "Gallegos, hidalgos y pícaros en la España del siglo XVII. Estebanillo González y Salvatierra de Miño", en Cuadernos de Estudios Gallegos. Tomo XL (105), Galicia, Consejo Superior de Investigaciones Científicas, 1992, pp 259-287, p 260.
}

${ }^{37}$ Fernando Cabo Aseguinolaza, op cit, $\mathrm{p} 46$. 
coyuntura en que se encuentra el pícaro cuando realiza su relato halla su explicación a partir de la historia que cuenta el protagonista y que comienza con la de sus padres, dando un sentido unitario a su vida (que constituye un ineludible derrotero marginal) y explicando la situación de la narración, la actitud del protagonista y la forma en que accede a la palabra. Además, los autores se valen de la reflexión del pícaro respecto a su existencia a la hora de presentar la evaluación moral de su criatura porque allí se puede asistir a la redención del personaje (Guzmán), su aceptación de la marginalidad (Lazarillo) o bien su condición de delincuente incorregible (Pablos). En este marco Cabo Aseguinolaza sostiene también la necesidad de establecer las bases de un modelo enunciativo que contenga el relato autobiográfico en todos sus planos, incluido el de su situación narrativa, de modo que, mediante la diferencia entre la enunciación del autor y la del narrador, se puede dar cuenta del papel de la autobiografía en estas novelas, tal como veremos más adelante ${ }^{38}$.

Por otro lado, la autobiografía puede asumir diversos formatos. Puede desarrollarse como un diálogo en el cual el pícaro cuenta su vida (El donado hablador Alonso), o también una extensa epístola (El Lazarillo). En general se trata de confesiones que son motorizadas a partir de la demanda de otra persona (el narratario). Más adelante veremos la diferencia entre este agente de la narración y el lector real.

Otra característica del género que, si bien secundaria, está presente en todas las novelas y las acciones de los protagonistas, radica en que estas existencias tienen lugar en una sociedad en cuyo seno las apariencias revisten una gran importancia, particularidad que posibilita y explica la mayoría de las prácticas del pícaro. Los mecanismos puestos en marcha por estos personajes son fruto de la cultura en cuyo seno surgen estas producciones ${ }^{39}$.

La simulación de diversas dolencias que ponen el práctica los pícaros será estudiada en el capítulo quinto, pero por lo pronto indicamos, siguiendo a Cavillac, que en los grupos acusados de fingimientos malintencionados (mercader, mendigo o noble), la falsedad está vinculada a la ociosidad, oponiendo estos tres grupos a las ideas de caridad, trabajo y mérito ${ }^{40}$. Gracias a las cualidades negativas de la élite que se retrata, tiene lugar un cambio en la función cómica del pícaro que, de víctima se convierte -

\footnotetext{
${ }^{38}$ Ibídem, pp 46 y 71.

${ }^{39}$ Sobre la cultura de las apariencias, ver José Antonio Maravall, La cultura del Barroco. Barcelona, Ariel, 1990, pp 501 y ss. Sobre la relación entre ella y la picaresca, ver Katharina Niemeyer, El ser de... op cit, pp 92-95.

${ }^{40}$ Michel Cavillac, Pícaros y mercaderes... op cit, pp 327 y 328.
} 
aunque sea efímeramente- en burlador, gracias a los vicios de los representantes de los estratos sociales más altos, permitiendo la sátira de la organización de una sociedad parasitaria y amoral, mediante el ejemplo antagónico. De esta manera, el "orden" de la sociedad secreta de los mendigos es moldeado como espejo del desorden de la sociedad oficial que posibilitaría la existencia de dichos grupos ${ }^{41}$.

\section{A- 3. El contexto}

La novela picaresca se ubica cronológicamente en el Siglo de Oro, con mayor precisión en un lapso que se inicia en 1554 (en que fue publicado El Lazarillo) hasta 1646 (cuando vio la luz Vida y hechos de Estebanillo González) ${ }^{42}$. Hemos observado en el capítulo anterior la emergencia de un sector marginalizado económicamente durante este período; ahora consideraremos cómo ese contexto impregnó y fue expresado por el sistema de ideas, influyendo en el género literario que nos ocupa ${ }^{43}$.

En el marco de nuestro trabajo no podemos eludir las conclusiones de Cavillac sobre El Guzmán, pues el crítico francés estudia esta obra como expresión de la burguesía. Acorde con ello, en su explicación acerca de los motivos del surgimiento de la picaresca, Cavillac considera clave la falta de afianzamiento de los valores burgueses y el consiguiente embate de la mentalidad nobiliaria. En tanto los beneficios se invertían en feudos, cargos y lujo ostentoso, el dinero se volvía improductivo y un valor aristocrático, pues los burgueses habían traicionado a su clase y estos nuevos ricos se convertían en gestores municipales de la oligarquía nobiliaria, exacerbando la ideología de su clase de adopción ${ }^{44}$. Este autor sostiene entonces que, al menos El Guzmán, sería

\footnotetext{
${ }^{41}$ Katharina Niemeyer, El ser de... op cit, p 100.

${ }^{42}$ Elizabeth Campuzano, op cit, p 190. Sobre la conceptualización de este período en torno a la literatura ver: Juan Manuel Rozas, "'Siglo de Oro': Historia y mito", en Rico, Francisco (ed.), Historia y crítica de la literatura española. Tomo 3. Siglos de Oro: Barroco, edición a cargo de Wardropper, Bruce. Crítica, Barcelona, 1980-2004, pp 64-68.

${ }^{43}$ Así, como sostiene V. N. Volóshinov, "En cada etapa evolutiva de la sociedad existe un específico y limitado círculo de temas expuestos a la atención de la sociedad y en los que esta atención suele depositar un acento valorativo. (...) Para que un tema, cualquiera que sea el nivel de la realidad al que pertenezca, forme parte del horizonte social de un grupo y suscite una reacción semiótico-ideológica, es necesario que dicho tema esté relacionado con los presupuestos socioeconómicos más importantes del grupo mencionado; es preciso que involucre siquiera parcialmente las bases de la existencia material del grupo señalado." Valentín Nikoláievich Volóshinov, El marxismo y la filosofía del lenguaje. Buenos Aires, Ediciones Godot, 2009, p 45.

${ }^{44}$ Fernand Braudel, Civilización material, economía y capitalismo. Siglos XV-XVII. Tomo 2. Los juegos del intercambio. Madrid, Alianza Editorial, 1984, pp 420 y ss; Michel Cavillac, Pícaros y mercaderes... op cit, p 212; José Antonio Maravall, "La época del renacimiento", en Rico, Francisco (dir.). Historia y crítica de la literatura española. Tomo II. Siglos de Oro: Renacimiento, edición a cargo de López Estrada,
} 
una defensa de los valores de la nueva clase, criticando la cultura orientada al gasto y por lo tanto en camino a la quiebra ${ }^{45}$.

Sin embargo, consideramos que la crítica de la picaresca apunta fundamentalmente a otro aspecto. Aunque no en todos los casos con la misma fuerza, vemos que la principal condena recae sobre los sectores marginales itinerantes. Se trata ante todo de una narrativa que propugna la estabilidad e inmovilismo de una sociedad que era, en términos de clase pero también espaciales, más dinámica de lo que los autores y los grupos dominantes deseaban y podían percibir y aceptar.

Se trata de una narrativa que brega por el sometimiento de los potenciales trabajadores, pues desde los últimos siglos medievales se había comenzado a tomar conciencia acerca del drenaje de metálico hacia otras zonas del continente en detrimento de Castilla y de la necesidad de detenerlo, para lo cual se consideraba imperioso convertir la sociedad al trabajo, promocionando su carácter dignificante y abriendo el camino honorífico a través del mérito ${ }^{46}$. Tal como indica Astarita, la balanza comercial castellana era desfavorable para el reino, lo cual condujo a la imposición, desde la Baja Edad Media, de diversas y posteriormente fracasadas regulaciones para evitar la salida de distintos bienes, especialmente de las monedas de oro y plata. El déficit consecuente del comercio de no equivalentes, obligaba a la Monarquía española a pagar los bienes que ingresaban de otras regiones a un tipo de cambio relativamente muy alto. Parte de este comercio estaba destinado a proveer el consumo de bienes suntuarios de los señores castellanos, que pudo sostenerse gracias al ingreso constante de metal ${ }^{47}$.

El debate en torno al realismo de la picaresca, luego de ser ampliamente admitido y exagerado el valor documental del género, suscitó una reacción absolutamente esteticista, que se fundamentó en minimizar las diferencias entre las condiciones españolas, que habrían dado lugar a este fenómeno, respecto al resto de Europa, así como en tachar de positivista el intento de apreciar a este corpus como una

\footnotetext{
Francisco. Barcelona, Crítica, 1980-2004, pp 44-53, pp 48 y ss.

${ }^{45}$ Michel Cavillac, Pícaros y mercaderes... op cit, p 327. En este contexto, el crítico relaciona el género picaresco con las problemáticas que estructuran al moralismo español del siglo XVII (la usura, la limosna y el honor).

${ }^{46}$ Ibídem, pp 335, 336 y 337. En este punto no podemos dejar de mencionar el aporte de M. Molho, quien encuentra en la picaresca una diatriba contra el trabajo, de acuerdo con la ideología de la nobleza. Maurice Molho, "El pícaro de nuevo", en MLN. Hispanic Issue. Vol. 100, №2, Baltimore, The John Hopkins University Press, 1985, pp 199-222, pp 203-206.

${ }^{47}$ Carlos Astarita, Desarrollo desigual en los orígenes del capitalismo. El intercambio asimétrico en la primera Transición del feudalismo al capitalismo. Mercado feudal y mercado protocapitalista. Castilla, siglos XIII a XVI. Buenos Aires, Tesis 11 Grupo Editor, 1992, pp 147 y ss.
} 
fuente válida para el análisis histórico ${ }^{48}$. En este marco, los estudiosos intentaron leerlo exclusivamente a la luz de sus filiaciones literarias o folklóricas, en un plano puramente estilístico $^{49}$. Consideramos por nuestra parte que la realidad provee al artista de ideas, de modo que la obra resultante nos informa acerca de la conciencia del autor y su capacidad de seleccionar y moldear esa realidad en otra nueva y peculiar ${ }^{50}$.

Desde el ámbito de los estudios sociocríticos, E. Cros sostiene que el origen socioideológico de las formas literarias implica que la obra estudiada sea considerada como una totalidad organizada de acuerdo con unas leyes específicas que se articulan con el momento histórico de la sociedad en que aquélla fue escrita. Pero cuando aparece un texto de ficción, también lo hacen las leyes de repetición y de acuerdo con esto la picaresca reproduce varios esquemas, tanto del propio género como de otros anteriores $^{51}$.

El crítico francés sostiene que cada uno de los elementos que componen el texto se corresponde con un valor social o moral cuestionado por su contrario. Los componentes que estructuran las prácticas sociales o el discurso social son considerados como productos de la historia y pueden proceder de dichas acciones o de las mencionadas enunciaciones que se producen en la realidad contemporánea del texto, de modo que en el caso que nos ocupa las dos polémicas que están implicadas en la picaresca (teológica y social) dan forma al texto ${ }^{52}$.

En este sentido, H. White encuentra que las teorías actuales disuelven la distinción entre discursos realistas y ficcionales, argumentando que hay una condición común de aparatos semiológicos. La narración constituiría una producción de significados, por ese motivo los grupos dominantes se interesaron por controlar la autoridad epistemológica de la narración ${ }^{53}$.

Queremos distanciarnos de los estudios posmodernos y especialmente el que ha llegado a su paroxismo con el giro lingüístico, que sostiene no sólo la autosuficiencia del relato, sino que incluso lo postula como lo único existente, dado que la realidad

\footnotetext{
${ }^{48}$ Así reseña el debate A. Francis. Ver Alan Francis, op cit, p 25- 31.

${ }^{49}$ Ibidem, p 31.

${ }^{50}$ Esta interpretación es postulada también por Francis, en discusión con Parker, quien, según el crítico, "ha establecido una escisión arbitraria y excesiva entre las presiones que el ambiente ejerce sobre el escritor y la obra misma". Ibídem, p 25. Entretanto, Bataillon sostiene un "desacuerdo fundamental con la estimación del género como cuadro "realista" de las clases sociales inferiores, y hace hincapié en la aversión de los pícaros al prurito de la honra exterior y social". Ibídem, p 27.

${ }^{51}$ Edmond Cros, "La noción de la novela picaresca como género desde la perspectiva sociocrítica", en

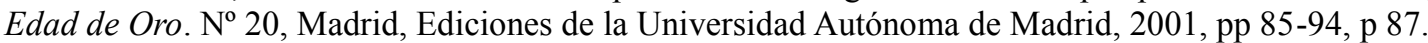

${ }^{52}$ Ibidem, pp 87 y 92.

${ }^{53}$ Hayden White, El contenido de la forma. Barcelona, Paidós, 1992, p 12.
} 
pasada que informa ya no existe. Ideas afines ya habían sido esgrimidas no sólo por las corrientes mencionadas, sino que, anteriormente, el estructuralismo había propuesto la independencia del lenguaje.

Por nuestra parte, consideramos fundamental tener en cuenta las condiciones materiales, sociales y políticas de producción del discurso. P. Bourdieu critica el análisis estructuralista porque supone "la ilusión de la autonomía del orden propiamente lingüístico, que se afirma en el privilegio concedido a la lógica interna de la lengua, en detrimento de las condiciones sociales de su utilización" ${ }^{25}$. Este problema es fundamental en el marco de la discusión que estamos planteando en torno al realismo del género, ya que sostenemos que, si bien la picaresca no es una transparencia de la realidad, ésta no sólo otorgó las condiciones de su producción sino también las de su recepción en tanto género que apela al conocimiento de los sectores sociales representados. Insistimos en la necesidad de distinguir entre la enunciación y la realidad, pues consideramos que la primera sólo representa a la segunda y, en nuestro caso, traza un retrato relativamente verosímil que, basado en datos de la materialidad, exagera algunos e ignora otros en pos de la construcción de estereotipos.

En los debates en torno a este género se plantea cuál es la situación de las novelas que presentan las características de la picaresca pero cuyo protagonista es una mujer $^{55}$. El problema que se presenta es si se elige considerarlas como "pícaras" o no. Siguiendo la lógica que hemos planteado acerca de lo que consideramos un pícaro (un marginal, marginado también en lo que hace a su representación literaria), no encontramos ningún motivo razonable para descartarlas. Al mismo tiempo, evaluamos a estas novelas como parte del género literario que en un principio había tenido protagonistas masculinos $^{56}$. Sin duda que estos personajes plantean un problema

\footnotetext{
${ }^{54}$ Pierre Bourdieu, El sentido práctico. Villa Ballester, Siglo XXI, 2007, p 54.

${ }^{55}$ La primera obra picaresca con una protagonista mujer fue La pícara Justina, que vio la luz en 1604 , seguida por La hija de Celestina (1612), La niña de los embustes (1632) y La garduña de Sevilla (1642).

${ }^{56}$ Así lo explica K. Niemeyer, "Al retomar el término clave para el género, pero darle la terminación femenina y agregar un nombre de mujer, el título introduce una ampliación considerable de la intención y la extensión del lexema, antes reservado a caracterizar un determinado tipo humano masculino. Bien puede verse en la feminización algo como un recargamiento de los tintes cómicos de la figura del pícaro por antonomasia, el Guzmán -si éste es una figura cómica, en atención al discurso vigente sobre los géneros, caracterizado por una notable misoginia, aún más lo debe ser una pícara. Mas también es dado suponer que se trata simplemente de la variación que todavía quedaba por introducir en la configuración y designación del tipo de protagonista decisivo para la novela picaresca." Katharina Niemeyer, "¿Quién creerá que no he de decir más mentiras que letras?' El libro de entretenimiento de la Pícara Justina, de Francisco López de Úbeda (Medina del Campo, 1605), en Meyer-Minnemann, Klaus y Schlickers, Sabine
} 
particular, su prostitución, pero se trata de un aspecto que ya estaba presente en las novelas de pícaros, a través de la descripción del entorno social. Además, esta ocupación en la que se desempeñan de manera temporal es parte de las estrategias de supervivencia que los marginales pueden poner en práctica, pues incluso en varias obras del género los pícaros actúan como proxenetas.

En tanto nosotros trabajamos con una de estas novelas, consideraremos la prostitución en el marco de la marginalidad de Elena en La hija de Celestina. El estudio de esta actividad en la picaresca ya ha sido atendido por muchos estudiosos, cuyas conclusiones parciales recogeremos llegado el caso ${ }^{57}$. Hemos tomado esta decisión metodológica ya que la prostitución constituiría un problema en sí mismo que puede distraernos de nuestro eje de análisis, referido a la movilidad, la socialización, el empleo y la limosna por parte de los pícaros como consecuencia de su marginalidad socioeconómica.

Por otra parte, los críticos han destacado la misoginia de este género, que se expresa aun más en las novelas de pícaras, por este motivo amerita su comparación con aquellas en las cuales las mujeres constituyen personajes secundarios o son sólo parte del escenario donde se mueven sus pares varones ${ }^{58}$. En este último caso, la óptica acerca de las mujeres es diferente, pues su carácter de prostitutas -además jóvenes y bonitasestá ausente. Cuando los autores están prestando atención a la condición de mujer marginal observan esto, pero cuando no lo hacen (otorgando una visión más "transparente" respecto al problema representado), la condena de las mujeres recae con

(eds.). La novela picaresca. Concepto genérico y evolución del género (siglos XVI y XVII). Madrid, Iberoamericana Verbuert, 2008, pp 193-221, p 197.

${ }^{57}$ Denis Menjot, "Prostitutas y rufianes en las ciudades castellanas a fines de la Edad Media", en Temas medievales. N²4, Buenos Aires, Consejo Nacional de Investigaciones Científicas y Técnicas, 1994, pp 189-204; Mary Elizabeth Perry, "Deviant Insiders: Legalized Prostitutes and Consciousness of Women in Early Modern Seville”, en Comparative Studies in Society and History. Vol. 27, No 1, Cambridge, Cambridge University Press, 1985, pp 138-158; Ketty Zafra, "El mundo de la prostitución en La hija de Celestina: el castigo del desorden", en Actas del 40 Congreso de la ACH. Winnipeg, Universidad de Manitoba, 2004,

http://fis.ucalgary.ca/ACH/Congreso_abierto/2004/Ketty_Zafra.htm

58 En este sentido resulta interesante la propuesta de $\bar{M}$. Carbonell Esteller, quien encuentra que la reinserción de las mujeres marginalizadas (entendida, a través de algún tipo de tutela, familiar o institucional) tuvo lugar en una proporción ínfima de los casos, mientras en general su vida tenía lugar "en otro marco bastante distinto al del deseo de la reinserción o al de la consciencia de la victimización. Transcurría, contrariamente, en el marco de la búsqueda de estrategias de supervivencia individuales o compartidas, sin vínculos, en muchos casos, familiares de referencia, haciendo de su actitud y experiencia un testimonio de rebeldía más que de victimización". Consideramos, con la autora, que este era motivo suficiente para condenarlas. Por último, Carbonell Esteller sostiene que dicho discurso patriarcal presente en las fuentes oficiales laicas o eclesiásticas fue retomado por la historiografía. Montserrat Carbonell Esteller, "Las mujeres pobres en el setecientos", en Historia Social. № 8, Valencia, Universidad Nacional de Educación a Distancia, 1990, pp 123-134, p 129. 
la misma intensidad y por los mismos motivos que sobre los varones, por ser marginales itinerantes.

Por último, las filiaciones religiosas de los autores de estas novelas también han sido debatidas. Si bien queda fuera de duda el anticlericalismo presente en este corpus, en el cual son retratados los personajes pertenecientes a las jerarquías más bajas del clero y sus desviaciones, no se trata de novelas que critiquen la religión o religiosidad de sus protagonistas más de lo que lo hacen respecto a todo el conjunto social. Fuera de este común acuerdo, hay distintas posturas respecto a cuáles pueden ser las procedencias religiosas de estas novelas. Teniendo en cuenta el éxito del erasmismo en España, parte de la crítica se esfuerza en hallar en esta corriente las motivaciones para la postura religiosa en este tipo de producciones ${ }^{59}$. También encontramos autores que niegan la influencia del erasmismo y sostienen que se trataría de manifestaciones del anticlericalismo español, que había sido además un terreno propicio para la entrada del pensamiento del filósofo flamenco ${ }^{60}$. E. Cros encuentra un origen de la picaresca diferente, pues sostiene que estas novelas nacen del cuestionamiento por el protestantismo de las normas sociales que organizaban la sociedad española del siglo XVI, como parte de una inadecuación de las mentalidades castellanas a un contexto socioeconómico importado. Por nuestra parte, creemos que si las novelas presentan algunas diferencias, comparten la censura en cuanto a la falta de observancia del clero que, en la mayoría de los casos, recae sobre su conducta sexual, su afición por el dinero y la ausencia de valores cristianos ${ }^{61}$.

El estudio de esta narrativa por parte de los historiadores cuenta con dos grandes antecedentes para nuestra investigación. Dentro de la historiografía española, J. A. Maravall abordó la literatura picaresca como un documento social ${ }^{62}$. En su libro analiza diversas cuestiones planteadas por este género, como las visiones relativas al trabajo, al juego, a las mujeres, al urbanismo, etc., pero sin rastrear de manera pormenorizada a los pícaros en el plano empírico ni a sus precursores, durante los siglos anteriores, ni cotejar de manera suficiente la representación de los marginales en la narrativa con la de otro tipo de documentación. Su estudio se basa en el concepto de anomia-entendido como

\footnotetext{
${ }^{59}$ Ver Thomas Hanrahan, "Lazarillo de Tormes: Erasmian satire or protestan reform?" en Hispania. Vol. 66, No3, Madrid, Consejo Superior de Investigaciones Científicas, 1983, pp 333-339.

${ }^{60}$ Elizabeth Campuzano, op cit, pp 192-194.

${ }^{61}$ Edmond Cros, La noción de novela... op cit, $\mathrm{p}$ 93-94.

${ }^{62}$ José Antonio Maravall, La literatura picaresca desde la historia social. Madrid, Taurus, 1987.
} 
la falta de reacción de la sociedad ante los comportamientos que no se adaptan a sus normas- y de conducta desviada, que causa el desplazamiento y la desvinculación de los sujetos en la sociedad. Siguiendo a T. Parsons, Maravall tiende a evaluar las conductas de los marginales a partir de su individualidad, y no desde la estructura social. Divergimos respecto a este punto de vista, ya que nuestro análisis parte de la noción de marginalidad como consecuencia derivada del sistema social, atendiendo fundamentalmente a la diferencia entre esta categoría y la de pobreza, que también es confundida con la primera por el autor español.

El segundo antecedente refiere al aporte metodológico de Geremek respecto a la relación entre los marginales y su representación ${ }^{63}$. Este autor indaga sobre el vínculo entre el contexto social y la narrativa, considerándola una fuente en la que es posible rastrear la realidad, cotejando esta información con otros documentos como los judiciales o los legislativos. En su investigación sobre el devenir de los marginales en la literatura europea, el autor polaco expone una interesante relación entre la realidad social y la genealogía y actitudes de los grupos excluidos. Consideramos fundamental el aporte de este historiador, pero su análisis sobre este problema en Europa incluye sólo subsidiariamente a España, lo que impone la necesidad de una investigación específica sobre la forma en que se presentó allí esta problemática, aprovechando la riqueza de la literatura picaresca y la documentación.

\section{A- 4. Los autores}

Hemos considerado entonces las cuestiones formales de las novelas así como el contexto cultural en el cual fueron producidas y que las motivó. Pero entre este entorno y las obras se encuentra la intervención del autor, que hace que no sean una transparencia de la realidad, pues, tal como sostiene A. Francis, el autor se la apropia estéticamente, para crear una entidad nueva, "múltiplemente comunicada con lo extraestético" ${ }^{\prime 64}$. Las ideas de los literatos resultaban condicionadas materialmente por la historia individual del autor, el mecenazgo y las expectativas del público, aunque tampoco hay una relación directa y unívoca entre esta realidad y las obras ${ }^{65}$.

\footnotetext{
${ }^{63}$ Bronislaw Geremek, La estirpe... op cit.

${ }^{64}$ Alan Francis, op cit, p 32.

${ }^{65}$ N. Salomon distingue tres tipos de escritores en España durante el Siglo de Oro: los aristócratas, los artesanos y los de mercado. Noël Salomon, "Algunos problemas de sociología de las literaturas de lengua
} 
El literato se pronuncia explícitamente a través de los diversos paratextos de su obra y, puesto que dentro de la ficción no tiene voz propia, la forma de asumir dicha actitud es sólo implícita. En estas pseudoautobiografías, novelas narradas en primera persona por parte de un marginal, encontramos una duplicidad en la voz del narrador (el pícaro luego de su trayecto, escarmentado o no), que al contar su vida y sometiendo su existencia a juicio, hace presente la palabra del autor (implícito) que a través de aquélla, ajena a él, se comunica. Se trata de una doble voz en el discurso del narrador, pues mientras relata su historia, las palabras cobran un significado doble, si por un lado está lo literal de su significado, por otro deja ver la opinión del autor que, como no se expresa de manera independiente en el mundo narrado, se sirve de su criatura para hacerlo ${ }^{66}$.

Las condiciones de la escritura para los autores fueron diversas, situación en la cual debemos reparar y observar las diferencias entre los escritores que nos ocupan en nuestro estudio, para entender de qué individualidades parten las novelas y, así, explicar el sentido de su prosa.

El Lazarillo quizás sea una de las obras más controvertidas en cuanto a su autoría, que no ha sido develada, mientras son varias las propuestas en torno a los posibles autores. M. Bataillon atribuyó esta obra a fray Juan de Ortega, general de la orden de los Jerónimos entre 1552 y 1555, lo cual sería suficiente argumento para explicar el anonimato de una novela que se destaca por el anticlericalismo ${ }^{67}$. La hipótesis de M. Asensio la atribuye a Juan de Valdés, basándose en la similitud de su ideario estilístico y lingüístico con el del anónimo autor ${ }^{68}$. La idea de una autobiografía

española" en Botrel, Jean François y Salaün, Serge. (coord.). Creación y público en la literatura española. Barcelona, Castalia, 1974, pp 15-39.

El mecenazgo fue limitado en España, pues si la burguesía mercantil protegía a los escritores en otros países, aquí su peso fue menor. El clero tampoco patrocinó especialmente a los autores laicos, aunque publicó un gran número de obras teológicas. En cambio, la nobleza y la corona sí financiaron a los hombres de letras, tal como veremos entre los autores aquí atendidos. Ricardo Gracía Cárcel, "La identidad de los escritores del Siglo de Oro", en Stvdia Histórica. Historia Moderna. Vol. VI, Salamanca, Ediciones de la Universidad de Salamanca, 1998, Tomo II, pp 327-337, pp 327-329. Sobre el mecenazgo ver también: Marina Núñez Bespalova, "El mecenazgo nobiliario en la literatura de la época de los Reyes Católicos" y Ainara Herrán Martínez de San Vicente, "El mecenazgo de los jerarcas eclesiásticos en la época de los Reyes Católicos", en Salvador Miguel, Nicasio y Moya García, Cristina (eds.). La literatura en la época de los Reyes Católicos. Madrid, Iberoamericana Verbuert, 2008, pp 167-188 y pp 79-101 respectivamente.

${ }^{66}$ Klaus Meyer-Minnemann, El género... op cit, p 35. Ver Antonio Rey Hazas, Deslindes de la novela picaresca. Málaga, Servicio de Publicaciones de la Universidad de Málaga, 2003, p 18.

${ }^{67}$ Marcel Bataillon, Novedad y fecundidad del Lazarillo de Tormes. Salamanca, Anaya, 1968, p 21.

${ }^{68}$ Manuel Asensio, "La intención religiosa del Lazarillo de Tormes y Juan de Valdés", en Hispanic Review. Joseph E. Guillet Memorial Volume, Part I, Vol. 27, №1, Filadelfia, University of Pennsylvania 
cercana a la realidad del personaje, fue sostenida por F. Abrams, quien adjudicó su paternidad a Lope de Rueda, pregonero toledano en $1538^{69}$. Los críticos que sostienen que el autor podría ser un marginal como Lázaro, se basan en que, si bien hay cierta desaprobación respecto a las prácticas de Lazarillo así como de la sociedad inmoral que lo rodea, el distanciamiento del autor respecto al personaje no es absoluto, pues aunque aquél se separa retóricamente del narrador, en el prólogo ambos se manejan en un plano de realidad comparable ${ }^{70}$. En un estudio reciente, se ha leído El Lazarillo relacionando a sus personajes con el ámbito de la corte, al protagonista de la novela con el secretario Gonzalo Pérez y al arcipreste con Francisco de los Cobos $^{71}$.

Entretanto, quienes sostienen que se trata de un escritor que está diferenciado socialmente de su criatura encuentran que si bien Lázaro narra su biografía mostrando conformidad moral consigo mismo como personaje narrado, el autor asume una posición diferente, pues mientras el protagonista da cuenta de su vida por escrito a pedido de "Vuestra Merced" para explicar su situación actual, el escritor la ha inventado con un fin condenatorio ${ }^{72}$.

Como hemos observado anteriormente, creemos que esta novela es la que tiene una posición más condescendiente respecto al marginal que es retratado, lo cual es una decisión del autor que, sospechamos, tiene que haber tenido contacto directo con el mundo disgregado de los hombres que eligió representar.

Se ha especulado mucho acerca del autor de El Guzmán y ha sido estudiado minuciosamente por diversos especialistas. Cavillac parte de la biografía de M. Alemán para sostener que su obra fue producida para la concientización de la burguesía, pues se trata de la vida de un mercader frustrado, experiencia a partir de la cual conoció los mecanismos comerciales. El literato también compartió la fiebre financiera que tuvo lugar en España en este período, aprovechando una coyuntura de bonanza económica

Press, 1959, pp 78-102, passim. Sobre otras hipótesis, ver Pedro M. Piñero, "Lazarillo de Tormes", en Rico, Francisco (ed.). Historia y crítica de la literatura española. Tomo 2. Siglos de Oro: Renacimiento, edición a cargo de López Estrada, Francisco. Barcelona, Crítica, 1980-2004, pp 340-351, pp 341 y 342.

${ }^{69}$ Fred Abrams, “¿Fue Lope de Rueda autor del Lazarillo de Tormes?”, en Hispania. Vol. 47, N², Madrid, Consejo Superior de Investigaciones Científicas, 1964, pp 258-267, pp 258-267.

${ }^{70}$ Douglas Carey, "Lazarillo de Tormes and the Quest of Authority", en PMLA. Vol. 94, No1, Nueva York, Modern Language Association, 1979, pp 36-46, p 42. F. Lázaro Carreter también sospecha que el autor es un marginado. Fernando Lázaro Carreter, op cit, p 186.

${ }^{71}$ Eduardo Torres Corominas, "Gonzalo Pérez, Francisco de los Cobos y El Lazarillo de Tormes", en Libros de la Corte. №4, año 4, Madrid, Universidad Autónoma de Madrid, 2012, pp 74-104.

${ }^{72}$ Klaus Meyer-Minnemann y Sabine Schlickers, “Es el Lazarillo de Tormes una novela picaresca? Genericidad y evolución del género en las versiones, continuaciones y transformaciones de La vida de Lazarillo de Tormes desde las ediciones de 1554 hasta la refundición de 1620 por Juan de Luna", en Meyer-Minnemann, Klaus y Schlickers, Sabine (eds.). La novela picaresca. Concepto genérico y evolución del género (siglos XVI y XVII). Madrid, Iberoamericana Verbuert, 2008, pp 41-75, p 44. 
individual durante la cual compró terrenos para lucrar, negocio que lo condujo a la ruina en los años previos a la publicación de la novela que nos ocupa, lo cual puede explicar la diatriba contra los especuladores que encontramos en ella. Amén de la experiencia personal del autor, la coyuntura de la que podía testificar era desalentadora, pues en el decenio 1596-1607 España experimentó un colapso económico y un brote de peste bubónica que diezmó la población urbana ${ }^{73}$. Alemán escribió El Guzmán impulsado por el deseo de reforma social ${ }^{74}$, no sólo a partir de lo antedicho, sino que también influyó su testificación directa de la vida de los galeotes que retrató, pues ocupado como funcionario interino en el consejo de hacienda, llevó a cabo una investigación en las minas de Almadén, a partir de la cual conoció el trabajo de aquéllos ${ }^{75}$. Su observación de la pena de galeras se relaciona también con su amistad con C. Pérez de Herrera, con quien compartió su preocupación por el problema de la pobreza y la falta de alternativas para solucionarlo, relación que emparenta su obra con El Guzmán, publicado por las mismas fechas ${ }^{76}$.

Si con Alemán partimos de la idea de un escritor proveniente de las filas de la burguesía (y probablemente converso), El Buscón tiene su origen en una pluma muy diferente, pues Quevedo escribió decididamente para la aristocracia. A diferencia de otras obras que aquí analizamos, en aquélla el autor no demuestra ninguna simpatía por su criatura, a la cual degrada ${ }^{77}$. Nacido en 1580 en una familia hidalga madrileña, hijo de un secretario de la princesa María y de la reina Ana y de una dama de honor de la reina, Quevedo pasó gran parte de su vida en la corte, donde se dedicó a las letras y escribió El Buscón. También ocupó cargos muy altos, incluso el de secretario de Felipe IV, ostentó títulos y poseyó un señorío.

Se sabe que en 1596 estudiaba en Alcalá de Henares y luego en Valladolid, cuando fue residencia momentánea de la Corte y donde el literato encontró la breve

\footnotetext{
${ }_{73}^{73}$ John Huxtable Elliot, La España Imperial. 1469-1716. Barcelona, Vicens Vives, 1993, pp 324 y ss.

${ }^{74}$ "A nivel literario, este anhelo se concreta a través del nuevo género de la novela picaresca que por este hecho empieza a adquirir validez normativa". Sabine Schlickers, "Segunda parte de la vida de Guzmán de Alfarache. Atalaya de la vida humana, por Mateo Alemán, su verdadero autor (Lisboa 1604)", en MeyerMinnemann, Klaus y Schlickers, Sabine (eds.). La novela picaresca. Concepto genérico y evolución del género (siglos XVI y XVII). Madrid, Iberoamericana Verbuert, 2008, pp 145-175, p 172.

${ }_{75}^{75}$ Michel Cavillac, Pícaros y mercaderes... op cit, $\mathrm{p} 235$.

${ }^{76}$ La reflexión sobre la mendicidad fue parte del mercantilismo, tal como reveló Pérez de Herrera al sostener que el bien de los "pobres" coincidía con el de la corona en tanto ellos iban a fabricar las mercancías necesarias para incrementar su riqueza. Ibídem, p 365.

${ }^{77}$ Tilmann Altenberg, op cit, $\mathrm{p} 375$.
} 
protección de la duquesa de Lerma ${ }^{78}$. En 1611 fue a Italia, llamado por el duque de Osuna, entonces virrey de Sicilia, de quien era consejero, pero luego de la rebelión tuvo que huir a Génova. En 1615 volvió a Madrid con un donativo para el duque de Uceda, con la finalidad de que el duque de Osuna lograra el cargo de virrey de Nápoles y tras el éxito en esta misión ocupó el cargo de secretario de hacienda ${ }^{79}$.

A pesar de haber defendido al duque de Osuna de los enemigos que tenía en la corte, sus relaciones se enfriaron. Con la llegada del duque de Uceda, Quevedo fue preso y desterrado, mientras aumentaban sus deudas. Cuando el conde duque de Olivares asumió como privado del rey, Quevedo intentó congraciase con el monarca y consiguió permanecer en la corte hasta 1622, cuando fue desterrado nuevamente. La relación entre el conde duque y Quevedo tuvo períodos de amistad y alejamiento. Pese a ello, el escritor buscó su protección hasta alrededor de 1630, cuando fue abiertamente rechazado, dando lugar a las sátiras del poeta respecto a los privados y a la corte del favorito, provocando su abierta enemistad ${ }^{80}$.

Además de estas desavenencias, Quevedo llevó una vida desordenada en el plano personal y frecuentó prostíbulos y tabernas, de donde pudo sacar algún tipo de modelo para su obra picaresca. A lo largo de El Buscón, el protagonista y sus pares son denostados como una casta insalvable. Así, Don Diego, el único personaje representante de la nobleza, juzga como bellaco a Pablos, sugiriendo un vínculo causal entre su bajo nacimiento y su ruindad. La aristocracia defendía la nobleza de la sangre, atributo que en este período de intensa movilidad social era el único medio para salvaguardar a este grupo amenazado por el crecimiento de la burguesía. Por lo tanto, personajes como Quevedo temían la ambición de movilidad social que demostraban hombres de baja ascendencia.

La degradación de Pablos a lo largo de la novela y su falta de redención y escarmiento se oponen a la propuesta de salvación en la novela de Alemán, de modo que no sólo se invierte el carácter edificante de aquella obra sino que también demuestra el desprecio de Quevedo por su pícaro ${ }^{81}$ y la suposición del autor de que los delitos de esta clase de sujetos no eran castigados.

\footnotetext{
78 Emilio Carilla, Quevedo. Tucumán, Universidad Nacional de Tucumán. Instituto de Lengua y Literatura Española, 1949, p 17.

${ }^{79}$ Ibidem, pp 18-22.

${ }^{80}$ Ibídem, pp 22-28.

${ }^{81}$ Tilmann Altenberg, op cit, pp 372 y 383.
} 
A. J. de Salas Barbadillo (Madrid, 1581-1635) fue hijo de un indiano que había llegado a detentar altos cargos para la corona, cuyos negocios heredó pero, sin un trabajo conocido, llevó una vida ociosa y descuidada en la corte, donde protagonizó varios episodios escandalosos que le valieron el destierro en varias oportunidades (para regresar en 1613). Luego de haber estudiado en Alcalá de Henares (1598), en los primeros años del siglo XVII, cuando empezó a publicar sus primeros versos, ya se había insertado en el campo literario de Madrid. El autor sobrevivió gracias a la protección de nobles como el Duque de Sessa y Juan Andrés Hurtado de Mendoza, a quien sirvió como hayo de su hijo (1618-23). También cosechó la amistad de grandes literatos como Vicente Espinel y Cervantes y fue parte de la academia poética de Madrid, espacio que compartió con Quevedo y A. Castillo Solórzano, autores de otras dos novelas que aquí analizamos. Estas experiencias dieron conocimiento al autor de la vida en la corte, donde se mezclaban los miembros díscolos de la clase dominante quienes, como él, se confundían con diversos sujetos más o menos desviados, experiencia que se proyecta en la novela que nos ocupa, pues en ella constatamos características de la narrativa cortesana con presencia de pícaros ${ }^{82}$.

También Castillo Solórzano (1584?), fue un cortesano pobre sostenido por la nobleza tras perder la fortuna familiar. En 1620 era gentilhombre de cámara del Conde de Benavente y luego servidor del Marqués de Villar. En 1628 le fue otorgado el cargo de maestresala del virrey de Valencia, donde vivió varios años, aunque intermitentemente, y produjo diversas obras (nueve, entre 1631 y 1637). El Bachiller Trapaza (1637), impresa por Pedro Vergés, primer editor de El Buscón, contiene variados episodios relativos a la corte y sus diversos habitantes, así como acerca de los vínculos que tenían lugar en dicho espacio ${ }^{83}$.

Los autores de las novelas que analizaremos en adelante tenían diversas procedencias, intereses e inclinaciones. En el caso del anónimo de 1554, no podemos constatar la adscripción social del autor de la obra, sin embargo, la descripción de su criatura es mucho más benévola que la realizada por los otros escritores. La obra retrata una pobreza rural, de la cual se intenta salir por caminos marginales, pero en general mediante el servicio a un señor, a quien sólo traiciona cuando está hambreado. Se trata de un autor que no busca ilustrar la picardía de la corte, pero con cuya criatura inicia la

\footnotetext{
${ }^{82}$ Alonso J. de Salas Barbadillo, La hija de Celestina. Madrid, Cátedra, 2008. Edición a cargo de Enrique García Santo Tomás, pp 11-26.

83 Alonso de Castillo Solórzano, Aventuras del Bachiller Trapaza. Madrid, Cátedra, 1986. Edición a cargo de Jacques Joset, pp 11-14.
} 
forma que adoptará este género, que se modificará en adelante, aunque pervivan algunos rasgos $^{84}$. En segundo término, M. Alemán, ni noble ni cortesano, realiza un retrato crítico respecto a su criatura, pero, al autorizar la redención del personaje al final de la novela permite vislumbrar que se trata de una crítica de la dinámica social que conduce a la degradación de los sujetos, quienes, no obstante, pueden ser rescatados. Si Alemán dirige su crítica contra los marginales, también lo hace contra la nobleza parasitaria y los financistas. En tercer lugar, tenemos a Quevedo, cuya procedencia aristocrática, frecuentación de la corte y participación en la burocracia real explica la violencia de su escritura hacia los hombres sin estado, condición que considera desordenada y peligrosa $^{85}$. Por último contamos con otros dos escritores cortesanos cuya pobreza y vida bohemia condujo a la necesidad de financiación, lo que los acercó a la nobleza que podía otorgarla, pero también a una vida desordenada que los contactó con los sujetos que retratan. Sus novelas cortesanas con pícaros -aunque pertenecen a un tipo secundario del género- nos muestran cómo, a pesar de abandonar la autobiografía, pueden valerse de estos personajes para llegar al retrato crítico de la sociedad en su conjunto a través de una escritura más ligera, cuyo fin es divertir.

Consideramos que lo que emparenta estas obras en relación a la observación del marginal es que se caracterizan por la lejanía respecto del protagonista, cuya palabra es concebida y recibida como un discurso ajeno tanto a los autores como a los lectores ${ }^{86}$. Esta no identificación es uno de los elementos fundamentales de la relación entre literatos y público, definida sobre todo por la distancia que se quiere crear respecto a los personajes condenados. Veamos, entonces, cómo es la relación de los lectores con este tipo de obras.

\section{A - 5. El público}

\footnotetext{
${ }^{84}$ Estos estereotipos serán analizados en los capítulos cuarto, quinto y sexto.

${ }^{85}$ Los salones, la academia y la corte son los espacios culturales en el siglo XVII, pues allí se encuentran literatos, protectores y público. Tal como sintetiza L. Bodin, "Retirada en la cima de la sociedad, la literatura del siglo XVII no pretende por eso hallarse fuera de la vida. Muy al contrario, el gusto por la vida, el estar en la actualidad, inspiran las obras maestras de aquella época". Louis Bodin, Los intelectuales. Buenos Aires, Eudeba, 1965, p 30.

${ }^{86}$ Fernando Cabo Aseguinolaza, op cit, p 75.
} 
Los críticos acuerdan en que el público lector de la picaresca fue un grupo culto $^{87}$, aunque el conocimiento concreto acerca de los individuos que lo conformaban es escaso. Algunos autores postulan que está compuesto por el sector aristocrático ${ }^{88}$, mientras otros lo identifican entre la burguesía, de acuerdo con las distintas reconstrucciones que los críticos han realizado acerca de él, basándose en la posición asumida respecto a diversos problemas sociales ejemplificados en las novelas.

Cavillac postula a El Guzmán como un libro que representa la opinión de la burguesía, sector que también conformaría el público para esta novela. Según el crítico, mientras la aristocracia constituía el público para la literatura de evasión, los medios mercantiles que contaban con formación cultural sentían curiosidad por obras que pudieran tener relación con sus actividades, explicando su lectura de la literatura moralista, que estaba en consonancia con sus aspiraciones. Cavillac coloca a El Guzmán entre las obras leídas por la burguesía y explica su éxito en que los lectores tenían las mismas preocupaciones que el escritor ante los problemas relacionados con la aceleración del tiempo histórico, frente a los cuales ambos buscaban explicaciones ${ }^{89}$. Por otro lado, en un período de cambio social como el que estamos considerando, es necesario que tanto el uno como el otro se identifiquen como diferentes del pícaro representado, pues, tal como sostiene Cabo Aseguinolaza, uno de los elementos fundamentales de la picaresca es la separación entre los lectores y el protagonista literario $^{90}$. Sin embargo debemos reparar en que dicho alejamiento no es absoluto sino más bien ideal, pues si bien los autores se distanciaban del modelo que podían representar, conocían su existencia y podían tener eventualmente experiencias con el mundo marginal.

En el capítulo cuarto analizaremos cómo los sujetos integrados en la burguesía urbana o la baja nobleza convivían con los marginales que se insertaban en el marco del hogar, por ejemplo. Sin embargo, las novelas muestran que algunos aspectos de la

\footnotetext{
${ }^{87}$ Klaus Meyer-Minnemann y Sabine Schlickers, op cit, p 50 y Sabine Schlickers, "Segunda parte de la vida del pícaro Guzmán de Alfarache. Compuesta por Mateo Luján de Sayavedra, natural vecino de Sevilla (Valencia, 1602)", en Meyer-Minnemann, Klaus y Schlickers, Sabine (eds.). La novela picaresca. Concepto genérico y evolución del género (siglos XVI y XVII). Madrid, Iberoamericana Verbuert, 2008, pp 117-144, p 118.

${ }^{88}$ Tilmann Altenberg, op cit, pp 379-380,

${ }^{89}$ F. Rico también sostiene que fue un público lector fundamentalmente burgués. Cavillac hace una reconstrucción de la audiencia a través del contenido de la obra, que encuentra esencialmente burguesa y, por lo tanto, dirigida a un sector dispuesto a tomar nota de su mensaje. Michel Cavillac, Pícaros y mercaderes... op cit, pp 22-25 y 42 y 147.

${ }^{90}$ Fernando Cabo Aseguinolaza, op cit, $\mathrm{p} 86$.
} 
cultura que conformaban serían herméticos al resto de la sociedad, aspecto que implica el desconocimiento tanto del público cuanto de los autores.

Por su parte, los críticos que quieren distanciar a la picaresca de su contexto social apelan al argumento de que este género reutilizó, desde una perspectiva problemática, algunas estructuras y figuras del cuento popular, cuyas formas ya eran conocidas para su público. De esta manera, esta narrativa tuvo influencias de otras, populares, vinculadas a la oralidad ${ }^{91}$, así como al carnaval, ambos provenientes de los sectores bajos de la sociedad, pero que en este caso se reutilizaban en un género relacionado con otro estrato social.

Finalmente, no podemos eludir la mención de R. Chartier, quien sostiene que los lectores pertenecen sobre todo a los grupos urbanos, especialmente artesanos y mercantiles, aunque entre ellos, solo una minoría poseía libros. Los lectores "populares" leían obras que no les estaban especialmente destinadas, por lo tanto lo que los caracterizaba como público no era el corpus que manejaban (pues no habría lecturas exclusivas si los humildes podrían acceder a ellas de distintas formas), sino su manera de abordarlo y apropiarlo ${ }^{92}$. Este fenómeno podría explicar que la intención didáctica de esta literatura no estaba dirigida sólo a la burguesía y a la aristocracia, sino también al resto de la sociedad.

En la literatura picaresca, la autobiografía narrada por el pícaro no está destinada a la escucha o lectura por parte del público lector, sino hacia un narratario ("Vuestra Merced" en El Lazarillo, Montúfar pasajeramente en la obra de Salas Barbadillo, el "Señor" a quien se dirige Pablos). Por otro lado, también es posible el desdoblamiento del narratario o la presencia de más de uno en un texto (como en El Donado Hablador Alonso). También pueden aparecer distintos destinatarios concretos ("el discreto letor" de Alemán) exponentes de una determinada cualidad o grupo social.

Cabo Aseguinolaza piensa en "una percepción 'alienada' de la narración y del propio personaje del pícaro, que abre las puertas a la ironía, la parodia y, desde otro punto de vista, a la moralización" $" 93$. La recepción inmanente está relacionada con el comportamiento narrativo del pícaro, con la consideración acerca de la manera en que

\footnotetext{
${ }^{91}$ Por ejemplo, en El Lazarillo se retoma la idea del molinero ladrón y del nacimiento en el río, o bien la ausencia del padre como preludio a la desgracia económica familiar, motivo que se repite en otras novelas.

${ }^{92}$ Roger Chartier, Libros, lecturas y lectores en la Edad Moderna. Madrid, Alianza, 1993, pp 416 y ss. Estas comprobaciones son también compartidas por C. Ginzburg. Carlo Ginzburg, El queso y los gusanos. Barcelona, Muchnik, 1994, pp 62 y ss.

${ }^{93}$ Fernando Cabo Aseguinolaza, op cit, $\mathrm{p} 76$.
} 
va a ser leída la historia de su vida y por el efecto que van a causar, por estos motivos no descuidan la instancia de la recepción. La picaresca muestra una relación autobiográfica ficcional del pícaro, de ahí la importancia del lector implícito y la fuerte presencia explícita del narratario picaresco, que harían más creíble la narración ${ }^{94}$.

Los literatos se sirven del lenguaje para distanciarse de los marginales, así como para condenarlos, pues lo contrario produciría que se supusiera su aprobación o complicidad. Veamos, antes de continuar, una pequeña introducción a este aspecto de la picaresca, que observaremos a lo largo del análisis de las novelas.

\section{A- 6. El lenguaje}

La observación y descripción de ese mundo conformado por los marginales, extraño a los escritores y lectores, suscitó el interés de los sectores letrados, que acompañaban ideológicamente el fenómeno político que tenía lugar en torno a su persecución. En este marco, mientras la picaresca se ocupaba de retratar esta sociedad, el vocabulario especializado de los ladrones y mendigos fue tema de numerosos tratados y publicaciones de la época, lo que indica la curiosidad de las clases letradas y el temor que despertaban los marginales, explicando asimismo, el estupor del discurso erudito de los siglos XVI y XVII ante la riqueza de la jerga, en la cual veían el instrumento más importante del estilo de vida criminal $^{95}$.

Sin embargo, también debemos reparar en el uso del lenguaje de quienes describieron ese mundo marginal y cómo lo constituyeron como chivo expiatorio mediante su enunciación, poniendo en juego los usos clasificatorios que se aplican sobre los sujetos que conviven en una sociedad ${ }^{96}$.

Tal como veremos en el último capítulo de esta tesis, el lenguaje cobra gran relevancia para entender el fenómeno de la segregación de los vagabundos por dos motivos: en primer término, es el medio para definir a los marginales desde afuera; en segundo lugar, el carácter críptico de su lengua resulta parte de la constitución del sector

\footnotetext{
${ }^{94}$ Ibídem, p 112.

${ }^{95}$ Bronislaw Geremek, La estirpe... op cit, pp 218 y 219. Según el estudio de C. Hernández Alonso y B. Sanz Alonso, la germanía perdió su valor críptico pero incrementó su importancia y presencia en todas las clases sociales cuando fue publicada por los literatos. César Hernández Alonso y Beatriz Sanz Alonso, Germanía y sociedad en los Siglos de Oro la cárcel de Sevilla. Valladolid, Universidad de Valladolid, 1999, p 40.

${ }_{96}$ Bourdieu sostiene que los individuos o los grupos son definidos no solamente por lo que son, sino también por su reputación. Pierre Bourdieu. El sentido práctico... op cit, p 217.
} 
que la comparte. Sobre el primer punto, Geremek agrega respecto a lo que puede aportar la literatura para el estudio de esta problemática que, tras los esquemas y representaciones mentales, se vislumbra no sólo el mundo de los marginales sino la óptica respecto a ellos de quien los describe ${ }^{97}$. Por otro lado, el historiador propone que el lenguaje delimitaría el sector marginal, que convive con el resto de la sociedad, porque sería su única frontera posible.

Una de las cuestiones más características del género es el estilo extraño y conflictivo en que se expresan estos pícaros. Tal como sostiene Cabo Aseguinolaza, a pesar de proceder de un narrador primopersonal, la palabra del pícaro no es monológica, porque acude a otras expresiones pertenecientes a un sector ajeno (el del escritor) que, aunque muchas veces están emparentadas con aquella en la que se integran por el tema o el tono, cuando esto no ocurre se percibe un conflicto, pues el pícaro asume e interioriza lenguajes muy diversos, dando lugar a un discurso internamente contradictorio a causa de que los distintos lenguajes entran en contacto polémicamente. El estilo picaresco nace como elemento fundamental en la construcción de una expresión ajena, que depende de la situación social e ideológicamente escindida en que se concibe la narración. Los dos rasgos fundamentales de esta narrativa son la "oralidad y la heterología" ${ }^{98}$, cuya combinación da lugar a una multidimensionalidad de estilos y argumentos, apóstrofes, reiteración semántica, tono coloquial, implicación de los gestos y tono de voz, tendencia a la digresión, al comentario, a las asociaciones de ideas, referencias al momento de la narración, a la relevancia y tono de la recepción, propias de la oralidad ${ }^{99}$.

Teniendo en cuenta estas consideraciones acerca de la picaresca, compararemos el discurso de algunos de sus ejemplares con otras clases de fuentes tales como las peticiones y las respuestas de Cortes, que también ameritan, antes de su tratamiento particular, algunos reparos. Los avances críticos en torno a este tipo de documentación

\footnotetext{
${ }^{97}$ Esta descripción procedería de los miembros de la "sociedad global”. Bronislaw Geremek, La estirpe... op cit, $\mathrm{p} 104$.

98 Fernando Cabo Aseguinolaza, op cit, $\mathrm{p} 78$.

${ }^{99}$ Ibídem, pp 76, 77,78, 104, 105 y 107. Estos aspectos serán ilustrados a lo largo del análisis de las novelas, en los próximos capítulos.
} 
han sido aportados ampliamente por la historiografía, por lo tanto aquí atenderemos a los que conciernen a nuestro estudio.

\section{B - Las Cortes}

En un período de consolidación monárquica, el discurso emitido desde las asambleas que la legitimaban no sólo es representativo de una política real, sino también de los sectores que eran convocados, las oligarquías urbanas y la aristocracia, para dar auxilio al rey. Las Cortes de los Antiguos Reinos de León y de Castilla recogen las peticiones realizadas al monarca por parte de los procuradores que se reunían en ellas, representando al reino. Sin embargo, el peso que tuvieran la monarquía o las ciudades era objeto de una puja permanente que debía resolverse en negociaciones en un balance de poder. De ellas se desprendía parte de la normativa que regiría a partir de entonces, y se debatían los asuntos que inquietaban al monarca. El rey convocaba al reino en estas asambleas para discutir y decidir acerca de aspectos centrales de la política. Las convocatorias citaban a la nobleza, clero y procuradores de las ciudades, que eran representadas por sus oligarquías aunque en el siglo XVII muchos procuradores eran nobles y manifestaban las inquietudes de su propio sector.

En el próximo capítulo veremos las cuestiones referentes a los marginales cuya mención hemos hallado entre 1268 y 1628. Tendremos en cuenta en esta sección un marco cronológico bastante más amplio que el que consideramos para el examen de la literatura, evaluando lo pautado por los ordenamientos durante varias centurias hasta llegar a la decimosexta. Esto se debe a que encontramos una interesante evolución en la legislación que culmina en el siglo XVI, testigo del debate sobre los pobres, las propuestas de fundación de Casas de Misericordia y la emergencia de la literatura picaresca. En el próximo capítulo veremos especialmente cuáles eran las peticiones que se hacían al rey, mostrando las inquietudes de los sectores representados en estas asambleas. En algunos casos dichos reclamos arribaron a un plano resolutivo, emitiéndose normas a partir de ellos; en otras oportunidades esto no sucedió, dando lugar a su repetición en convocatorias sucesivas ${ }^{100}$. En ciertas ocasiones el rey aceptaba las peticiones, pero en otras no les daba satisfacción porque aquéllas no eran vinculantes para el poder real. Sin embargo, nos interesa observar que, a pesar de las leyes que se

\footnotetext{
${ }^{100}$ Sobre este fenómeno ver: José Ignacio Fortea Pérez, Las Cortes de Castilla y León bajo los Austrias. Una Interpretación. Valladolid, Junta de Castilla y León. Consejería de Cultura y Turismo, 2008, p 41.
} 
desprendieran de las peticiones en las Cortes, la gravedad y falta de resolución del problema que los marginales planteaban daba lugar a que se modificara fundamentalmente la normativa acerca del tema, modelando diversas soluciones posibles para un mismo conflicto.

La reglamentación en torno a las labores en pos de domesticar la mano de obra se dio de manera simultánea a la persecución de quienes no poseían un oficio manual conocido o adscripción a un señor y la regulación y el ordenamiento de las formas de contratación, cuyo objetivo era dominar a los sectores trabajadores e intervenir en la competencia entre quienes los contrataban. Al mismo tiempo no sólo se avalaba la limosna institucionalizada, sino que a nivel concejil también se autorizaba su recolección por parte de viejos y niños, pero no por quienes pudieran realizar trabajo asalariado, a quienes se buscó obligar a contratarse a jornal mediante diversos mecanismos. Veremos a través de las peticiones efectuadas en las Cortes el esfuerzo realizado para establecer cuestiones concernientes a la paga, duración de la jornada, forma de labor, etc., problema que enmarca la dificultad para someter a los hombres a nuevas condiciones laborales.

En el siglo XVI estas medidas adquirieron pleno sentido no sólo en calidad de castigo de la disidencia, sino especialmente como imposición de la disciplina que exigía el sistema de trabajo asalariado que acabaría por imponerse más tarde, mientras los valores de la clase dominante censuraban la ociosidad y la mendicidad. Las normativas que conciernen a nuestro problema son de diversa índole, pues se intentaba regularlo desde muchos aspectos. Aclararemos, antes de proseguir, cuáles son los grupos de peticiones que observaremos:

- Las peticiones en torno a la represión de los vagabundos, las cuales varían a lo largo del tiempo especialmente en torno al castigo que se intenta aplicar sobre ellos.

- El conjunto de ordenamientos que se emitieron en pos de regular el trabajo asalariado, esto es, los de labores en sus distintas formas, que analizaremos en relación con el disciplinamiento de la fuerza laboral.

- Los reclamos en torno al problema de los sirvientes, que, tal como los tres temas que mencionamos a continuación, veremos sobre el final del período considerado.

- Las normas en torno a los vendedores ambulantes.

- Los intentos de regular los desórdenes en la corte. 
- La procuración acerca de los gitanos, que recibirá una breve mención, pues si bien es un grupo diferente del que nos ocupa, nuestro interés en él radica en que su descripción es similar a la de los vagabundos.

Además de estas fuentes, contamos, a nivel de las comunidades, con las ordenanzas locales, que nos brindan información acerca de lo que se regulaba en el marco de las aldeas. Se trata de textos normativos que nos informan acerca de la reglamentación de diversas prácticas, lo que que retomaremos oportunamente cuando resulten ilustrativas respecto a lo que queremos observar.

\section{B-1. Las peticiones en torno a los hombres baldíos en su contexto}

La temprana modernidad asistió al problema de la masificación de los hombres baldíos que, tal como observamos en el capítulo precedente, se enmarcó en un proceso de cambio económico del cual resultaba que cada vez más personas se encontraran en una situación de no sujeción respecto a un señor o un amo, tal como había sido hasta entonces. Esto generaba a su vez al menos dos problemas: uno era político, en tanto los hombres debían permanecer domiciliados, y el otro, económico, por cuanto debían ser dóciles para su contratación como asalariados en el marco de la comunidad. Sin embargo, ambos estarían imbricados, pues junto al aspecto económico encontramos el conflicto generado por la sujeción, determinado por la falta de encuadramiento de algunos hombres, pues si no se enmarcaban jurídicamente tampoco lo hacían económicamente, entonces el problema era cómo sujetar a esos individuos en pos de mantener el orden, pues esta idea teológico política englobaba lo económico. La sociedad que nos ocupa era pensada como una comunidad de órdenes en la cual cada uno tenía una posición teóricamente inalterable, aunque en la práctica existía cierta movilidad en dos sentidos, geográfico y económico. La confusión de los estamentos llevaba al desorden, ya que las jerarquías en la Tierra habían sido instauradas por Dios para que los hombres participaran de las riquezas celestes por semejanza ${ }^{101}$.

\footnotetext{
${ }^{101}$ Ver: Georges Duby, Los tres órdenes o lo imaginario del feudalismo. Barcelona, Argot, 1983, p 170. También Carmen López Alonso, op cit, pp 313-317. Por su parte, J. I. Fortea Pérez repara en la imagen estática respecto a la sociedad de órdenes que se planteaba en las Cortes. Sobre este problema ver: José Ignacio Fortea Pérez, Las cortes... op cit, p 45.
} 
Esta inmovilidad debería proyectarse en el plano del espacio, esto es, los hombres no sólo debían mantenerse en su estado sino que también se pretendía que estuvieran fijos en un lugar. El problema de su movilidad se enmarca en una sociedad sedentaria en la cual los sujetos eran conocidos y garantizados dentro de la comunidad, mientras el extranjero resultaba sospechoso ${ }^{102}$. Su movilidad era además pavorosa para la comunidad porque se pensaba en la posible contaminación, tal como observamos respecto a los tiempos de peste en especial. Estos otros factores, además del económico, hacían temibles a los vagabundos. En el próximo capítulo veremos que todos estos aspectos aparecen mencionados en la procuración, a través de la regulación de cuestiones muy diversas.

\section{B-2. Las Cortes, el rey, las ciudades y los procuradores}

El origen de las Cortes se remonta a 1188, tratándose de un consejo celebrado entre rey y reino, cuya finalidad era que, a partir de ellas, surgieran ordenamientos que se pusieran en práctica en los reinos cuyas ciudades eran convocadas, para su mejor gobierno. Sin embargo, esta institución fue cambiando paulatinamente, y no se mantuvo siempre igual en su composición, ni en sus objetivos ni en su forma. Para la corona, lo más importante, a partir del siglo XVI, era que asistiesen los representantes de las ciudades con voto a Cortes, que eran las que trataban los tributos. Los procuradores de las capitales convocadas tenían la voz de la totalidad del reino, lo cual implicaba el problema de su representatividad. El gobierno estaba entonces en manos de una tríada compuesta por corona, Cortes y ciudades, lo que condujo a la contienda entre la primera y las últimas por el control de la institución legislativa.

Tampoco asistían procuradores de todas las ciudades del reino. Su número fue cambiando hasta que con los Reyes Católicos se estableció en dos por cada una de las diecisiete ciudades representadas (en 1498 se agrega Granada y en el siglo XVII Galicia y Extremadura). Además, las ciudades y regiones excluidas se hallaban en conflicto continuo con sus ciudades delegadas, desafiando a la estructura tradicional de la representación.

La monarquía utilizó las Cortes para publicar leyes y ordenamientos, aprovechando la presencia de los procuradores, como portavoces de las comunidades,

\footnotetext{
${ }^{102}$ Jean Delumeau, op cit, pp 206 y 208.
} 
porque de ese modo obligaba a todos a su cumplimiento ${ }^{103}$. Sin embargo, existía una diferencia entre lo que ellas consentían y lo que realmente se cumplía en cada localidad del reino.

Durante el siglo XV y principios del XVI se firmaron acuerdos en pos de resolver conflictos electorales y repartir procuraciones entre los regidores, linajes y otros grupos enfrentados entre los cuales estaban divididas las ciudades, cuya variedad daba lugar a formas de elección muy diversas. La monarquía fue disminuyendo progresivamente el poder de las ciudades y, entrado el siglo XVI, las ciudades no tenían la libertad para nombrar a sus representantes en Cortes, porque la monarquía obligaba extraoficialmente a los concejos a elegir unos candidatos determinados ${ }^{104}$. Sin embargo, los procuradores no tenían plena libertad de acción en cuanto a sancionar lo solicitado por el rey, pues muchas ciudades, aunque otorgaban poderes cumplidos, restringían a sus procuradores con instrucciones, juramentos y pleitos homenaje que los obligaban a guardar esas instrucciones.

Los procuradores debían ser "personas honradas" que no pertenecieran al grupo de labradores y sesmeros. De esta manera, la representación recaía en las clases dirigentes de las ciudades, pero posibilitando el ingreso de otros grupos sociales, pues además de hidalgos y caballeros se introdujeron los burgueses ${ }^{105}$. Los grupos que entraban correspondían a lo que se llamaba "la mejor parte" de la sociedad, que admitía circulación vertical, pero lentamente. En los grandes concejos no participaban los grupos que pagaban menos de una cierta capitación y quienes no eran propietarios. Los burgueses, por entrar en alguna de esas dos categorías podían concurrir al concejo, si eran naturales y vecinos. Los había tratantes, banqueros, financieros, ganaderos, vinicultores y productores y vendedores de granos. Del mismo modo, sus bienes eran mayorazgos, adquiridos o heredados, tierras, casas y propiedades urbanas, oficios y rentas. Así, los procuradores representaban tanto los intereses rurales como los urbanos, de ello provenía su preocupación particular en la prosperidad de la economía local pues el afán en la defensa de sus regiones se aparejaba por el que mostraban en su

\footnotetext{
${ }^{103}$ Juan Manuel Carretero Zamora, Cortes, monarquía, ciudades: las Cortes de Castilla a comienzos de la época moderna. Madrid, Siglo XXI de España Editores, 1988, pp 47 y 54. El procurador ratificaba con su presencia el poder absoluto del monarca, porque materializaba y hacía vinculante su poder para el pueblo. Las Cortes y sus representantes fueron criticados por su inutilidad política y por contribuir a elevar la presión fiscal. Ibídem, pp 251 y 252.

${ }^{104}$ Ibídem, pp 29 y 31. Irving Thompson, "Cortes y ciudades: tipología de los procuradores (extracción social, representatividad)", en AAVV. Las Cortes de Castilla y León en la Edad Moderna. Valladolid, Junta de Castilla y León, 1989, pp 191-248, pp 196 y 197.

${ }^{105}$ Juan Manuel Carretero Zamora, op cit, p 250.
} 
explotación, pues, como sostiene J. M. Carretero Zamora, lo que los identificaba entre el poder dirigente del reino "... no era la pertenencia específica a la ciudad, al régimen señorial y a la administración de manera aislada, sino, por el contrario, la presencia en todas y cada una de esas realidades políticas y sociales a la vez" ${ }^{\prime 106}$.

Entre 1550 y 1660 el estado de los procuradores ascendió, mientras la aristocracia, durante el siglo XVII estuvo cada vez más interesada en participar, proceso que las ciudades no podían impedir, de modo que en el último período uno de cada cinco procuradores era señor de vasallos y otros tenían heredades de tierras y viñas, sobre todo en Andalucía. Nos interesa observar que éstos eran los sectores representados en Cortes, y quienes procuraban el sometimiento de los hombres libres al trabajo asalariado, en tanto pertenecerían a estos mismos estratos quienes los contratarían para la labor en sus propiedades.

En el capítulo tercero veremos la manera en que la procuración sufrió variaciones desde la Baja Edad Media para llegar en el siglo XVI a un tratamiento que buscaba fijar a los hombres en el espacio, que los pobres recibieran caridad en sus propias comunidades y que cada una de éstas se hiciera cargo de ellos. En este contexto, la preocupación también se manifestaba en otras esferas de la élite, como ya vimos entre los literatos, pero también entre los teólogos, cuyas principales producciones observaremos en la tercera y última parte de este capítulo.

\section{C- Las propuestas teológicas en torno a los pobres}

La misma dinámica que conducía a la persecución de los hombres sin amo llevó también a que este problema se discutiera en su plano teórico por parte de religiosos que proponían diversas formas de considerar la indigencia y la libertad de los hombres. En el marco del debate sobre los pobres que tuvo lugar en el siglo XVI, las propuestas que se presentaron para su resolución fueron muy variadas y giraban en torno a la relación entre trabajo y pobreza y la división entre pobres verdaderos y fingidos, que en última instancia se derivaba del anterior, en tanto los últimos serían aquellos físicamente aptos para el trabajo.

\footnotetext{
${ }^{106}$ Ibídem, p 271. Los procuradores de hecho pertenecían a estratos de raíz oligárquica con intereses (que hacían efectivos en las Cortes) difícilmente extrapolables a la realidad social del reino. Ibíem, p 47.
} 
Estas cuestiones fueron analizadas desde el paradigma de la ley natural y en función de la unidad y estabilidad de la sociedad. Los doctores españoles entendieron este problema como una consecuencia de la existencia de la propiedad privada que, al introducirse en la sociedad, la había dividido entre aquellos que la poseían y quienes no. Estos últimos, los pobres, debían tener derecho a ser garantizada su subsistencia, esto es, cierta participación en los bienes de los cuales gozaba la humanidad, pero uno de los aspectos a debatir era de qué manera podría hacerse efectiva esa seguridad. De este modo, se entendía el derecho natural por encima del positivo, creado por el hombre, que garantizaba la propiedad privada, mientras la relación entre ésta y el objetivo comunitario de las riquezas determinaba el modo de concebir la limosna, por eso los pobres debían ser libres de comer donde pudiesen y por ello transitar libremente. Estas premisas se corresponden con el proceso de separación de los trabajadores (efectivos o potenciales) de su fuente de trabajo y subsistencia, esto es, la tenencia de la tierra y el acceso a los comunales, que hasta entonces les habían garantizado cierta participación legítima en la riqueza ${ }^{107}$.

De esta manera, aquellos que no detentaban propiedad, tenían dos formas de garantizarse la subsistencia, el trabajo a cambio de una paga y la mendicidad, pero el derecho al ejercicio de esta última era objeto de debate. ¿Podían mendigar legítimamente todos los pobres? ¿En qué términos? ¿Podían hacerlo en cualquier lugar? Todas estas materias serían puestas en cuestión por los escolásticos.

Los teólogos intentaron precisar las circunstancias en las que era legítimo mendigar. Los hombres pertenecientes al estamento de los laboratores estaban obligados a la actividad manual a menos que estuvieran impedidos físicamente para desempeñarla. Entonces se justificaba que acudiesen a la limosna, en tanto el primer derecho era la conservación de la vida porque lo contrario era suicidio y estaba penado por la ley divina. Desde ese punto de vista, si no se le suministraba recursos para sobrevivir, no se podía impedir a una persona que mendigase. En este contexto, los autores trataron de analizar las vías de participación de los pobres en los bienes que se consideraban patrimonio común de la humanidad (entregados por el Creador), participación asegurada por el derecho natural, anterior al de propiedad ${ }^{108}$. Por eso resultaba necesario armonizar propiedad y asistencia para lograr un acuerdo entre el orden económico y la

\footnotetext{
${ }^{107}$ Francisco Gómez Camacho, Economía y filosofía moral: la formación del pensamiento económico europeo en la escolástica española. Madrid, Síntesis, 1998, pp 109 y 110.

${ }^{108} \mathrm{La}$ interpretación acerca de la relación entre la propiedad privada y el objetivo comunitario de las riquezas determinaba el modo de concebir la limosna.
} 
ley natural, pues la falta de bienes propios no debería privar al indigente del derecho natural a la supervivencia.

Por otra parte, se definía la necesidad de considerar de manera diferente a los pobres, según sus condiciones. El verdadero -que podía solicitar lícitamente la solidaridad de la sociedad- era entendido como pobre involuntario, y el fingido o voluntario era aquel que físicamente sí era apto para el trabajo pero decidía no hacerlo, y por lo tanto era vinculado con la pereza, lo cual lo equiparaba a los delincuentes, justificando que se le negara la limosna y se le obligara a trabajar. Al pobre "verdadero" no se le podía negar la posibilidad de pedir limosna si no se le compensaba, mientras que al fingido se le debía impedir esa práctica, porque su elección significaba una carga para la sociedad. Esto conduce a otro aspecto de esta producción teórica, referido a las formas de inserción social de los pobres a través de la limosna y el salario, y quiénes podían proporcionarlos: las organizaciones benéficas y el mercado de trabajo respectivamente.

En un contexto de reformas que tiene lugar no sólo en España sino en el continente, el debate cuenta con un antecedente en la obra De Subventione Pauperum, de J. L. Vives, publicada en 1526, que ponía en discusión una serie de medidas que sirvieron a la contienda intelectual posterior y varias de las cuales resultaban un perfeccionamiento de tareas que ya se hacían, como el encargo a los municipios de la atención a los pobres propios, la centralización de los recursos necesarios para ello, la identificación de los necesitados locales y la expulsión de los extranjeros, la prohibición de la mendicidad puerta a puerta y la restricción de la acogida a los peregrinos ${ }^{109}$.

El edicto de 1540 que limitaba la libertad de los pobres hizo que esta inquietud resurgiera entre los teóricos. D. de Soto defendió la práctica religiosa de la misericordia, así como la circulación de los indigentes y su derecho a mendigar, pues la libre movilidad les permitiría buscar los medios de subsistencia donde les fueran proporcionados de la mejor manera. El dominico también planteó la libertad que tiene cada persona que realiza la limosna a elegir a quién, cuándo y dónde entregarla, mientras desconfiaba de la vía institucionalizada para hacerla efectiva. Sin embargo, Soto no negaba que la autoridad debiera ocuparse del mantenimiento de los pobres, sino que sólo si dicha intervención garantizara efectivamente la subsistencia de los

\footnotetext{
${ }^{109}$ Javier López de Goicochea Zabala, "De Subventione Pauperum: Los tratados sobre la pobreza en los orígenes del Estado Moderno", en Saberes, revista de estudios jurídicos, económicos y sociales. Vol. I, Villanueva de la Cañada, Universidad Alfonso X el Sabio, 2003, pp 1-26, p 24.
} 
miserables, se les podría impedir la mendicidad. Además defendió la libre movilidad de manera universal, borrando en este aspecto las fronteras entre reinos, entendiendo que la obligación de la solidaridad compete a la humanidad ${ }^{110}$. Si Soto consideraba la necesidad de distinguir entre pobres verdaderos y fingidos, no lo hacía respecto a los locales y a los forasteros, pues todos deberían merecer asistencia ${ }^{111}$, ya que el destierro y la expulsión eran penas que deben aplicarse a los criminales y pedir, si se tiene verdadera necesidad, no es un crimen. Además, sería injusto prohibir a los miserables que salieran de su lugar de origen si no se demandaba en cada localidad que mantuviera a sus propios pobres ${ }^{112}$. Para defenderse de otros argumentos como el referido a la posibilidad de que personas que teniendo hacienda fueran a pedir a otro lugar, sostenía que estos casos eran muy pocos para ser considerados ${ }^{113}$. Respecto a las pestilencias, esgrimía que no eran adjudicables sólo a la circulación de los hombres, pues también podían generarse y contagiarse entre los pobres locales.

Respecto a la inmoralidad que se achacaba a los indigentes, Soto aducía que en todos los sectores sociales había personas cuestionables desde este punto de vista, de esta manera denunció la injusticia social que hacía que a los pobres se los acusara mientras los otros sectores robaban en grandes cuantías ${ }^{114}$. Además, entendía que las faltas de los miserables podrían ser producto de las circunstancias que atravesaran. Por último, también reparaba en el problema de los vergonzantes, quienes preferirían padecer la necesidad antes que publicarla ${ }^{115}$.

J. de Robles respondió inmediatamente a la tesis de Soto, defendiendo la intervención de la autoridad en torno a la manutención de los indigentes, cuya libertad quedaría subordinada. Robles acordaba con el dominico acerca de la necesidad de diferenciación entre pobres verdaderos y fingidos, aunque disentía en los otros aspectos abordados por Soto. En principio, el benedictino creía que las pautas introducidas por la

\footnotetext{
${ }^{110}$ Francisco Gómez Camacho, op cit, p 127.

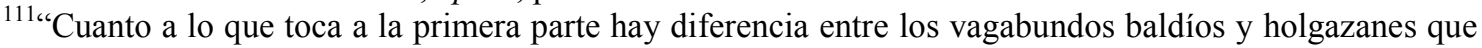
no siendo pobres, fingiendo pobreza andan pidiendo limosna, y los que siendo legítimamente pobres, andan fuera de sus naturalezas a pedir por todo el reino. Porque de los primeros, no solamente es ley antigua del reino, empero es más antigua de derecho común y mucho más antigua de derecho divino y natural, que no sean permitidos ni se sufran sin castigo. Y lo segundo, que es de lo que ahora se trata, salvo el parecer de otros que mejor lo supieren, a mi pobre juicio es cosa nueva y no fundada en ley común ni en ley antigua del reino, antes no conforme a lo que por el Evangelio y buena razón parece." Félix Santolaria Sierra (ed.), El gran debate sobre los pobres en el siglo XVI. Domingo de Soto y Juan de Robles 1545. Barcelona, Ariel, 2003, p 57.

${ }^{112}$ Ibídem, pp 64 y 65.

${ }^{113}$ Ibídem, p 71.

${ }^{114}$ Ibídem, pp 89 y ss.

${ }^{115}$ Ibídem, p 85.
} 
reforma de 1540 respecto al tratamiento de los pobres eran efectivas. Por otro lado especificaba las cuantías de las raciones que debían ser entregadas de manera insitucionalizada, en pos de ordenar la limosna, incrementar su efectividad y evitar que pudiera acabar en manos de los pobres fingidos ${ }^{116}$. En este sentido, su tratado hace hincapié en los malos comportamientos de los miserables ${ }^{117}$, mientras asume que sólo basta con querer trabajar para hacerlo y que el jornal sería suficiente para la subsistencia. Robles modeló un plan para la administración efectiva del suministro de la limosna, en pos de saldar lo planteado por Soto acerca de su mala ejecución por parte de las instituciones ${ }^{118}$.

Hubo otros autores que, de diversas maneras, retomaron el debate y se pronunciaron en torno al problema de los indigentes. M. de Giginta ofreció a las Cortes en 1576 una propuesta basada en el modelo de las Casas de Misericordia, con una óptica diferente a la de las instituciones que funcionaban en ese entonces en el continente. El canónigo sostuvo que, si bien el mendigo no era culpable de su situación, eso no era argumento para negar su reforma ${ }^{119}$. Para su plan institucional propugnaba tres cuestiones, la sencillez en su arquitectura y administración y el ingreso voluntario ${ }^{120}$. Sin embargo, se colige que todo aquel que limosneara, teniendo estos hospicios como opción para subsistir sin hacerlo, sería un mendigo falso ${ }^{121}$. Las casas darían sustento y ocupación a todos, pobres verdaderos y fingidos, en el marco de un proyecto pedagógico que combinaba la vigilancia permanente y el trabajo ${ }^{122}$.

C. Pérez de Herrera, redactó entre 1592 y 1598 Amparo de pobres, a partir de su experiencia acerca de las condiciones en que vivían quienes habían sido condenados a galeras, donde se desempeñaba como protomédico. El derrotero de los pobres y pícaros era para este autor una preocupación que compartía con Alemán, quien un año más tarde publicaría El Guzmán. Herrera propugnaba la conversión de los hombres ociosos en mano de obra para las manufacturas, comenzando por las que funcionaban o podrían instalarse en Madrid, lo cual se llevaría a cabo mediante una enseñanza profesional

\footnotetext{
${ }^{116}$ Ibídem, pp 125 y ss.

117 Ibidem, p 128.

${ }^{118}$ Proyectaba, a lo largo de veinte puntos, perfeccionar los instrumentos puestos en práctica anteriormente, considerando que consistían en una buena planificación pero que era necesario mejorar su ejecución. Ibídem, pp 191 y ss.

${ }^{119}$ Miguel de Giginta, Tratado de remedio de pobres. Barcelona, Ariel, 2000. Edición a cargo de Félix Santolaria Sierra, p 77.

${ }^{120}$ Ibídem, passim.

${ }^{121}$ Ibidem, pp 87 y ss.

${ }^{122}$ Ibidem, pp 114 y ss.
} 
específica en las casas de recogimiento (luego el Hospital General) en combinación con un sistema de cédulas para identificar a los pobres verdaderos ${ }^{123}$.

\section{Conclusión}

En las páginas precedentes hemos repasado cuáles fueron los diversos discursos que se elaboraron en torno a los marginales durante la temprana modernidad española. En primer lugar era necesario establecer un estado de la cuestión acerca de los problemas que presenta la novela picaresca para nuestro análisis: se trata de un género producto de su tiempo y especialmente de las preocupaciones que la realidad social planteaba a los autores, a partir de la inquietud ante la crisis económica, social y política de la Corona peninsular de los Habsburgo. La novela picaresca se dedicó al retrato de los sectores marginales, que no sólo tenían una baja inserción en el mercado de trabajo sino que además se caracterizaban por ser sujetos móviles, condición que por sí misma los hacía sospechados de conductas desviadas.

Las discusiones en torno al pícaro lo muestran como una figura marginalizada y nómade, que encuentra la subsistencia mediante trabajos ocasionales, en general en la órbita del servicio, alternados con la mendicidad, entonces condenada, y otros artilugios como pequeñas estafas o la prostitución (en calidad de proxenetas los varones o meretrices por parte de sus pares mujeres). Reparamos en que la observación de las mujeres marginales varía según ellas ocupen un rol protagónico o no en el relato. En el primer caso, su condena se basa en que no se someten a la potestad de un hombre; pero si ellas son sólo parte del mundo del pícaro, su marginalidad (amén de la misoginia que sobrevuela todas las producciones del género y de la incomprensión acerca de la eventual prostitución de las marginales con el objetivo de sobrevivir ante el fracaso de otras estrategias), es más similar a la de los varones, son mendigas, criadas, vagabundas. Los literatos imprimieron a su discurso sobre los pícaros una condena también variable, lo cual se explica por la particularidad de la experiencia social de cada uno de ellos.

En el plano de la narración, la autobiografía ficticia abrió la posibilidad de presentar las existencias de estos sujetos y otros aspectos de las mismas como la proyección de sus apreciaciones e ideas acerca de sus propias existencias y de las de otros sectores sociales sobre ellas, incluido el del propio autor. Novelas posteriores

\footnotetext{
${ }^{123}$ Cristóbal Pérez de Herrera, Amparo de pobres. Madrid, Espasa Calpe, 1975. Edición a cargo de Michel Cavillac, passim.
} 
conservaron la figura del pícaro como protagonista, aunque abandonaron la forma autobiográfica, pero el camino para este tipo de descripciones ya se había iniciado.

Creemos que algunos aspectos relatados, que los autores suponían como reales pero que eran mal conocidos para ellos y por tanto peligrosos, eran ciertamente parte de una proyección que, si bien estaba basada en algunos rasgos de la realidad, era una construcción ideológica para la condena de los vagabundos.

Las novelas quisieron mostrar el distanciamiento social entre sus protagonistas y el mundo de los autores-lectores, sin embargo, encontramos en estas líneas diversos puntos de contacto entre ambos grupos, marginados e integrados. Por este motivo es concebible que los primeros hayan sido objeto de un retrato atemorizador que tenía por objetivo generar rechazo hacia quienes estuvieran en situaciones fronterizas (por ejemplo en la estigmatización que se opera respecto a los sirvientes domésticos temporales).

Por último, observamos la problemática en torno al lenguaje, que en la realidad constituía una frontera con un mundo inintelegible para los autores, pero que, en el marco de la narración, resultaba funcional a la definición del mundo marginal. Asimismo, reparamos en que ese lenguaje resulta ambivalente, y esto por dos motivos, quien escribe no es marginal y por eso se vale de su propia lengua para hacerlo, pero además, en el interior del relato, el marginal presenta la cualidad de estar en una situación de bisagra que lo convierte en un agente en quien se puede imprimir esta dualidad, que corresponde a la capacidad del pícaro de sobrevivir fingiendo ser otro que el que realmente es, pero que a la vez, es la representación que hace el autor del marginal.

En la segunda parte de este capítulo examinamos cuáles fueron las condiciones de producción del discurso de las Cortes, cuyo contenido analizaremos en el próximo. Observamos que estas convocatorias resolvían no sólo las cuestiones concernientes al reino y a las ciudades allí convocadas, sino también a las tensiones entre uno y otras. Pero reparamos fundamentalmente en la conformación social de los procuradores, cuya característica más importante radica, respecto a nuestro tema, en que constituían el sector más cercano al propietario que demandaba el sometimiento de los hombres al trabajo asalariado y por eso propugnaban la conversión de los sujetos sin ocupación a una actividad con jornales fijados por los propios concejos. 
Por último, nos detuvimos en el discurso teológico y político en torno a la pobreza, cuyo gran desarrollo durante el siglo XVI coincide cronológicamente y está en consonancia con la emergencia de la picaresca. El debate parte del acuerdo acerca de la presencia de la misericordia y la justicia en el acto de la limosna, pero fuera de ello, los autores muestran muy diversas posturas sobre cómo debería ser efectivizada y quiénes merecían dicha asistencia. El aspecto que más nos interesa en este sentido radica en la preocupación generada por los hombres baldíos, es decir, los que no tenían trabajo u ocupación, que se repite en los otros dos discursos analizados. Por otro lado, vemos en esta clase de escritos la intervención de distintas lógicas que van de la condena del pobre a la comprensión de su conducta en el marco social, así como a una idea de castigo y otra de reforma del vagabundo, dando cuenta de la amplitud del pensamiento político, teológico y social en torno a los hombres que combinaban la carencia de lazos de dependencia y la pobreza, y que constituyen un fenómeno anómalo en esta sociedad. Los postulados que inician y que se desprenden de este debate nos ayudarán a comprender las normativas emitidas en torno a los mendigos, así como la representación de la mendicidad callejera, que será analizada en el quinto capítulo, donde podremos ver la postura de los literatos, pero también vislumbrar la práctica retratada en la narrativa.

Teniendo en cuenta estas ideas preliminares en torno a los discursos que nos ocupan en esta tesis, nos dedicaremos en los próximos capítulos a analizar la manera en que aquéllos fueron utilizados para proponer soluciones sobre los problemas en torno a los marginales. Comenzaremos por observar las peticiones y ordenamientos de las Cortes, producción colectiva que no sólo tenía la intención de retratar, sino especialmente de incidir sobre la realidad social. 
CAPÍTULO 3

LA REPRESENTACIÓN DE LOS MARGINALES EN LAS ACTAS DE LAS CORTES 


\section{Introducción}

En los capítulos anteriores hemos definido la materia de nuestra investigación y delineado el concepto de marginalidad que emplearemos en la presente tesis, pues observamos que la amplitud a la cual ha arribado el uso de esta categoría demanda que se haga este tipo de precisiones cada vez que la utilicemos para una investigación histórica. En este marco, reparamos en que el estudio de la representación de un fenómeno social obliga a un análisis exhaustivo de los documentos utilizados, teniendo en cuenta su institucionalidad, quiénes los formulan, así como cuáles son sus propósitos y sus destinatarios. Los interrogantes que hemos planteado serán esclarecidos a partir de la comparación del contenido de distintas clases de fuentes, que representan el mismo fenómeno social de diversas maneras. El análisis de las Cortes tiene como finalidad ser cotejado con la representación literaria, para lo cual observaremos qué cuestiones son adjudicadas a los marginales por los literatos y por el discurso político, así como las diferencias y similitudes en su forma de enunciación.

En el presente capítulo veremos la manera en que los vagabundos fueron retratados en las actas recogidas durante las sesiones de Cortes, así como en la normativa que se desprendía de ellas. Observaremos los cambios en el modo de representación de los marginales, teniendo en cuenta un marco temporal más amplio que el que manejamos en los capítulos cuarto, quinto y sexto. Si bien nuestro estudio atiende especialmente al siglo XVI, debemos retrotraernos a lo que ocurrió a partir del siglo XIV respecto a la persecución de los hombres baldíos, e incluso antes, en pos de observar las variaciones que mantuvo la política adoptada respecto al proceso de marginación hasta llegar al Siglo de Oro, pues el fenómeno de la criminalización y persecución de los hombres sin señor es parte de un proceso que se originó en el ocaso de la Edad Media.

Analizaremos la homologación entre este tipo de marginados (vagabundos $\mathrm{u}$ hombres baldíos) y otros sectores excluidos en diversos grados (prostitutas, moros, gitanos, etc.) como enemigos internos contra quienes los aparatos político y religioso debían aplicar su fuerza coercitiva. No nos detendremos especialmente en la segregación de los últimos grupos mencionados (ni de otras minorías, como los judíos), dado que cada uno de ellos presenta particularidades que ameritan un minucioso 
estudio. Compararemos la forma de su enunciación como enemigos, valiéndonos también de las conclusiones a las cuales han arribado los especialistas.

Examinaremos el discurso empleado en las Cortes acerca de diversos sectores segregados para comparar la forma de enunciar lo diferente. En este marco también analizaremos las políticas que se ensayaron en pos de erradicar a los marginales del espectro social, finalmente poco eficaces. Dichas propuestas son de gran interés por su diversidad dado que la representación de aquellos hombres varía paralelamente al cambio de la normativa. Entretanto, en el plano teológico y filosófico se generaban debates al respecto: el acecho de las desviaciones fue acompañado por aquel discurso, pues en una sociedad que no tiene organismos policiales, el mejor instrumento de corrección es la internalización de lo negativo de los caracteres de ese otro peligroso, dinámica que requiere la intervención de variados discursos. La clasificación del mendigo falso no es original de esta época, pero es entonces cuando adquiere mayores dimensiones, cuando se toma noción del problema social que significa la pobreza. Entonces se despliega una calificación que es resultado de una estrategia de control desarrollada sobre los miembros de los sectores más pobres que no asumieran el sistema de valores establecido ${ }^{1}$.

Veremos a los marginales como hombres móviles que se insertaban sólo de manera temporal en el trabajo manual y vivían intermitentemente de la rapiña. Otro conflicto respecto a los vagabundos reside en el desorden que su existencia genera en la sociedad antiguorregimental, amenazadora por su movilidad, que dificulta su control por la comunidad o el poder. Ello explica que se los pene por un lado con el destierro, sellando su exclusión, o buscando su inclusión forzada por el otro, aunque entre estos dos extremos había también salidas intermedias.

Así, durante la temprana modernidad se inició una determinada política que fluctuaba entre dos polos: el de la represión, por un lado, y el de la asistencia, por otro, ambos vinculados entre sí, ya que aquél que no merecía ser socorrido debía ser reprimido. La definición de la línea que separaba a ambos dependía de dos variables: en primer lugar el status -el pobre de familia noble no debía trabajar físicamente y siempre merecía socorro-, en segundo término, las condiciones físicas -quien procedía de un sector no noble debía ocuparse, siempre que estuviera corporalmente capacitado para hacerlo-.

\footnotetext{
${ }^{1}$ Raúl Susín Betrán, "Los discursos sobre la pobreza. Siglos XVI-XVIII", en Brocar. No 24, La Rioja, Universidad de La Rioja, 2000, pp 105-135, p 106.
} 
Este tipo de políticas emergieron en la Península Ibérica durante el siglo XIV, como parte de un fenómeno compartido también por el resto de Europa Occidental ${ }^{2}$. A partir de su simultaneidad con la peste y sus consecuencias demográficas, se ha insistido sobre la falta de brazos como producto de su embate, sin embargo, mientras había menos hombres para labrar las tierras, también se registran más personas separadas de dicho medio de producción, como resultado de la pulverización de la tenencia ${ }^{3}$. La pulverización de la tenencia condujo a la separación del campesino de la tierra, luego de lo cual la reinserción laboral fue muy difícil desde que se inició el proceso de marginalización de las primeras generaciones, acentuado en las subsiguientes, mientras el poder negaba la realidad de la falta de trabajo para los desposeídos.

Debemos descartar la hipótesis de que la persecución de los hombres baldíos se vinculaba directamente con la escasez de trabajadores, aunque sí se relacionaba con el mercado de mano de obra en tanto imperaba la necesidad de domesticarla, debido a los novedosos problemas que presentaban los marginales (potenciales asalariados) por su falta de sujeción.

\section{Identificación del hombre baldío}

El primer indicio acerca de la estigmatización de los marginales se encuentra en nuestra documentación en las Cortes de Jerez de 1268:

Ningund peon non ande baldio e sy lo fallaren dé rrecabdo ${ }^{4}$ con quien ande, e sy lo non diere prendanlo ${ }^{5}$, e sy fuere omme que ande comiendo delo ageno pidiendolo o

\footnotetext{
${ }^{2}$ Ver acerca de este problema en el marco continental: Michel Mollat, op cit, pp 261 y ss; Bronislaw Geremek, La piedad... op cit, pp 94 y ss; Jean Delumeau, op cit, pp 301 y 633; Carmen López Alonso, op cit, p 542; Félix Santolaria Sierra, “¿Dar limosna o enseñar un oficio? El debate sobre la caridad en el Siglo de Oro", en Torre de los Lujanes. N ${ }^{\circ}$ 51, Madrid, Real Sociedad Económica Matritense de Amigos del País, 2003, pp 31-54, p 34.

${ }^{3}$ Carmen López Alonso, op cit, p 150. Según la autora se testifica la falta de brazos, mientras también se evidencia el descenso de la población, no tanto por la mortandad sino por la emigración, proceso que fue agravado por la peste. En este marco, la autora se refiere al problema de la inflación en los salarios, Ibidem, p 246. Ver también Bronislaw Geremek, La piedad... op cit, pp 116 y ss; José Antonio Maravall, “Trabajo y exclusión. El trabajador manual en el sistema social de la primera modernidad”, en Estudios de historia del pensamiento español. Madrid, Ediciones Cultura Hispánica, 2001, Vol. 2, capítulo XIII, pp 325-352, p 345.

${ }^{4}$ El recabdo es una condición que establece que alguien declare que lo tiene a su servicio mediante un contrato de algún tipo.

${ }^{5}$ La utilización de la expresión "préndanlo" es confusa, pues en las ordenanzas aparece en general como una pena pecuniaria. En El Tesoro...: "Prender: Vale asir, pero comúnmente se toma por llevar a la cárcel, latine prenidere vel prehendere. De aquí se derivan preso, el encarcelado, prisionero, el cautivo de
} 
tomandolo por fuerça o rrobandolo o prendandolo, enforquenlo por ello; e sy fuere labrador e non quisiere labrar prendanlo e faganlo labrar por fuerça, e sy lo non quisieren tomar a soldada por este preçio sobre dicho, prendanlo e tenganlo preso fasta que dé buenos fiadores que sirua el tienpo para que lo quisieren ${ }^{6}$.

Aquí encontramos dos cuestiones referidas a los labradores y los peones. La distinción entre ambos atiende a la estratificación de una masa de semidesposeídos no uniforme. El primero constituiría el sector que figuraba en el padrón tributario con residencia fija en la aldea y que contaba con instrumentos de producción, pero que, evidentemente, apelaba también a otras fuentes de subsistencia ${ }^{7}$, aunque su estatuto lo obligaba a la labranza y debía, por lo tanto, dedicarse a ella ${ }^{8}$. Es posible que su resistencia a cumplir con dicho deber ("no quiere labrar") fuera porque encontraba otras formas de reproducción más convenientes. En el pasaje citado, la mención del "peon" (el que va a pie), refiere a un sujeto errante y la disposición de que "si no lo diere prendanlo" señala que se requiere tenga conchabo. Los que vivían a jornal eran los más pauperizados, que apelaban a los derechos comunitarios e incurrían en el delito para obtener los recursos para su supervivencia. Entre el sector empobrecido, había quienes disponían de herramientas de trabajo, cuya contratación estaba regulada en las ordenanzas, por medio de las cuales se los compelía a que asistieran a las plazas en determinados horarios, con sus instrumentos de labor, con el objeto de que ofrecieran su mano de obra a quienes desearan contratarla por las condiciones establecidas 9 .

rescate, prisiones, preso y prisión, término de caçadores para significarlos que mata el halcón.” Sebastián de Covarrubias, op cit, p 880.

Labrador, según El Tesoro...: "Se dize no sólo el que actualmente labra la tierra, pero el que vive en la aldea; porque las aldeas se hizieron para que en ellas se recogiesen con sus bueyes, mulas y hato los que labravan las tierras vezinas, y concurriendo muchos en un puesto hizieron los lugares y aldeas; y comúnmente los que viven en ellas se ocupan poco o mucho en cultivar la tierra y labrar los campos." Ibídem, $\mathrm{p} 746$.

Peón, entretanto, es definido como: "El que camina a pie, el que en las obras mercenarias trabaja por su jornal; y assí llamamos peonadazo que un hombre puede labrar al día en las viñas o en otra cosa. Peón, el soldado de a pie, dicho infante, y de allí se dixeron los peones del axedrez." Ibídem, p 861.

${ }^{6}$ Cortes de Jerez de 1268, petición 36. Real Academia de la Historia, op cit, Tomo I, p 78.

${ }^{7}$ En las Ordenanzas de Liébana, vemos que los labradores son propietarios y tienen la obligación de labrar anualmente una cantidad mínima de tierras. Así, en el capítulo 31 de las Ordenanzas del concejo de Baró del año 1620: “...ordenamos que ningún vecino deje de sembrar una fanega de pan, y de no lo hacer deje el concejo". Juan Baró Pazos y Rogelio Pérez Bustamante, El gobierno y la administración de los pueblos de Cantabria. Tomo I Liébana. Santander, Institución Cultural de Cantabria, 1988, p 116.

${ }^{8}$ Respecto a los labradores, N. Salomon nos informa que esta designación se usa en contraposición al noble, aludiendo de este modo también al aldeano, sin considerar su oficio ni nivel de vida, así, la división entre los nobles y quienes no lo eran se reflejaba en el plano lingüístico. Noël Salomon. La vida rural castellana en tiempos de Felipe II. Barcelona, Ariel, 1982, pp 261-264.

${ }^{9}$ Así, en el título 3 del "Ordenamiento de menestrales y posturas entregado a las ciudades, villas y lugares del arzobispado de Toledo y obispado de Cuenca en las cortes de Valladolid de la era MCCCXXXIX (año 1351)" leemos: "... que todos los carpenteros et albaines et tapiadores et peones et obreros et obreras et 
Ante la falta de ocupación conocida de un hombre, se lo podría prender y obligarlo a trabajar a soldada $\mathrm{y}$, en caso de que nadie los quisiera tomar, debía permanecer preso, posiblemente para que no pudiera alegar que no conseguía empleador. Esto se hacía hasta que se hallara fiadores (al menos y eventualmente de la misma condición o superior y vecino), en quienes recaía la supervisión y respecto a quienes se los subordinaba. Su función era obligarlos a trabajar, pues eran responsables por ellos, es decir que se delegaba en el resto de la comunidad la vigilancia de la conducta del baldío para evitar que estuviera desligado y circulando.

A continuación, la petición se refiere a la previsión de sus posibles robos o a que vivieran de la caridad, pues si no tenían trabajo conocido, se suponía que subsistían gracias a estos medios ${ }^{10}$. Las alternativas plantean todas las formas en que un hombre podía comer sin trabajar, igualándolas en el delito, pero también se supone que se sostenía mediante la rapiña, pues el baldío podía argumentar que había pedido y le dieron, pero si robaba no podía alegar nada en su favor y era azotado públicamente. Así, que no anduviera baldío significaba que debía estar cumpliendo trabajos (a soldada, lo que es decir por dinero o bien por techo y comida que se descontaba del jornal) en tierras de otro, que podía ser un señor, pero también un aldeano.

En cierta forma se estaba regulando que trabajo productivo era "trabajar para otros”, ya fuera tanto por la vía del salario, como por la del tributo, por eso, a quien no lo estaba realizando, se lo asociaba de manera directa con la actividad delictiva, identificándolo con el malhechor, porque la persona que no trabajaba rompía con el orden social establecido: el estar ocioso propiciaría la comisión de actos delictivos, entre los cuales el esencial era vivir a expensas del resto de la comunidad, además de exponerse a poder "contagiar" a los demás con su conducta, como veremos más

jornaleros et los otros menesteriales que sse ssuelen alogar, que ssalgan alas plazas de cada vn lugar do sson moradores et han acostunbrado desse alquilar, de cada dia en quebrando el alua, con ssus fferramentas et su vianda, en manera que ssalgan de la villa o del lugar para ffazer las lauores aque ffueren alquilados en ssaliendo el ssol, et que labren todo el dia." Real Academia de la Historia, op cit, Tomo II, p 76.

${ }^{10}$ Así, en relación con el tema vemos también en las Ordenanzas del Concejo de Pedraza de 1346 que se establecen penas para el merodeo nocturno para evitar el robo en viñas y huertas: "Otrosy porque ay algunos hombres e mugeres e moços e menores de hedad que andan faziendo daño en las viñas e en las ortaliças en las syestas o en la fría de la noche e dizen que no ay quantía de que pechar la pena e las mugeres que no an hedad ni son tomados a la pena, e por tirar esto e porque todas estas cosas sean mejor guardadas ordenamos e ponemos que qualquier que en estas cosas cayere e non oviere quantía para pagarlas e otrosy a los moços que les den a cada vno por cada día diez açotes, e por de noche veynte públicamente por la plaza de la villa." Alfonso Franco Silva, "Pedraza de la Sierra. El proceso de formación de unas Ordenanzas de Villa y Tierra en los siglos XIV y XV", en Historia. Instituciones. Documentos. № 18, Sevilla, Universidad de Sevilla, 1991, p 129. 
adelante. Así, con la idea de ociosidad se vincularía al rufián, al malhechor y al vagabundo $^{11}$.

Aunque encontremos su esporádica mención en las Cortes y algunas propuestas al respecto en el siglo XIII, el gran conflicto que significaron los marginales no fue generalizado hasta la centuria siguiente, cuando vemos sucederse numerosas normativas concernientes a los hombres baldíos ${ }^{12}$. Así vemos en las Cortes de Valladolid de 1351, que consideramos la piedra de toque de este proceso, que a la petición 33, el rey responde:

Alo que me pedieron por merçed porque en la mi corte e en las çibdades e villas e lugares de mis regnos andan muchos omes baldios que son sanos e podrian seruir e no quieren, e por no afanar, dexan algunos menesteres que saben, por do podrien beuir, e porque non pueden escusar de comer, ponense a furtar e a rrobar e a fazer otros muchos males andando baldios; que ordenase e mandasse que en la mi corte nin en algunas de las çibdades e villas e lugares de mis rregnos non anden omes baldios e sin ssennores sin husar de ssus ofiçios e menesteres ssi los supieren... ${ }^{13}$.

Los jornaleros eran hombres baldíos en potencia, cada vez que se encontraban sin estar ocupados, por ejemplo en las estaciones muertas, y serían las primeras víctimas de las situaciones de crisis. De manera inversa, los hombres baldíos eran jornaleros en potencia, pero para que tal posibilidad se pusiera en acto debía apelarse a toda la serie de regulaciones y coacciones que permitían esa inscripción en la relación laboral. La causa de esta ambigüedad puede encontrarse en que, de hecho, se trataba de un mismo agente que podría estar ocasionalmente trabajando para otros y temporalmente no. La respuesta real supone, pues no lo afirma con certeza, que puesto que tenían qué comer a pesar de estar baldíos, debían robar, pues no podrían tener otra forma de sobrevivir. Se sospechaba que esto se debía a una elección personal por la que se volcaban deliberadamente a la vida delictiva. En las siguientes páginas veremos la asimilación directa entre baldíos, ladrones y mendigos, así como la homologación de las penas. Se

\footnotetext{
${ }^{11}$ Antonio Collantes de Terán Sánchez, "Actitudes ante la marginación social: malhechores y rufianes en Sevilla”, en Actas del III Coloquio de Historia Medieval Andaluza. La sociedad medieval andaluza: grupos no privilegiados. Jaén, 1984, pp 293-302, p 298.

${ }_{12} \mathrm{La}$ aparición de la juridicidad tiene que ver también con un avance técnico del derecho.

${ }^{13}$ Cortes de Valladolid de 1351, Petición 33. Real Academia de la Historia, op cit, Tomo II, pp 19 y 20.
} 
definía a los primeros como aquellos que no trabajaban ni tenían señor ${ }^{14}$, mientras se suponía que debían tener algún tipo de especialización anterior a su marginalización ("menesteres que saben"), pues podían ser labradores o artesanos, aunque luego esta noción es relativizada ("ssus ofiçios e menesteres ssi los supieren").

Observamos asimismo la aclaración acerca de su salud, pues "son sanos y no trabajan”. Esta cuestión sería fundamental en lo sucesivo, dado que los únicos hombres que tendrían derecho a la mendicidad serían los enfermos e impedidos, de hacerlo por esa causa, aspecto que dio lugar al estereotipo del limosnero que simulaba dicho estado, adoptado y amplificado por la literatura. El Ordenamiento de menestrales de 1351 recoge, como lógica, la obligación de vivir por el trabajo de sus manos y el sudor de su frente (proveniente de la condena divina) según las capacidades físicas, siendo exceptuados niños, viejos, enfermos o lesionados ${ }^{15}$, a quienes la sociedad debería ayudar, así como la represión de aquellos que no trabajaban siendo válidos y estando obligados a hacerlo por provenir del estamento de los laboratores.

El carácter urbano de la mendicidad también es detallado; sus protagonistas eran aquellos que deambulaban en torno a la corte (que era trashumante), villas y ciudades: “... que non anden omes baldios en la mi corte nin en los otros lugares del mi sennorio que non ayan sennores, e que husen todos de sus maestres e de sus ofiçios los que los sopieren, e los que non ouieren maestres nin supieren ofiçios, que labren a jornales en quales quier llabores; e los quelo asi non fezieren, quelos den la pena que se contiene enel hordenamiento que yo fiz en rrazon delos lauores"16.

Mediante la lectura de esta petición, vemos que su presencia en esos lugares se hizo mucho más frecuente y visible, así como la movilidad y no instalación permanente de este sector. Se aspiraba a fijar a los hombres al menos como jornaleros (aunque también se consideraba que fueran aprendices u oficiales), de acuerdo con lo estipulado en la reglamentación gremial, vinculando de este modo el problema del vagabundeo con el de la domesticación de los trabajadores, que incluía la obligación del trabajo físico así

\footnotetext{
${ }^{14}$ El baldío podía ser definido como "escusado, inútil, por demais supérfluo e desnecessário". Joaquim de Santa Rosa de Viterbo, Elucidario das palavras, termos e frases que em Portugal antegamente se usaram e que hoje regularmente se ignoram. Lisboa, Livraria Civilização, 1966, p 13.

15 “... que ningunos omes nin mugeres, que ssean et pertenescan para labrar, non anden baldios por el mio ssennorio, nin pediendo nin mendigando; mas que todos lazren et viuan por lauor de ssus manos, ssaluo aquellos et aquellas que ouieren tales enfermedades e lissiones o tan grand vejez quelo non puedan ffazer, et moças et moços menores de hedat de doze annos". Ordenamiento de menestrales y posturas entregado a las ciudades, villas y lugares del arzobispado de Toledo y obispado de Cuenca en las Cortes de Valladolid de la era MCCCXXXIX (año 1351), Ítem I, Cortes de Valladolid de 1351, en Real Academia de la Historia, op cit, Tomo II, p 76.

${ }^{16}$ Petición 33 de las Cortes de Valladolid de 1351. Ibídem, Tomo II, p 20.
} 
como la regulación de su paga. Vemos otro ejemplo, algo posterior en que el rey concede la petición:

“...tenemos por bien e mandamos quelos nuestros alcalles e justiçias e alguaziles e merinos de todas las çibdades e villas e lugares de nuestros rregnos que non consientan en los lugares andar ommes baldios, mas quelos apremien que labren por jornales por los preçios sobredichos, e a los quelo non quisieren fazer que les den pena de açotes e otras penas corporales, aquellas que entendieren que cunplen, fasta que lo fagan asi”"17.

Domesticación del trabajo y regulación del salario se conjugan entre sí, ya que aquel que hallare a un hombre baldío podía tomarlo por los jornales estipulados en las ordenanzas según la demanda local. Esta cuestión es central en este intento de obligar a los hombres a trabajar por una paga, a lo cual se negaban. No menos importante es la mención de estos agentes como aquellos que no tenían señor, quienes, al no trabajar, salían del encuadramiento laboral pero fundamentalmente del jurídico y del orden social.

Cada una de las villas y ciudades echaría a los pobres forasteros de su jurisdicción ("quelas justiçias que los puedan escarmentar e echar fuera delos lugares, saluo alos muy viejos e flacos e dolientes que non son para fanar" ${ }^{, 18}$ ), tal como se había hecho anteriormente, pero no se daba una solución general, pues sólo se podría echar fuera de sus lugares a los pobres ajenos, no a los propios. Esta medida no resolvía el problema a nivel del reino, sino que lo esparcía. La monarquía no lograba desarrollar una política general para evitar ese desplazamiento físico, que aprovechaba la fragmentación feudal de la soberanía, con lo que el problema quedaba librado a nivel de las autoridades de las ciudades y de los señoríos. En la normativa que nos ocupa se produce una novedad porque el rey empieza a tomar el conflicto a su cargo desde el momento en que comienzan a darse disposiciones vinculantes sobre todo el reino.

La primera necesidad sería clasificar quiénes debían trabajar, quiénes no podían hacerlo, y con qué condiciones, e impedir que las personas salieran de este esquema. Sin embargo, evidentemente había quienes lo hacían, generando un conflicto por su falta de sumisión y sujeción al orden. Como anticipamos, en este tipo de regulaciones se retomaba la combinación de la represión y la asistencia, pues cuando se estipulaba la

\footnotetext{
${ }^{17}$ Petición 57 de las Cortes de Toro de 1369. Ibídem, Tomo II, p 180.

${ }^{18}$ Cortes de Valladolid de 1351, petición 33, Real Academia de la Historia, op cit, Tomo II, p 20.
} 
obligación de trabajar, también se organizaba la ayuda a los pobres locales y se intentaba reintegrar a las mujeres que han salido de la prostitución y dotar doncellas ${ }^{19}$.

Entre la primera disposición que vimos aquí (1268) y las numerosas cláusulas emitidas en 1351 tenemos un lapso de más de sesenta años, antes de que el problema de la persecución de los pobres se volviera constante en las sesiones de Cortes. Podemos aducir que esta fugaz aparición se debió a una necesidad puntual de mano de obra por parte de los sectores representados en estas asambleas, pero en adelante refleja la presencia de múltiples conflictos: de pobreza, de delincuencia, tributario -para la hacienda regia- y de orden social, jurídico y teológico, pues el trabajo estaba sancionado como castigo bíblico.

\section{Las penas}

A partir de los documentos políticos podemos definir a los hombres que la sociedad no podía integrar como consecuencia de su situación ambigua: ni excluidos absolutos ni insertos en ella. Paralelamente, comenzaron a proponerse diversos castigos que funcionarían de distintas maneras: escarmentando al culpable, sometiéndolo al trabajo y adiestrando al resto de la población.

Aquel que no cumpliera con la obligación de estar ocupado sería abandonado al margen, lo que convertía al parado en delincuente a quien se podía ajusticiar, castigo que, dada la condición social, debía consistir en la aplicación de una pena corporal, equiparando al baldío con el conjunto de los dependientes, porque constituía la manifestación de su status subordinado en oposición a los privilegiados ${ }^{20}$. El escarmiento era público, teniendo como objetivo no sólo disciplinar al penado en su cuerpo, sino fundamentalmente advertir sobre las consecuencias de sus acciones al resto de la población que asistía a ver este espectáculo con euforia y pavor. A diferencia de otras puniciones que se aplicarían más tarde, que no consistían en publicitar sino en

\footnotetext{
${ }^{19}$ Respecto a lo primero, los niños expósitos: "votóse sobre una limosna que se pide para criar los niños de la puerta de la iglesia, atentos que son muchos, y se acordó por mayor parte, que se den de limosna quinientos reales para ayuda á criar los dichos niños." Sobre el segundo aspecto: “...votóse sobre una limosna que se pide para ayuda á sustentar y poner en estado á las mugeres que han salido de pecado, y se acordó por mayor parte, que se den de limosna quinientos reales para ayuda al sustento y poner en estado las dichas mugeres." Cortes de 1593, petición del 15 de marzo de 1594. Congreso de los Diputados, op cit, Tomo XIII, p 226.

${ }^{20}$ En palabras de C. López Alonso, "El trabajador, convertido en delincuente y juzgado como culpable, se convierte en sancionador del sistema mismo que lo expulsa y, en cierto modo, en testimonio vivo de su bondad". Carmen López Alonso, op cit, p 665.
} 
ocultar y apartar al delincuente en un espacio cerrado, en este momento lo marcaban (con azotes o desorejamiento, por ejemplo), de modo que exhibiría a partir de entonces una señal por su delito.

Si durante el medioevo el proceso era considerado entre personas privadas, en la Edad Moderna se lo evaluaba como un asunto público, un conflicto entre la sociedad representada por el rey, en el ejercicio de la justicia, y el individuo. Por ello las condenas ejemplares serían severas ${ }^{21}$. En las mencionadas Cortes de Valladolid de 1351 se propone la pena de azotes para quien no cumpliera la normativa: veinte en la primera oportunidad, y luego un incremento de la cantidad por cada reincidencia. Así, la reglamentación del castigo preveía el caso de que se saliera nuevamente del orden social impuesto y estipulaba entonces la magnitud del escarmiento ${ }^{22}$. Sin embargo, veremos más adelante la escasa efectividad de este tipo de penas, según lo que se observa en la documentación.

El gran problema radicaba en que, si la forma de vida de los vagabundos era perturbadora por su deambular y su falta de inserción social según las pautas tradicionales, las penas que se impusieran deberían adaptarse a dicha condición para garantizar efectividad. Veremos cómo a lo largo del período que estudiamos, las normas fueron modificándose, pues era posible amedrentar a los vagabundos y, probablemente, estimular su deambular, pero ellos aprovecharían su movilidad y su modo de vida al margen de las redes de socialización tradicionales para eludirlas, de manera que la normativa tendría en cuenta también este aspecto. Los procuradores considerarían más variables a medida que perfeccionaban los medios para lograr su objetivo de erradicar a los vagabundos, pues no sólo se evaluaba como necesario penarlos, sino también contar con la colaboración de las personas integradas en el cuerpo social para aislarlos. Así, la normativa tendría en cuenta tanto el castigo para quienes no hicieran cumplir este tipo de normas, como la recompensa para aquellos que sí lo lograran ${ }^{23}$. Así, en el proceso de

\footnotetext{
${ }^{21}$ Jean Delumeau, op cit, p 546. Sobre la espectacularidad de las penas aplicadas a los mendigos ver Carmen López Alonso, op cit, pp 569-572.

22 “... quel den por la primera vegada veynte açotes, et por la segunda vegada quarenta açotes, et por la terçera vegada ssessenta açotes publicamentre (...) Et de la terçera vegada en adelante (...) quel den por cada vegada ssessenta açotes como dicho es". Cortes de Valladolid de 1351, petición 43. Ibídem, Tomo II, p 88. Debía ser el límite admitido para castigar duramente sin matar.

23 “.... ordenamos quelos que asy andudieren vagabundos e folgazanes que non quisieren afanar de ssus manos nin beuir con sennor, que qual quier de nuestros rregnos los pueda tomar por su abtoridat e seruirse dellos vn mes ssyn ssoldada, saluo queles den comer e beuer. E ssy alguno non los quisiere tomar asy, quelas justiçias delos lugares den alos dichos uagabundos e folgazanes ssesenta açotes e los echen dela villa. E ssylas justiçias asy non lo fezieren, que pechen por cada vno delos dichos folgazanes sseys çientos mr. Para la nuestra camara, e los duzientos ssean para el acusador." Cortes de Briviesca de 1387, petición
} 
tipificación del delito, se comenzó a considerar cada vez más variables, como las acciones de otros sectores del cuerpo social, asumiendo que los vagabundos se relacionaban con diversos actores integrados en la comunidad. Por esto, se planteó la necesidad de desterrarlos y separarlos de la sociedad en la cual se enmarcaban, aumentando la pena en caso de rebeldía ${ }^{24}$.

La circulación de los marginales explicaría la ineficacia para su control, pero debemos tener en cuenta el paulatino aumento de la población de las ciudades y villas, sobre todo las de mayor tamaño, que exigirían un trabajo cada vez más intenso para ello, con oficiales que en muchos casos recibían una paga mísera o se desempeñaban gratuitamente por sus obligaciones de vecino. Se consideraba que quien hubiera delinquido, pudiendo trasladarse a otra comunidad donde no fuera conocido, volvería a hacerlo, pues los castigos corporales no tenían el suficiente poder disuasorio y no los temían o, acaso, no tenían alternativas.

En este momento se pensaba en dos formas de condena que se aplicaban a la élite, como la condena pecuniaria y el destierro (salvo que se tratara de traición o lesa majestad). Por otro lado las capas populares eran castigadas con azotes y escarmientos corporales, que podían ser acompañados por las galeras, según veremos más adelante. La pena capital tenía un carácter ejemplar que era sustancial en ella. Las sentencias debían ejecutarse públicamente, aunque algunas, como el trabajo forzado, no siempre lo permitían. Por eso iban acompañadas previamente por la flagelación que sí se podía visibilizar y servía, no para corregir al delincuente, sino como ejemplo para el resto de la población.

La cohesión de la vecindad era muy fuerte y había otras instituciones como las cofradías, los gremios, las parroquias, etc. que la reforzaban con la vigilancia de sus miembros. En este marco, el modo de vida diferente de los vagabundos ponía en cuestión la forma de existencia de los otros miembros de la sociedad que mantenían una existencia sedentaria y acorde con las normas. De allí el miedo al contagio, y su "prevención”, que se difundía a través de variados discursos. Así, las Cortes de 1544 se extendieron sobre la cuestión, mostrando cómo los individuos castigados con pena

5. Ibídem, Tomo II, pp 370-371. Aquí se trata de dos casos, por un lado los que no quieren trabajar solos, y por otro los que no quiren trabajar tampoco bajo un señor.

24 “... que los costringan e apremien a quelo fagan e cunplan, o los echen luego fuera dela tal çibdad o villa o logar do lo tal acaesçiere e de su juridiçion, e si fueren rrebeldes e non lo quisieren asy conplir o despues que salieren se tornaren ala tal çibdad o villa o logar do acaesçiere, que las tales justiçias les den pena criminal". Cortes de Madrid de 1435, petición 38. Ibídem, Tomo III, p 236. No es posible aplicarlo a un vecino, de manera que sólo está hablando de gentes que pueden trabajar a jornal o a censo. 
infamante, deshonrados y despreciados, ya no tenían nada que perder ${ }^{25}$. Lo peor de la pena era que los colocaba al margen de la comunidad, conduciéndolos a reincidir en el delito, pues ya despreciados por la sociedad podrían, sin embargo, hacerse temer o ser admirados por otros de su misma condición.

También se señala que a los delincuentes no los disuadía el posible castigo, pues serían incorregibles, de acuerdo con la idea que se tenía de ellos y de su imposible reforma en esa época. Esta irreversibilidad que ya se ha asumido, se evidencia en los calificativos con los que se los menciona ("personas vaxas y viles y vagamundos y de poca onrra). Los dos primeros adjetivos se relacionan con el estamento y los últimos con su falta de domicilio fijo, en tanto hay una asociación entre personas honradas y su pública fama. Más adelante, se trataría de tomar medidas preventivas que alertaran a la sociedad ante la presencia de un delincuente que había reincidido.

El temor a todo aquello que pudiera perturbar a la sociedad, a lo desconocido y a lo extraordinario constituía una pauta central para su cosmovisión -que se consideraba que los vagabundos no compartirían-, además de una herramienta del discurso represivo, dado que muchos límites se imponían a través de este sentimiento, tal como veremos en la reiteración acerca de la peligrosidad de la disidencia a lo largo de las Cortes. El carácter temerario que se imputaba a los marginales se evidencia en la convocatoria de $1544^{26}$, donde podemos corroborar que había además de azotes, marcas que indicaban que una persona había recibido castigo por un delito previo, mientras se asimilan ladrones y vagabundos, presuponiendo que ambos son una misma clase de personas, deshonradas, bajas, viles y, sobre todo, no temerosas ya del castigo que los había marcado. Por otro lado, se conjeturaba la posibilidad de evasión de la pena a partir de la movilidad, que les permitiría reincidir en el delito, a lo cual se aparejaría la imposibilidad de comprobar lo que se hubiera hecho en otras localidades (además, se tenía conciencia de la escasa penetración territorial de la justicia real), cuestiones que se vinculaban estrechamente con la desconfianza respecto al extraño y que fueron una

\footnotetext{
25 "Una de las mayores causas que ay para aver tantos ladrones (...) es la pena de açotes que se les da y esta estituyda por el primer hurto que como los ladrones comunmente son personas vaxas y viles y vagamundos y de poca onrra y no son conosçidos no temen esta pena y despues que una vez los azotan no tienen en nada ser azotados muchas vezes y por temor de la pena no dexan aquel mal oficio y azotados en una ciudades e villas e lugares se pasan a otros a hurtar confyados". Cortes de Valladolid de $1544, \mathrm{~N}^{\circ} 8$, petición 17. Ibídem, Tomo V, p 312.

26 “... que aunque los tomen con los hurtos no les an de dar mas pena de los azotes porque no se les puede provar que an sydo otra o otras vezes azotados en otras partes e siempre son castigados como por primer hurto aunque lo estan otras vezes y cuando ya se puede prouar otro alguno le cortan las orejas ques otra dilaçion grande y licençia de hurtar y por el tercero los ahorcan y entonces an hecho mill hurtos...”. En Cortes de Valladolid de 1544, No8, petición 17. Real Academia de la Historia, op cit, Tomo V, p 312.
} 
justificación para penar con una marca inexorable del delito. La pena capital tampoco era considerada conveniente, por lo tanto se ensayó otra vía para solucionar el problema: la marca en el cuerpo se haría ante el primer hurto (además de los azotes) y sería, en adelante, prueba de su falta, sin necesidad de otra certificación ${ }^{27}$.

Pero el castigo se incrementó al adicionar el de galeras $^{28}$, que constituía una muerte diferida pero casi segura, si consideramos el nivel de mortalidad en ellas: si el barco era incendiado o se hundía, morían todos los remeros, sin contar las enfermedades, el hambre y el frío. Si se los enviaba al trabajo forzado, morían por las terribles condiciones en que era llevado a cabo en minas que eran poco redituables y explotadas desde la antigüedad. Durante el reinado de Carlos V, ésta se convirtió en la pena por antonomasia, pues en 1530 se dispuso el servicio forzoso de remo, mientras las mutilaciones y destierros podían cambiarse por el destino de galeras por más de dos años. Antes de Lepanto, Felipe II extendió la duración de esta pena, mientras cada vez más delitos eran castigados con este mecanismo. Como los vagabundos eran asimilados con los ladrones, desde 1552 también comenzaron a ser penados con cuatro años de galeras, pues constituía un recurso legal que dotaba de mano de obra a la corona ${ }^{29}$. En el plano objetivo ambos grupos eran diferentes, pues unos cometían actos de violencia con los cuales atentaban directamente contra la propiedad privada, mientras los otros no se sometían al trabajo. Pero en el plano subjetivo, al equipararlos, los poderes hacían de ellos una utilización política y de regulación social, pues el no trabajar para otro se homologaba en su discurso -que tenía incidencia en la realidad- con el delito.

La propuesta de aislamiento ("quitallos dentre la gente") ${ }^{30}$ significa que se pensaba que eran un peligro cierto para el resto de la sociedad por su violencia (criminalizándolos) y permitiría ahorrar la muerte de otros forzados "útiles" e

\footnotetext{
27 “....y es cosa muy neçesaria que se prouea çerca desto como çesen tantos hurtos los quales se podran escusar y tambien las muertes de los ladrones con que vuestra magestad mande por ley que de aqui adelante al que fuere convençido por ladron por el primer hurto de mas de los azotes se le de una tijerada en una de las orejas la qual le quede endida o se le faga otra senal en que se conosca ques ladron y que a sydo castigado una vez por ello sin que sea menester otra provança”. Cortes de Valladolid de $1544, \mathrm{~N}^{\circ} 8$, petición 17. Ibídem, Tomo V, p 312.

28 “y que fallandoles ansy senalados por el segundo hurto que tras aquel hizieren les hechen a las galeras de que se reportaran dos provechos el primero es que no fagan mas hurtos e quitallos de entre la gente y el segundo que serviran en ellas a vuestra magestad y no sera menester andar a tomar otros forçados y con esto tambien se escusara la muerte dellos...". Cortes de Valladolid de 1544, №8, petición 17. Ibídem, Tomo V, p 312.

${ }^{29}$ José Luis de las Heras Santos, "Los galeotes de los Austrias: la penalidad al servicio de la armada", en Historia Social. No6, Valencia, Universidad Nacional de Educación a Distancia, 1990, pp 127-140, passim.

${ }^{30}$ Cortes de Valladolid de 1544, No8, petición 17. Real Academia de la Historia, op cit, Tomo V, p 312, anteriormente citada en la nota 29 de este capítulo.
} 
integrados, que debían ser producto de levas. La conveniencia de esta medida se explica porque así se impedirían los delitos y se conseguiría el servicio económico y militar para el rey, que se entendía que también lo era para el bien común (mientras la muerte del condenado simplemente se difería).

Algunos años más tarde, se demandaría la persecución de nuevas generaciones de vagabundos con argumentos y políticas similares a la que acabamos de observar ${ }^{31}$, repetición que se utilizó para incrementar los azotes, mientras la marca física sería más visible y se vincularía a una locación. Existía una relación entre dicho flagelo infamante y la movilidad de los hombres, aspecto que estaba en relación con la expulsión de la comunidad, pena también ensayada ${ }^{32}$. La inscripción en el cuerpo serviría para que el sujeto tuviese vedada la entrada en la villa donde había delinquido y donde generalmente tendría cómplices.

Vemos en la petición 33 de las Cortes de 1351 que, teniendo en cuenta las características de los hombres baldíos, se decidió desterrarlos de los lugares mencionados en ella, probablemente para que la mano de obra que había ido a ocupar trabajos posibles en villas, ciudades y lugares pero que tenía empleo ocasional volviese a los sitios de donde había partido, donde la comunidad vecinal vigilaría la sumisión del sujeto al trabajo.

El destierro era una medida cautelar que funcionaba como una sanción ante los comportamientos tenidos por peligrosos, sin juicio ni cargos ${ }^{33}$. Debemos considerar que, en el marco de una cultura que contaba con la fuerza de la comunidad y los vínculos personales como uno de los principales aspectos de la existencia social de una persona, el destierro conducía a la marginación y degradación sociales, si tenemos en cuenta que pocos hombres que habían sufrido dicha condena tenían una vida honesta en un nuevo

\footnotetext{
31 “... dezimos que en estos reynos es notorio hay gran numero de ladrones, los quales dexan de tener escarmiento por que tienen en poco el primer castigo que ordinariamente es azotes: y es muy necessario que se acresciente la pena porque de alguna manera se ataje su mal uso. Suplicamos a V. M. mande establecer que de aqui adelante por el primer hurto se le den cien azotes y se le ponga una señal en un brazo escribiendole en él el nombre de la ciudad o villa donde fue azotado para que si otra vez fuere preso se vea que es ladron y se haga en la ciudad o villa diligencia que conviene y sea castigado como tal, conforme a la calidad de sus delitos." Cortes de Toledo de 1559, petición XC. Ibídem, Tomo V, p 854. Se pretendía que tal tratamiento sería preventivo para la sociedad, cuando objetivamente se perseguía obtener un contingente disponible para trabajos forzados por parte de la Corona. La española no fue la única que lo hizo. La inglesa, por ejemplo, dispuso de la misma manera de deudores, ladrones o disidentes para la población de sus colonias.

${ }^{32}$ Sobre la pena de destierro ver Carmen López Alonso, op cit, pp 570-571.

${ }^{33}$ Villalba Pérez, op cit, p 175.
} 
$\operatorname{lugar}^{34}$. Desde el punto de vista de la comunidad, el destierro consistía en una pena de exclusión absoluta que significaba la muerte civil de una persona, si tenemos en cuenta la concepción corporativa según la cual el hombre era concebido como parte de la comunidad a la cual pertenecía y se debía, y no como un individuo. Por eso eran importantes las consecuencias que producían a sus familias, ya que el castigo infamante de un miembro deshonraba al grupo ${ }^{35}$.

Sin embargo, ante el fracaso de las penas se pretendió imponer un sistema inverso: no extraer a los sujetos considerados como disolventes de la comunidad del seno de la misma sino atarlos a ella porque los parientes y los vecinos eran los primeros interesados en la supervisión del individuo. El fracaso de las medidas ensayadas para su control se evidencia una vez más en las peticiones correspondientes al siglo XVI, donde el eje del reclamo ya no se encontraba en la necesidad de subordinarlos, sino que planteaba la limitación de su circulación. Así, en las Cortes de Valladolid de 1518, localizamos el siguiente pedido: “...suplicamos a vuestra Alteza que mande que non anden pobres por el Reyno, sy non que cada uno pida en su naturaleza, y los que estovieren dañados de las bubas ${ }^{36}$ esten en casa cierta y alli pidan para ellos"37. La necesidad de cambiar el contenido de la petición sugiere el fracaso de las medidas anteriores en cuanto a la contención de la marginalidad y sus consecuencias sociales y está enmarcada en el debate que entretuvo a los escolásticos durante el siglo XVI acerca de la licitud de la limosna y el cuestionamiento de la libertad para su ejercicio. En la petición citada vemos también la asimilación de la pobreza y la enfermedad (el pobre es generalmente quien no se puede sustentar a sí mismo a causa de la enfermedad o la incapacidad física o psíquica para hacerlo) dando cuenta de que la idea medieval acerca del pobre asimilado al sufriente y a Cristo persistía y continuaba siendo una realidad que justificaba la limosna ${ }^{38}$. Ambas condiciones reciben tratamiento en el mismo apartado, aunque dando soluciones diferentes: para los enfermos (sifilíticos ${ }^{39}$ en este caso), la reclusión y la limosna mediada por otros, y para los sanos, una libertad restringida.

\footnotetext{
${ }^{34}$ Bronislaw Geremek, Les marginaux... op cit, pp 24 y 25.

${ }^{35}$ Por otro lado, también es necesario observar el destino que significaba ese destierro, por ejemplo, los presidios del norte de África u otras colocaciones militares que implicaban ir a una guerra.

${ }^{36}$ Tumores inguinales que se identificaban como enfermedades venéreas.

${ }^{37}$ Cortes de Valladolid de 1518, petición 42. Real Academia de la Historia, op cit, Tomo IV p 272.

${ }^{38}$ Aaron Gurievich. Las categorías de la cultura medieval. Madrid, Taurus, 1990, p 270.

${ }^{39}$ La sífilis se asociaba al vicio y por lo tanto desprestigiaba a quien la contraía.
} 
En la época, los lazos locales y personales eran esenciales para la inserción social de la persona: quien los perdía quedaba al menos momentáneamente desvalido. Por esto se identificaba peregrino y pobre ${ }^{40}$, noción que encuentra su explicación en la condición errante de estos hombres. Debemos tener en cuenta que diversos sectores estigmatizados compartían esta característica, como causa o consecuencia de su segregación.

Ante la imposibilidad de erradicarlos a partir de la expulsión de las comunidades, se buscó la vía de su integración, mediante su retención en ellas, ya no como trabajadores, sino como pobres de la comunidad, tal como lo habían sido durante la Edad Media. Como consecuencia del cambio social que había tenido lugar, la actividad de estos hombres debía ser regulada ${ }^{41}$. En las Cortes de Madrid de 1534, observamos su reglamentación. Los mendigos que no estuvieran registrados, serían desterrados. Sin embargo, la primera opción guardaba un carácter muy particular, pues serían insertados y legitimados como mendigos, otorgándose un status formal a su situación. Así, se procura: “...que en cada ciudad y villa aya un diputado por el ayuntamiento, sin que haya licencia y cedula no puedan pedir los pobres, y que se saliere un executor que a los que no deuieren pedir los haga salir fuera, el qual tenga cargo de visitar las mugeres públicas si estan limpias, y que la ciudad le señale salario"42. Aquí se evidencia la noción del marginado, pues los mendigos son vinculados con las prostitutas y se legisla acerca de unos y otras con un mismo argumento, sin diferenciarlos, asociación que demuestra que se los consideraba parte de un mismo fenómeno, posiblemente porque las mujeres, aun mendigando, incurrirían en la prostitución, según su edad. Éste es definido como un problema municipal o concejil, porque el ayuntamiento debe diputar a alguien para su control, además de nombrar un ejecutor para expulsar a los mendigos válidos ${ }^{43}$. Seguidamente, se exponen las penas que se aplicarían al respecto y que demuestra la madurez del despliegue del problema.

\footnotetext{
${ }^{40}$ Carmen López Alonso, op cit, pp 417 y 418. Los peregrinos también eran errantes pero, al igual que los jóvenes de la nobleza y los mercaderes, si bien constituían un problema social, no eran abordados con la misma mirada por los poderes políticos.

41 “...que mande que no anden pobres por el rreyno, vezinos e naturales de otras partes, syno que cada vno pida en su naturaleza, porque de lo contrario viene mucho daño y se da causa que aya muchos vagamundos e holgazanes." Cortes de Valladolid de 1523, petición 66, Real Academia de la Historia, op cit, Tomo IV, p 384.

${ }^{42}$ Cortes de Madrid de 1534, petición 67. Ibídem, Tomo IV, p 617.

${ }^{43}$ Recordemos que en las ordenanzas, los pobres extranjeros o extraños que no están trabajando bajo un amo en la aldea deben permanecer solamente un día en ella.
} 
...por euitar los dichos inconuenientes mandamos que de aquí adelante en la nuestra corte todos los pobres vagamundos que pudieren trabajar y anduuieren mendigando, sean echados della y castigados conforme a las leyes destos reynos; y que ningun estranjero destos nuestros reynos que anduuiere pidiendo limosna no pueda estar so color de romero en la nuestra corte mas de un dia natural, y que los que verdaderamente paresciere que son pobres y enfermos, sean curados en los Obispados donde son naturales, poniendolos en hospitales, buscando para los curar y dar de comer; y que los muchachos y niñas que anduuieren pidiendo, sean puestos á officios con amos, y si despues tornaren a andar pidiendo, sean castigados ${ }^{44}$.

Aquí localizamos en una sola disposición el prototipo de las medidas que se adoptarían para solucionar el problema de los mendigos: institucionalización para los enfermos, a partir de la existencia de hospitales municipales, expulsión de los sanos y, si hubiera plazas disponibles, inserción en el servicio o en el trabajo para los menores, que debían ser tutorados al menos. Esta clase de normativas se repetiría en varias regiones de Europa con el objetivo de domesticar la mano de obra que requería el incipiente capitalismo, sistema que demandaba que las personas libres fueran disciplinadas por y para su integración al orden social en calidad de asalariados. Sin embargo fue necesario un desarrollo más avanzado del modo de producción para someter a los hombres mediante los mecanismos propios del mercado.

\section{Movilidades y representaciones}

La movilidad es un problema objetivo, en un contexto en el que cada vez circulaban más hombres sin amo, pero también lo es subjetivamente. El discurso político plantea como verdadero aquello que puede ser testificado a través de la imagen, de manera que la cultura de la observación constituye parte de esta problemática por diversas cuestiones: el delincuente debía exhibir la señal de su condena para ser segregado, el enfermo su dolencia para merecer asistencia y el noble su status, a través del lujo. Así, cada categoría de personas debía mostrar sus atributos para que, de este modo, quedara esclarecido el estado de cada uno y recibir el tratamiento social que se le asignaba. Este mecanismo influía en la dinámica de la marginalidad y era reconocido por el lenguaje político, tal como veremos a través de las peticiones.

\footnotetext{
${ }^{44}$ Cortes de Madrid de 1534, petición 67, Ibídem, Tomo IV, p 617.
} 
Las normativas estaban dirigidas a regular la situación de aquéllos que no mantenían ningún vínculo de dependencia, situación que además se correspondía con la laboral. Cuando se disponía acerca de los hombres baldíos y su obligación de ocuparse, también se hacía referencia a quienes quedarían exentos de esta imposición. El pueblo llano -los laboratores, que constituían la enorme mayoría de la sociedad- debía trabajar. Sin embargo, algunos miembros de dicho estado estaban exceptuados de estas disposiciones. Las Cortes nos informan acerca de cómo serían considerados esos sujetos y cuáles eran sus atributos. En las de Madrid de 1435, hallamos la mención de los enfermos y los viejos ${ }^{45}$, cuya imagen era relevante porque no sólo representaba sino que constituía su debilidad, en el marco de una cultura que apelaba a la emoción y sensibilidad a partir de la testificación visual, que permitiría conocer la realidad ${ }^{46}$. La simulación de enfermedades y la ostentación de las dolencias sería en consecuencia un tópico de la literatura sobre mendigos.

En la sociedad antiguorregimental, la condición de vecindad legitimaba a los que residían en una comunidad, y dependían de su pública fama: quienes no fueran reconocidos positivamente por sus cohabitantes serían infames, de mala reputación, por lo tanto sospechosos ${ }^{47}$. En este contexto, la autorrepresentación que una persona hiciera de sí frente a la comunidad era parte de su existencia social en todos los niveles. Así, veremos más adelante cómo las simulaciones de los personajes que representan diversos status constituyen un importante argumento en el marco de la picaresca. El problema del desorden que podía generar la falsa representación respecto al estrato social objetivo al que se pertenecía dio lugar a variadas y numerosas leyes suntuarias, pues quien formaba parte de determinado estamento debía ostentarlo (representación que constituía dicha

\footnotetext{
45 “... saluo aquellos que fueren tan viejos e de tal dispusiçion o tocados de algunas dolençias o enfermedades que conosçida mente paresca por su aspecto que non son omes nin mugeres que por sus cuerpos puedan trabajar en ningunos nin algunos ofiçios de que se puedan proueer nin mantener...". Cortes de Madrid de 1435, petición № 38. Ibídem, Tomo III, p 236. Las cursivas son nuestras.

${ }^{46}$ José Luis Sánchez Lora, "Barroco y simulación: Cultura de ojos y apariencias, desengaño de ojos y apariencias, en AAVV. Cultura y culturas en la historia. Salamanca, Ediciones Universidad de Salamanca, 1995, pp 75-86. Se trataba de un mundo dominado por la apariencia, que reemplazaba a la realidad y donde el aspecto externo contaba mucho en orden al trato social que se recibiera. Carmen López Alonso, op cit, pp 347 y 438.

${ }^{47}$ S. de Covarrubias define al infame como: "El que es notado de ruin fama; y particularmente son infames aquellos a los quales el derecho señala por tales, como los expressa en el título propio de his qui notantur infamia y en otros lugares, a los quales me remito. Latine infamis, qui ob vitium aliquod aut turpitudinem male audit, aut cui fama est parum secunda aut nigra." Entretanto, define a la infamia como "La mácula, la nota torpe y ruin, la mala fama y reputación; infamar, afrentar con oprobio en la manera dicha; infamarse uno a sí mismo, hazer por donde sea tenido por infame; infamado, el que tiene mal nombre en el pueblo." Sebastián de Covarrubias, op cit, p 735.
} 
condición), mientras quienes no estuvieran en dicha posición, tenían prohibido hacerlo ${ }^{48}$.

El impedimento se justifica mediante la preocupación por el gasto excesivo que conduce a la miseria del reino, pero lo real es que se busca la identificación clara de la posición social a través de la vestimenta. Durante el período en que tuvo lugar el surgimiento y auge de la novela picaresca, hubo un movimiento ascendente que partía del tercer estado hacia la nobleza, rompiendo con el principio de la sangre como transmisora de status y valores nobiliarios, así como los cimientos en que se fundaba la sociedad, asentada teóricamente en la idea de linaje ${ }^{49}$. Sin embargo, tal como sintetiza A. Marcos Martín, esta movilidad fue un factor de estabilidad que contribuyó a la consolidación de una rígida jerarquía estamental y a la permanencia de la vieja estructura social, aunque con actores nuevos ${ }^{50}$.

Durante el renacimiento, con la difusión del dinero, el rico era quien tenía a su disposición los signos de riqueza y a quien por ello se concedía una fuerte capacidad de crédito -avalado mediante una opinión o fama que le atribuían los demás-. Nuevos actores sociales necesitaban acudir a la ostentación como instrumento para potenciar su posición social $^{51}$.

Durante la temprana modernidad se expandió la práctica del servicio personal en España y se incrementaron los testimonios contra tal fenómeno ${ }^{52}$. La multiplicación de los sirvientes puede explicarse por la cantidad de hombres a disposición de los poderosos para cumplir este rol, pero especialmente por la demanda de este tipo de servicios, que provenía de la baja nobleza y también de un grupo social que formaría la moderna burguesía, para quienes el enriquecimiento debía manifestarse públicamente a fin de ganar la fama y honra que podrían proveerles nuevas riquezas y el poder

\footnotetext{
${ }^{48}$ Damos un ejemplo de una normativa suntuaria para ilustrar el espíritu de este tipo de reglamentaciones: "debe suplicar a su magestad que mande moderar el vestir de la gente noble destos rreynos e quitar del todo la seda en la gente comun y no fuere una vayna despada o una gorra o uno o lo otro porque haziendose desta manera Dios nuestro señor y su magestad seran seruidos y los rreynos estaran mas rricos e aprovechados y escusarse an los exçesos que se vehen y cada dia va en creçimiento. [al márgen] no. Cortes de Valladolid de 1542, petición 6, en Real Academia de la Historia, op cit, Tomo V, p 182. Se argumentaba que la ostentación del lujo es cara para el reino y su monarca, pero se establecían también límites diferentes para los distintos estatutos sociales, para impedir su confusión.

${ }^{49}$ Alberto Marcos Martín, "Movilidad social ascendente y movilidad social descendente en la Castilla Moderna", en Gómez González, Inés y López-Guadalupe Muñoz, Miguel Luis (coord.), La movilidad social en la España del Antiguo Régimen. Granada, Comares, 2007, pp 19-47, p 23.

${ }^{50}$ Ibídem, $\mathrm{p} 35$.

${ }^{51}$ José Antonio Maravall, "Individualismo y libertad. Presencia de aspiraciones democráticas", en Estado moderno... op cit, Tomo I, Parte II, Capítulo 3, pp 401-447, pp 414 y 415.

${ }_{52}$ Ibídem, Tomo I, p 428. Entre estos discursos se enmarca la novela picaresca, tal como veremos en el cuarto capítulo.
} 
aparejado a ellas ${ }^{53}$. F. Braudel ha señalado la conversión de los burgueses en nobles a partir de la acumulación, herencia y ampliación del capital a lo largo de algunas generaciones, creando enormes fortunas. Así, según el autor, hubo una movilidad social ascendente que nutría a este nuevo sector, que invertiría en la adquisición de cargos, en lujo y en educación. El historiador francés sostiene que la sociedad no oponía obstáculos a la promoción social, contribuyendo de esta manera a la formación de una clase de nuevos nobles ${ }^{54}$.

La movilidad de estados, la venta de cargos, la emergencia burguesa y el ingreso de metálico americano contribuyeron a que el fenómeno de la aspiración a la hidalguía se agravara ante los ojos de quienes deseaban mantener una utópica inmovilidad social, tal como vemos en la convocatoria de 1593, donde se da cuenta de la posibilidad del ascenso social, al negarse a realizar determinadas actividades quienes pertenecían al status correspondiente para desempeñarlas, con la esperanza de adquirir otro superior ${ }^{55}$. Los historiadores franceses interpretan el fenómeno de la compra-venta de oficios reales o municipales como la forma legal de acceso de los no nobles a las posiciones que hasta entonces estaban monopolizadas, o casi, por la nobleza, evitando que ésta pudiera protestar, mientras los españoles lo atribuyen exclusivamente a los problemas económicos de los Habsburgo ${ }^{56}$. Las oligarquías caballerescas representadas en las Cortes estaban reparando entonces en dicha dinámica en el marco de una sociedad que evaluaba que los estados debían ser inalterables. Por este motivo consideraban nociva la ostentación por parte de quienes no poseyeran el status que la respaldara, pues de ese modo se estaba mostrando algo que no se correspondía con la realidad pretendida, que desorientaba porque representaba una falsedad, pues confundían verdad y

\footnotetext{
53 José Antonio Maravall, "Manifestaciones mentales de un precapitalismo. Tradición e innovación”, en Ibídem, Tomo II, Parte III, Capítulo 3, pp 101-145, p 114.

${ }^{54} \mathrm{La}$ secuencia anterior describe la "traición de la burguesía" que según F. Braudel se amolda a las prácticas de la nobleza. Fernand Braudel, op cit, pp 420-422. El autor da cuenta del cambio en la forma de vida de los grandes comerciantes y de la inversión que realizaban en lujos que antes eran privativos de la nobleza, que rechaza su utilización por la clase ascendente. Ibidem, pp 327 y 328.

${ }^{55}$ Aquí se fustiga el rechazo de la práctica de oficios manuales por parte de la población, que teme que dicha actividad constituya un obstáculo para su posible elevación social: "Que sea la causa de no hauer quien sea oficial de curiosidad, y que no haya mucha copia de oficiales de todos los oficios, la ociosidad tan hija y madre de nuestra España, quién lo duda, pues ha venido á tan lastimoso tiempo, que se afrente el otro que se tiene ya por hidalgo que le nombren á su padre porque fué oficial, y se contenta á vezes con no comer ni beber por no desdezir del punto de hidalgo, sustentándose con esta vanidad sin querer tener oficio." Cortes de Madrid de 1592-1598, petición del 19 de mayo de 1593. Congreso de los Diputados, op cit, Tomo XII, p 464.

${ }^{56}$ Sobre la movilidad social como motivo para la venta de cargos, ver el estudio sobre este fenómeno en diversas partes del continente en Fernand Braudel, op cit, pp 410 y ss. Ver asimismo, para el caso español: Antonio Maravall, La literatura picaresca... op cit, Capítulo II "Los ricos y los cambios de naturaleza y formas de la riqueza en el renacimiento", pp 86-137.
} 
representación en la percepción de los demás. Pero veamos otro aspecto presente en la citada petición de mayo de 1593: la cuestión del status era fundamental cuando se consideraba la obligatoriedad de la actividad manual, de la que estaba exenta la nobleza. Las Cortes se hacían eco de este problema, mientras asimilaban estas cuestiones con el conflicto de la ociosidad, pues la posibilidad de movilidad entre estados daba lugar a que muchos hombres que estaban obligados al trabajo por su status heredado, no quisieran aceptar su carga ${ }^{57}$. Esto se relacionaba con el problema de la ociosidad, considerada la causa de la pobreza del reino. Si bien aquí esta situación se vinculaba con el dinamismo de los estados, también era aludida cuando se trataba acerca de los hombres baldíos y vagabundos.

Variados estudios atribuyen la emergencia del problema del cambio de estado, retomado por la picaresca, a la particularidad de España durante el siglo XVI, cuando estaba circulando riqueza de una manera excepcional ${ }^{58}$. En el marco urbano, los criados eran funcionales para la exhibición de status, por eso los hombres libres y a disposición para ocuparse serían tomados en las casas de los poderosos, saldando de esta manera uno de los problemas fundamentales que generaban, porque se enmarcaban en una red social y respondían a un superior que, por su parte, sería su garante social.

El rechazo hacia los servidores que se muestra en otros fragmentos de la lectura de las Cortes es discutido en la petición del 19 de mayo de 1593 que nos ocupa, pues la normativa debía limitar su encuadramiento en el marco de las casas de las oligarquías ${ }^{59}$. Cuando comenzamos a evaluar cómo eran representados los marginales y observado el problema de la ociosidad, los encontramos como mendigos que circulaban por el reino y evadían el trabajo, por lo cual fueron luego estigmatizados como delincuentes y obligados a ocuparse y, más tarde, ante la ineficacia de estas medidas, constreñidos a no

\footnotetext{
${ }^{57}$ La movilidad en el interior de la nobleza que se testifica desde la Baja Edad Media. Las executorias de hidalguía que consiguieron algunos sectores emergentes produjeron malestar entre la vieja nobleza, así como entre otros sectores que debían seguir tributando. Ante esto, "Cellorigo pretendía la restauración de la república, para lo cual, entre otras cosas, la sociedad debía retornar el orden natural, que entendía como la justa proporción entre mayores, medianos y menores. Criticaba de modo contundente la polarización social entonces existente por considerarla perniciosa para el buen funcionamiento de la república (...) Por otra parte, además, Cellorigo criticaba que día a día se ordenaran 'semejantes disposiciones' que permitían la constitución de vínculos y mayorazgos por las cuales resultaban beneficiados en muchos casos quienes no alcanzaban los merecimientos necesarios para obtener tales privilegios". Elsa Caselli. "La España de fines del siglo XVI en la mirada de un abogado de la Inquisición: Martín González de Cellorigo", en Prohistoria. No 6, Rosario, Prohistoria Ediciones, 2002, pp 49-78, pp 59 у 60.

${ }^{58}$ Pierre Vilar, "El tiempo del Quijote", en Crecimiento y desarrollo. Barcelona, Ariel, 1983, p 343.

59 "Que haya en nuestra España tanta copia de lacayos y pages y gente vagamunda y perdida que se salen de las azadas y guardas de ganados como á ser prebendados, y no hay quien halle un mozo para labrador, ni que quiera guardar ganado, dándose todos á la ociosidad, madre de todos los vicios". En Cortes de Madrid de 1592-1598, 19 de mayo de 1593. Congreso de los Diputados, op cit, Tomo XII, p 463. Se atribuye a la inflación de la servidumbre la imposibilidad de hallar mano de obra campesina disponible.
} 
moverse de su comunidad. Sobre el ocaso del siglo XVI también se asimiló el problema de los vagabundos con el de los criados, lo que alarmó a las autoridades respecto a este tipo de ocupaciones, tal como se testimonia en las peticiones de 1593. En el marco de la crítica por la falta de trabajadores para ocupaciones productivas, se confunden los pajes con los vagabundos, siendo considerada la existencia de ambos (que probablemente no eran sino un mismo agente) producto la ociosidad y causa de la pobreza del reino.

En 1594 se señala la abundancia de hombres jóvenes y solos en las ciudades, disponibles para las diversas ocupaciones de servicio, así como la falta de aprendices, consecuencia de este desarreglo ${ }^{60}$. La solución que se reclamaba era limitar este gasto ostentoso por parte de los señores, limitando la cantidad de hombres que podrían mantener en el marco de su casa. La normativa da cuenta de la relación de variadas problemáticas que se ilustran en la picaresca, como la representación social y la noción del marginal como objeto suntuario y su ocupación no productiva. Esto encarna una contradicción, pues si en otras disposiciones éste era estimado como un sujeto que decidía inclinarse a la vida ociosa, aquí era considerado una consecuencia de la oferta de quien lo empleara en funciones no productivas. En cualquier caso, se observa la alarma por la falta de mano de obra en el campo, que responde a la necesidad de los sectores que emitían este discurso en pos de someter a los baldíos al trabajo asalariado, aspecto que hemos examinado.

Las relaciones fluidas entre los marginales y otros sectores pueden corroborarse también en variados pasajes de las peticiones de los procuradores, que demuestran que los hombres baldíos no siempre eran perseguidos en las villas, tal como se demandaba a la sociedad que lo hiciera. Tempranamente, en las Cortes de Briviesca de 1387, se indica la posibilidad de que no se cumpliera la normativa, tanto porque quienes deberían prenderlos no lo hacían, cuanto por negligencia de la justicia ${ }^{61}$. Esta permisividad por parte de la población puede ser consecuencia de la necesidad social de la existencia de estos hombres, en tanto constituían por un lado un ejército que podía ser contratado sólo por temporadas, dado que permitiría esta forma de utilización, mientras por el otro,

\footnotetext{
${ }^{60}$ Así se denuncia "...la mucha cantidad que hay de hombres mozos en los lugares grandes destos reynos para servir de escuderos, pajes o lacayos, atento á lo qual hay mucha falta de oficiales en todos los oficios de la república, y suplica al Reyno trate desto y vea si será bien pedir se ponga y señale la cantidad de pajes que se han de poder traer y de que edad serán los escuderos.” En Cortes de Madrid de 1592-1598, 31 de agosto de 1594. Ibídem, Tomo XIII, pp 384-385.

61 "E ssy alguno non los quisiere tomar asy, quelas justiçias de los lugares den a los dichos uagabundos e folgazanes ssesenta açotes e los echen dela villa. E ssy las justiçias asy non lo fezieren, que pechen por cada vno de los dichos folgazanes sseys çientos mr. para la nuestra camara, e los duzientos ssean para el acusador". Cortes de Briviesca de 1387, petición 5. Real Academia de la Historia, op cit, Tomo II, p 371.
} 
seguían siendo funcionales en el plano ideológico como oportunos receptores de limosna, que continuaba constituyendo un medio para acceder al perdón divino. Los vínculos de los vagabundos con el resto de la comunidad resultaban necesarios para la reproducción de los primeros, que sobrevivían gracias a su inserción epidérmica en el espacio de una sociedad que los condenaba, pero toleraba su presencia física. El premio a los denunciantes y las multas a los oficiales de justicia estaban presentes también en las ordenanzas y constituían una constante de la organización de las aldeas, de las villas y de las ciudades ${ }^{62}$. Dichos recaudos respecto al posible incumplimiento de la voluntad de que los vagabundos fueran denunciados y la consiguiente motivación económica que se propuso para alentar su persecución, sugieren que los marginales no eran hostigados por otros agentes sociales que podían llegar a colaborar con ellos, por eso se puede sospechar la existencia de relaciones fluidas entre estos diversos sectores ${ }^{63}$, en una trama comunitaria que los muestra insertos dentro de las prácticas y representaciones de las aldeas.

En las Cortes de Madrid de 1419 reconocemos la confusión entre rufianes (que eran asociados con la violencia), y los "vagamundos", contra quienes se quiso imponer la pena de destierro. Pero eran los propios señores quienes encubrían a dichos hombres, debido probablemente a la funcionalidad que podían tener entre su clientela ${ }^{64}$. Los marginales a quienes estamos analizando, cuyas desobediencias estaban atravesadas por la falta de ocupación (identificada con la vagancia) y pequeños delitos contra la propiedad, resultaban homologados con otros "rufianes", a quienes se asociaba con la violencia física hacia otras personas. Quizás pueda tratarse de los mismos sujetos, pero esto es incierto. Sin embargo, podemos aventurar la hipótesis de que estos marginales podían cometer actos violentos por encargo de los señores que los tomaban en

\footnotetext{
62 “... V. M. mandó en las cortes de Valladolid quelos pobres mendigantes no andoviesen a pedir por Dios fuera de su naturaleza, y los corregidores no lo quieren executar. Suplican a V. M. mande que esto se ponga en los capitulos delos corregidores y en las provisyones que seles dieren, con ynpusiçion de pena, asy a los dichos corregidores que no lo executaren, como alos dichos pobres." Cortes de Madrid de 1528, petición 45, Ibídem, Tomo IV, p 469.

${ }^{63}$ Carmen López Alonso, op cit, p 218.

64 "A lo que dezides que en algunas çibdades e villas e lugares delos mis rregnos rrecresçen muy grandes dannos e rroydos e volliçios e muertes, por rrazon de los rrufianes e algunas otras personas vaga mundos sin sennor e sin ofiçio que enellos estan, e que commo quier quelos alcalles e rregidores delas dichas çibdades e villas querrian proçeder contra ellos mandando los sallir de los dichos lugares, e por otra manera que se non conplian sus mandamientos, asi por que algunas personas poderosas de los dichos lugares los defendiauan e dauan fauor, commo por que dezian los dichos ruffianes e vaga mundos que de derecho non podian proçeder contra ellos". Cortes de Madrid de 1419, petición 10. Real Academia de la Historia, op cit, Tomo III, p 16.
} 
servicio $^{65}$. Del mismo modo, los desertores de la soldadesca que no estaba guerreando también eran confundidos con los vagabundos y éstos con aquéllos ${ }^{66}$.

En la normativa también vemos una contradicción indicativa de los lazos volátiles que estos marginales mantenían con sus eventuales amos. Mientras se los llamaba "vaga mundos sin sennor", luego se sostenía que no era posible subordinarlos, ya que quienes deberían denunciarlos actuaban en su favor ("por que algunas personas poderosas de los dichos lugares los defendiauan e dauan fauor"), entonces cabe interpretar que se trataba de amos temporales que respondían por ellos ${ }^{67}$. Así, la inserción en una red clientelar de manera transitoria no significaba la salida de la marginalidad, sino que, por el contrario, podría perpetuar esta condición, pues las conductas que los sujetos reproducirían en dicho ámbito no serían necesariamente aceptables para la comunidad y siempre permanecían sospechosos de reiterarlas de manera disimulada. Los marginales establecían con la sociedad una relación que implicaba la rapiña, que refractaría en los vínculos que tendieran en las casas en las que se insertaran eventualmente, tanto en los lazos verticales como en los horizontales. Por estos motivos, esta forma de subordinación sería diferente de la de aquellos que se encontraban en una situación de pobreza -relativa- integrada ${ }^{68}$.

Las oligarquías y aristocracias se servían de la existencia de esta clase de individuos, a quienes contratarían para diversas ocupaciones. En las Cortes de Toledo de

\footnotetext{
${ }^{65}$ De hecho hay fuentes judiciales que avalan esta hipótesis, donde vemos a los mozos interviniendo en delitos en favor de sus amos. Por ejemplo, “...que venyendo Alfonso de Coya, moço de espuelas de su señoria, de Valladolid e trayendo çierto despacho de sus letrados e fatores para su señoria e venyendo por el camyno Françes, que el sabado pasado que fueron catoreze (sic) dias de este presente mes, por mandado del marques de Villafranca, llegando el dicho moço de espuelas a do dize la Pena de Abade salieron a el quatro criados del dicho marques e le tomaron e robaron las cartas e ynboltorios que traya a el e a un criado de Galaor Osorio, que le pedio y pedio que reçiba juramento del dicho moço de espuelas para que sus dichos e deposyçiones lo digan, para que su señoria sea remediado e proveydo del dicho robo. (...)y el dicho moço de espuelas del conde se venyeron su camyno derecho para esta villa de Monforte por el camyno Françes y llegando a un paso que se llama la Pena del Abad que vio salir alli quatro peones con sus medias lanças y espadas e broqueles e uno con una ballesta e que de estos quatro, que los dos de ellos eran de los que yvan con el marques por la dicha villa al canpo, (...)y le preguntaron que de donde era y el dixera que era de Galaor Osorio de Astorga (...)e este al tienpo les dixera "avysen por tomarnos los dineros" y que los peones respondieran "non que non nos mandaron tomar sy non las cartas" (...)Y dixo mas este testigo que este dicho dia que lo susodicho acaesçio, que bolvyeron asy que por que hallaron un onbre e les dixo que aquellos, dezia, que los robaron, que todos los dias estavan a la mesa comer con los del marques e que aquella ora faltavan..." Archivo General de Simancas. CCA, DIV, 43, DOC.10. Fols. $71 \mathrm{r}-72 \mathrm{v}$.

${ }^{66}$ Por ejemplo, podemos ver en los "Capítulos de buen gobierno de Lon y Brez del año de 1594", capítulo 5 , que se ordena que “... no acojan ni consientan acoger en este concejo soldados afugados, y si alguno acudiere le pueden prendar y lleven ante la justicia de la villa de Potes, lo cual cumplan que serán castigados por todo rigor.” En Juan Baró Pazos y Rogelio Pérez Bustamante, op cit, p 172.

${ }^{67}$ Cortes de Madrid de 1419, petición 10, en Real Academia de la Historia, op cit, Tomo III, p 16.

${ }^{68}$ Aquí los estamos diferenciando asimismo de los criados rurales, cuya funcionalidad era productiva y conducía a la cohesión social.
} 
1559 vemos que “... una de las cosas que causa haver mucha gente holgazana en estos reynos es la desorden que los grandes y cavalleros tienen en recivir en sus casas gran numero de lacayos...”69, lo cual trae aparejado otro problema, pues “... por andar en este havito mayormente quando les dan libreas muchos dexan sus officios y otros las labores del campo: lo qual ha venido a tanto que ya no se hallan peones para cavar y segar ni hazer las otras cosas del campo, sino a muy excesivos precios..."70.

Paralelamente a la desorganización en el marco del trabajo, se hacía referencia a la ruptura de la célula familiar, que también era parte del proceso de marginalización, tal como hemos referido ${ }^{71}$ y que implicaba la condena moral ${ }^{72}$. Sin embargo, en este caso la crítica no recaía sólo en los marginales, sino que se estimaba que sus empleadores no eran menos culpables de la situación ${ }^{73}$. Se entendía que estas nuevas relaciones darían lugar a que nobles y pueblo llano desarmaran sus antiguas redes para desarrollar vínculos diferentes, en perjuicio de los tradicionales sistemas de contención de los pobres y de la parentela menos favorecida dentro de su entorno social. Nuevamente, la solución se buscaría en la prohibición de este tipo de gastos para los señores ${ }^{74}$, por ejemplo mediante la norma en la que se confirman los estamentos y su legitimación a la hora de justificar el gasto lujoso -según la dimensión del prestigio que fuera necesario sustentar-.

La regulación de los usos suntuarios se justifica en la de los gastos, pero esconde la preocupación por la preservación de la inmovilidad del status de cada uno en la sociedad, inquietud que es retomada obsesivamente por la novela picaresca, en cuyas obras el cambio de situación del protagonista es simbolizado a partir de la variación en su atuendo ${ }^{75}$. Las leyes suntuarias impedían que se efectivizara el deseo de vestir como noble por parte de quienes no lo fueran, evitando toda posible confusión en las

\footnotetext{
${ }^{69}$ Cortes de Toledo de 1559, petición XCVI. Real Academia de la Historia, op cit, Tomo V, p 856.

${ }^{70}$ Cortes de Toledo de 1559, petición XCVI. Ibídem, Tomo V, p 856.

71 “...y lo que peor es que los tales hombres puestos en havitos de lacayos dexan sus mugeres y hijos perdidos en sus tierras...”. Cortes de Toledo de 1559, petición XCVI. Ibídem, Tomo V, p 856.

72 “....y son rufianes y biven vida libre harto lexos de parescer christianos...”. Cortes de Toledo de 1559, petición XCVI. Ibídem, Tomo V, p 856.

73،....y aun esto es ocasion para que los grandes y cavalleros por mantener esta gente dexan de tener y mantener en suscasas parientes pobres y honrrados y otros muchos buenos que en sus casa solian sustentarse...”. Cortes de Toledo de 1559, petición XCVI. Ibídem, Tomo V, p 856.

74 “...que ningun perlado ni señor de titulo pueda traer mas de quatro lacayos, y otra ninguna persona que no sea perlado o señor de titulo no pueda traer mas de dos, pues para aquel servicio basta esta cantidad". Cortes de Toledo de 1559, petición XCVI. Ibídem, Tomo V, p 856.

${ }^{75}$ Esto también se corrobora en las fuentes aquí analizadas, por ejemplo en las Cortes de Toledo de 1559: “...una de las cosas que causa haver tantos ladrones en España es igualmente disimular con tantos vagamundos porque el reyno esta lleno dellos, y son gente que muchos dellos traen cadenas y aderezos de oro y ropas de seda y sus personas muy en orden sin servir a nadie y sin tener hazienda, officio ni beneficio..." Cortes de Toledo de 1559, petición LXXXIX. Ibídem, Tomo V, p 853.
} 
apariencias externas que las definían. La gravedad de que esto sucediera radicaba en que se consideraba una subversión contra un orden que aseguraba la estabilidad social y que había sido querido por Dios. De esta manera el conflicto cobraba mayores dimensiones, pues el sistema instaurado era garante de paz social y salvación eterna. Esto puede significar además que una persona que se autorrepresentase como perteneciente a un status superior, fuera puesta por encima de otra que poseyera dicho estatuto realmente, lo que atentaba no solo contra el orden social, sino contra el honor del último. Si las leyes suntuarias venían elaborándose desde tiempos muy anteriores, la ostentación en las ropas es relacionada en este período también con la falta de sujeción a otra persona y la insuficiencia de bienes y ocupación, condiciones que significaban una red de contención del individuo.

El problema de la limosna radicaba en su falta de regulación, es decir, en su desorden. En el capítulo quinto nos extenderemos sobre este conflicto, pero recordemos por ahora que esta preocupación se enmarcaba en una cultura cristiana, en la cual la limosna jugaba un rol dentro de la lógica reciprocitaria de la salvación eterna (lo que se diera al pobre en la Tierra sería retribuido en la vida ultraterrena). Por ende, la caridad era aceptada y promovida a través de la normativa, siempre que se enmarcara en la regulación y por lo tanto no fuera desordenada y descontrolada, pues testificamos que mientras la mendicidad era censurada, se proponía el otorgamiento de limosnas en el marco ceremonial ${ }^{76}$. La integración social de los pobres debía realizarse a través de una

\footnotetext{
76 “...nos ordenamos e mandamos que se faga en la manera que por vos fue dicho, e que se faga la dicha proçesion muy solepne con proçesion e misa en todas las çibdades e villas de nuestros rregnos, e quelos conçejos dellos ordenen la alimosna que se deue dar segund su buena discreçion dellos e que nos en nuestra casa ordenamos de fazer la dicha proçesion con misa e predicaçion, e de mandar dar a quarenta pobres de vestir aonor dela santa Trinidat, e que den de comer a trezientos. (...) que podriamos conplida mente fazer conosçimiento a Dios segund las muchas merçedes que del rresçibimos, commo quier que deuemos trabajar quanto pudieremos para lo cunplir; e por que esto avemos ordenado de fazer algunas leyes, las quales entendemos que guardando las se seguiria seruiçio a Dios, e bien a nos e a nuestros rregnos." Cortes de Briviesca de 1387, petición 1, en Real Academia de la Historia, op cit, Tomo II, pp 379- 380 .

Así vemos que los pobres extranjeros eran tolerados en las villas por un día, mientras los verdaderos pobres debían ser atendidos en sus propias localidades: “ A esto vos respondemos que por euitar los dichos inconuenientes mandamos que de aquí adelante en la nuestra corte todos los pobres vagamundos que pudieren trabajar y anduuieren mendigando, sean echados della y castigados conforme a las leyes destos reynos; y que ningun estranjero destos nuestros reynos que anduuiere pidiendo limosna no pueda estar so color de romero en la nuestra corte mas de un dia natural, y que los que verdaderamente paresciere que son pobres y enfermos, sean curados en los Obispados donde son naturales, poniendolos en hospitales, buscando para los curar y dar de comer..." Cortes de Madrid de 1534, petición 67. En Ibídem, Tomo IV p 617.

La ritualización de la limosna se puede comprobar en esta misma documentación. El 11 de enero de 1595, en las Cortes de Madrid de 1592-1598, Fray Gerónimo de Vallejo, miembro de la orden de San Benito
} 
fórmula consustancial con el orden aristocrático dominante, haciéndolos participar del complejo aparato de distribución del producto por la vía de la limosna individual y disposiciones testamentarias o bien mediante las instituciones de caridad. De este modo, existía un contrato tácito entre los grupos privilegiados y los sectores más desfavorecidos que aseguraba la paz social y preservaba el orden jerárquico establecido $^{77}$, en un sistema que pretendía capturar a los últimos, para funcionalizar hasta los fenómenos más extremos dentro de un orden social contradictorio que los combatía tanto como los necesitaba.

Nos referiremos sucintamente a la representación de los vendedores ambulantes en las peticiones de las Cortes $^{78}$. Revisaremos algunos pedidos en torno a ellos por dos motivos: su fuerte asociación con la figura del marginal, por un lado, y la frecuente aparición de este tipo de personajes en las novelas que examinaremos a partir del próximo capítulo, por el otro. La figura del ropavejero y la funcionalidad de su ocupación son retomadas por la picaresca, así como su relación con el hampa. En las novelas los comerciantes venden atuendos para que los pícaros puedan llevar a cabo sus tretas, mientras en las peticiones se confunden con los ladrones o son considerados sus cómplices. Así, el problema del ropavejero se relacionaría directamente con el de reducir el producto del robo, y ambos con el desplazamiento de los hombres ${ }^{79}$. Se sospechaba de estos comerciantes o mercaderes (tal como reflejan la literatura y la legislación) porque llevaban una vida de vagabundos y resultaban tratados como tales, mientras su comercio perjudicaba a los artesanos locales.

Su problema era la falta de radicación en una villa, aldea o ciudad determinada ${ }^{80}$, pues si se desconfiaba del extranjero que no tuviese vecinos que lo avalasen, se lo hacía

pide limosna para la fiesta de San Jacinto, en la cual se pretende vestir quinientos niños pobres que fuesen en la procesión, así como alimentar a algunos pobres durante ocho días, petición que es atendida, Congreso de los Diputados, op cit, Tomo XIII, p 426.

${ }^{77}$ Alberto Marcos Martín, Movilidad social ascendente... op cit, $\mathrm{p} 43$.

${ }^{78}$ Así vemos que se suplica que: "no anden tantos regatones y ropavejeros por la corte y otros oficios, porque encarecen las posadas y no sirven de otra cosa, que se establezca un numero cierto de ellos y no anden otros que los que fueren nombrados". Capítulos generales de Madrid de 1542, N8, petición 15. Ibidem, Tomo V, p 210.

79 “... los mas de los hurtos que se hacen en vuestra corte, y en todos los otros lugares donde hay ropavejeros se hacen en confianza de la venta que alli pueden aber, y de saber como saben que no se han de descubrir los dichos hurtos por que los dichos ropavejeros en el barato que se les haze entienden que son las tales ropas hurtadas y asi las deshacen y desbaratan y ocultan luego, por manera que no se puede haver razon de lo hurtado" Cortes de Valladolid de 1548, petición 83, en Ibídem, Tomo V, p 403.

${ }^{80} \mathrm{En}$ las mismas actas los forasteros son mencionados como: "sanguijuelas que chupan toda nuestra sustancia y virtud, haziéndoles grande acoxida y regalo á los que en su tierra nos hazen ir como moriscos, 
también respecto al vendedor ambulante ${ }^{81}$, quien era extraño en todos los lugares salvo su villa. Si en principio se sostiene el problema de la circulación debido a la posibilidad de que comerciaran con objetos robados, contribuyendo de este modo con los ladrones, luego en las peticiones se va aún más lejos, al sostener que son los mismos ladrones quienes luego venden el botín ${ }^{82}$, criminalizando de este modo a los regatones y ropavejeros y generando una sospecha generalizada sobre estos vendedores, lo que justificaría la limitación del intercambio en manos de extranjeros ${ }^{83}$. Se intentaba poner coto a la trata por parte de quienes no fueran vecinos de la ciudad, villa o aldea donde ejercían su comercio, a partir del establecimiento de pruebas sobre la procedencia de los bienes que vendían y de la posibilidad de prendarlos. Evidentemente, el temor hacia estos potenciales delincuentes es sobredimensionado en la norma, pero no siempre es compartido por la comunidad, pues vemos que también se debía amedrentar a los posibles compradores (que podrían ser engañados y por lo tanto perder el bien adquirido, pero también lo podían obtener a bajo precio, de mala fe) con una pena pecuniaria ${ }^{84}$, indicando que estos comerciantes eran depositarios de -al menos- una relativa confianza por parte de la población ${ }^{85}$. Sin embargo, la legislación tiene en cuenta la diferencia entre el vendedor, respecto a quien se debe dudar, y el comprador, un vecino conocido, que a pesar de esta condición se está vinculando con personajes sospechosos. Por lo tanto, también repara en este aspecto, pues propone “... que no se salve de la dicha pena con provar buena fama por que la pruevan todos los que quieren,

sin armas, y si nos coxe la noche fuera de la posada, nos quitan la vida". Cortes de Madrid de 1592-1598, reunión del 19 de mayo de 1593. Congreso de los Diputados, op cit, Tomo XII, p 464.

81 “... por que muchos ladrones y encubridores de ellos llevan ropas, joyas, bestias, y ganado á vender de unos pueblos á otros, y de esto se siguen grandes daños, y de ladrones se tornan mercaderes y tratantes...”. Cortes de Valladolid de 1548, petición LXXXI. Real Academia de la Historia, op cit, Tomo V, pp 402403.

82،... en los pueblos grandes, los ladrones venden cosas que hurtan y sin conocerlos se las compran á menos precio...". Petición LXXXII, Cortes de Valladolid de 1548. Ibídem, Tomo V, p 403.

83 “... mande que el que fuere forastero y vendiere qualquiera de las dichas cosas sea obligado á mostrar testimonio de como son suyas, y al que no lo mostrare las justicias le prendan hasta que se averigue...". Cortes de Valladolid de 1548, petición LXXXI. Ibídem, Tomo V, pp 402-403.

84 “... que el que comprare qualquier cosa de hombre no conocido que paresciere ser hurtada y no mostrare del veedor de ella que demas de la perder sea condenado con el doblo, la mitad para la camara y la otra mitad para la parte...” Petición LXXXII, Cortes de Valladolid de 1548. Ibídem, Tomo V, p 403. La pérdida del doble de lo pagado indica que las autoridades creen que adquirió el bien a sabiendas de que era robado.

85 “.... y el que comprare qualquier cosa semejante sin el dicho testimonio despues de perderla, incurra en pena de otro tanto para el dueño por las costas que de fuerza hará en cobrarla, por que con esto se remediarán muchos de los daños, que ladrones hazen." Cortes de Valladolid de 1548, petición LXXXI. Ibídem, Tomo V, pp 402-403. En este pasaje se completa lo anterior, porque si se llega a conocer el dueño del bien robado y revendido y éste reclama en juicio, se le debe pagar además las costas del pleito. 
y asi salen libres para tornar á comprar y encubrir hurtos" ${ }^{\nexists 6}$, dando cuenta de la vinculación permanente entre los sujetos integrados en la sociedad, que se aprovechaban oportunamente de los marginales, y aquellos que no lo estaban.

El discurso plasmado en las Cortes supone que las actividades en las cuales se involucrarían todos los hombres sin lazos serían ilícitas: “...y sacando en limpio, unos se sustentan de ser fulleros y traer muchas maneras de engaños, y otros de jugar mal con naipes y dados, y otros de hurtar...”. Todas estas prácticas picarescas implican la racionalidad de un hombre solitario, quien se ha socializado de manera que el individualismo ha prevalecido en su conducta ${ }^{87}$. Sin embargo, y en contradicción con esta lógica, se les achacaba la pertenencia a una comunidad que los enmarcaría: “...y hay entre ellos capitan de ladrones que traen cuadrillas repartidas en las ferias, y repartidas por todo el reyno, y lo que se hurta en unos pueblos se lleva a vender a otros..., ${ }^{, 88}$.

Mientras se los acusaba de ladrones, estafadores, jugadores y rufianes, en síntesis, de no vivir según los preceptos que promueve la religión cristiana, también se presentaba la idea de la existencia de una asociación de marginales que poseía su propia autoridad, organización y objetivos. El problema de formación de la corporación de vagabundos con el propósito de delinquir es relevante por varios motivos: por un lado plantea, además del temor a la conspiración, la idea de un mundo al revés ${ }^{89}$, con su propio orden; en segundo lugar supone la fidelidad y encuadramiento de hombres que, según la descripción que se hace de ellos en otros pasajes que hemos revisado de esta documentación (que los presenta como traicioneros e insubordinados), no podrían mantener relaciones estables. Respecto al primer aspecto, la conspiración, también se planteó esta clase de presuposiciones para la persecución de diversos sectores minoritarios cuyo objetivo sería atacar a la comunidad de una u otra manera (envenenar aguas, difundir la enfermedad, raptar niños o robar). En segundo término, la idea de que se agruparan en una formación jerárquica, con sus propias reglas y autoridades, indica que se trataba de la construcción de un submundo que reflejaría las mismas estructuras que organizaban a la sociedad, en cuyos resquicios se escondería dicho grupo, tal como veremos en los capítulos quinto y sexto. Pero si tenemos en cuenta otros fragmentos de

\footnotetext{
${ }_{87}^{86}$ Petición LXXXII, Cortes de Valladolid de 1548. Ibídem, Tomo V, p 403.

${ }^{87}$ Juan Carlos González Hernández, op cit, p 163.

${ }^{88}$ Cortes de Toledo de 1559, petición LXXXIX. Real Academia de la Historia, op cit, Tomo V, p 853.

${ }^{89}$ Stuart Clark, Thinking with Demons: the idea of witchcraft in Early Modern Europe. Oxford, Oxford University Press, 1997, pp 20-33.
} 
la misma documentación, la propia libertad de estos hombres y su forma de vincularse o mejor dicho, de no hacerlo de modo permanente-, así como su movilidad, imposibilitarían este tipo de formaciones de manera permanente.

Entre todos los problemas que plantearían los marginales, el del proxenetismo se presenta como el más grave ${ }^{90}$. La relación entre marginalidad, prostitución y rufianería es también recurrente en la novela picaresca, donde la tarea del macró aparece como uno de los indicadores de mayor inescrupulosidad de los personajes. Esta temática demuestra ser un motivo de preocupación, pues este período vio una mayor presencia de las actividades de los prostíbulos, especialmente en las zonas más urbanizadas, ya que aumentaba la clientela ${ }^{91}$. Los delincuentes fueron definidos por este tipo de normativa como malfechores o rufianes, los últimos estaban estrechamente vinculados con la prostitución y con la ociosidad, que era entendida como uno de sus vicios, mientras la figura del malhechor resultaba más compleja o amplia, refiriéndose a todo aquel que no viviera de un oficio honesto ${ }^{92}$.

Estas imágenes se relacionan con otro motivo de preocupación en la documentación que aquí analizamos. Se trata de la desorganización social como caldo de cultivo para la delincuencia. Las luchas civiles y los enfrentamientos banderizos propiciaban un control laxo y la eventual contratación como integrantes de una fuerza armada. En este ambiente convulsionado existía la posibilidad de emplearse de este modo y así evadir el control real, protegidos por los señores, mientras la inseguridad endémica favorecía la violencia y conducía al relajamiento de su vigilancia por los concejos $^{93}$.

La idea de que el control de los hombres baldíos era imposibilitado por su movilidad también justificó la pesquisa sobre su forma de vida ${ }^{94}$. La libertad de estos

\footnotetext{
90 “...y muchos se sustentan de ser rufianes, que es la mas perniciosa y mala gente que ay en el mundo: y es cosa bien entendida quan lexos anda toda esta gente de bivir christianamente..." Cortes de Toledo de 1559, petición LXXXIX. Real Academia de la Historia, op cit, Tomo V, p 853.

${ }^{91}$ Denis Menjot, op cit, p 189.

${ }_{92}$ Antonio Collantes de Terán Sánchez, op cit, p 294.

${ }^{93}$ Denis Menjot, op cit, p 201.

94 “...que en esta corte se haga siempre gran inquisicion de como bive la gente baldia, y que los corregidores y otras justicias destos reynos hagan lo mismo en sus jurisdiciones y distritos: porque con esto parece que se yra poniendo algun remedio en tanto daño". Cortes de Toledo de 1559, Petición LXXXIX. Real Academia de la Historia, op cit, Tomo V, p 853. Los argumentos a favor de tal pedido fueron “... que una de las cosas que causa haver tantos ladrones en España es igualmente disimular con tantos vagamundos porque el reyno esta lleno dellos, y son gente que muchos dellos traen cadenas y aderezos de oro y ropas de seda y sus personas muy en orden sin servir a nadie y sin tener hazienda, officio ni beneficio: y sacando en limpio, unos se sustentan de ser fulleros y traer muchas maneras de
} 
sujetos, que no tenían un garante social o patrono que respondiese por ellos, y su falta de inserción en una red que les proporcionara sostén y control imponían la necesidad de tomar medidas particulares: si la vigilancia estaba garantizada usualmente a través de una estructura piramidal, la evasión de dicha configuración imponía que esta cuestión fuera tratada como un asunto público, tal como continuaremos corroborando.

\section{EI desorden y la propagación}

A través del examen de las normativas a lo largo de los siglos, podemos observar diferencias sutiles que indican cómo la política contra los vagabundos mostraba caracteres cada vez más violentos no sólo en las medidas que se implementarían, sino especialmente en la forma de representarlos. Volvamos a la petición cinco de las Cortes de Briviesca de $1387^{95}$. El pedido comienza describiendo la condición de los vagabundos como una elección personal pero aquí aparece un agravante: se sustentaban a costa del trabajo de otros, dado que vivían de la caridad sin ser lisiados o impedidos. La normativa estipulaba que serían condenados quienes perteneciendo al estamento obligado al trabajo manual no lo ejercieran, pues se especificaba que se requería que “... ningunos omes nin mugeres, que ssean et pertenescan para labrar non anden baldios por el mio ssennorio" "96. Esta expresión que destacamos trasunta una idea de naturalización del estamento condicionado por el orden de la creación y por el derecho natural que los obligaba al trabajo físico. Por otro lado la semántica de la petición

engaños, y otros de jugar mal con naipes y dados, y otros de hurtar, y hay entre ellos capitan de ladrones que traen cuadrillas repartidas en las ferias, y repartidas por todo el reyno, y los que se hurta en unos pueblos se lleva a vender a otros, y muchos se sustentan de ser rufianes, que es la mas perniciosa y mala gente que ay en el mundo: y es cosa bien entendida quan lexos anda toda esta gente de bivir christianamente...”. Cortes de Toledo de 1559, petición LXXXIX. Ibídem, Tomo V, p 853.

95 "Grand danno viene alos nuestros rregnos por ser en ellos consentidos e gouernados muchos vagabundos e folgazanes que podrian trabaiar e beuir de su afan e non lo fazen; los quales non tan sola mente biuen del sudor de otros ssyn lo trabaiar e meresçer, mas avn dan mal enssyenplo alos otros que les veen fazer aquella vida, por lo qual dexan de trabaiar e tornan sse ala vida dellos, e por ende non sse pueden fallar labradores e fincan muchas heredades por labrar e vienen sse a hermar". Cortes de Briviesca de 1387, petición 5, en Ibídem, Tomo II, p 370.

${ }^{96}$ Cortes de Valladolid de 1351, petición 1. Ibídem, Tomo II, p 76. En otra oportunidad encontramos referencias en el mismo sentido, “... que (...) ay e andan muchos omes e mugeres valdios e vaga mundos (...) con entençion de non trabajar nin afanar sus cuerpos a ningund ofiçio, seyendo omes e mugeres para ello et tales que si quisiesen meter los cuerpos a afan e trabajo fallarian ofiçios que fiziesen e personas con quien biuiesen elos tomarian a soldada e en otra manera, e les darian mantenimientos e otras cosas queles fuesen menester, e las gentes se podrian seruir dellos e ayudarian a labrar e guardar ganados e fazer otras cosas e ofiçios e que podrian aprouechar al pueblo, e ellos non andarian valdios commo andan nin comerian su pan folgando. ”. Cortes de Madrid de 1435, petición 38. Ibidem, Tomo III, p 236. 
trasluce la idea de que estos hombres optaban por una forma de vida no acorde con dicho mandato.

La normativa examinada testimonia el cambio paulatino de lo que se imputaba a los marginales a partir de pequeñas variaciones en el discurso, que comienza con la persecución de los hombres baldíos en el siglo XIV y cuyo desarrollo, llegado el siglo XVI implica variadas clasificaciones y penalidades para los hombres libres que no tenían lazos sociales. Hemos indicado cómo la referida petición de las Cortes de Briviesca de 1387 guardaba bastantes similitudes con aquélla realizada en las de Valladolid en 1351 que citamos primeramente, que continuaba acusando a los vagabundos por no trabajar "nin beuir con sennor" ${ }^{97}$, de manera que el cargo contra ellos era doble, porque su ociosidad y su insubordinación constituían dos obstáculos respecto a la posibilidad de sujeción por el poder. Este aspecto reviste especial interés, pues la falta de inserción en una red social (en este caso de dependencia) fue el eje de la criminalización de estas existencias. En las Cortes de 1387 hay una diferencia fundamental con la solución sugerida por las celebradas en Valladolid treinta y seis años antes: la salida no sería la exclusión absoluta sino la inclusión a través de la subordinación a un amo. Podríamos pensar que este recurso daba lugar a la adquisición de mano de obra que sería ocupada en el trabajo manual aunque no de manera exclusiva.

Pero un elemento fundamental aquí es que se les atribuía, a través de la idea del contagio como consecuencia de la imitación ${ }^{98}$, la responsabilidad de la pobreza del reino. De allí podemos inferir varias cuestiones. En primer lugar diremos que se invertían las causas y los efectos del fenómeno: no se consideraba el incremento de los mendigos como consecuencia de una dinámica general contradictoria del feudalismo que generaba gentes sin tierra (por la señorialización del espacio, la adquisición de tierras por agentes urbanos, la polarización de la masa campesina, etc.) sino que por el contrario se los culpabilizaba de la pobreza. La noción de la propagación por la imitación -concepción ausente en peticiones anteriores- constituía una acusación cualitativamente diferente, en tanto la expansión de este problema social también sería su responsabilidad. Además, a partir de esta premisa se podía pensar en una gravedad

\footnotetext{
97 “...por ende nos por dar rremedio aestos dannos, ordenamos que los que asy andudieren vagabundos e folgazanes que non quisieren afanar de ssus manos nin beuir con sennor, que qual quier de nuestros rregnos los pueda tomar por su abtoridat e seruirse dellos vn mes ssyn ssoldada, saluo que les den comer e beuer." Cortes de Briviesca de 1387, petición $\mathrm{N}^{\circ}$ 5. Real Academia de la Historia, op cit, Tomo II, pp 370-371.

${ }^{98}$ Este tópico se repite en la novela picaresca más adelante.
} 
potencial infinita si no se erradicaba con celeridad. Este concepto involucraba la idea de la invisibilidad, pues la propagación es silenciosa $\mathrm{y}$, consecuentemente, tanto más peligrosa. Además, a través del ocio, aparecía la inducción diabólica al pecado, omitida por el lenguaje político.

Por otro lado, el contagio se presenta también en el plano biológico, con la enfermedad que podrían propagar potencialmente los hombres y mujeres del hampa. La necesidad de apartarlos de la población compuesta por "hombres y mugeres onestas" se fundamentaba en motivos médicos. Pero el problema de la prostitución se vinculaba también con la confusión de estamentos y el contagio de las malas conductas que se le asociaba, por eso se exigía que se ejerciese la profilaxis ${ }^{99}$. De tal manera, se consideraba imperiosa la separación de las mujeres públicas para evitar que fueran imitadas por las "tenidas por buenas"100. Como vemos en la petición CXLVII de las Cortes de 1548, cuando se trataba sobre las prostitutas, la normativa se extendía primero en la forma de definirlas y en su comportamiento pero luego se explayaba sobre la cuestión de la enfermedad contagiosa. Cuando se reparaba en este problema, se aclaraba que aquéllas no sólo estarían enfermas, sino que el principal riesgo que implicaba el contacto con ellas radicaba en que mantendrían relación con personas de diversos estados, propiciando el desorden de la sociedad y promoviendo la contaminación ${ }^{101}$.

La prostitución significaba un problema mayor en las grandes ciudades con amplia circulación de individuos y riqueza, donde el anonimato hacía posible que se produjera la confusión de la calidad de las personas, aumentaba la "peligrosidad" de estas mujeres para ambos sexos ${ }^{102}$. Por estas razones vivían el doble juego de exhibición

\footnotetext{
${ }^{99}$ Enrique Villalba Pérez, op cit, p 178.

100 “... por que la onestidad de los hombres y mugeres se conserve y aumente, no dando lugar a las mugeres conoscidamente malas que conversen con las mugeres que son avidas y tenidas por buenas, y no dando lugar á que por las calles ni en otras partes se digan cantares suzios, y pullas, y otras cosas feas, que ofenden las orejas de los hombres, y mugeres onestas, Suplicamos a V. M. mande que en su corte, y en todas las cibdades, y villas, y lugares de estos reynos, las mugeres conoscidamente malas que llaman rameras, ó mugeres enamoradas, ó cantoneras, esten en lugares apartados de la conversacion de las mugeres onestas, y que en la Cortes vuestros alcaldes diputen lugar conveniente para las dichas mugeres, que sea apartado, sin que se mesclen con las mugeres casadas y honestas...". Petición CXLVII de las Cortes de Valladolid de 1548, Real Academia de la Historia, op cit, Tomo V, p 436. Sobre el problema del contagio de las malas conductas ver Carmen López Alonso, op cit, p 559.

${ }^{101}$ Cortes de Madrid de 1551, petición CXXXVII: “en estos reynos ay mucha enfermedad contagiosa, y es la causa las mugeres publicas estar muy enfermas dello, y como las personas que con ellas conversan sirvan a todos generos de estados, de la comunicacion se estiende el mal a otras muchas gentes (...) que las justicias del reyno hagan que las dichas mugeres publicas sean cada mes miradas por un cirujano, y la que hallare estar enferma la prohiban que no lo sea, que sera gran parte para escusar enfermedades tales." Real Academia de la Historia, op cit, Tomo V, pp 559-560.

${ }^{102}$ Así, por ejemplo, en Sevilla durante el siglo XV se dictaron leyes suntuarias respecto a la prostitución ver María Elizabeth Perry, op cit, p 141.
} 
y ocultamiento con que era tratada su actividad $^{103}$, que durante este período fue regulada, llegando al intento de confinarlas en un gueto como parte de un plan de moralización de la vida pública y disciplina de las costumbres, que se acompañaba de una política de segregación social cuyo objetivo era evitar el contagio por el mal ejemplo.

Este recorrido nos conduce nuevamente al problema de la confusión de los estados y la obligación del buen gobierno para subsanarlo. También implicaba el problema del rey como juez y garante del orden y su obligación de dar a cada uno lo suyo, mantener a cada cual en su estamento, sin permitir que quienes pertenecieran a un estrato social vivieran como los de otro. Estos factores convertían al vagabundo y al baldío en enemigos del orden, mientras su ociosidad ofendía a Dios.

En la sociedad feudal los hombres no eran identificados como individuos sino que se los evaluaba en razón de sus vínculos (familiares, sociales, de vecindad, etc.), como parte de diversos cuerpos en cuyo seno se tendían relaciones horizontales y verticales que, en conjunto, regulaban y limitaban la vida de sus integrantes. La libertad de los vagabundos radicaba en no encuadrarse en este tipo de redes, independencia que exacerbaba el temor sobre su peligrosidad y era equiparada con la ausencia de actividad productiva, tal como comprobamos en la documentación ${ }^{104}$.

\footnotetext{
${ }^{103}$ Enrique Villalba Pérez, op cit, p 177.

104 “... e todos los otros omes e mugeres asi vaga mundos que fueren para seruir soldadas o guardar ganado o fazer otros ofiçios que rrazonable mente puedan fazer, que luego caten sennores con quien biuan e a quien siruan e les den sus mantenimientos e las otras cosas que fueren ygualados de que puedan beuir...". Cortes de Madrid de 1435, petición 38. Ibidem, Tomo III, p 236 (las cursivas son nuestras).

Veamos por otra parte qué quiere decir igualar en Covarrubias. Aunque dice que es pasar un rasero o tratar igualmente, añade que es pernicioso si se practica en una comunidad religiosa y que conviene que la igualdad no sea aritmética sino geométrica: "Emparejar unas cosas con otras. Igualarlos a todos, es tratarlos igualmente y llevarlos (como dizen) por un rasero. Si esto se practica en una comunidad religiosa, dificultosamente irá el gobierno con acierto. Diferentemente ha de ser tratado el letrado que el ignorante. Miren los superiores que el querer que todos se igualen no sea la causa que ninguno se señale. Es verdad que conviene que aya igualdad en la comunidad, pero no aritmética sino geométrica, "que no sería buen orden calçar todos con unas hormas, sino que el calçado ha de ser conforme al pie', que ésta es verdadera igualdad, como dize un sabio: 'Confusis et permixtis ordinibus, nihil inaequalitate ipsa inaequalitate ipsa inaequalius". Sebastián de Covarrubias, op cit, p 731. Se trata de un principio de justicia distributiva por el cual a cada uno debe hacérsele justicia según su estado.

Que fueren para servir soldadas significa que no eran tenentes, sino que servían por paga, que eran trabajadores ocasionales, ya que se los contrataba para una tarea determinada y por un tiempo limitado. A los pastores se los identificaba en esa categoría porque solían ser los más pobres de las aldeas quienes hacían ese tipo de trabajo, contratados por los concejos, aunque eventualmente podían trabajar para un señor. Su situación era ambigua porque ellos viajaban con el ganado, pero su mujeres e hijos eran habitualmente habitantes de la aldea, pues el vivir con el señor si lo tenía, o como vecino o morador de la aldea era un factor de fijación y les permitía habitar en el ámbito que el señor dispusiera o en la aldea con concejo; finalmente, la referencia al servicio -a un señor o soldadas- se refería a su naturaleza social.
} 
Nos referiremos brevemente a las peticiones cuya intención es ordenar la corte, porque las novelas picarescas recurren frecuentemente a dicho espacio como escenario de las peripecias narradas en ellas. Allí, los hombres sin señor podían desarrollar diversas actividades, pues sobrevivían y actuaban con una libertad poco controlada, haciendo uso del anonimato y la inserción epidérmica en el cuerpo social ${ }^{105}$. Por otro lado, probablemente establecieran relaciones de sociabilidad particulares con agentes de diferentes sectores como compañeros de juerga, miembros del mismo grupo etario, cultivadores de algún arte como la música o la poesía y con las prostitutas. No se trataba de un sector social homogéneo, ya que entre ellos podían mezclarse miembros díscolos de los estamentos dominantes, pues la corte, en tanto centro político, habría debido mostrar poder ejemplarmente, pero la circulación de personas produciría lo contrario $^{106}$. Aunque la procuración intenta demostrar la gravedad del problema, por otro lado también menciona la laxitud del control al respecto ${ }^{107}$.

En la corte también aparecen los peligrosos vínculos entre los hombres con status y sus dependientes ocasionales, que podían ser marginales a quienes ellos encubrían a cambio de los servicios que pudieran prestarles ${ }^{108}$. Los propios criados

\footnotetext{
105 “... que todos los que no tovieren sennor en la corte e andan en ella, quelos destierren della, porque ay muchos que andan en avito de cavalleros e de honbres de bien e no tienen otro ofiçio sy non jugar e hurtar e andarse con mugeres enamoradas". Cortes de Madrid de 1528, petición 153, en Real Academia de la Historia, op cit, Tomo IV, p 518. Encontamos una petición bastante anterior en referencia a esta cuestión, en la cual también se mezclan diversas clases de marginales y en la cual vemos una menor tolerancia al respecto del conflicto en el seno de la corte: “... mando al mio alguazil que eche dela corte los omes que andudieren en ella ssin ssennores e las mugeres baldias e dannosas, et que ffaga luego pregonar que sse vayan ssopena de çient açotes cada vna; e del primer pregon adelante ssi falar alguno destos tales en la mi corte, mando que les fagan dar çient açotes acada vno, e quel echen della; e ssil ffallaren y la ssegunda uez, quel corten las oreias; et si la terçera uez y ffuer ffallado, quel maten por ello." Ordenamiento de las Cortes celebradas en Valladolid en la era MCCCL (año 1312), título 54, en Ibídem, Tomo I, p 210.

106 “... que aquí en vuestra corte donde prinçipal mente se deuia tomar enxenplo para todo el rreyno, se teme muy poco e se fazen muchas cosas de grandes atrevimientos". Cortes de Valladolid de 1447, petición 23, en Ibídem, Tomo III, p 524. También observamos la reiterada asociación entre la violencia física y los rufianes, a quienes se presenta en relación con las prostitutas: "Muchas vezes ha vuestra merçed mandado e ordenado que en vuestra corte non trayan armas omes de pie nin se consientan estar rrufianes que tengan mançebas e mugeres del mundo, nin se jueguen dados...". Cortes de Valladolid de 1447, petición 23, en Ibídem, Tomo III, p 524.

107 “... quando algunas vezes se faze alguna diligençia dura çinco o seys dias e non mas.” Cortes de Valladolid de 1447, petición 23, en Ibídem, Tomo III, p 524.

108 “... por que en los lugares donde reside vuestra magestad y su corte acaesçe muchas vezes prenderse fuego a algunas casas principales que valen mucho y a otras de gente pobre que no alcançan otra cosa de que sustentarse y por questo muchas vezes de haze por culpa de los criados de aquellos que son aposentados en las dichas casas por mandado de vuestra magestad y huyen e no tienen con que pagar el dicho daño." Capítulos generales de Madrid de 1542, petición 17, en Ibídem, Tomo V, p 210.
} 
ocupados regularmente, protegidos por su amo causaban desórdenes en la corte, donde las casas señoriales podían llegar a devenir en asilos para marginales ${ }^{109}$.

\section{Similitudes con otros grupos minoritarios}

En la documentación que consultamos aparecen tres minorías segregadas, moros, judíos y gitanos, en cuyo tratamiento no nos extenderemos ya que merecen sus estudios particulares. Sin embargo, nos interesa reparar en la referencia simililar a la de los marginales que aquí nos ocupan. Nos dedicaremos al ejemplo de los gitanos, minoría que era calificada de manera análoga a los vagabundos, pues las otras dos presentan particularidades muy diferentes.

Los gitanos constituían una minoría que llegó a la península durante la Baja Edad Media y que el discurso político homologaba a los vagabundos ${ }^{110}$. La pragmática sobre gitanos emitida por las Cortes de Toledo de 1559 los trataba de manera similar a los marginales de los cuales nos ocupamos en nuestro estudio, aunque los últimos fueron segregados por motivos diferentes a los que movían la acusación contra los gitanos ${ }^{111}$. La imputación comienza a partir de su condición nómade, para continuar con la falta de una ocupación conocida. Por esta razón se sospechaba que robaban, pues no se les conocía medios regulares de vida. Pero luego las ordenanzas aclaran las estrategias a través de las cuales estos hombres conseguían subsistir: “... pidiendo limosnas y hurtando, trafagando e haviendolos hechiceros y adevinos y haciendo otras cosas no devidas ni honestas..."112. A partir de esta clase de suposiciones que recaían sobre ellos y los vinculaban de manera directa con otros ámbitos marginados, se sostenía nuevamente el mismo tipo de argumentos que observamos sobre los hombres baldíos: la falta de sometimiento implicaba una ofensa contra Dios, constituía además

\footnotetext{
${ }^{109}$ Antonio Collantes de Terán Sánchez, op cit, p 301.

${ }^{110}$ Así, en las Cortes de Valladolid de 1542, petición 18, se pide "que no anden gitanos por la cantidad de hurtos que de ello resulta". Real Academia de la Historia, op cit, Tomo V, p 185. En el mismo sentido se expresan las Ordenanzas y Autos De Buen Gobierno cántabros del siglo XVI. Por ejemplo, las “Ordenanzas de Lon y Brez de 1597" en el capítulo 14: "que ninguna persona del dicho concejo no consienta (entre líneas: 'en el lugar') andar ningunos gitano ni gitanos, ni otros vagamundos ni siomeros, ni pobres extrangeros, antes los prendan e invíen presos ante su merced, y no pudiendo prenderle, den aviso y noticia a su merced de (e)llo para que se remedie, so las dichas penas contenidas y leyes de (e)stos reinos...”. Juan Baró Pazos y Rogelio Pérez Bustamante, op cit, p 177.

111 “... los egypcianos que andais vagando por estos nuestros Reynos y señorios con vuestras mugeres y hijos y casas (...) andays de logar en Lugar muchos tiempos e años ha sin tener oficio ni manera de vivir alguna de que vos mantengays..." Cortes de Toledo de 1559, "Pragmática contra los gitanos", en Ibídem, Tomo V, p 870.

${ }^{112}$ Cortes de Toledo de 1559, "Pragmática contra los gitanos", en Ibídem, Tomo V, p 870.
} 
un mal ejemplo, dañando al resto del cuerpo social ${ }^{113}$. Observado el conflicto, se decidía solucionarlo a través del asentamiento compulsivo de estos hombres en las ciudades, villas y aldeas, sujetándolos a la dependencia de un señor que respondiera por ellos y les diera una ocupación ${ }^{114}$, pero esto era sólo una parte de la solución, pues se decidía también desestructurar sus células de socialización, con lo que se incidía sobre su identidad cultural $^{115}$.

El aumento de las penas que corroboramos se explica por su ineficacia, pero se fundamenta discursivamente en la "peligrosidad" de este grupo ${ }^{116}$. Además, resultaría imposible identificarlos ya que otros, no sólo del propio reino sino también extranjeros, se les unían adoptando su cultura ${ }^{117}$. Por eso se los conminaba a que abandonaran sus actividades usuales $^{118}$, además de reiterar las acusaciones que guardaban el mismo tenor que aquellas que se hacían a los vagabundos, así como se reparaba en el artilugio que empleaban para evadir la persecución mediante la conformación de grupos reducidos, es decir, basándose en una disgregación que les permitía ser vistos como menos peligrosos ${ }^{119}$. Mientras se temía el castigo divino sobre el reino como consecuencia de la conducta de estos grupos, el discurso acerca paulatinamente a este enemigo interno a la herejía, a través de argumentos análogos a los esgrimidos en torno a los vagabundos ${ }^{120}$.

113 “...siendo como soys los mas de vosostros personas dispuestas para travajar y servir a otros que vos mantengan y de lo que aveis menester o para aprender oficios y usar de ellos de lo qual Dios nuestro Señor es deservido y muchos de nuestros subditos reciben de ello agravio y mal exemplo y son dannificados". Cortes de Toledo de 1559, "Pragmática contra los gitanos", en Ibídem, Tomo V, p 870.

114 “.... vos vivais por sitios conoscidos de que vos supieredes aprovechar estando de estada en los Lugares donde acordaredes de asentar o tomaredes vivienda de Señores a quien sirvays que hos den lo que hubieredes menester..." Cortes de Toledo de 1559, "Pragmática contra los gitanos". Ibídem, Tomo V, p 871. Es importante nuevamente la condición del servicio, que los encuadra y los limita.

115 “...y no andeys mas juntos vagando por estos nuestros Reynos como agora lo haceis..." Cortes de Toledo de 1559, "Pragmática contra los gitanos". Ibídem, Tomo V, p 871.

116 “...porque somos informados que las penas contenidas en las dichas leyes no son bastante remedio para que los dichos egipcianos..." Cortes de Toledo de 1559, "Pragmática contra los gitanos". Ibídem, Tomo $\mathrm{V}, \mathrm{p} 872$.

117 "...y aun con ellos otros muchos y naturales de estos nuestros Reynos y de otras naciones que han tomado su lengua y habito y manera de vivir...". Cortes de Toledo de 1559, "Pragmática contra los gitanos". Ibídem, Tomo V, p 872.

118 “...no anden por las Ciudades, villas y lugares de estos vagando y hurtando y diciendo que son adivinos los quales en daño de nuestros subditos y mal exemplo de la republica de que Dios nuestro señor es deservido y queriendolo proveer y remediar...". Cortes de Toledo de 1559, "Pragmática contra los gitanos". Ibídem, Tomo V, p 872.

119 “... somos informados que contra el tenor y forma de la dicha nuestra carta muchos gitanos y gitanas andan vagando por nuestros Reynos hurtando y robando por los lugares y por evadirse de las penas en la dicha pregmatica concedidas andaban juntos de tres en tres y de quatro en quatro, diciendo que de aquella manera no se comprendia contra ellos la dicha pregmatica ni la pena de los dichos azotes y destierro..." Cortes de Toledo de 1559, "Pragmática contra los gitanos". Ibídem, Tomo V, p 873.

${ }^{120}$ Se sostienen diversos argumentos para inculpar a los gitanos, que se relacionan con su forma de vida, actividades, pero también con su condena moral: “...cuya vida y trato es la mas perdida que hay en toda la republica cristiana, ni aun bárbara, que parece que son gente sin ley, porque no sauen que guarden ninguna, sino que del todo viven llenos de vicios sin ningun género de recato, con grande escándalo 
A partir de estas premisas se propuso como solución para su asimilación social, separar hombres de mujeres y apartar a los niños menores de diez años para adoctrinarlos, mientras se prohibirían los casamientos con quienes no fueran gitanos ${ }^{121}$.

La referencia a este grupo nos permite observar la similitud en las formas de enunciación de distintos sectores perseguidos, esgrimiendo argumentos parecidos para estigmatizarlos y soluciones también comparables a los problemas que ocasionaban al orden social. Por otro lado, a pesar de tratarse de una problemática diferente, uno de los puntos en común más importantes para la acusación de ambos grupos se fundamentaba en su falta de domiciliación, motivo suficiente para constituirlos en enemigos del orden.

\section{Conclusión}

A través del análisis expuesto en las páginas precedentes podemos arribar a algunas conclusiones acerca del tratamiento de la marginalidad en el discurso político ibérico durante la Baja Edad Media y la temprana modernidad. Los vagabundos fueron representados por las actas recogidas en las Cortes como delincuentes contra quienes la sociedad debía reaccionar. A lo largo de este capítulo hemos examinado testimonios acerca de cómo los hombres sin señor fueron objeto del discurso político desde 1268 , pero especialmente a partir del siglo XIV, intensificando la violencia en su calificación y ensayando diferentes maneras para su erradicación a medida que el conflicto se volvía endémico.

Las acusaciones de los procuradores exhiben un incremento en cuanto a la severidad con la que se definía a los marginales, ya que, además de adjudicarles acciones reales más condenables, también varía la apreciación subjetiva de las mismas. Si en las Cortes de 1351 se los acusaba de no trabajar dañando al reino, en las de 1387 se les adjudicaba el peligro de encarnar agentes de contagio y, por lo tanto, ser la causa

destos reynos y de los naturales dellos. Son gente vagabunda, sin que jamás se halle ninguno que trabaje ni tenga oficio con que sustentarse; son públicamente ladrones, embuidores, echando juizios por las manos, haziendo entender á la gente que por alli alcanzan y entienden lo que he de suceder.

Son gente que no guarda en los matrimonios la forma de la iglesia, porque se casan parientes con parientes sin ninguna dispensacion, y aun sin matrimonio se mezclan unos con otros sin tener quenta con deudo de parentesco, ni afinidad, ni las demas prohibiciones del derecho, y jamás se verá ninguno confesar ni recibir el Santísimo Sacramento, ni oir misa no conocer parroquia ni cura, y plegue é Dios que el consentir pecados tan públicos no sea causa de parte de nuestros castigos." Cortes de Madrid de 15921598, reunión del día 15 de marzo de 1594, Congreso de los diputados, op cit, Tomo XIII, p 220.

${ }^{121}$ Cortes de Madrid de 1592-1598, reunión del día 15 de marzo de 1594, Ibídem, Tomo XIII, p 220. 
de la propagación del problema. En 1379 no sólo encontramos la mendicidad y el robo en la imputación de sus acciones objetivas, sino que el conflicto arribó al plano celestial $^{122}$. De esta manera se agregó la idea de la subversión de la voluntad divina, elemento fundamental porque convertía la falta en un delito contra la autoridad y el derecho divino, que estaba por encima del natural.

La principal apelación contra ellos fue el recelo y la desconfianza, mostrándolos como seres nocivos y peligrosos, tanto más porque existía la posibilidad de su propagación si la comunidad no estaba alerta. Este mecanismo también fue accionado en contra de otros actores que funcionaron como chivos expiatorios de un sistema que invocaba al temor a la subversión y a la conspiración. Pero en el caso que nos ocupa, su perturbación no era sólo ideológica (no encuadramiento dentro de los órdenes) sino objetiva y práctica, desde el delito y las acciones que desafiaban el orden dominante hasta la negativa al trabajo y la subsistencia por fuera del vínculo de dependencia laboral, que amenazaba la propia dinámica productiva. Pero también hubo otros peligros que adjudicarles a los vagabundos, como el contagio de enfermedades. Además, se los acusaba de dispersar su conducta, a partir de la potencial imitación por parte de otros que, comprobando con ellos la posibilidad de vivir holgando, abandonarían su actividad.

Teniendo en cuenta el proceso de domesticación de la fuerza laboral, podemos afirmar que esta óptica se debe a que quienes produjeron la documentación que empleamos representaban a los sectores que buscaban someterlos al trabajo de acuerdo con la cosmovisión de la época. El problema se enmarca en un movimiento de elaboración legislativa que abarca al continente, que en un período de cambio intenta regular cuestiones que incluyen las socioeconómicas y las exceden, avanzando sobre la cultura toda del sistema. Aunque vemos normativas que modifican la fórmula a lo largo del tiempo para conseguir efectividad, y pedidos en las Cortes que se reiteraban una y otra vez, el conflicto planteado por los hombres baldíos no encontró resolución inmediata y a lo largo de este período vemos sucederse de manera más o menos veloz diversos ensayos para su control. Dado que los mecanismos económicos eran

\footnotetext{
122 "Otrosy nos mostraron en commo en los nuestros rregnos andan muchos omes e mugeres baldios pediendo e en otras maneras e non quieren trabajar nin deprender ofyçios, por lo qual se fazen muchos furtos e rrobos e otros males de las tales personas e que se yerman muchas heredades, lo qual es deseruiçio de Dios e nuestro". Petición 20 de las Cortes de Burgos de 1379. Ibídem, Tomo II, p 294 (las cursivas son nuestras).
} 
insuficientes para disciplinar a los trabajadores, se buscaba la intervención política para ello.

Observamos que las penas evolucionaron a través de intentos que se sucedieron durante varias centurias. El incremento en la severidad de la condena y las penas dan cuenta de la ineficacia de las medidas anteriores. Esto podría ser resultado de la imposibilidad del propio sistema de conjurar un fenómeno que él mismo producía en su seno, a partir de sus contradicciones. Si en un principio se apuntó a la exclusión absoluta, luego se intentó la inclusión, primero, bajo la tutela de un señor; pero ante el fracaso de esta medida, se optó por la inserción regulada de los mendigos dentro de la comunidad. A este tipo de normas se sumaban dos modos de corrección: el castigo físico - enmarcado en un esquema de pedagogía social- y la inserción laboral.

La ley intentaba imponerse sobre los marginales a través de una lógica diferente de la que ellos mantenían en sus formas de vida, pues algunos tenían una existencia itinerante, mientras las normas partían de la idea del control de los hombres a partir de su fijación en el espacio, lo cual provocó la esterilidad de dichas regulaciones. Se trataba de medidas que buscaban erradicar a los vagabundos ciudad por ciudad, sin dar una solución sistémica, con lo cual dichos menesterosos se movían de un lugar a otro, por un lado por ser obligados a ello, pero también para evadir las penas. Su nomadismo era además atemorizador y considerado una fuente de propagación y contaminación, tanto en el plano cultural como biológico para quienes mantenían domicilio fijo. La segregación de los vagabundos también se explica por la apreciación subjetiva por parte de la sociedad de su situación ambigua por su intermitencia como productores y consumidores y su falta de domicilio, por lo cual se consideraba ajeno a los deberes y derechos que generaba la residencia prolongada ${ }^{123}$.

El otro elemento para dominar a los hombres, relacionado con el anterior, consistía en su subordinación a un amo, que sería su garante social. Por ello los procuradores insistían en la necesidad de la integración de estos individuos en unas estructuras estamentales que, según las propias fuentes permiten interpretar, también estaban en crisis. Además, si se solicitaba su sometimiento, se indicaban los conflictos que se generaban a causa de los vínculos entre estos sujetos y sus eventuales protectores. 123 Respecto al temor generado por los vagabundos, ver Jean Delumeau, op cit, pp 177, $251 \mathrm{y}$
especialmente 297 y ss. 
En tercer lugar, la propia sociedad que debía velar por el cumplimiento de la normativa no sólo no lo hacía de manera completa, sino que mediante conductas individuales cuestionaba la legitimidad del control y exacerbaba el problema. Es importante atender a la presión que se ejercía sobre los propios agentes de la justicia con penas pecuniarias para que los castigaran, que serían invertidas en parte para pagar a quienes acusaran al vagabundo. Todo esto da cuenta de la necesidad de alentar a la sociedad a que colaborara con la subordinación de los marginales, pues la denuncia implicaba y estimulaba, en defensa activa del orden, una postura no indiferente ante la actitud del marginal y de su tendencia a salirse de los cauces sociales.

Entre los marginales, la movilidad de los ladrones, que eran asimilados con los vagabundos (a quienes, además, se considera personas bajas, viles y de poca honra), no sólo afectaba a la posibilidad de hallarlos y capturarlos para condenarlos, sino que además la pena no podía aplicarse como había sido pensada, porque tampoco era factible probar la reincidencia, como consecuencia de su circulación. A pesar de que algunos ladrones habían sido señalados con la marca infamante para impedir que volvieran a delinquir en otros lugares, es indudable que diferentes formas de castigos como los azotes también dejaban señales identificables en el cuerpo, por lo que se podía imaginar sus antecedentes. En una sociedad en la cual, a falta de organismos efectivos de regulación, la comprobación visual resultaba suficiente prueba del estado de las personas, la exhibición permanente de las señales de la pena sería la solución más efectiva para el problema.

Sin embargo, la condena moral de los sectores no privilegiados y su asociación con prácticas degradantes aparecía también respecto a los tributarios, plenamente instalados. La exclusión como herramienta ideológica y configuradora de estados y representaciones sociales trascendía la condición objetiva, de manera que el tipo de penas que les estaban destinadas los homologaba a los dependientes, configurando al otro desde la sociedad de privilegio.

Si bien la documentación considerada nos ha mostrado bastante acerca de la forma en que se representaba a los marginales, las explicaciones que se otorgaban a su existencia y las soluciones que se consideraban en pos de reprimir los problemas que se suponía que generaban, son insuficientes para las preguntas que nos hacemos. En los capítulos subsiguientes examinaremos la representación que la narrativa construía en torno a la forma de sobrevivir de los marginales y su reproducción social. 
CAPÍTULO 4

LA INSERCIÓN INTERMITENTE: LOS CRIADOS 


\section{Introducción}

En los capítulos anteriores hemos revisado el carácter contravencional y la condición itinerante de la existencia de los marginales, así como las dificultades que presenta la interpretación de las fuentes que tratan acerca de ellos. En el presente apartado revisaremos el retrato de las formas de socialización que tienen lugar cuando los pícaros son empleados como sirvientes. La importancia de esta ocupación en nuestro estudio radica en dos aspectos. En primer lugar señala que su segregación era considerada bastante más tenue de lo que se puede creer a través de la lectura de la documentación política, la teoría, y las propias novelas (que encarnan esta contradicción) y nos acerca a una nueva dimensión en cuanto a las relaciones sociales entre los sectores afincados en el orden y aquellos que eran segregados. En segundo término, estos personajes establecían vínculos entre ellos en el marco de integración que les otorgaban las casas donde se empleaban: se trataba de relaciones marginales en un espacio que no lo era.

En las siguientes páginas pretendemos indagar sobre la representación de las relaciones que establecían los domésticos dentro de una casa, así como los vínculos entre ellos y su amo. Analizaremos por qué el trabajo de servicio, lejos de cambiar las conductas de los marginales, parece exacerbar ciertas características de su condición, ya que la casa del señor acaba por convertirse en un ámbito de socialización marginal que funciona en el seno de un área integrada ${ }^{1}$.

Comenzaremos con la observación de las distintas funciones que podían tener los criados. Luego daremos lugar al análisis del servicio tal como es descripto en las novelas: la forma de contratación y las conductas de los mozos. También examinaremos la socialización de los criados en las casas a cuya servidumbre se integraban. Nos detendremos en los episodios en los cuales los pícaros se insertaron en una unidad doméstica como aprendices de algún oficio. Por último, veremos los motivos que, según la narrativa, conducían a su expulsión. Comencemos, entonces, por el primer aspecto, que radica en identificar la importancia de la posesión de criados para los poderosos, especialmente como medios para la reproducción del capital simbólico y social.

\footnotetext{
${ }^{1}$ Antonio Collantes de Terán Sánchez, op cit, p 301.
} 


\section{La posesión de criados como capital social}

En el marco doméstico existían diversas clases de subordinados, dedicados a variadas funciones y con grados de cercanía y fidelidad al patrono, también disímiles ${ }^{2}$. Las diferencias en cuanto a este aspecto daban lugar a que los menesteres asignados a esta forma de ocuparse fueran sumamente heterogéneos. Por eso deslindaremos las incumbencias laborales de distintos tipos de criados que los historiadores han localizado en el período, antes de adentrarnos en la representación de los trabajos que desarrollaban los pícaros.

Los mozos ocupados en la agricultura tenían una clara función económica dentro de la estructura doméstica ${ }^{3}$. Se trataba de un mecanismo de integración social en el ámbito rural heredado del período medieval mediante el cual las familias regulaban la cantidad de trabajadores necesarios para la explotación de la tenencia, mientras trababan también lazos en el seno de la comunidad.

En el período que estudiamos, una gran parte de la población desheredada debía "alquilarse". Sin embargo, esto traía aparejados otros problemas, pues la contraprestación de trabajar a cambio de una paga no obligaba a los hombres a atarse a un espacio o un señor, por eso para ellos ésta era una opción junto a diversas formas de recolección. Dada la existencia de dichas alternativas, los sectores dominantes buscaron obligarlos a someterse al trabajo asalariado, aunque no siempre lo lograron.

Las casas aristocráticas y oligárquicas contaban con criados a quienes los unían costumbres y cultura compartidas con del amo y que eran valiosos debido a su fidelidad hacia él, como aquellos que se encargaban de controlar la economía de su casa. Normalmente éstos resultaban dependientes muy estables que heredaban el oficio paterno y medraban bastante. Los criados eran, en principio, personas cuya educación había estado a cargo de personas que no eran sus padres, respecto a quienes quedaban en posición de inferioridad o de dependencia. Sin embargo, los había de muchos tipos que no pueden ser asimilados, pues desde las casas más ricas hasta las que lo eran menos, contaban con este tipo de miembros, cuyas funciones resultaban, de acuerdo con las capacidades económicas de las mismas, también, diferentes.

\footnotetext{
${ }^{2}$ María del Carmen Carlé, "La sociedad castellana en el siglo XV: los criados", en Cuadernos de Historia de España. No LXIX, Buenos Aires, Universidad de Buenos Aires, 1987, pp 109-121, p 121.

${ }^{3}$ Ver sobre este tema: Isidro Dubert, "Criados, estructura económica y social y mercado de trabajo en la Galicia rural a finales del antiguo Régimen", en Historia Agraria. N $^{\circ}$ 35, Murcia, Universidad de Murcia, 2005, pp 9-26.
} 
Por último, los aprendices de oficio también se integraban a la casa del maestro, quien los educaría e introduciría en el arte. En dicho espacio, el joven se incorporaba a una unidad doméstica, que constituiría su nueva familia, y se responsabilizaría de satisfacer sus necesidades básicas ${ }^{4}$. La diferencia entre los pícaros que aquí vemos y la esfera del artesanado radica en que estos aprendices no cortaban los lazos con sus padres, que seguían siendo sus garantes y, en muchos casos, los jóvenes servían de nexo entre varias unidades de artesanos ${ }^{5}$. En las novelas picarescas encontramos similitudes formales con los aprendices, alteradas por la esencia de la relación establecida: los criados que aquí abordamos no tenían vínculos parentales o éstos eran laxos y no servían a la configuración de redes.

También había criados cuya relevancia radicaba en que eran ostentados como bienes de lujo, cuya función implicaba un aprendizaje y lealtad poco apreciables respecto a los anteriores. Su retribución resultaba menor y su circulación más fluida. Este tipo de domésticos es el que más nos interesa, porque los pícaros que estudiamos son representados habitualmente desempeñando esta clase de funciones.

La importancia de estos mozos en la estructura social radicaba en que eran funcionales a la acumulación de capital simbólico por parte de quien los empleara ${ }^{6}$. Estos servidores eran indicadores del status alcanzado por una familia que los tenía a su servicio, pues la exhibición de un gran número de ellos resultaba en la plasmación visual de la riqueza del colectivo en que se inscribían. Esta era una manera de diferenciarse de la población no privilegiada, y que servía para reforzar la posición "natural" de cada grupo, preservando el orden ideal que había creado Dios y consagrado la sociedad. Pero en la España del siglo XVI, los signos de respetabilidad se podían comprar y ya no eran sólo hereditarios, por eso era imperioso y relativamente fácil mantener un gran número de dependientes diversos para ostentar en la corte y en las

\footnotetext{
${ }^{4}$ Pablo Buchbinder, Maestros y aprendices. Estudio de una relación social de producción (España, siglos $X V-X V I I)$. Buenos Aires, Biblos, 1991, p 44.

${ }^{5}$ Sobre la funcionalidad de la crianza en la sociabilidad de los artesanos, ver Ibídem, p 51.

Entretanto, los criados rurales eran "conscientes de su continuidad en la masía, el aprovechamiento por parte de ellos o sus familias de determinados recursos de ésta." Pere Roca Fabregat, op cit, p 73.

${ }^{6}$ Bourdieu sostiene que "Si se sabe que el capital simbólico es un crédito, pero en el sentido más amplio del término, es decir una especie de avance, de cosa que se da por descontada, de acreditación, que sólo la creencia del grupo puede conceder a quienes le dan garantías materiales y simbólicas, se puede ver que la exhibición del capital simbólico (siempre muy costosa en el plano económico) es uno de los mecanismos que hacen (sin duda universalmente) que el capital vaya al capital" Pierre Bourdieu, El sentido... op cit, p 190.
} 
residencias provinciales ${ }^{7}$. Pero vivir conforme a los modos de la nobleza conllevaba un elevado costo económico, que frecuentemente rebasaba las posibilidades de las familias nobiliarias, conduciéndolas al endeudamiento, situación que, sumada a la asunción de la forma de vida de las clases privilegiadas por parte de los grupos sociales que no lo eran, condujo a la competencia y a una confusión en los modos de diferenciación social que alteró dicho sistema ${ }^{8}$.

Los espacios públicos servían para expresar las diferencias sociales mediante la imagen que los potentados proyectaban acerca de sí mismos allí ${ }^{9}$, para ello se acompañaban de sus criados, símbolo de su poder y prestigio social. Pero la necesidad de distinguirse socialmente también se proyectaba en el interior de las residencias de las clases dirigentes con la intención de impresionar al visitante. Además debemos tener en cuenta que durante el período que estudiamos se confundían lo público y lo privado.

El funcionamiento de las casas de la nobleza castellana recaía en una amplia servidumbre, que también estaba diferenciada ${ }^{10}$. Entre los servidores podemos identificar al pícaro representado en la literatura, que constituía un tipo específico de marginal porque no generaba mercancías y sobrevivía -en parte- a través de actividades relacionadas con el servicio doméstico. De ese modo, construía el status de su amo, siendo contratado por la baja nobleza y la burguesía urbanas, que lo utilizaban como instrumento de ostentación para erigir la imagen de su poder. Aquí encontramos una contradicción, ya que un actor marginal de la sociedad se convertía de esta manera en parte de la configuración del status de un individuo de una capa superior. Las novelas los muestran poco constantes en el servicio de sus patronos y prestos a desvincularse de ellos ante los conflictos. La existencia y experiencia itinerante y desvinculada de estos hombres impedía que mantuvieran relaciones estables con el resto de la sociedad y entre ellos, dando lugar a la ruptura de sus vínculos, con mayor o menor celeridad.

\footnotetext{
${ }^{7}$ En esta caterva de servidores se podían encontrar "lacayos, ayudas de cámara, mayordomos, caballerizos, damas de honor e incluso gentileshombres". Enrique Soria Mesa, "La imagen del poder. Un acercamiento a las prácticas de visualización del poder en la España moderna", en Historia y Genealogía. $\mathrm{N}^{\circ}$ I, Córdoba, Universidad de Córdoba, 2011, pp 5-10, pp 8 y 9.

${ }^{8}$ Ángel María Ruiz Gálvez, "Guardar las apariencias. Formas de representación de los poderes locales en el medio rural cordobés en la Época Moderna”, en Historia y Genealogía. № I, Córdoba, Universidad de Córdoba, 2011, pp 167-188, p 170.

${ }^{9}$ Ibídem, p 172.

${ }^{10}$ Ver sobre este fenómeno en el espacio privado: Ibídem, p 180. La palabra criado refería a todo aquel que que trabajaba para la casa. El autor ejemplifica nuevamente con el personal de los marqueses de Priego en 1633, constituido por 76 criados, entre ellos once eran doñas (quienes tenían ese destino por parentesco con servidores anteriores), 28 criadas y 37 criados. Estas cifras reflejan la enorme capacidad de esta casa para movilizar tanto personal, además de mostrar también la trama de relaciones entre criados y señores de manera intergeneracional. Ibídem, p 183.
} 
Durante la Edad Media, el señor amparaba a un joven que pertenecía a un sector algo inferior al suyo, lo educaba y de este modo lo sumaba a su comitiva y servicio o al de sus herederos, así como se aseguraba también la lealtad de su padre. Estos criados podían y solían tener funciones militares, pero fundamentalmente se integraban al servicio de la familia del señor y le respondían a él. En la modernidad la institución de la crianza sufrió modificaciones, pues si bien en ciertas oportunidades los criados provenían de sectores cercanos a quien los tomaba a su servicio, en general parientes segundones y descendientes de sus propios dependientes, cuando analizamos la representación de quiénes eran contratados por la baja nobleza y burguesía urbanas podemos encontrar eventualmente a una parte de los desclasados marginales entre sus servidores $^{11}$.

Los mozos tenían un rol doméstico, función que, en tanto que no requería habilidades especiales por parte de quien la desempeñara (aunque pueden luego adquirir determinadas competencias y cambiar su posicionamiento entre los subalternos), podía ser cumplida por los hombres "sin oficio", eventualmente marginales que estaban disponibles para ello, ya que las normativas los obligaban a ocuparse. La dependencia, sostiene J. M. Imízcoz, "no sólo se imponía desde los poderosos, sino que se buscaba desde abajo como vía para sobrevivir y medrar" ${ }^{\prime 2}$. Las novelas picarescas -que si bien no muestran la realidad, sí debieron de tener cierto grado de verosimilitud- exponen cómo los marginales entraban y salían permanentemente de las redes sociales, por este motivo los designamos cómo tales y no como excluidos absolutos.

Imízcoz explica este tipo de relaciones a partir de una "economía vertical de intercambio de servicios y contraprestaciones entre desiguales" que componían una "economía moral" regida por "obligaciones mutuas vinculantes"13. En El Guzmán observamos que las fidelidades se guardan no sólo por parte de los mozos hacia sus señores, sino que éstos también reconocen a los criados como parte de la clientela de cada uno de ellos. Así, el embajador de Francia estima esta lealtad al no solicitar el

\footnotetext{
${ }^{11}$ En El Guzmán se alude a la importancia social de los criados que contribuyen a la construcción del status ajeno y de la oscuridad de su papel: “¿Qué sabes o quién sabe del mayordomo del rey don Pelayo ni del conde Fernán González? Honra tuvieron y la sustentaron, y dellos ni della se tiene memoria" Mateo Alemán, Guzmán de Alfarache. Madrid, Cátedra, 2006, edición a cargo de José María Micó, Primera Parte, $\mathrm{p} 293$.

${ }^{12}$ José María Imízcoz, "Las redes sociales de las élites. Conceptos, fuentes y aplicaciones", en Soria Mesa, Enrique, Bravo Caro, Juan Jesús y Delgado Barrado, José Miguel (eds.). Las élites en la época moderna: la monarquía española. Vol. I Nuevas Perspectivas, Servicio de Publicaciones de la Universidad de Córdoba, Córdoba, 2006, pp 77-111, p 94.

${ }^{13}$ Ibidem, p 95.
} 
servicio de Guzmán hasta la muerte del Cardenal, su antiguo empleador ${ }^{14}$, aspecto en el que encontramos una similitud con la situación de los aprendices de oficio, pues los maestros debían respetar la adscripción de los dependientes ajenos. La lealtad seguía siendo un deber moral y a pesar del relajamiento de las relaciones feudales, el cambio de patronos se entendía como una forma de traición.

Si los amos ganaban prestigio a través de la inscripción de criados en su clientela, este mercado también sufrió variaciones, pues las diversas categorías de dependientes podían depreciarse por haberse popularizado. Según la representación picaresca, toda la sociedad evaluaba a los poderosos por la caterva de criados que ostentaban. Cuando se narra el robo por Trapaza del caballo de un forastero que asiste a un pleito en Córdoba, se describe a este último como una “... persona que, por miserable, no traía un criado consigo, teniendo hacienda para tener dos, y así con toda su calidad (de que se preciaba no poco), iba a echar paja y cebada a su rocín, sin remitir este cuidado siquiera a un mozo del mesón, entendiendo que le había de sisar el pienso" 15 . Aquí corroboramos la idea de la necesidad de mostrar criados para imponer respeto y una imagen de largueza, indispensable para el status caballeresco. Si bien se trataba de una sociedad en la cual la ostentación era lo más importante, se introducía también el cálculo, pues los demás podían estimar cuántos mozos podría pagar una persona. Se observaba si poseía un capital mayor del que exhibía, como en esta oportunidad (y entonces adquiría fama de mezquino), o a la inversa, si ostentaba más de lo que tenía (como en el caso de don Tomé, en la misma novela). Pero aquí aparece otra cuestión: este hombre tampoco paga a un mozo del mesón para cuidar su caballo, bajo la excusa de que sisaría parte del alimento, siguiendo con el estereotipo de que quienes trabajaban en estos parajes eran sujetos sospechosos, que se repite en varias novelas.

La utilización de los criados para la exposición de la generosidad, terminaba por drenar ciertos beneficios para dichos dependientes que complementaban su paga miserable gracias al derroche ostentoso (y necesario en términos de status) de los $\operatorname{amos}^{16}$.

La picaresca también retrata a diversos personajes que pretendían mentir respecto a su riqueza, bien porque no pertenecían a un sector social acaudalado, o

\footnotetext{
14 "Entré a servir al embajador de Francia, con quien monseñor, que está en la gloria, tuvo estrechas amistades, y en su tiempo gustaba de mis niñerías. Mucho deseaba servirse de mí, mas no se atrevió a recibirme por el amistad que estaba de por medio.” Mateo Alemán, op cit, Primera Parte, p 464.

${ }^{15}$ Alonso de Castillo Solórzano, Aventuras del bachiller... op cit, pp 139 y 140.

${ }^{16}$ Por ejemplo, cuando gana cierto dinero en el juego, Trapaza lo reparte entre la mujer a la que pretende seducir, sus criadas y su escudero. Ibídem, p 284.
} 
debido a que habían perdido el capital económico que acompañaba su status. Entre esta clase de personajes, encontramos al amo empobrecido de Trapaza, que muestra en la comedia su nuevo criado, donde los señores conocidos pueden apreciarlo; sin embargo, ellos se sorprenden de tal sirviente y encuentran graciosa esa "nueva autoridad" que detenta, reacción que da cuenta de que los pares podrían conocer la realidad objetiva que se pretende ocultar mediante la posesión de un dependiente que no es posible pagar $^{17}$. El criado resulta, en este caso, un objeto de alarde debido a las cualidades que puede mostrar frente a los demás, pues su ingenio (atributo que caracteriza al pícaro literario) es reconocido por los compañeros de su amo ${ }^{18}$. Se trata de una ironía que pone de manifiesto las burlas que podían cruzarse los amos en torno a la posesión de ciertos criados y que es retomada en la novela. Sin embargo, a medida que se despliega el relato vemos que, en el marco de socialización entre señores y dependientes, el pícaro es reconocido por sus habilidades para la conversación ${ }^{19}$, cualidad que lo hace valioso como criado. Si bien Trapaza ha podido inscribirse en el ámbito de la educación formal temporalmente -que termina por abandonar debido a sus inconductas-, la mayor o menor formación de los criados se vinculaba, en muchos de los casos, con la recibida en las propias situaciones de servicio que habían atravesado anteriormente. Por otro lado, asociamos esta noción del marginal educado con el ámbito de socialización del autor, que pudo haber contribuido a la gestación de esta idea en él. A pesar de su procedencia no privilegiada, Trapaza accede a estudios mayores, donde, sin embargo, fracasa como consecuencia de su comportamiento, instalando e ilustrando en la novela el concepto de que es inherente al vulgo no ser educable.

La obra describe cierto vínculo afectivo entre Trapaza y su amo. No obstante ello, el pícaro decide irse "determinando dejar aquel empleo y buscar el que le estuviese más a cuento" 20 , insinuando la escasez de la paga, determinada por la pobreza del amo. En este mismo sentido, encontramos una reflexión por parte de Estebanillo González sobre la necesidad de que quien tuviera criados, contara con el capital suficiente para sustentarlos ${ }^{21}$, reproduciendo la crítica en torno a la obligación de respetar el vínculo entre el capital económico y el social que examinamos en las actas de las Cortes.

\footnotetext{
${ }^{17}$ Ibídem, p 188.

18 “esta alhaja teneis nueva? -Sí (...) este criado he recibido”. Ibídem, p 194.

${ }^{19}$ Ibídem, p 187.

${ }^{20}$ Ibídem, p 188.

21 “...despedí los criados, porque sólo los ha de tener quien tiene renta segura para sustentarlos, que para matarlos de hambre y traerlos desnudos, cualquiera se los tendrá”. Antonio Carreira y Jesús-Antonio Cid (eds.), Vida y hechos de Estebanillo González. Barcelona, Cátedra, 1990, Tomo II, p 248.
} 
En esta ambigüedad entre cercanía y lejanía entre amos y criados, vemos cómo la sociabilidad tenía lugar en el ámbito público. En la comedia los mozos se sientan apartados de sus patronos y se relacionan "en la comunidad de los bancos de la plebe"22, donde comparten algunas cuestiones concernientes a las casas en que se inscriben, contribuyendo de este modo a la reproducción del capital social de los amos, que no sólo reposaba en el reconocimiento de la imagen de los señores por sus pares o por los sectores inferiores, sino también en la reproducción de dicha representación entre los sectores subalternos. Guzmán explica así su despido de la casa del embajador: "No faltó un amigo suyo y por el consiguiente mi enemigo, que, cogiéndolo a solas, le dijo cuánto le importaba para su calidad y crédito despedirme, por la publicidad con que se hablaba de sus cosas y que cada cual sentía dellas como quería. Que los caballeros de su profesión y oficio debían proceder según lo que representaban, porque de lo contrario, resultaría en perjuicio de la reputación de su dueño"23. Aquí se ilustra la intromisión de diversos personajes en las cuestiones que conciernen a la familia de uno de ellos, como la relación con sus criados, recordando la falta de distinción entre el ámbito público y el privado y la densidad de las relaciones y su representación en la trama comunitaria, en la cual se introducian los marginales. Podemos corroborar la importancia de la conducta de los criados para la reproducción del capital social de sus amos, ya que su existencia y comportamiento implica la reputación de su garante, quien es presionado por parte de los pares para que adecúe su conducta a lo que demanda su estado. En el marco de una sociedad corporativa, la laxitud en la imposición del respeto correspondiente al propio status, era una falta que se atribuía a todo el sector, cuyos miembros podrían reaccionar, porque “... real y verdaderamente la muestra del paño del amo son sus criados" ${ }^{24}$. Sin embargo, la novela también da cuenta de la contradicción entre las obligaciones del status y el marco de los afectos, dado que el amo podía desarrollar cierto aprecio respecto de los $\operatorname{criados}^{25}$. En algunos de los protagonistas de la novela picaresca, el desengaño es del criado respecto del amo, lo que explica que, cuando notan que le

\footnotetext{
${ }^{22}$ Alonso de Castillo Solórzano, Aventuras del Bachiller... op cit, p 188.

${ }^{23}$ Mateo Alemán, op cit, Segunda Parte, p 128. "Pasose aquesto y quedose mi amo pensativo, la mano en la mejilla y el cobdo sobre la mesa, con el palillo de dientes en la boca, malcontento de que mis cosas corriesen de manera que le obligasen a lo que no pensaba hacer; aunque le convenía para evitar mayores daños, empeñándose tanto, que diese notable nota contra su reputación, por mi defensa." Ibídem, p 130. ${ }^{24}$ Ibidem, p 130.

25 Así, a partir de la traición al amo por parte del criado, la novela describe la pena del último y, especialmente, su percepción por parte de los subalternos: "Mandóme bajar a comer y nunca de allí adelante yo ni otro alguno de mis compañeros por muchos días le vimos el rostro alegre ni tan afable como tenía de costumbre". Ibídem, p 130.
} 
cobran afecto, prefieren abandonar su servicio, alternativas que ilustran la contradicción de la condición de los criados.

\section{La contratación}

La novela picaresca representa a menudo las maneras en que amos y criados potenciales entraban en contacto y cómo establecían el contrato verbal mediante el cual uno se sometería al poder del otro, ya que no se trataba de una relación entre iguales. Si el ingreso como servidor tenía un carácter azaroso, la permanencia -y el eventual ascenso- no lo serían, pues dependían de la voluntad del señor, que resultaba movilizada por diversos aspectos que iban desde la necesidad social de emplear al servidor, la posesión del capital para hacerlo, el desempeño del criado -y su competitividad entre la caterva de pares- y la emotividad del amo, aspectos que analizaremos comenzando por las maneras en que la contratación de sirvientes fue representada por la novela picaresca.

La narrativa describe en la mayoría de los casos un compromiso individual, a diferencia de otros convenios como los de aprendices o criados agrícolas, en los cuales el marco social posee mayor importancia en tanto tiene lugar entre personas conocidas de la comunidad e incluso los padres que entregan a sus hijos para cumplir una labor que se retribuye con su calificación y probablemente con la dote que les permite acceder al matrimonio, mientras a nivel social contribuye a la consolidación de lazos interfamiliares en el marco de la comunidad ${ }^{26}$. En los casos que nos ocupan, por el contrario, esta relación de servicio no se enmarca en las redes comunitarias, pues el pícaro es contratado individualmente al arribar a una nueva ciudad donde es absolutamente desconocido.

La narrativa picaresca se detiene meticulosamente en la manera en que amos y criados entraban en contacto, destacando la manera azarosa, flexible y heterogénea en que podía tener lugar esta relación. El retrato literario ejemplifica cómo se ponían en práctica las normas que promovían el empleo de los hombres baldíos. Sin embargo, revelan la brevedad de estas relaciones, bien por el desdén del criado o incluso por su mala fe. Si bien la crítica recae sobre los pícaros, la narración nos permite observar como otro factor posible el maltrato de los amos o la mala paga como estímulos para

\footnotetext{
${ }^{26}$ Pere Roca Fabregat, “QQuién trabajaba en las masías? Criados y criadas en la agricultura catalana (1670-1870)", en Historia Agraria. № 35, Murcia, Universidad de Murcia, 2005, pp 49-92, pp 52 y 79.
} 
que los marginales abandonaran sus tareas, se fugasen o robasen. En este sentido, se trata de una crítica (en este caso con un objetivo también disciplinante) a los vínculos entre personas relativamente desconocidas, tal como sostienen las cortes en las quejas respecto a los $\operatorname{criados}^{27}$.

Lazarillo conoce al primer amo en el mesón donde trabaja su madre. El ciego le pediría a la mujer su hijo y ella se lo daría ${ }^{28}$. En el relato se expone cómo la mujer encomienda su hijo al ciego pidiendo que lo cuide y recordando la desdicha del niño por ser huérfano. El nuevo amo promete tratarlo como a un hijo (aunque más adelante esto no sucede), lo cual denota el establecimiento de un lazo filial. Así comienza la relación de servicio, oculta tras una supuesta o fingida adopción, pues aparentemente se reemplazaría una familia por otra. Este convenio oral que establecía el traslado del vínculo, era análogo a los contratos de aprendizaje que fijaban los padres con los artesanos a quienes les encomendaban sus hijos ${ }^{29}$. A lo largo de la novela pueden verse otros paralelismos entre la relación amo-mozo y la que tendían los aprendices con sus maestros $^{30}$

En el último diálogo con la madre se puede leer la pena de la mujer: "Hijo, ya sé que no te veré más. Procura de ser bueno y Dios te guie. Criado te he e con buen amo te he puesto: valete por ti" ${ }^{31}$. La emotividad de la escena puede ser expresión del amor hacia los niños, que algunos historiadores niegan para el período que nos ocupa ${ }^{32}$ y está de acuerdo con el imaginario acerca de los mendigos que tullen a sus hijos para provocar aflicción en pos de conseguir limosnas, tal como veremos en el próximo capítulo. De aquí en más, el personaje sigue su rumbo en soledad durante varios años, hasta establecerse de manera marginal en una comunidad. Lázaro relata su paso de las manos maternas a las del ciego, "E assi me fuy para mi amo, que esperandome

\footnotetext{
${ }^{27}$ Cortes de Toledo de 1559, Petición XCVI. Real Academia de la Historia, op cit, Tomo V, p 856, revisada en la página 113 de esta tesis.

28 “....vn ciego, el qual, paresciéndole que yo sería para adestralle, me pidió a mi madre y ella me encomendó a él, (...) e que le rogaua me tractasse bien y mirasse por mi, pues era huérfano. El respondió que assi lo haria y que me recibia, no por moço, sino por hijo..." (las cursivas son nuestras). Anónimo, La vida de Lazarillo de Tormes. Madrid, Espasa-Calpe, 1969, pp 75 y 76.

${ }^{29}$ Ver: Pablo Buchbinder, op cit, p 55.

${ }^{30}$ El narrador sostiene que el ciego le enseña las artes de la mendicidad y la jerga. También demuestra sus habilidades al ciego en una serie de "pruebas" en las cuales intenta timar a su amo.

${ }^{31}$ Anónimo, op cit, $\mathrm{p} 76$.

${ }^{32}$ Varios historiadores aducen que debido a que estaban habituados a que probablemente sus hijos morirían jóvenes, evitaban depositar en ellos mucho afecto por lo cual las muertes de niños se aceptarían con más calma. Cuestionan si es innato a la naturaleza humana el amor a los niños. Philippe Ariés, $E l$ niño y la vida familiar en el Antiguo Régimen. Madrid, Taurus, 1987, Capítulo 2 "El descubrimiento de la infancia". Ver también Michael Mullet, La cultura popular en la Baja Edad Media. Barcelona, Crítica, 1990, p 178.
} 
estaua" ${ }^{33}$, reconociéndolo en este acto como su patrono. A partir de este momento, se ejemplifica la formación del pícaro a través del cambio de amos, que es el hilo conductor que atraviesa la novela en sus siete tratados.

Esta imagen de El Lazarillo se repite en Vida y hechos de Estebanillo González, quien al entrar como aprendiz de barbero, entregado por su padre, sostiene que se quedaba sin él y con amo $^{34}$. Esta afirmación confirma el reemplazo de los lazos filiales en el marco del taller en el cual entraban aprendices, aunque en el contexto que estudiamos el servicio perdía su sentido formativo y de inclusión social, para convertirse en un trabajo asalariado encubierto. Las novelas parodian la situación de la adscripción en una casa, subordinación que no aparta al pícaro de la soledad, sino que contribuye a su marginalización. La crítica picaresca tiene lugar en un estadio de desarrollo del trabajo asalariado particular, cuando los mecanismos propios del capitalismo aún incipiente no eran suficientes para dominar a los hombres que aún tenían otras formas de sobrevivir, ni para absorber a la masa de sujetos libres.

El problema del servicio en El Guzmán ha sido minuciosamente analizado por Cavillac, cuyas conclusiones retomaremos, aunque hay varios aspectos que debemos revisar aún. El segundo libro de esta obra abarca la etapa del derrotero del protagonista en la que el servicio, si bien es alternado con períodos de vagabundeo, cobra un papel predominante en su supervivencia. Su contratación es azarosa según vemos desde el primer convenio y constatamos a lo largo de la novela. Quien lo emplea presupone el carácter fugitivo del muchacho que estaría "huyendo de casa de su padre o de su amo" 35 , mostrando así la personalidad esquiva que se imputa a este tipo de servidores, característica que, aunque resulta conocida, no genera aversión, sino que se admite que estos jóvenes están en disponibilidad para servir y son adecuados a esta función, poniendo en cuestión la imagen de su rechazo, que el autor presenta a título personal en el prólogo a la obra. El ventero le ofrece asentarse a soldada y le informa que su ocupación sería alimentar a los caballos teniendo "buena cuenta" de lo que diere. La tarea consistía en robar, sisar y engañar en favor del amo. Las ventas eran lugares de paso y por lo tanto sus encargados también aparecen estereotipados en las novelas como sujetos infames, así como todo el ámbito del mesón era objeto de desconfianza.

\footnotetext{
${ }^{33}$ Anónimo, op cit, p 76.

${ }^{34}$ Antonio Carreira y Jesús-Antonio Cid (eds.), op cit, Tomo I, p 44.

${ }^{35}$ Mateo Alemán, op cit, Primera Parte, p 270.
} 
Cuando el Buscón entra al servicio de don Diego, la subordinación del niño se encubre con la amistad, pues luego de un tiempo el pícaro se hospeda con el joven aristócrata, ingreso similar al del dependiente que no es remunerado con salario sino criado. Esta pintura probablemente dependa de una preconcepción del autor, quien pudo tener en mente sólo este modelo de subordinación. La novela de Quevedo, a diferencia de las otras que aquí analizamos, no ilustra un marginal contratado eventualmente para desarrollar ciertas tareas a cambio de una paga, sino que esta es la única oportunidad en que lo encontramos como dependiente. Se trata de una situación de crianza, que rememora la forma tradicional que había iniciado esta relación: “... determinéme de no volver más a la escuela ni a casa de mis padres, sino de quedarme a servir a don Diego o, por mejor decir, en su compañia, y esto con gran gusto de sus padres, por el que daba mi amistad al niño"

Fuera de esta experiencia como criado de un estudiante, que refiere a la situación desviada que los jóvenes de la aristocracia podían compartir temporalmente con otros muchachos del mismo grupo etario, la novela no relata otras experiencias del pícaro como sirviente. Podemos interpretar esta particularidad de El Buscón en el marco de su crítica a los sectores bajos que no se subordinarían y se inclinarían tendencialmente a la vida marginal, pues en esta obra el pícaro sobrevive principalmente a través de la estafa y la mendicidad. Asimismo, los padres de Pablos también están vinculados al delito y no al servicio, relación que se repite en el género entre las familias de algunos pícaros, como veremos en el sexto capítulo.

Cuando Trapaza llega a Madrid, con la intención de ostentar un status que no posee, toma escudero y paje, además de recurrir al cambio de ropas ${ }^{37}$. Para justificar ausencia de criados a su servicio, Trapaza aduce ante el dueño de una posada a quien pide los mozos, que acaba de despedir a los suyos por haberle robado dinero. Existe en la literatura del tiempo la figura del criado-ladrón, casi un estereotipo por su reiteración -aunque coexiste con la figura del sirviente fiel y leal-. Esta atribución por parte del autor puede responder a la realidad objetiva o ser parte de una deformada percepción, pero sí debió ser verosímil la idea de que una persona desconocida, sin fama pero con medios económicos para representarse como integrante de la clase superior, pudiera aducir el robo por parte de los criados y ser creído.

\footnotetext{
${ }^{36}$ Francisco de Quevedo, La vida del Buscón llamado Don Pablos. Salamanca, Acta Salmanticensia, 1965 , pp 30 y 31.

${ }^{37}$ Alonso de Castillo Solórzano, Aventuras del Bachiller...op cit, p 269.
} 
La forma de entrar en contacto entre patronos y sirvientes se cumple a través de la recomendación y vínculo del dueño de la posada, que localiza a los segundos inmediatamente: "los trajo esotro día, con las fianzas necesarias para que Trapaza estuviese seguro de que no le faltaría nada de su hacienda"38. Vemos aquí la intermediación de un hombre que trabaja entre personas que circulan y que hace las veces de garante, que de otro modo los criados no tendrían. Es asombroso es que los patronos contraten de esa manera, sin conocer y no tener otra garantía que el aval del posadero, quien adquiere, gracias a esa posibilidad de obtener trabajo para otros, cierto poder y prestigio, además de la posición adecuada para lograr alguna modesta ganancia, lo que da lugar a la sospecha de que hace de esas contrataciones un segundo negocio. Los fiadores que aparecen en la picaresca trabajan habitualmente en lugares de paso como tabernas, posadas o diversas instituciones (colegios, monasterios u hospitales).

En El Bachiller Trapaza localizamos el encuentro en la plaza entre el potencial trabajador y un médico que necesita un criado. El hombre le pregunta al pícaro si busca amo y Trapaza asiente y muestra sus virtudes ${ }^{39}$, en tanto el amo especifica su oferta ${ }^{40}$. La inquisición sobre la disponibilidad de Trapaza es una forma de obligarlo a trabajar, porque los hombres baldíos podían ser tomados por quienes los encontraran, sin embargo, la predisposición de Trapaza contradice la resistencia que se les imputaba desde el discurso jurídico. Este contrato es particular en la narrativa picaresca porque especifica las actividades que realizaría el criado, en este caso ayudar al amo en su trabajo, además del salario. En pocas oportunidades encontramos la representación de este tipo de acuerdos, pues habitualmente la retribución no se especifica y consiste en techo y comida, única paga por la que debían emplearse los hombres baldíos.

Mientras los ordenamientos de labores establecen que los hombres debían concurrir a la plaza para encontrar posibles empleadores ${ }^{41}$, la picaresca da cuenta de

\footnotetext{
${ }^{38}$ Ibídem, p 270.

${ }^{39}$ Trapaza se muestra modesto y ansioso por obtener el trabajo: “-Señor, yo me holgara de encontrar dueño a quien servir, que, conociendo mi servicio, me le gratificara al paso que le sirviera, que de mí presumo que le sabría agradar.” Alonso de Castillo Solórzano, Aventuras del Bachiller...op cit, p 214.

${ }^{40}$ El médico pauta la tarea y especifica el monto y carácter de la retribución: “-Yo he menester un criado dijo el médico-, que se ande tras mí a las visitas que hiciere teniéndome cuenta con esta mula. Si gustáis de servirme en este ministerio, de mi trato no os descontentaréis, ni de la paga de vuestro salario, que la que acostumbro a dar son doce reales al mes". Ibidem, p 214.

41 "Et tengo por bien et mando que todos los carpenteros et albanniles et tapiadores et peones et obreros et obreras, jornaleros, et los otros omes menesteriales que sse ssuelen alogar, que salgan alas plaças de cada vn lugar do sson moradores et que an acostunbrado de sse alquilar", en "Ordenamiento de menestrales y posturas otorgado a las ciudades, villas y lugares del arzobispado de Sevilla y obispado de Córdoba y Cádiz, en las Cortes de Valladolid de la era MCCCLXXXIX (año1351)", en Real Academia de la Historia, op cit, Tomo II, pp 92 y 93.
} 
cómo este espacio era utilizado para diversas prácticas que se presentaban como alternativas a la ocupación, pero también hacían uso de él para conseguir un amo, tal como constatamos en El Bachiller Trapaza: "Viendose Trapaza sin dinero alguno que gastar, porque el que había hecho de la espada que vendió ya se había acabado, determinó entrar en servicio de alguna persona de lustre. Fuese para esto a Gradas, que es en la iglesia mayor de Sevilla, donde vio un corrillo de hombres bien vestidos. Llegóse cerca dél y vio que eran caballeros, según oyó de los nombres con que se nombraban" ${ }^{42}$. Mientras los sectores dominantes insistían en la necesidad de someter a los hombres libres al trabajo asalariado, la novela permite atisbar que un sujeto busca amo sólo si se le acabaron los otros recursos para sobrevivir. Por eso, como observamos, la legislación debe velar no sólo por obligarlos a trabajar (y regular su actividad), sino que también debe procurar que no encuentren otra forma de vida. Por otro lado, este párrafo ilustra la selección del amo o de la ocupación que busca quien ha decidido emplearse, en este caso "una persona de lustre". Finalmente, la narrativa describe el conocimiento del espacio público que cada sector frecuenta para poder encontrar amo y la apreciación visual en pos de distinguir el estrato social de las personas (que corrobora a través de los nombres).

Luego vemos la descripción del amo elegido (don Tomé, a quien se pinta desde el principio como una figura extravagante), el ofrecimiento y la inspección por parte de éste $^{43}$. Luego de observar al muchacho y con la testificación visual como única información acerca de él, lo acepta: “-De buena gana os recibiré por mi doméstico, porque vuestra fachada me indica benévolo aspecto y apto para cualquiera cosa. ¿Cuál es vuestra nativa patria?"44. Aquí vemos además la importancia del ser "apto para cualquier cosa", es decir, no sólo libre, sino también no especializado, la corroboración de la importancia del buen aspecto. Finalmente, la pregunta por la procedencia, que se repite en muchos actos de contrato en la picaresca, indica el carácter errante $-\mathrm{y}$ forastero- de este tipo de personajes.

La valoración visual a partir de la imagen se reitera en El Guzmán, pues cuando el pícaro está harapiento y sucio, no es contratado por su apariencia de "galeote",

\footnotetext{
42 Alonso de Castillo Solórzano, Aventuras del Bachiller...op cit, p 179.

43 “ ¿- Vuesa merced, señor mío, necesita de sirviente, que el que presente tiene se halla con voluntad de servirle?

Miróle el don Tomé atentamente y, dando un paseo, cuando volvió a emparejar con él, volvióle a dar otra miradura; desta suerte fueron tres veces las que le miró...” Ibídem, p 180.

${ }^{44}$ Ibidem, p 180.
} 
expresión que iguala a los miserables y menesterosos con los delincuentes ${ }^{45}$. Sin embargo, es excepcional que se exprese la idea de que no lo quieran tomar a servicio en la casa por miedo al robo, que no observamos en otras ocasiones pero que puede ser posible. Todo el retrato de la percepción del pícaro apunta a la presunta criminalidad del marginal que arriba a la ciudad -imagen que en general los relatos confirman-, además de que su único crédito consiste en sus "buenas palabras". El pícaro es imaginado no sólo como un marginal, además joven, sino también locuaz e ingenioso, cualidades gracias a las cuales sobrevive. Estas características se hacen más creíbles con la narración autobiográfica, en la que se confunden los recursos del autor con la voz del narrador.

Hemos repasado la manera en que estos criados entraban en contacto con los eventuales empleadores. Tras un conocimiento casual, el pícaro se ofrece para el trabajo, o el amo se lo sugiere sin necesidad de compelerlo, ya que ello va implícito. En la mayoría de los casos, los presumibles empleadores preguntan al interesado por su procedencia por diversos motivos que no implican rechazo, aunque es frecuente la desconfianza hacia el forastero desconocido. En algunas oportunidades encontramos la intercesión de fiadores, que pueden ser los propios padres del personaje (en muy pocos casos), determinadas instituciones, pero también se busca a los posibles servidores en espacios de conocimiento público. Así, los garantes pueden ser desconocidos, indicando que sería relativamente fácil obtener dicho rédito.

Las novelas muestran tanto la falta de lealtad de los mozos como la de los empleadores, ya que los criados eran contratados a veces por hombres que no podían responder a su parte del contrato, pero en más oportunidades lo primero que lo segundo.

\section{Las conductas de los criados y su socialización}

La novela picaresca es una fuente valiosa porque en sus representaciones encontramos una descripción minuciosa de lo que podría ocurrir en las casas de los señores, en relación a la ocupación y conductas de los criados, además de dar cuenta de su percepción por parte de los literatos. Respecto a otras proyecciones sobre los

\footnotetext{
45 "De manera que cuando llegué a Madrid, entré hecho un gentil galeote, bien a la ligera, en calzas y en camisa: eso muy sucio, roto y viejo, porque para el gasto fue todo menester. Viéndome tan despedazado, aunque procuré buscar a quien servir, acreditándome con buenas palabras, ninguno se aseguraba de mis obras malas ni quería meterme dentro de casa en su servicio, porque estaba muy asqueroso y desmantelado. Creyeron ser algún pícaro ladroncillo que los había de robar y acogerme”. Mateo Alemán, op cit, Primera Parte, p 275.
} 
marginales, como las que observaremos en los próximos capítulos, las que aquí abordamos sí pueden corresponder con una experiencia directa por parte de los autores de las novelas -aunque también con sus presupuestos y prejuicios-, quienes convivían con criados domésticos.

Guzmán es contratado por primera vez mediante un convenio "a soldada", expresión que exterioriza su sentido económico e implica la reducción del servidor a la condición de asalariado, trastornando los modos tradicionales de relación entre amo y criado $^{46}$. Este fenómeno contribuye a la explicación de los robos y traiciones por parte de los mozos hacia sus amos. La forma del contrato demuestra que no existe una adscripción del trabajador a la persona a quien sirve, por lo tanto su propia existencia no se halla inherentemente subordinada a otro sujeto.

En El Guzmán observamos cuál es la visión que se imputa al protagonista respecto de sí mismo y de los demás criados. Guzmán es un desclasado que no puede aceptar su condición social y, además de mentir al respecto en variadas ocasiones, él mismo niega su rol de sirviente, pues tiene una visión transitoria de su ocupación ("no me pareció para de presente malo") ${ }^{47}$. Sin embargo, si bien se trata de una situación temporal con cada uno de los señores, no lo es en la totalidad de la carrera del pícaro, ya que el servicio para amos diversos compromete gran parte de su existencia. Desde el inicio de la novela, el narrador da cuenta de su aversión a dicho empleo, vinculando este sentimiento con su posición social pretérita, ya que se identifica con el estamento de los $\operatorname{amos}^{48}$. Por estos motivos, se inclina por diferenciarse respecto a los demás criados, lo que se reitera a lo largo de la obra. Este inconformismo y falta de aceptación de la propia condición son los mayores blancos de la crítica hacia estos marginales, cuya principal falta sería no someterse a lo que consuetudinariamente les ha sido asignado.

En este contexto, en que no se corrobora la resignación y el conformismo que eran esperables socialmente y que debían conducir al sometimiento de los hombres,

\footnotetext{
46 "Los cambios en el sistema socioeconómico también producen un cambio en las relaciones de poder entre el amo y su mozo. Mientras en el caso del Lazarillo el protagonista llega a emanciparse del amo, quien al revés finalmente depende del pícaro, dado que su honor está subordinado a la discreción y el silencio del pícaro sobre el caso, Guzmán de Alfarache trata personalmente su suerte con el rey. En los dos casos, a pesar de su vida amoral, el pícaro presenta una autoridad ética que muestra, bajo la máscara del pícaro y a través del espejo de la sátira, una sociedad en vías de transformación". Michaela Peters, "Estructuras de poder y percepción de la autoridad en la novela picaresca del Siglo de Oro", en Arellano, Ignacio; Strosetski, Christoph y Williamson, Edwin (eds.). Autoridad y poder en el Siglo de Oro. Madrid, Iberoamericana Verbuert, 2009, pp 101-116, p 115.

${ }^{47}$ Mateo Alemán, op cit, Primera Parte, p 270.

48 "No me pareció para de presente malo; aunque se me hacía duro aprender a servir habiendo sido enseñado a mandar." Ibidem, Primera Parte, p 270.
} 
Guzmán oscila entre el elogio de la vida vagabunda y la valoración de la cómoda existencia del criado ${ }^{49}$, libertad y ociosidad que eran condenadas por la sociedad cuando eran cualidades presentes en un subalterno. Alemán proyecta en su criatura la adopción, por parte de un criado, de la manera de pensar la sociedad desde las clases superiores, que se reservaban cualidades específicas como el valor, la libertad, la honra o la inteligencia.

En toda la narrativa picaresca también comprobamos la presuposición de la delincuencia de los criados, así vemos en El Guzmán: “...llegaron dos cuadrilleros en seguimiento de un paje que a su señor había hurtado gran cantidad de joyas y dineros; $y$ por las señas que les dieron debía ser otro yo"50. Como corroboramos en diversas novelas con distintos grados de condena hacia las criaturas representadas, siempre era posible acusar al servidor propio, ajeno o potencial de cualquier falta, idea cuya repetición retroalimenta la imagen del criado-marginal-ladrón. Pero en este pasaje constatamos asimismo la generalización (esto es, la no individualización), pues el acusado paje "debía ser otro yo", dando cuenta de la homogeneización del grupo y su invisibilización, que daba lugar a que lo único que se observara de ellos fuera el estereotipo con que se los había etiquetado. Aquí también se indica que se espera que todos los criados sean ladrones, pues Guzmán hubiera hecho lo mismo que el paje en cuestión.

Encontramos numerosos y diversos ejemplos de la refracción de las conductas marginales en el espacio doméstico, prácticas que imposibilitarían los lazos estables entre pícaros porque el robo se presenta como habitual, no sólo hacia los amos sino también entre los sirvientes. Esto alude a la traición y la competencia en el interior de dicho grupo, aspectos que constituyen una observación relevante en el marco de una sociedad corporativa.

Guzmán critica las conductas condenables de los demás criados. El pícaro considera vergonzosa la servidumbre debido a la clase de sujetos que están ocupados en ella, con quienes él no se identifica. Así, los criados son considerados como ladrones de

\footnotetext{
49 "Siendo aquella para mí una vida descansada, nunca me pareció bien, y menos para mis intentos. Porque, al fin, era mozo de ventero, que es peor que de ciego. Estaba en camino pasajero: no quisiera ser allí hallado y en aquel oficio, por mil vidas que perdiera. Pasaban mozuelos caminantes de mi edad y talle, más y menos, unos con dinerillos, otros pidiendo limosna. Dije: 'Pues pese a tal, ¿he de ser más cobarde o para menos que todos? Pues no me pienso perder de pusilánime'." Ibídem, Primera Parte, $\mathrm{p}$ 274.

${ }^{50}$ Ibídem, Primera Parte, p 210.
} 
poca monta, mentirosos, necios, si son criadas incluso prostitutas ${ }^{51}$. A tono con la misoginia del género, observamos que la crítica de las mujeres es aún más acerba, pues se suma la condena social aparejada a su carácter de virtuales prostitutas y ladronas, con el objetivo mantener a otros hombres ${ }^{52}$.

A diferencia de sus compañeros, el protagonista promete, cuando lo contratan, hacer "Lo que mandaren y supiere hacer o pudiere trabajar; que quien se pone a servir ninguna cosa debe rehusar en la necesidad, y a todas las de su obligación tiene alegremente de satisfacer..."53, exponiendo de este modo lo que podríamos considerar el ideal del buen criado, que radica en la subordinación y fidelidad. Según el autor, dichas características no pueden existir porque las malas conductas de los sujetos contratados para este tipo de ocupaciones son substancialmente opuestas a tales cualidades.

Con un punto de vista diferente, El Lazarillo muestra un mozo que es víctima de sus amos, pues los robos que realiza al ciego y al buldero son en pos de sobrevivir, mientras no los comete contra los patronos que le dan buen trato y lo alimentan. Su fidelidad lo conduce incluso a encargarse del sustento de su amo pobre, el escudero, en un tratado que muestra la diversidad de la masa pauperizada que circula por la ciudad (los pobres flagelados, Lazarillo, las costureras, el escudero y las prostitutas a quienes frecuenta), pero también la eventual solidaridad entre ellos, a pesar de lo efímero de sus vínculos.

Trapaza se emplea en servicio dos veces, con don Tomé y con el médico. En el primer caso, el criado vale por su educación, formación que el amo capitaliza simbólicamente. Este episodio es uno de los más característicamente cortesanos de la picaresca y en él se representa la interacción entre los criados, entre ellos y sus patronos, y con señores ajenos ${ }^{54}$, dando cuenta de la sociabilidad entre ambos sectores en el marco de la corte. En el retrato de estos vínculos se puede observar minuciosamente la

\footnotetext{
51 “...un criado bellaco, sisador, mentiroso, como los de hogaño. Y si va por atajo, ha de ser tonto, puerco, descuidado, flojo, perezoso, costal de malicias (...) necio y desvergonzado en gruñir. Una moza o ama que quiere servir de todo, sucia, ladrona, con un hermano, pariente o primo, para quien destaja tantas noches cada semana; amiga de servir a hombre solo, de traer la mantilla en el hombro, que le den ración y ella se tiene cuidado de la quitación, cuando halla ocasión...”. Ibídem, Primera Parte, pp 295 y 296.

52 En la última secuencia en la que Guzmán es contratado en una casa, donde tiene a cargo la administración de la hacienda de una viuda, el pícaro se amanceba con una esclava que es cómplice de sus latrocinios, personaje respecto al cual la narración es especialmente crítica. Ibídem, Segunda parte, p 477.

${ }_{53}^{54} \mathrm{Ibidem}$, Primera Parte, $\mathrm{p} 301$.

${ }^{54}$ Alonso de Castillo Solórzano, Aventuras del Bachiller... op cit, pp 188 y ss.
} 
falta de distanciamiento entre amos y mozos, tanto en el ámbito público como en el privado, aspecto que la picaresca pretende socavar a partir de la denuncia de los últimos.

La novela ilustra también el uso de los criados en los conflictos entre los señores. Cuando Trapaza es utilizado para satirizar a un caballero, éste encarga su persecución, provocando la huida del protagonista. La secuencia bufonesca (que aparece de manera similar en varias novelas, como el episodio en la mesa del embajador del Francia de El Guzmán), da lugar a una caza a cargo de un grupo de sicarios, que confunden a otro mozo con Trapaza y lo matan, relación que indica, nuevamente, que se homologa a todos los subalternos ${ }^{55}$. El castigo ejemplar para quien no respetase las jerarquías y a los superiores no se efectivizaba sólo desde el aparato de justicia, sino también en el marco doméstico. En esta representación, dicho mecanismo da lugar al requerimiento de otros caballeros que hacen uso del sirviente para resolver sus disputas porque probablemente su status y las reglas inherentes a él no les permitirían realizarlo de manera directa.

Posteriormente, Trapaza es empleado por un médico. Si bien entonces se especifica su función como ayudante, es confinado al ámbito doméstico, donde se inmiscuye en los vínculos de los amos, pues el servicio seguía guardando características de adscripción personal ${ }^{56}$. En el mismo domicilio también hay una esclava negra, único personal admitido por una mujer celosa, dato que informa acerca de su invisibilización ${ }^{57}$, tal como constatamos respecto a Zaide en El Lazarillo. Además, su subordinación respecto a Trapaza muestra la estratificación jerárquica entre los subalternos incluso en las pequeñas propiedades.

En la narrativa que nos ocupa, los pícaros también ayudan al amo a evadir los engaños que llevan a cabo otros personajes marginados. Cuando Guzmán sirve al embajador de Francia, el protagonista interfiere cuando otros pícaros pretenden engañar a su amo ${ }^{58}$. Por ejemplo, cuando un bodegonero cordobés que se hace pasar por soldado llega a la mesa del embajador, Guzmán, que conoce la treta, elige no agasajarlo y servirle poco y mal. Vemos en este caso que en el marco de volatilidad de las relaciones personales, el sirviente responde en defensa del amo en lugar de favorecer a otro pícaro.

\footnotetext{
55 "Buscaron al pobre Trapaza en la quinta de don Enrique, donde sabían que acudía de ordinario, y, errando el tiro, encontraron con un criado de don Álvaro; preguntáronle si era Hernando, él calló, y, pensando que de temor se encubría, le dieron dos cuchilladas, de modo que dentro de cuatro días acabó la vida." Ibídem, p 211.

${ }^{56}$ Ibidem, pp 215 y ss.

${ }^{57}$ Ibidem, p 215.

${ }^{58}$ Mateo Alemán, op cit, Primera Parte, pp 467 y ss. Este personaje es además extranjero y judío.
} 
En el antiguo régimen, la familia es una corporación, de manera que todos los criados sufrían la suerte del amo en situaciones violentas. Los dependientes estaban comprometidos con su señor y lo seguían, por eso no formarían un estrato solidario.

La familiaridad entre amos y criados es aun más nítida en el caso de El Buscón aunque aquí debemos observarla como una característica del grupo etario, pues Pablos sirve sólo a un estudiante. Sin embargo allí vemos que los robos que realiza para sustentar al colegial son objeto de gracia por parte de otros jóvenes aristócratas, que favorecen al pícaro, quien a pesar de todas las arengas, es fiel a su señor por el amor que le atribuye ${ }^{59}$. En contradicción con las características que se imprimen en el pícaro, en este período se entrega a la autoridad del joven amo y tolera dócilmente su condición de subalterno en el ámbito estudiantil.

Cuando Guzmán entra a trabajar con un cocinero, muestra al principio una conducta ejemplar como criado (o lo que él considera que debería ser). El pícaro narra que no sólo puso gran empeño en servir a su amo, sino que también lo hizo en pos de cooperar con las tareas que llevaban a cabo otros subalternos (desde quien ocupa la posición más alta hasta quien desempeña la más baja en la casa ${ }^{60}$. En primer lugar, integrarse en una familia implica no solamente el vínculo con el amo, sino también con el resto de sus miembros, entre quienes entendemos al personal doméstico. Por otro lado también se representa la diferenciación de tareas por género, así como los vínculos familiares y amorosos en el interior de este espacio.

La relación entre la obligación de trabajar y el derecho a la limosna se sintetiza en el episodio que narra cómo Guzmán es encontrado por un monseñor en situación lastimosa y, luego de ser mantenido por un tiempo, una vez sano, colocado en la posición de paje: “... me mandaron hacer de vestir y pasar al cuartel de los pajes, para

\footnotetext{
59 "Y por no ser largo, dejo de contar cómo hacía monte la plaza del pueblo, pues de cajones de tundidores y plateros y mesas de fruteras -que nunca se me olvidara la afrenta de cuando fui rey de gallossustentaba la chimenea de casa todo el año. Callo las pensiones que tenía sobre los habares, viñas y huertos, en todo aquello de alrededor. Con estas y otras cosas, comencé a cobrar fama de travieso y agudo entre todos. Favorecíanme los caballeros, y apenas me dejaban servir a don Diego, a quien siempre tuve el respecto que era razón por el mucho amor que me tenía". Francisco de Quevedo, op cit, pp 88 y 89.

60 "Anduve a los principios con gran puntualidad, y él me regalaba cuanto podía. Mas no sólo a mis amos -que era casado- procuré agradar, sirviendo de toda broza en monte y villa, dentro y fuera, de mozo y moza, que sólo faltó ponerme saya y cubrir manto para acompañar a mi ama, porque las más caserías, barrer, fregar, poner una olla, guisarla, hacer las camas, aliñar el estrado y otros menesteres, de ordinario lo hacía, que por ser solo estaba puesto a mi cargo; pero a todos los criados del amo procuraba contentar. Así acudía en un vuelo al recaudo del paje como del mayordomo; del maestresala, como del mozo de caballos. Uno me mandaba le comprase lo necesario, otro que le limpiase la ropa, aqueste que le enjabonase un cuello, aquel que le llevase la ración a su mujer y esotro a su manceba" Mateo Alemán, op cit, Primera Parte, p 301.
} 
que, como uno dellos, de allí adelante sirviese a su señoría ilustrísima"61. Mediante el acto de piedad, el religioso se hace de un trabajador. Este episodio da cuenta de la delgada frontera entre las instancias de mendigar y de emplearse en oficios no especializados, así como la que separa la posibilidad de ser caritativo y sacar provecho de esta circunstancia. También es posible pensar que el monseñor contemplase la situación como otra obra de caridad, pues le proporciona mayor seguridad a Guzmán. Por último, con el mismo mecanismo, el marginal resulta funcional como depositario de limosna y como criado para la ostentación de status.

El episodio en la casa del monseñor ha sido ampliamente estudiado por Cavillac, sin embargo nos interesa destacar en el marco de las conductas de los criados que, si bien muchas faltas de Guzmán son admitidas por el religioso, no lo es el juego, vicio al cual se inclina el protagonista, motivando su despido con una intención disciplinante ${ }^{62}$. En el presente de la narración, el pícaro arrepentido deplora haber sido expulsado de la casa cuya descripción se asemeja más al país de jauja que a la sobriedad con que debería vivir el religioso, a quien se culpa de la desviación del protagonista (o al menos de haber contribuido a ella).

En La hija de Celestina, Elena no se pone en ningún momento al servicio de otros. Sin embargo, esta función aparece cuando la banda que integra toma criados, de quienes se dice que imitan las conductas de los amos ${ }^{63}$. Los sirvientes son maltratados, pero debemos reparar en que los criados advierten al amo acerca de la situación. Son los dependientes los que denuncian a la banda, en un acto que aúna la traición y la defensa ante los ataques del $\mathrm{amo}^{64}$. Si la novela da cuenta de que éste maltrata a los dependientes más de lo tolerable, está asumiendo por otro lado la licitud de dicha práctica que no debe sobrepasar ciertos límites consuetudinarios en pos de garantizar la convivencia y la paz. La violencia es representada, tal como corroboramos en otras novelas, como una herramienta de disciplinamiento que tiene que ser cuidadosamente administrada por quienes la detentan.

Observamos en La hija de Celestina el tema de los criados amancebados, prototipo que se repite en varias novelas, como en el pasaje citado de El Guzmán o en el destino final de El Lazarillo, cuya funcionalidad como servidor del arcipreste de San

\footnotetext{
${ }^{61}$ Ibidem, Primera Parte, p 428.

${ }^{62}$ Ibídem, Primera Parte, pp 459-461.

63 "Tenían dos criados, macho y hembra, aprendices del arte, y tanto, que también en el modo de dormir imitaban a sus señores." Alonso J. de Salas Barbadillo, op cit, p 143.

${ }^{64}$ Ibidem, pp 144 y 145.
} 
Salvador se justifica con su casamiento con la manceba del clérigo. El estereotipo del marginal temporariamente criado se vincula con la explicación presente en la picaresca respecto a la procedencia de los protagonistas, que resultan en varios casos hijos de criados díscolos. Tal como veremos en el capítulo sexto, las novelas que nos ocupan representan la progenie de los pícaros, cuya estirpe es imaginada como el reverso de las heroicas genealogías presentes en las novelas de caballería, haciendo hincapié en la reproducción de un sector social que debe ser sometido.

Fuera de Lazarillo, que sirve siempre en soledad, las demás novelas consideradas representan grandes catervas de lacayos en las casas de los poderosos, algunos de los cuales son parte de la configuración de la casa, mientras otros se encuentran de manera temporal en ella. Este personal establece vínculos de competencia y cooperación, tal como demuestran las conductas descriptas por Guzmán, que incluyen los robos y engaños entre los propios criados, en contradicción con la posibilidad de que formaran alianzas o grupos de pertenencia consolidados y estables, según la óptica del autor. Esto implica un contrasentido en la propia novela, que pinta una cofradía de mendigos, conformada por marginales (individuos que, según otras descripciones presentes en la novela, no podrían establecer este tipo de solidaridades) ${ }^{65}$.

La obra ilustra la falta de identidad colectiva entre marginales que no conformaban un grupo homogéneo, a través del desprecio que siente el protagonista por sus pares y su convicción de ser más astuto y más inteligente, sentimientos que lo conducen a traicionarlos, tal como constatamos en la descripción y justificación de las incursiones de Guzmán en las escasas pertenencias de sus compañeros, que luego puede intercambiar $^{66}$. La venta inmediata de la prenda conseguida o su trueque es parte de la rapiña dentro de la casa que los servidores llevan a cabo contra sus amos pero también entre ellos. Esto se relaciona con otras prácticas picarescas como la relación con vendedores ambulantes de poca monta, con quienes se vinculan en sus intercambios.

La novedosa profundidad psicológica de los personajes de baja jerarquía social permite retratar, además de la competencia, otra clase de relaciones ambiguas y contradictorias. Si bien los sirvientes no manifiestan solidaridad como grupo, pueden

\footnotetext{
${ }^{65}$ Analizaremos minuciosamente la cofradía de mendigos romanos y sus reglas en los próximos capítulos. 66 “.... que todos eran unos leños, lerdos, poco bulliciosos, así delante como detrás de su señor. Tan tardos en los mandados, como en levantarse de la cama. Flojos, haraganes, descuidados, que por ser tales holgaba de hacerles tiros, acomodándolos de medias, ligas, cuellos, (...) y lo más que podía, de que poblaba el jergón de la cama de mi compañero, porque no lo hallasen en la mía. En los aires lo trocaba por otro y, aunque fuera por hierro viejo, no había de quedar en mi poder. Tuviera cada uno buena cuenta con su hatillo, que si un punto se descuidaba, ojos que lo vieron ir, nunca lo vieran volver." Mateo Alemán, op cit, Primera Parte, pp 437 y 438.
} 
formar alianzas ocasionales para realizar raterías. El mundo de los dependientes llega a convertirse en una subcultura carnavalesca que funciona en la casa del señor, donde se reproducen las conductas de los subalternos. Estas prácticas rebeldes trasuntan que no hay una absorción pasiva de lo que se les impone en el medio, sino que éste es resignificado a partir de su experiencia marginal. A lo largo de El Guzmán se reitera que el pícaro se pierde por la mala influencia que ejercen los criados con quienes él socializa $^{67}$. Según la narración, las causas de los vicios son la condición vulgar (y la innata desviación que implica si no se corrige mediante el trabajo), las malas compañías y la ociosidad, que era una premisa para la persecución del vagabundeo y una preocupación en las sociedades tradicionales, concepción social que es reproducida por la picaresca con intención moralizante ${ }^{68}$.

El juego es una práctica común con los demás criados ${ }^{69}$, pero a lo largo de la obra constatamos que no sólo es parte de la socialización de los servidores, sino que también está presente entre las licencias que se otorgan los amos, con quienes el narrador pretende compartir algunas características identitarias, porque la novela picaresca no solo fustiga los vicios de los pícaros, sino los de toda la sociedad.

La escisión entre Guzmán (quien cree distinguirse del grupo, al cual asimila a una jauría de fieras terribles ${ }^{70}$ ) y los otros servidores, idealizada por el narrador, es utilizada para justificar su propia desviación ${ }^{71}$. Así, en la novela de Alemán, queda anulada la posibilidad de que puedan encontrarse mozos honrados, pues en caso de que un hombre lo fuera en el momento de ingreso en la servidumbre, su corrupción sería ineludible por la propia socialización dentro del ámbito doméstico. En El Guzmán, el servicio se utiliza para medrar gracias a los hurtos domésticos, otorgándole a la ocupación un sentido diferente del original y naturalizando el robo por parte de los

\footnotetext{
${ }^{67}$ En varias obras picarescas encontramos también la mala influencia que pueden ejercer los criados sobre los jóvenes de la casa, así como sobre las mujeres, comenzando por un antecedente del género, $L a$ Celestina. Asimismo en los "avisos" de A. Liñán y Verdugo, más asociados a las recomendaciones de los moralistas, encontramos esta idea. Antonio Liñán y Verdugo, Guía y avisos de forasteros que vienen a la Corte. Madrid, Editorial Nacional, 1980, "Novela y escarmiento catorce", pp 249-264.

68 "La ociosidad ayudó gran parte y aun fue la causa de todos mis daños. Como al bien ocupado no hay virtud que le falte, al ocioso no hay vicio que no le acompañe". Mateo Alemán, op cit, Primera Parte, $\mathrm{p}$ 318.

69 "Todos jugaban y juraban, todos robaban y sisaban: hice lo que los otros". Ibídem, Primera Parte, p 315.

70 "Sólo quiero decir que estas desórdenes en todos me hizo a mí como a uno dellos. Andaba entre lobos: enseñéme a dar aullidos". Ibídem, Primera Parte, p 315.

71 “... pues degeneré de quien era, haciendo lo que no debía. Perdíme con las malas compañías, que son verdugos de la virtud, escalera de los vicios, vino que emborracha, (...). Cuando comencé a servir, procuraba trabajar y dar gusto; después los malos amigos me perdieron dulcemente". Ibídem, Primera Parte, $\mathrm{p} 318$.
} 
criados: "No puse los ojos en mí, sino en los otros. Parecióme lícito lo que ellos hacían, sin considerar que, por estar acreditados y envejecidos en hurtar, les estaba bien hacerlo, pues así habían de medrar y para eso sirven a buenos. Quise meterme en docena, haciendo como ellos, no siendo su igual, sino un pícaro desandrajado" ${ }^{, 72}$. En el inicio de su experiencia dentro de la casa, el pícaro confunde valorativamente el actuar de sus compañeros; según vemos, el personaje ha hecho una evaluación al respecto e indica el comienzo en la carrera en la que se destacará más tarde por ser sus robos mayores y arriesgados. Sin embargo, con el objetivo de singularizarse en el medio de los criados, reconoce que empieza siendo "inocente" respecto a sus compañeros, a quienes imita a pesar de su diferencia de origen, de tal manera desplaza la responsabilidad de sus culpas hacia los demás servidores.

Guzmán utiliza el tiempo ocioso dentro de la casa para ampliar su "riqueza", ocupándose de vender los trastos de los demás criados, actividad en la que adquiere una destreza que lo distingue entre los $\operatorname{mozos}^{73}$. De este modo, tanto la socialización marginal en la casa del señor como la propia relación entre él y los otros servidores fomentan sus actividades delictivas.

El pícaro comienza a hurtar valiéndose de la confianza ganada previamente, en una relación ambigua que da lugar a vínculos familiares, de modo que la apelación a la credulidad del amo es una herramienta fundamental para su éxito ${ }^{74}$. El autor promueve el descrédito hacia los subalternos, pues sostiene que si cumplen con su deber sólo lo hacen con el objetivo de poder garantizarse oportunidades para traicionar a sus amos. Pero Guzmán gana una credibilidad exclusiva que, sumada a su ingenio - virtud que no comparten los demás criados-, le permite hacer recaer la sospecha sobre sus compañeros. La perspicacia, fundamental para la supervivencia del pícaro y basada en la adaptación veloz a diversas circunstancias, se aplica aquí a la sisa doméstica, pero también podemos observarla en otro tipo de actividades urbanas en las cuales el pícaro

\footnotetext{
${ }^{72}$ Ibidem, Primera Parte, p 318. De manera ambigua, Guzmán hace su descargo, no puede ser igual a los otros y explica por qué.

${ }^{73}$ Ibidem, Primera Parte, p 311. Aquí debemos referir la asimilación ladrón-mercader, que está latente en la novela.

74 “Luego que allí entré, no se hacía de mí mucha confianza. Fui poco a poco ganando crédito, agradando a los unos, contentando a los otros y sirviendo a todos; porque tiene necesidad de complacer el que quiere que todos le hagan placer". Ibídem, Primera Parte, p 308.
} 
necesita contar con la confianza de aquel a quien engaña, estafa o roba. Parte del éxito de Guzmán en los hurtos dentro de la casa se debe a que traiciona a los otros mozos ${ }^{75}$.

El engaño mutuo y el duelo de astucia contribuyen al entrenamiento del pícaro que se constituye como tal a lo largo de su existencia ${ }^{76}$. Las actitudes que vemos en el ámbito doméstico, vinculadas con la mentira, la traición y el robo, refractan las que el marginal establece con el resto de la sociedad, tal como constatamos en el ejercicio de otras formas de rapiña. Debemos tener en cuenta esta particularidad de los lazos entre marginales porque impide que pueda caber una relación de lealtad permanente con sus amos, pero tampoco entre ellos, desechando la posibilidad de que exista una comunidad compacta, tal como es denunciado en variados escritos del período, que apelan a exhibirlos como una contracultura con organizaciones estables. En este caso vemos que el desprecio por la propia situación - esto es, la ausencia de resignación respecto a su condición, que no es asumida por el pícaro, pero que él reconoce como compartida por los otros- constituye la motivación para la traición.

Según la representación picaresca, la mayoría de los criados acostumbran a robar, práctica considerada como parte inherente a la ocupación ${ }^{77}$. Como observamos anteriormente, Guzmán encuentra en principio que había considerado lícito lo que los criados hacían, denotando que se trataba de una equivocada apreciación suya. Pero cuando ha avanzado en su experiencia como servidor, refiere que los demás mozos evalúan este tipo de robos como parte de un hábito admitido consuetudinariamente en la casa, pues es consentido por sus patronos, que tienen un control laxo sobre el personal, autoridad que se activa ante situaciones puntuales que sirven como ejemplos disciplinantes.

Los subalternos toman pequeñas porciones de los alimentos que son derrochados en banquetes en los cuales ellos no tienen participación, pero eso es considerado parte

\footnotetext{
75 "Muchas cosas que hurtaba las escondía en la misma pieza donde las hallaba, con intención que si en mí sospechasen, sacarlas públicamente, ganando crédito para adelante; y si la sospecha cargaba en otro, allí me lo tenía cierto y luego lo trasponía". Ibídem, Primera Parte, p 304.

${ }^{76}$ Así, cuando sirve a un cocinero, Guzmán describe este proceso: "En mí hacían anotomía. Otras veces para probarme hicieron cebaderos, poniéndome moneda donde forzosamente hubiese de dar con ella. Querían ver si era levantisco, de los que quitan y no ponen; mas, como se las entendía y les entrevaba la flor, decía: ¿No a mí que las vendo, a otro perro con ese hueso, salto en vago habéis dado, no os alegraréis con mis desdichas ni haréis almoneda de mis infamias.' Allí me lo dejaba estar, hasta que quien lo puso lo alzase, teniendo cuenta que otro no lo traspusiese y dijesen que yo. Otras veces lo alzaba y daba con ello en manos de mis amos, andando con gran recato en hacer mis heridas limpias, a lo salvo, como buen esgrimidor; que dar una cuchillada y recebir una estocada es dislate." Ibídem, Primera Parte, p 310.

77 "Despensero, cocinero, botiller, veedor y los más oficiales, todos hurtaban y decían venirles de derecho, con tanta publicidad y desvergüenza como si lo tuvieran por ejecutoria". Ibídem, Primera Parte, p 308.
} 
de la paga $^{78}$. Por un lado se trata de la necesidad de satisfacer el hambre, pero también podría ser una forma de rebeldía inherente a su convivencia con personas con riqueza y status cuya desigualdad es notoria y ostentosa.

El autor puede mostrar al pícaro como una víctima de las circunstancias o como un delincuente, imagen que se completa con la del trato que dan los amos a sus criados. Encontramos dos casos, como el de El Lazarillo o El Bachiller Trapaza, en los cuales el pícaro lejos de robarle a su patrono, lo ayuda, movido por la lástima que siente hacia é$^{79}$. Lazarillo tiene dos amos pobres (el ciego y el escudero), pero podemos diferenciar la actitud que sostiene ante ambos, en consonancia con el trato que recibe por parte de ellos $^{80}$. La piedad es determinante de la actitud del pícaro, aludiendo al ámbito de religiosidad en el que han sido educados estos marginales que han interiorizado la misericordia con el desheredado.

El vínculo entre Tomé y Trapaza muestra una situación similar. En ella el pícaro es benévolo con este amo empobrecido, pero aquí se trata de un recurso literario vinculado a la vertiente cortesana presente en esta obra, que muestra a los dos personajes de manera bufonesca, aparejándolos.

Las relaciones entre los criados pueden tener diversas formas y objetivos. El Bachiller Trapaza nos representa, más que otras novelas, cómo estos vínculos tenían motivos diferentes a los planteados por otros autores, quienes ven poco más que conductas marginales. La obra de Castillo Solórzano puede ser más interesante desde este punto de vista por varias cuestiones, porque se trata de una narrativa más cercana a la cortesana y no tiene por único objetivo la observación de las conductas desviadas de los pícaros, aunque su protagonista lo sea. Por otro lado, su autor vivió en los ambientes descriptos y su condición de status empobrecido nos informa también cómo aquellos sujetos provenientes de la hidalguía no resultaban todos por igual confiables para sus eventuales criados, que también consideraban las condiciones en que eran contratados. En el capítulo XI de El Bachiller Trapaza encontramos un interesante episodio en el

\footnotetext{
78 "No había mozo tan desventurado, que no ahorrase los menudillos de las gallinas o de los capones, (...), desde lo más necesario hasta lo de menos importancia que en una casa de un señor se gasta". Ibídem, Primera Parte, p 308.

79 "Tanta lastima aya dios de mi, como yo auia dél, porque senti lo que sentia y muchas vezes auia por ello pasado y passaua cada dia.” Anónimo, op cit, p 171.

${ }^{80}$ Respecto al ciego: “... jamas tan auariento ni mezquino hombre no vi, tanto que me mataua a mi de hambre y assi no me demediaua de lo necesario." Ibídem, p 81. Respecto al escudero: "Contemplaua yo muchas vezes mi desastre, que, escapando de amos ruynes, que auia tenido, y buscando mejoría, viniesse a topar con quien, no solo no me mantuuiesse, mas a quien yo auia de mantener. Con todo, le quería bien, con ver que no tenía ni podia más. Y antes le auia lástima, que enemistad. Y muchas vezes, por lleuar a la posada con que él lo passasse, yo lo passaua mal.” Ibídem, pp 174 y 175.
} 
cual el protagonista y su amo don Tomé van a jugar a la casa de un noble donde constatamos la socialización entre criados de diversos señores, mientras estos últimos hacen lo propio. El enmarcarse en las clientelas también implicaba hacerlo en su lógica de socialización, ya fuera en la amistad como en las disputas. Pero estos vínculos sirven a los criados para evaluar el mercado del servicio en el cual están insertos, tal como Trapaza averigua acerca de la historia y riqueza de su amo gracias a la información que recibe por parte de los mozos de otros caballeros ${ }^{81}$.

La representación picaresca testifica conductas diversas y lógicas contradictorias en la socialización entre los criados, en consonancia con la procedencia marginal de una parte de quienes ocupaban este tipo de posiciones. Estas conductas refractan las que el pícaro mantiene con el resto de la sociedad, que son ambiguas, debido a que su posición (en una casa, pero también en la comunidad) es inestable. Podemos encontrar vínculos solidarios entre los criados que llegan a ser, posterior o paralelamente, competitivos y que se relacionan no sólo con el lazo que mantienen entre ellos, sino también con el patrono.

\section{Amos y criados}

La novela picaresca representa la relación entre amos y criados como un vínculo complejo que incumbe la mayor o menor cercanía entre dos personas que pertenecen a sectores sociales diferentes (aunque en algunas oportunidades los amos también provienen de un sector marginal). Sin embargo, se trata de dos individuos que tienen escalafones disímiles en la casa y ante la ley. Observamos además que en variadas ocasiones el vínculo se inicia de manera azarosa y repentina.

Si tenemos en cuenta todos estos aspectos (convivencia entre desconocidos que provienen de status diferentes, insertos en jerarquías desiguales, y de los cuales uno es marginal -sector al cual la narrativa imputa diversas conductas desviadas-, además del generalizado maltrato por parte del amo y la miserable paga) podemos imaginar que el resultado es la traición por parte del criado. Sin embargo, no en todos los casos resulta de este modo. Este aspecto es relevante porque contradice las imágenes de los marginales que son difundidas a partir de las diversas fuentes analizadas en esta tesis.

\footnotetext{
${ }^{81}$ Alonso de Castillo Solórzano, Aventuras del Bachiller... op cit, pp 190 y ss.
} 
El primer tratado de El Lazarillo expone la avaricia del amo, también marginal. Según el narrador, el ciego "... con todo lo que adquiria y tenia, jamas tan auariento ni mezquino hombre no vi, tanto que me mataua a mi de hambre..." ${ }^{, 2}$. La lucha por la supervivencia conduce a Lazarillo a percibir a su miserable amo como rico, aunque, según la descripción, subsiste magramente, en una pelea permanente por la comida que le escatima al niño. El mozo le roba en varias oportunidades con el único objetivo de alimentarse (así con la longaniza, las uvas y el vino), pero cuando es descubierto, es golpeado cruelmente por el patrono, quien luego de disciplinarlo se encarga paternalmente de curarlo ${ }^{83}$.

El permanente maltrato por parte del $\mathrm{amo}^{84}$ despierta el rencor del joven, quien a partir de esta experiencia formativa con el viejo demuestra haber aprendido sus artes, tal como constatamos en su venganza, que constituye una representación paródica de la superación del maestro por su discípulo ${ }^{85}$. A pesar de lo habitual que pudiera ser el maltrato, otros personajes se sorprenden del agravio del ciego, mientras observan asimismo el comportamiento del criado, que en este caso es humillado por su conducta. Dicha mirada podría representar la posición del autor anónimo frente a la brutalidad en que estaban sumergidos los miserables. Aquí se testimonia la intervención de la comunidad en el vínculo entre amo y criado, que no existe independientemente de ella sino que, por el contrario debe ser visualizado y sostener la diferencia de status entre ambos para que sea válido. Aunque se respeten los vínculos asimétricos, lo que se espera del patrono es que, si es noble, responda a su nobleza, pero si es miserable, que no sea brutal cuando ocupa un lugar de superioridad, que es lo que se censura en el ciego. En la sociedad de antiguo régimen las relaciones de subordinación se legitimaban si todos se mantenían en su posición, por eso no sólo cada uno debía velar por las suyas, sino que toda la comunidad era responsable de vigilar que se respetaran los vínculos asimétricos, tanto en el ámbito público como en el privado.

\footnotetext{
${ }^{82}$ Anónimo, op cit, pp 80 y 81.

${ }^{83}$ El narrador describe el golpe propinado por el ciego, quien luego se encarga de su cura: "Fué tal el golpezillo, que me desatinó y sacó de sentido, y el jarrazo tan grande, que los pedaços dél se me metieron por la cara, rompiendomela por muchas partes, y me quebró los dientes sin los quales hasta oy dia me quedé. Desde aquella hora quise mal al ciego y, aunque me quería y regalaua y me curaua, bien vi que se hauia holgado del cruel castigo". Ibídem, p 88.

84 “Aunque yo quisiera assentar mi coraçon y perdonalle el jarrazo, no daua lugar el maltratamiento, que el mal ciego dende alli adelante me hazia, que sin causa ni razon me heria, dandome coxcorrones y repelandome." Ibidem, p 89.

${ }^{85}$ Nos referimos al famoso episodio de la calabazada contra la estatua del toro, con la cual termina el primer tratado de El Lazarillo.
} 
El segundo tratado del Lazarillo se detiene en la avaricia de los clérigos, que es un lugar común en la literatura moralista de la época. No se censura a todos los religiosos, sino a los mezquinos. Este acápite consiste en una lucha permanente por parte del protagonista para conseguir los medios de supervivencia que el amo no le garantiza al escatimarle los alimentos. Aquí es donde se muestra más claramente al "cruel sacerdote" 86 como un pecador indigno del hábito que viste, por su avaricia y su gula. Entre las injurias proferidas contra el clérigo encontramos aquella que lo vincula de manera simbólica con un sector perseguido por la Iglesia durante el período ("bruxo de mi amo" $)^{87}$, refiriéndose a la dudosa ortodoxia del cura. Las críticas al clero, expresadas a través de las que recaen sobre este personaje, se incrementan, sugiriendo que posiblemente la conducta del religioso haya sido aprendida antes de ordenarse, en su noviciado, de esa manera extiende la sospecha a un ámbito sacerdotal más amplio ${ }^{88}$. Con este episodio se inicia la crítica a los religiosos en tanto amos de criados, mientras, como contraparte, hay en la narración una mayor densidad de expresiones referentes a la religión ${ }^{89}$. El protagonista incorpora el vocabulario del religioso a partir de entrar a su servicio, lo cual es un recurso sutil para describir su formación.

Mientras el marginal pide a Dios ser perdonado por desear la muerte ajena para comer, el cura se atiborra sin temer el castigo divino ("Mas el lazerado mentia falsamente, porque en cofadrias y mortuorios, que rezamos, a costa agena comia como lobo y beuia mas que vn saludador" $)^{90}$. Por este motivo el religioso es acusado de vivir de la rapiña que ejerce a través del ritual y la creencia de los demás. Esta imputación es importante, porque es la misma que se lanza en este período sobre los falsos pobres ${ }^{91}$. En este contexto, el ciego y el clérigo son comparados, pues mientras sostienen servir a Dios, hambrean a su criado ${ }^{92}$. A través de estas imputaciones se arriba a una crítica de la sociedad aun más radical, pues las conductas del clérigo son asimiladas a las de los marginales, aunque no es juzgado de la misma manera que ellos por la sociedad.

\footnotetext{
${ }^{86}$ Ibidem, p 143.

${ }^{87}$ Ibidem, p 141.

${ }^{88}$ Así, el narrador sostiene respecto al religioso: “...toda la lazeria del mundo estaua encerrada en éste. No sé si de su cosecha era, o lo auia anexado con el abito de clerezia”. Ibídem, pp 110 y 111.

${ }^{89}$ ¡Pluguiera a Dios que me demediara!” Ibídem, p 114; “¡Tal te la dé Dios!” Ibídem, p 117; “...si Dios y mi saber no me remediaran..." Ibídem, p 117; ;”Dios me lo perdone!" Ibídem, p 121.

${ }^{90}$ Ibídem, pp 118 y 119.

${ }^{91}$ Sobre estas acusaciones, ver: Félix Santolaria Sierra (ed.), El gran debate... op cit.

${ }^{92}$ Anónimo, op cit, pp 176 y 177.
} 
En el quinto tratado, el protagonista es mozo de un falso bulero, "desuergonçado", "falsario"94 y de "sotiles inuenciones"95. A través de la trama podemos ver cómo el amo soborna a los clérigos para que le permitan realizar su timo ${ }^{96}$, pues los párrocos locales convocan a los fieles para oír las predicaciones del farsante, quien les otorga alimentos a cambio. Pero los vínculos que establece este personaje para que le permitan estafar n..o se reducen a los que anuda con el clero, sino que abarcan también a los que logra con las autoridades locales, pues el farsante trama con un alguacil y un comisario una puesta en escena que le permite ganar dinero y el reconocimiento necesario para continuar con su estafa en la región ${ }^{97}$. Aquí se vinculan la amenaza con la excomunión para aquellos que no quieran tomar las bulas y el engaño a la población para infundir el miedo al castigo divino, con participación del alguacil ${ }^{98}$.

La crítica acerca de las conductas condenadas respecto al comportamiento que deberían mantener los eclesiásticos comienza en una breve pero contundente mención en el prólogo 99 , pero continúa cuando Lazarillo se acomoda junto a un fraile de la Merced. En el tratado cuarto se insinúan las transgresiones sexuales del clérigo, anticipando el tema del último tratado. El muchacho se vincula con el religioso a través de unas mujeres pobres que se ocupan como costureras y probablemente como prostitutas, “... al qual ellas le llamauan pariente" $" 100$. Se dice de él que es "Gran amigo del coro y de comer en el conuento, perdido por andar fuera, amicissimo de negocios seglares y visitar. Tanto, que pienso que rompía él mas çapatos, que todo el couento”. El narrador se refiere a la laxitud de la observancia de los frailes y religiosos así como a los negocios que les estaban prohibidos por la Iglesia, pero que hacían. Finalmente, el

\footnotetext{
${ }^{93}$ Ibidem, p 205.

${ }^{94}$ Ibídem, p 208.

${ }^{95}$ Ibídem, p 205.

${ }^{96}$ Ibidem, pp 205 y 206.

${ }^{97}$ Ibidem, pp 207 y ss.

${ }^{98}$ Muestra el aprovechamiento del clero, pero también de los funcionarios reales y municipales, del temor de la gente a la pérdida de la salvación. En la pragmática de Valladolid de 1524 se condenan los daños que ocasionan los agentes de la Santa Cruzada. Un año más tarde se reclama en las Cortes de Toledo por los perjuicios que algunos obispos y cabildos hacen sufrir a los pueblos con los diezmos, la adquisición desmedida de propiedades por las iglesias y la extralimitación del Santo Oficio, a partir de lo cual en 1525 piden que se refrenen los abusos de alcaldes, alguaciles y escribanos. Miguel Asensio, op cit, p 82.

99 "No nos marauillemos de vn clérigo ni frayle, porque el vno hurta de los pobres y el otro de casa para sus deuotas y para ayuda de otro tanto, quando a vn pobre esclauo el amor le animaua a esto". Ibídem, pp 72 y 73. Sugiere el abuso de los religiosos varones respecto de las mujeres devotas, a quienes seducirían con regalos, crítica de la cual ellas no escapan.

${ }^{100}$ Ver sobre la prostitución de las costureras y pequeñas comerciantes: Serrana Rial García, "Solas y pobres: las mujeres de las ciudades de Galicia ante la marginalidad y la prostitución", en Durán Villa, Francisco y Santos Solla, Xavier Manuel, (eds.). Semata $N^{o} 16$, Marginados y Excluidos. Un enfoque interdisciplinar. Santiago de Compostela, Universidad de Santiago de Compostela, 2005, pp 301-331, p 321.
} 
personaje termina la relación sin dejar de insinuar el abuso hacia él por parte del religioso $^{101}$. Esta crítica tiene lugar en un período en que la Iglesia católica revisaba especialmente la observancia de las reglas por parte de sus miembros y estaba encarando una reforma del clero.

La diferencia fundamental entre pobreza y marginalidad es retratada en el último tratado de El Lazarillo. Su lectura nos informa acerca de la manera en que el protagonista consigue establecerse en una localidad y tener garantizada la supervivencia, aunque lo hace de un modo también marginal. Lázaro se casa con la manceba de un clérigo y así obtiene su propia manutención, que queda a cargo del arcipreste. De este modo, continúa viviendo del favor ajeno y no de su trabajo como pregonero, que resulta subsidiario. El relato se extiende sobre la forma en que el eclesiástico le presenta inescrupulosamente el escenario a Lazarillo: la situación es deshonrosa, pero conveniente en el plano económico ${ }^{102}$. Así se concluye con las críticas hacia los hombres de la Iglesia, quienes llevan una forma de vida poco cristiana, además de condenada por los poderes laicos ${ }^{103}$. Finalmente, la novela representa varias prácticas de los religiosos, como la bigamia, la blasfemia, las supersticiones y la promiscuidad sexual, que fueron perseguidas con mayor rigor luego del Concilio de Trento ${ }^{104}$.

El Buscón presenta una sola situación en la cual el pícaro se somete, en el contexto educativo, a la autoridad de un amo muy joven. En este caso particular, la relación de servicio se confunde con la de amistad, según la óptica que se imputa al protagonista, aunque siempre se mantiene la asimetría entre las posiciones de ambos

\footnotetext{
${ }^{101}$ Así se describe su alejamiento del religioso, refiriendo que se debe a las faltas ya descriptas y otras que prefiere omitir: “...por esto y por otras cosillas, que no digo, sali dél”. Anónimo, op cit, p 204.

${ }^{02}$ Ibídem, p 238. De modo que el arcipreste abusa de su poder, aprovechándose de las debilidades humanas, según es responsabilizado por Lazarillo. Ver sobre este aspecto de la novela el artículo de Georgina Sabat de Rivers, "La moral que Lázaro nos propone", en MLN. Hispanic Issue. Vol. 95, №2, Baltimore, Johns Hopkins University Press, 1980, pp 233-251, p 247.

${ }^{103}$ Sobre la apreciación de la manceba de clérigo como pecadora pública ver: Serrana Rial García, op cit, p 308. El concubinato es la mayor queja contra inquisidores y oficiales diocesanos, Sara Nalle, "Inquisitors, Priests, and the people During the Catholic Reformation in Spain", en The Sixteenth Century Journal. Vol. 18, № 4, Kirksville, The Sixteenth Century Journal, 1987, pp 557-587, p 571.

En las Cortes de Briviesca de 1387, se penan las mancebas de clérigos, hábito que se testifica en $E l$ Lazarillo. El reclamo se repite en las de Toledo de 1480 y en las de Madrid de 1501, que se fundamentan en que los hombres de la Iglesia deben ser limpios y ensucian el templo con malas mujeres, teniendo mancebas públicas. La ley testifica acerca de las conductas irregulares del clero, pero no legisla contra estos hombres, sino contra quienes actuaran como cómplices de las prácticas cuestionadas. La legislación incita a la intervención de la comunidad en la represión de las costumbres sexuales de los eclesiásticos, promoviendo la acusación y denuncia de este tipo de conductas con recompensas. En la Pragmática de 1503, Ley V, se promueve la "amonestación y castigo de las mugeres casadas sospechosas que estuvieren en las casas de los clérigos". Allí se sostiene que muchas veces los clérigos encubren la mancebía casando a sus mujeres con sus criados u otras personas. Julián Viana Razola (ed.), Novísima Recopilación de las Leyes de España. Madrid, Julián Viana Razola, 1805-1829, Tomo V, p 421.

${ }^{104}$ Sara Nalle, Inquisitors, Priests... op cit, p 558.
} 
personajes, pues Pablos hace las veces de bufón o provee de alimentos al amo. En estos episodios el pícaro se forma como tal, dando cuenta del abismo entre los estratos sociales. La primera desviación de Pablos será la de tener aspiraciones elevadas siendo de condición vil. A partir de esto, al acercarse a personajes de sectores más altos, siempre se le otorga el lugar que merece y del cual no debería salir. El pícaro es objeto de burlas por parte de los demás estudiantes, que además hacen uso de él para que cumpla la función que se le atribuye en el marco social, pues se lo instiga a encargarse del suministro de alimentos para los demás, manteniéndolo en su esperada subordinación.

Hemos visto al Bachiller Trapaza con dos amos, el médico y don Tomé. En ambos casos observamos una relación afectiva entre él y sus señores. Con don Tomé hay una identificación y, como veremos, lamenta tener que abandonarlo ${ }^{105}$. Sin embargo también se trata de un vínculo ambiguo, pues el criado hace de su amo objeto de burla por parte de los demás cuando le resulta conveniente ${ }^{106}$. A pesar de recibir buen trato por parte de don Tomé y desarrollar cierta afición por él, no deja de perseguir su propia conveniencia y mantener secretos resentimientos, en tanto es un hombre libre que no está adscripto al dominio de quien lo ha contratado, aunque la relación no esté absolutamente despersonalizada.

En la misma novela, cuando Trapaza es contratado por el médico, si bien se le había pedido que lo acompañara en su trabajo, el criado finalmente se reduce a servirlo en el ámbito doméstico, retratando nuevamente la no especificidad de la ocupación del mozo. En este episodio el pícaro le roba a su patrono por pedido de una esclava, dando cuenta de, por un lado, la habitualidad con que se atribuía esta práctica a los sirvientes, pero por el otro, la traición al amo para favorecer a otra subordinada. Este episodio contradice parcialmente otros que dan cuenta de la falta de solidaridad al interior de este grupo, pero muestra una vez más lo ocasional de las alianzas entre los miembros de la servidumbre.

En La hija de Celestina, por oposición a los amos que son benévolos o cuyo trato hacia sus subordinados es socialmente tolerable, encontramos a la banda de estafadores que, además de tener comportamientos condenables con el resto de la

\footnotetext{
${ }^{105}$ Así describe Trapaza su decisión de abandonar a don Tomé: “....corrido quedó trapaza de que hubiese elegido tal amo, viendo que su renta no era fija sino al vuelo, y que tal vez se había de acostar sin cenar. Quiso entonces servirle algunos días, y también por ver en que paraba, que como él era también abufonado, secretamente le había cobrado un cierto cariño como a persona de su profesión". Alonso de Castillo Solórzano, Aventuras del Bachiller... op cit, p 191.

${ }^{106}$ Ibídem, pp 199 y ss.
} 
sociedad, los mantienen también respecto a sus criados. El autor no puede representar nada rescatable en ellos, pues en otros casos hemos corroborado la ambigüedad y hasta contradicción en la descripción de las conductas, pero aquí se trata de una exposición monolítica.

Las imaginadas bandas de bandidos que muestra la novela picaresca también tienen sus criados. Montufar, Elena y Mendez toman dos, “... macho y hembra, aprendices del arte, y tanto, que también en el modo de dormir imitaban a sus señores." ${ }^{107}$. Esto nos indica cuán arraigada estaba en la práctica tener servidores, que hasta se puede imaginar que un pequeño grupo de delincuentes cuenta con ellos.

En la descripción de la convivencia de los cinco marginales, observamos las traiciones mutuas, primero por el trato dado a los criados y luego por la delación por parte de uno de ellos. El amo, colérico, golpea a los mozos habitual y excesivamente (esta referencia en la novela indica un nivel de maltrato físico aceptable), lo cual conduce finalmente a la reacción por parte del subordinado, que denuncia la estafa del patrono $^{108}$. Sin embargo, este mismo trato hacia los criados se constata también por parte personajes que no son representados como despreciables, e incluso como inherente al sometimiento que merece la servidumbre ${ }^{109}$.

Alemán imprime en la enunciación del pícaro otra crítica social, cuando sentencia que los robos se deben a que los amos dan "corto salario" a sus criados y "se sirven de necesitados y dellos hay pocos que sean fieles" ${ }^{\prime 10}$. Esta es la explicación acerca de la resistencia de los marginales respecto al servicio para los sectores dominantes, que se lleva a cabo mediante, por un lado, la incursión contra sus bienes y, por otro, a través del desdén hacia el trabajo para aquéllos. Así, dice respecto al embajador de Francia "No me señaló plaza ni oficio: generalmente le servía y generalmente me pagaba. Porque o él me lo daba o en su presencia yo me lo tomaba en buen donaire"111. Aquí vemos la falta de ocupación precisa por parte del criado, quien

\footnotetext{
${ }^{107}$ Alonso J. de Salas Barbadillo, op cit, p 143.

108 Así se describe la brutalidad del trato por parte de Montúfar hacia sus criados: “...solia poner las manos mas veces de las que eran menester, en su criado; y aunque el le habia pedido que mudase de paso (...) no pudo vencer su condicion; y asi un dia, sobre pequeño interes, le hizo una sangria en las muelas: diole algunos bojicones con determinacion." Ibídem, p 145.

${ }^{109}$ En el capítulo cuarto de La hija de Celestina, don Sancho (un señor engañado por la pícara), ante una supuesta confusión de la caterva de criados, los subalternos esperan ser físicamente castigados por su malentendido: "Los pobres criados (...) les pareció que sin duda se habían engañado y que su amo tenía mucha razón culpándolos justamente y haciéndolos de cortesía el no cortarles las caras y romperles las cabezas" Ibidem, p 120.

${ }^{110}$ Mateo Alemán, op cit, Primera Parte, p 314.

${ }^{111}$ Ibidem, Primera Parte, p 465.
} 
tampoco tiene una paga certera y convive con la riqueza que le es negada, circunstancia que lo lleva a considerar que tiene derecho a hurtarle al señor aquello que debería pagarle.

Por otro lado, el narrador se detiene en las diversas intenciones de los amos respecto a él, cuando compara el tratamiento recibido por parte del cardenal y del embajador de Francia, quien aprecia la adulación por parte del criado ${ }^{112}$. Esto es indicativo de la posibilidad que tiene el "sin status" de legitimar la posición de quien sí lo posee.

La casa constituía un ámbito familiar que generaba conflictos característicos por la asimetría en las posiciones que sus miembros ocupaban allí. Debemos recordar que nos referimos particularmente a los casos en que jóvenes marginales se instalaban temporalmente en ella. La narrativa ilustra, además, una sociedad estamental en la cual amos y criados, aunque convivan cotidianamente, constituyen legalmente y jurídicamente dos sectores diferentes, como sucede en toda sociedad jerárquica.

En la representación de la picaresca, los mozos asimilan como naturales diversas transgresiones a partir de la relación con sus amos. Guzmán se instruye en variados trucos para estafar en su primer trabajo: el ventero a quien sirve lo induce a ello, incitándolo a sisar parte de lo que debería entregar a otros, o trocándolo por porciones de menor calidad, acción a partir de la cual el criado interioriza estas prácticas y las reproduce posteriormente ${ }^{113}$.

Se trata de una representación en la que los amos hacen uso de los servicios de estos mozos considerados a priori como traicioneros y poco confiables. La marginalidad del narrador habilita la crítica a los diversos sectores sociales, ya que no pertenece a ninguno de ellos. Así, Guzmán sostiene: “...mi amo y sus compañeros, yo y los míos, ayudantes y trabajadores, teníamos más que hacer en poner cobro a lo hurtado que sazón a los manjares ¡Cuál andaba todo, que sin orden, cuenta, ni concierto!”114. Todos los hombres son deshonestos y cada uno de ellos detenta a su modo este rasgo de la condición humana. Todos resultan delincuentes, juzgados por el pícaro, de acuerdo con la perspectiva pesimista de Alemán.

\footnotetext{
112 "Entré a servir al embajador de Francia, con quien monseñor, que está en la gloria, tuvo estrechas amistades, y en su tiempo gustaba de mis niñerías. Mucho deseaba servirse de mí, mas no se atrevió a recebirme por el amistad que estaba de por medio. En resolución allá me fui. Hacíame buen tratamiento, pero con diferente fin; que monseñor guiaba las cosas al aprovechamiento de mi persona y el embajador al gusto de la suya, porque lo recebía de donaires que le decía, cuentos que le contaba y a veces de recaudos que llevaba de algunas damas a quien servía." Ibídem, Primera Parte, p 464.

${ }^{113}$ Ibidem, Primera Parte, pp 270 y ss.

${ }^{114}$ Ibídem, Primera Parte, p 325.
} 
Podemos distinguir varios tipos de transgresión que involucran a amos y criados. En primer lugar, los patronos, robando en el marco de sus propias ocupaciones (recordemos al respecto los aportes acerca de los burgueses, usureros y financistas realizados por Cavillac), que no es rapiña menor ni doméstica, sino una maquinaria de la sisa del excedente social dañina para el reino ${ }^{115}$.

En segundo lugar, encontramos los hurtos que realizan los mozos sobre los bienes de los señores dentro de la economía doméstica, que pueden ser mayores o menores $^{116}$, dependiendo de la jerarquía del dependiente. Los pícaros que ocupan los últimos peldaños del escalafón en una gran casa (o que son de los pocos criados en otras menos ricas) sólo pueden tener acceso a pequeñas sustracciones que sirven para completar la escasa paga que reciben, siendo más o menos toleradas por las costumbres. Sin embargo, estos robos también pueden ser utilizados como motivo para despedir al sirviente $\mathrm{y}$, en caso de hacerse públicos, deben ser severamente castigados.

Por último, los hurtos menores realizados en conjunto por amos y criados dentro del ámbito doméstico. Si bien los autores se esfuerzan en mostrarnos el carácter traicionero de los pícaros, las novelas representan a menudo a los amos como un mal ejemplo que es imitado por sus criados. Hay variados ejemplos en este corpus, que van desde traiciones en el interior del estamento de los amos (dentro de la misma casa o hacia afuera de ella), hasta la necesidad de intervención de los criados en diversas transgresiones a las normas (generalmente sexuales) por parte de los amos. Cuando Guzmán roba el vaso de plata a su señor, encuentra la colaboración de su ama -quien engaña aquí al jefe de la casa en complicidad con un subalterno- para reemplazarlo y, gracias a esta alianza, logra su propio beneficio ${ }^{117}$. El robo realizado por el criado cobra un sentido diferente al original gracias a la intervención de su señora, quien necesita de los servicios del mozo, circunstancia que el servidor utiliza para obtener una ganancia, estafándola a su vez. La novela picaresca denuncia que todos los criados son

\footnotetext{
${ }^{115}$ Michel Cavillac, Pícaros y mercaderes... op cit, p 486. El autor entiende que la desviación se ha convertido en norma, por eso "todos reman en la misma galera".

${ }^{116}$ Aquí debemos referirnos a dos episodios que no trataremos en detalle porque pertenecen a otra parte de la obra y el enfoque de este trabajo no lo amerita. La estafa que realiza Aguilera, mozo de un mercader, en alianza con Guzmán y Sayavedra, que se desarrolla en el capítulo quinto del segundo libro de la Segunda Parte de la obra, donde vemos la intervención del criado en la actividad económica de su amo. Mateo Alemán, op cit, Segunda Parte, pp 228 y ss. En esta misma dirección, debemos aludir a la malversación que realiza el protagonista cuando administra la hacienda de su ama que es narrada en el capítulo séptimo, libro tercero, Segunda Parte. Ibídem, Segunda Parte, pp 473 y ss.

${ }^{117}$ Ibídem, Primera Parte, pp 305 y 306.
} 
ladrones $^{118}$, sin embargo los amos estrechan vínculos con ellos, que terminan por diluirse cuando se hace evidente la relación real de explotación, y la resistencia a ella, encubiertas habitualmente por vínculos que se asemejan a los filiales.

Guzmán sostiene que los criados buenos deben ser más amados que los hijos ${ }^{119}$, sin embargo esta afirmación resulta discutida dentro del propio argumento de la obra, que trata acerca de la imposibilidad de que la servidumbre se comporte correctamente. Según esta representación, el trabajo de servicio puede devenir en una forma de educación nociva para el criado cuando es consentido como consecuencia del favoritismo y tolerancia de sus señores, quienes, sin embargo, detentan una posición de superioridad respecto al dependiente, señalando así que defienden su decisión de otorgarle determinados beneficios a cambio de su lealtad ${ }^{120}$, como el obsequio de objetos residuales que el sirviente no podría adquirir de otro modo ${ }^{121}$.

Los señores reconocen como parte de los problemas de la casa las conductas marginales, que deben admitir y disculpar en algunos subalternos, generando un sistema de control relativamente laxo. Pero existen algunas reglas que los mozos no pueden quebrar, referidas al nivel de privacidad que se viola o al método que se utiliza para hacerlo, cuya vigilancia está a cargo de servidores de mayor jerarquía. La segmentación del servicio y la fidelidad que implica cada posición se relaciona con el conocimiento de las prácticas de los mozos de inferior condición, en un sistema de vigilancia coercitiva estratificada en el grupo de los subalternos. Así, a partir de un robo realizado por Guzmán que excede los límites permitidos, el cardenal decide poner en funcionamiento esta maquinaria ${ }^{122}$. Guzmán es "azotado y desterrado del servicio de la cámara", pasando

\footnotetext{
118 "De todas estas travesuras [pequeños hurtos], por maravilla llegaban de mil una en los oídos de mi amo, ya porque los agradaba, no querían ponerme mal y me echara de casa, o ya porque, aunque me lo reñían, viendo que todo el mundo era uno, de nada se admiraban.” Ibidem, Primera Parte, p 319.

${ }^{119}$ Ibídem, Primera Parte, p 452. Aseveración hecha en referencia al cardenal que, como no tiene hijos, ama a sus criados a quienes castiga -según la mirada cándida del protagonista respecto a dicho personajesólo con fines educativos. Sin embargo, el estudio de Cavillac demuestra que la influencia del prelado pervierte al pícaro. Michel Cavillac, Pícaros y mercaderes... op cit, pp 494 y ss.

${ }^{120}$ Incluso moralistas y costumbristas denunciaron el gasto de los amos por agasajar a las sirvientas. José Antonio Maravall, La literatura picaresca ... op cit, $\mathrm{p} 206$.

${ }^{121}$ “'Por cualquiera niñería que hiciera, todos me regalaban: uno me daba una tarja, otro un real, otro un juboncillo o sayo viejo..." Mateo Alemán, op cit, Primera Parte, p 302. Ver sobre esta forma de paga entre los criados rurales: Pere Roca Fabregat, op cit, p 81 e Isidro Dubert, op cit, p 10. Estos objetos son revendidos, tal como aquellos que roban. Así, una práctica legítima dentro de la microsociedad que conforma la casa puede reproducirse en -y aplicarse a- otra que no lo es.

122 "Como era pieza conocida y faltase de allí, comenzó la sospecha general. Mas nunca se entendió que se hubiera sacado menos que con llave contrahecha. Y desto pesara mucho monseñor, tener en su casa quien se atreviera a falsearle cerraduras y más las de dentro de su retrete. Llamó a sus criados principales, para que la verdad se supiera. (...) Era el mayordomo un capellán melancólico (...) dijo que llamasen a todos los criados para que, encerrados en una pieza, se hiciera en ellos cala y cata y en sus aposentos,
} 
a ser subordinado del camarero ${ }^{123}$, proceso que lo degrada porque implica servir a un subalterno. De acuerdo con la novela picaresca, los criados pueden ocupar posiciones diversas y cambiar de estado velozmente dentro de la configuración de status en una casa. A lo largo de la obra, el personaje se somete no sólo a sus amos sino también a otros empleados a quienes sirve, en el marco de la estratificación de diversos rangos entre los subalternos.

Poco tiempo después de haber entrado al servicio del cardenal, un mozo enseña a Guzmán cómo robar la cera de las hachas y la manera en que dicho artículo es intercambiado por los criados: “...El que puede acaudalar un cabo, ya ése tiene un patrimonio, hace grandezas, compra pasteles y otras chucherías" ${ }^{, 124}$. Vemos que este "patrimonio" es sólo lo necesario para poder comprar algo mísero, aunque el narrador irónicamente describa lo contrario, pues el más acaudalado apenas si podría contar con estos pequeños bienes. En varias obras se repite la idea de la riqueza del marginal (en su situación de criado, ladrón o mendigo), que consiste en una magra subsistencia, pero que es entendida de aquella manera porque no fue obtenida mediante el trabajo manual.

Los criados temen los castigos, aunque no respetan por ello las normas: "más acaso si en ello lo hallan, en azotes lo paga, que es un juicio. Sólo esto [la cera de las hachas] se permitía hurtar, digo se hurtaba, menos mal, que si se nos permitiera..."125. La función de esta pena es simbólica y reproduce en el marco de las casas el control que se ejerce en el espacio público y que sanciona la diferencia social. Por otro lado, los mozos conocen los parámetros de tolerancia respecto a su proceder, asumiendo que era prácticamente lícito robar (en este caso la cera) dentro de ciertos límites.

Guzmán critica la actuación limitada y temerosa de sus compañeros ${ }^{126}$. El protagonista sostiene que la diferencia se proyecta en la habilidad para hurtar y los bienes que son robados, según se vendan o consuman, estableciéndose también la distinción en la astucia para la sustracción que cada uno implica. Así discrimina los robos menores de los mozos de las estafas que él realizará porque quiere demostrar que él es superior, más inteligente y más astuto, y no merece estar en el lugar que le ha

porque obra semejante no era de hombre de razón, sino atrevimiento de criado mozo". Mateo Alemán, op cit, Primera Parte, p 440.

${ }^{123}$ Ibídem, Primera Parte, p 442.

${ }^{124}$ Ibídem, Primera Parte, p 436.

${ }^{125}$ Ibídem, Primera Parte, pp 436 y 437.

126 "Eran ellos tan rateruelos, que nunca les vi meter mano en otra cosa [que la cera], dejado a parte de comida, que las tales consúmense y nunca se venden. Y aun en esto hacían mil burradas...". Ibídem, Primera Parte, p 437. 
tocado. Los mozos no son grandes ladrones, sino que se dedican especialmente a la sisa en los alimentos. Los criados no sólo son acusados por el protagonista por viciosos y traicioneros, sino que se critica fundamentalmente su carencia de audacia y de ambición, además de su condición de perezosos, que destaca a Guzmán entre todos ellos, apreciación que proyecta su pretendida distinción social ${ }^{127}$, pues la valentía era una cualidad que le quedaba reservada a la clase señorial en la sociedad de privilegio.

Los pícaros también aparecen tomados eventualmente como aprendices para desempeñar tareas junto a diversos artesanos. Sin embargo, en las representaciones de las novelas, abandonan generalmente este tipo de ocupaciones por ser demasiado trabajosas o mal pagas, por querer volcarse a la vida ociosa o bien son despedidos debido a su ineficacia o deshonestidad. De este modo se subraya la idea de los vicios incorregibles de quienes delinquen impulsados por su pobreza, en la convicción de que no serían recuperables mediante el trabajo, mientras se confirmaría que existen plazas laborales para ellos, pero que no quieren ocuparlas.

Pero habría una importante diferencia en la naturaleza de las relaciones que pueden establecer los aprendices de oficio respecto a la situación de los pícaros que aquí analizamos. Los servidores cuya representación estudiamos proceden de un ámbito de pobreza marginada que no se adapta al mercado de trabajo porque no llega a integrarse a un grupo familiar o a una clientela de modo permanente, mientras los aprendices sí se incorporan como productores de manera permanente en una unidad familiar ${ }^{128}$. Esto también explica el contraste entre sus conductas respectivas, pues los pícaros no tienen nada que perder, dado que carecen de vínculos. Si bien los aprendices podían realizar pequeños robos en casa de sus maestros, consideramos que, a pesar de que pudieran ser más o menos frecuentes, eran realizados por jóvenes no marginales que, a partir de dicha conducta podían ser luego evaluados como delincuentes ${ }^{129}$. Veamos, entonces, algunos ejemplos.

Hay casos interesantes acerca de los aprendices en otras novelas que merecen ser citados por su representatividad. Por ejemplo, Estebanillo González se coloca como

\footnotetext{
127 "El diablo trajo a palacio necios y lerdos, que se dejan caído cada pedazo por su parte; gente enfadosa de tratar, pesada de sufrir y molesta de conversar. El hombre ha de parecer al buen caballo o galgo: en la ocasión ha de señalar su carrera y fuera della se ha de mostrar compuesto y quieto". Ibídem, Primera Parte, $\mathrm{p}$ 437. Le molesta la sociedad de torpes que lo rodea, pero así se lo expone a la censura de los lectores por su soberbia.

${ }^{128}$ Pablo Buchbinder, op cit, pp 44 y 45.

${ }^{129}$ Ver sobre los robos al patrón y la posterior marginación: Bronislaw Geremek, Les marginaux... op cit, pp 120 y ss.
} 
aprendiz en una barbería, donde afeita y corta el cabello a quienes lo piden como limosna ${ }^{130} \mathrm{y}$ donde, si por un lado auxilia en todo tipo de menesteres, por el otro aprende el oficio sobre los menesterosos. La novela describe a través de varios casos la torpeza del aprendiz y su falta de responsabilidad para el trabajo. El problema reside principalmente en que sus errores comprometen al maestro, que tiene que responder por él y cuya fama resulta dañada por el desempeño del subalterno. El narrador describe su indolencia respeto al trabajo, que podríamos considerar una forma individual de rebeldía. Esta posibilidad implica una diferencia con otro tipo de ocupaciones exclusivamente domésticas -siempre que la mala conducta del criado no fuera pública, ni pusiera en cuestión la autoridad o fama del amo-, pues el barbero es perjudicado en su ocupación por la desidia del criado ${ }^{131}$. Además, en la trama comunitaria, esto también involucra al padre del pícaro, que debe responder por las falencias del muchacho. Sin embargo, el mozo no es despedido por el amo, sino que permanece en la barbería desempeñando menesteres menores que lo humillan pero el muchacho, lejos de mantenerse ocioso, utiliza este tiempo para instruirse ${ }^{132}$. La novela también ilustra otros actos de rebeldía que los historiadores atestiguan entre los criados: el robo de los materiales de trabajo del amo y la fuga. La narrativa los representa como dos

\footnotetext{
${ }^{130} \mathrm{El}$ aprendizaje se hace sobre quienes no pueden pagar: "Pareciendo al cabo de algunos días a mi amo que ya sabría algo del oficio, por lo atento que me vía estar siempre a los tormentos de agua y fuego, me mandó quitarle el cabello y barba a un pobre que había llegado a pedirle una rapadura de limosna; que en las cabezas y rostros de los tales siempre se enseñan los aprendices, por que llueva sobre la poca ropa". Antonio Carreira y Jesús-Antonio Cid (eds.), op cit, Tomo I, p 122.

${ }^{131}$ El oficio de barbero era considerado indigno y se asociaba habitualmente al de sacamuelas y sangrador, oficios a los cuales alcanzaba el tabú de la sangre. Que se ejecutaban esas operaciones en la barbería lo delata el hecho de que Estebanillo estudiara en los libros de cirugía que tenía el barbero, durante el tiempo en que estuvo suspendido. Quizás por este motivo encontramos a varios pícaros interviniendo como aprendices de este oficio. "Quedó tan escarmentado mi maestro de ver en mí tan malos principios que, temiendo que fuesen peores los fines, jamás me quiso ocupar en dejarme afeitar a ninguna persona de importancia; sólo me empleaba en los de gratis y en los peregrinos pobres, los cuales llegaron a ser pocos y a desminuirse, porque el que una vez se ponía en mis manos no volvía otra, aunque anduviese como ermitaño del yermo". Ibídem, Tomo I, p 135.

${ }^{132}$ Luego de que Estebanillo lastima a un hombre al que afeitaba, cuando el barbero encuentra la situación "Echó toda la gente fuera y, quedándose solo con el herido y con su mujer (que ya lo había conocido por señas que le había dado y por el metal de la voz), envió a llamar a mi padre, el cual, imaginando que lo llamaba para remediar alguna travesura mía, de que no se engañaba, acudió al momento, y viendo aquel espectáculo horrible, con ser hombre muy severo, no dejó de sonreírse un poco. Trataron los dos de quietar y contentar aquella figura de león de piedra que tenían delante, por que no se querellase y diese queja a la justicia; y saliendo mi maestro a curarlo y darlo sano, y ofreciéndole mi padre diez escudos, quedó muy contento y se retiró a su casa. Supo mi maestro adónde yo estaba, y trayéndome a la suya, después de haberme reñido muy bien, me dio por castigo, como al fin mi juez competente, suspensión del oficio en el desbarbar por tiempo de un mes; en cuyo término estudiaba algunas veces en los libros de cirugía, tiniendo de los correspondientes de la tienda algunos provechos de limpiarles los sombreros (para lo cual había comprado una escobilla a mi costa) y quitarles los pelos de las capas, echándoselos y muchas veces encubiertamente para obligarlos a ofrecer." Ibidem, op cit, Tomo I, p 132.
} 
características del pícaro: su peregrinar (y la actividad en las posadas) y la esperanza de medrar en pos de acceder a los símbolos de un status superior ${ }^{133}$.

Luego de ese viaje, el pícaro se pone al servicio de un cirujano ${ }^{134}$. Esta ocupación es utilizada por Estebanillo para robar a quien está por morir o al difunto. En la descripción de esta práctica encontramos la utilización subversiva de la oración y la apelación a la divinidad, a la cual se convoca para que garantice al pícaro el éxito de su robo $^{135}$. Esto se vincula con la religiosidad marginal que representa la narrativa picaresca, que consiste en una creencia particular e individual, con un Dios que asiste al pícaro y al que apela para que lo auxilie.

Cuando Guzmán sirve al ventero aprende junto a su amo diversos trucos para engañar a las personas que pasan por la venta, relacionados con la medida y calidad del alimento para los animales y el recargo de los precios sobre los consumos de quienes paran allí ${ }^{136}$. Aquí se muestran varios estereotipos de interés, teniendo en cuenta que se

\footnotetext{
${ }^{133}$ El narrador describe su fuga (y el robo de las herramientas) como un acto de rebeldía por no aceptar la autoridad del amo. También el uso del oficio aprendido para sobrevivir en el camino: “... y fue tanta mi presumpción y desvanecimiento que me persuad[i]ó a que yo solo, con lo que sabía, podría sus[t]entar mi persona y traerla muy lucida y servida de criados. Y por verme fuera de dominio, y enfadado del poco caso que se hacía de mí, cogiéndole a mi amo las mejores navajas y tijeras, y una bacía y los demás aderezos de pelar lechones racionales, me salí tercera vez de Roma a la vuelta de Nápoles, en cuyo camino y posadas dél pasé plaza de barbero apostólico...” Ibídem, Tomo I, pp 135 y 136.

${ }^{134}$ En el requerimiento de trabajo, vemos al pícaro dirigirse al hospital, donde sabe que será recibido. Por otro lado, en la forma de ofrecerse, volvemos a ver la locuacidad e ingenio que caracterizan a los personajes de la picaresca: "Fuime derecho a Santiago de los Españoles, que estando a título de hospital es un ausilio y amparo de los desta nación y un edificio sumptuoso. Hablé con el dotor dél acerca de acomodarme, el cual se llamaba Cañizares, de quien fui remitido a Juan Pedro Folla, que entonces ejercía el oficio de cirujano mayor; di a entender ser barbero y cirujano examinado, y no de los peores en aquel arte, el cual me recibió para ser enfermero y uno de sus ayudantes". Ibídem, Tomo I, pp 136 y 137.

${ }^{135}$ Aquí vemos varias cuestiones, por un lado, el pícaro aprovecha la atención que brinda al moribundo para robarle, pero por otro, mientras realiza esta treta, encontramos también una apropiación subversiva de la religión: mientras reza y quienes lo ven piensan que ruega por el alma de la persona a quien atiende, él sabe que lo hace para evitar ser descubierto: "Yo, viendo que se llegaba la hora en que él diese cuenta a Dios, y yo tomase cuenta a su bolsa, envié con un compañero mío a que le trujese el capellán mayor, y yo, haciendo del hipócrita, desalado, más por el dinero que por el medio difunto, me eché de buces sobre la cabecera y diciendo 'JESÚS, MARÍA, en manos tuas, Domine, encomendó espiritu meun', le iba metiendo la mano debajo de la cabecera; y al instante que agarré con la breve mina de tan preciosos metales la fui conduciendo a mi faltriquera, volviendo a repetir:

-JESÚS, JESÚS, Dios vaya contigo.

Pensaban los circunstantes que el 'Dios vaya contigo' lo decía al enfermo, siendo muy al contrario, porque yo lo decía a la bolsa, por el peligro que corría desde la cabecera hasta llegar a ser sepultada en mis calzones." Ibídem, Tomo I, p 143.

${ }^{136}$ Así narra Guzmán el aprendizaje de diversas tretas junto al ventero, que incluyen el engaño y el estudio minucioso de los personajes a quienes timan: "Allí supe adobar la cebada con agua caliente, que creciese un tercio, y medir falso, raer con la mano, hincar el pulpejo, requerir los pesebres y, si alguno me encargaba diese recaudo a su cabalgadura, le esquilmase un tercio. Algunos mancebilletes de ligas y bigotes venían a lo pulido y sin mozo, haciendo de los caballeros. Con los tales era el escudillar, porque llegábamos a ellos y, tomándoles las cabalgaduras, las metíamos en su lugar, donde les dábamos libranza sobre las ventas de adelante para la media paga; que la otra media recebían allí luego de socorro, aunque mal medida (...) La cuenta de la mesa era para mí gracioso entretenimiento, porque siempre nos arrojábamos al vuelo y estábamos diestros en decir: 'tantos reales y tantos maravedís, y hágales buen
} 
trata de representar un momento de formación del pícaro. Constatamos por un lado el prototipo del ventero, personaje de mala fama que vive en un lugar de circulación de personas y está en relación con todo tipo de actividades y conductas condenables. Las ventas y posadas, como los caminos, son espacios a los cuales la picaresca recurre: los mozos apicarados que pasan por la venta simulan un status que no tienen a partir de su imagen y es el escenario habitual de los duelos de astucia, en los cuales se prueba quién es más ágil para la estafa, si ellos o el ventero. Este comerciante especula con la condición de forasteros de quienes circulan por su lugar, situación que habilita sus abusos. Las ventas son también lugares de prostitución, actividad con la que se familiariza el pícaro que es educado alli ${ }^{137}$. Guzmán aprende de la circulación de diversos personajes, a quienes imita y, a través del ensayo y error, el pícaro adquiere la experiencia de la marginalidad, que se define a lo largo de su propia existencia.

La venta resulta en la picaresca, como lugar de paso de forasteros, un espacio sospechoso, tanto como sus dueños y trabajadores, a quienes se les imputa todo tipo de estafas (recordemos el ejemplo inaugural de El Guzmán con los huevos empollados ${ }^{138}$ ). Son además lugares donde se alían distintos tipos de marginales, que no sólo circulan, sino que allí se constituyen como tales.

Otras obras también representan minuciosamente la vida del mesón. En La pícara Justina se dedica un capítulo completo a la descripción de este ámbito ${ }^{139}$. Justina se cría en un mesón, donde su padre le enseña diversas artimañas para robar y engañar a los huéspedes (como la forma de servir la comida, avalar el juego, lucir a las muchachas

provecho', cargando siempre un real más que una blanca menos.” Mateo Alemán, op cit, Primera Parte, pp 270 y 271.

Así se describe la oferta de prostitutas en la venta: "Teníamos también en casa unas añagazas de munición para provisión de pobretos pasajeros, y eran ellas tales que ninguno entrara en la venta a pie que dejara de salir a caballo". Ibídem, Primera Parte, p 272.

${ }^{138}$ Nos referimos a la primera desventura de Guzmán, que al iniciar su camino para en una venta, donde le sirven una tortilla hecha con huevos empollados, pues la ventera suele engañar mezclándolos con los buenos. Ibídem, Primera Parte, pp 167 y ss. La idea de la venta como lugar sospechoso también aparece en las ordenanzas: "Que los mesoneros no consientan dormir en su casa a personas de mal vivir. Otrosy, que ningún mesonero consienta en su casa dormir a ningún hombre de la çibdad o forastero con mujer de la mancebía de la çibdad ni de otra parte, que no sea su mujer propia e conocida, ni dé cama para ello de día ni de noche, so pena de çien açotes. (...) Que no se acoja gente de mal vivir. Otrosy, que ningún mesonero acoja en su casa a gente de mal bebir, y que no tenga en su casa a nadie más de tres días sin haçerlo saber a la Justiçia desta çibdad, para que sepa la manera de bevir de cada uno, so pena de mill maravedís, repartidos como dicho es". "Ordenanza de los fieles de los mesoneros", Capítulo XXXIX, Títulos 428 y 431, respectivamente, en Carlos del Canto de la Fuente y Victoriano Antonio Carbajo Martín, Ordenanzas municipales de Zamora. Siglos XV y XVI. Zamora, Diputación de Zamora, 1991, p 175.

139 Así es descrito metafóricamente el mesón: “Oh mesón, mesón! Eres esponja de bienes, prueba de magnánimos, escuela de discretos, universidad del mundo, margen de varios ríos, purgatorio de bolsas, cueva encantada, espuela de caminantes, desquiladero apacible, vendimia dulce..." Francisco López de Úbeda, La pícara Justina. Madrid, Cátedra, 1991. Edición a cargo de José Miguel Oltra, p 133. 
ante la clientela y, tal como aprende Guzmán, sisar parte de la cebada). El relato hace hincapié en la premeditación, técnica y sistematicidad aplicadas en este tipo de prácticas $^{140}$.

Entre los aprendizajes relacionados con la desviación en el ámbito de socialización, volvemos a remitirnos al Lazarillo. El hijo del molinero sirve a un falso bulero “...el más desembuelto y desuergonçado y el mayor echador dellas..."141. Este tratado describe las estafas efectuadas por el amo, que contribuyen a la corrupción de Lazarillo $^{142}$, pues entonces el muchacho aprende a estafar a través de la especulación con la creencia de los fieles, en una trama en que participan los estratos bajos del clero y el poder municipal.

Tal como entre los gremios e incluso en las normativas para ocupaciones agrícolas se establecía que se debía respetar la contratación ajena sobre el personal, la picaresca muestra a los eventuales amos de los pícaros respetándose los unos a los otros la disposición sobre los dependientes y no compitiendo por ellos, aunque los empleen una vez que han dejado de servir a su amo anterior (a pesar de que esto se debiera a una falta del subordinado) o encargándose de dotar con un nuevo amo a los servidores de quienes prescinden.

Hemos visto hasta aquí variadas ocupaciones que pueden desarrollar los pícaros, según la representación literaria. Observamos la celeridad con que cambian su empleo como consecuencia de un justificado despido o su deseo de abandonarlo. Los escritores buscan adjudicar a sus perezosos e inconstantes personajes la responsabilidad por no tener un trabajo. Sin embargo, también observamos la rapidez con que se los tomaría, la necesidad de estos hombres de obtener dichos empleos y su ductilidad para ocuparse en todas las tareas que se les presentan. La habilidad para obtener estos trabajos se debe a

140 "La cebada no se mida al ojo, antes el arca en que estuviere esté en otro aposento más adentro del portal, y sea oscuro, y, al medir, siempre la que midiere vuelva barras a quien le pidiere recado. Las medidas estén siempre dentro del arca, porque, mientras os dicen quíteme allá esas pajas, esté la medida conclusa. El rasero no os obligo a tenerle en el arca, que, si hay tiento, el rasero está en la mano. Y si por la prisa, o por comprarse cara la cebada, o con celo de hacer bien por vuestro padre, quisiéredes medir con el celemín del gusto y con el rasero del ojo, bien podréis, que más valen vuestras manos que un medio celemín y vuestros ojos más que mil raseros. Y por eso, os encargo que la cebada esté siempre en parte abscondida, y el arca no tenga otro fiador de la tapa más que vuestra cabeza; y con eso estorbaréis que os husmeen el arca." Ibídem, p 135.

${ }^{141}$ Anónimo, op cit, p 205.

142 “Quando él hizo el ensayo, confiesso mi pecado que tambien fuy dello espantado y crey que ansi era, como otros muchos; mas con ver despues la risa y burla, que mi amo y el alguazil lleuauan y hazian del negocio, conosci cómo auia sido industriado por el industrioso e inuentiuo de mi amo. (...)

Y aunque mochacho, cayome mucho en gracia y dixe entre mi:

'iQuantas destas deuen hazer estos burladores entre la innocente gente!'

Finalmente, estuue con este mi quinto amo cerca de quatro meses, en los quales passé tambien hartas fatigas." Ibidem, pp 218, 219 y 228. 
que el pícaro retratado como inteligente y ambicioso, aspectos que son parte de las criticas que hacen de ellos sus amos (también acusados de ser tan inmorales, avaros, estafadores, etc., como sus criados). Por tanto, si bien los autores responsabilizan a los hombres del vulgo de la crisis de empleo porque no serían voluntariosos para el trabajo, por otro lado también señalan su intención de ocuparse cuando lo necesitan.

\section{El final del servicio}

En las novelas picarescas se reitera que la no adecuación a la condición heredada, o a la cual se arribó a través de la acumulación de desventajas, explica las prácticas de los sirvientes en casa de sus señores. Cuando sus comportamientos resultan inadmisibles para el amo, conducen habitualmente a su despido, aunque éste no resulta un motivo excluyente, ni el único. La circulación de los criados es frecuente: entran rápidamente a servir, ocupación que mantienen durante un tiempo indeterminado, y luego continúan su existencia picaresca al separarse de la unidad doméstica.

Guzmán abandona su primer trabajo porque considera humillante servir al ventero (“...no quisiera ser allí hallado y en aquel oficio, por mil vidas que perdiera." ${ }^{143}$, mientras compara la cobardía de quien sacrifica su libertad en pos de la seguridad con la valentía de los jóvenes mendigos que deambulan por los caminos a pesar de los riesgos penales y económicos de dicha existencia ${ }^{144}$. Este pasaje pinta la ambición del pícaro, quien, según Maravall “... sabe que tiene que someterse al gobierno y a la fuerza de los poderosos; pero trata de ganar el máximo de libertad mediante renuncia o mediante engaño" ${ }^{" 145}$, pues la libertad picaresca persigue la autonomía del individuo respecto a cualquier otro, representación que refiere más a la realidad del autor que a lo que sucede con los pícaros en la sociedad.

El servicio de Guzmán para el capellán termina con el despido del joven como consecuencia de su inclinación al juego, que no es tolerada por el amo, quien por otro lado sí incentiva en él otras conductas condenadas. Pero cuando se describe la expulsión del criado, a quien se provee de vestimenta antes de salir, la intención reformadora del

\footnotetext{
${ }^{143}$ Mateo Alemán, op cit, Primera Parte, p 274.

${ }^{144}$ Este discurso que remite a la caballería y la heroicidad pero a través de la exposición de un antihéroe puede tener relación con el Quijote. Tácitamente se está comparando con un caballero errante.

${ }^{145}$ José Antonio Maravall, La literatura picaresca ...op cit, p 332.
} 
religioso es destacada por el pícaro arrepentido ${ }^{146}$. El narrador considera benévolo el propósito del eclesiástico (a pesar de la evidencia de que no lo sería, porque sólo es un amo permisivo como consecuencia de su propia desviación), mientras evalúa que la motivación del embajador para contar con un criado es el aumento de la estima social $^{147}$.

No solo es denunciada la deshonestidad sino que también lo es la cobardía de los criados, pues como consecuencia de este defecto (que se considera inherente al vulgo) no colaborarían con los amos en situaciones riesgosas. La disolución del vínculo puede ser motivada por la huida de los criados en situaciones adversas a los amos, mientras la sociedad de antiguo régimen condenaba a los infieles y desleales ${ }^{148}$. También eran motivo para la finalización de la relación laboral los malos tratos, que provocaban la fuga de los criados y de los aprendices.

En El Lazarillo encontramos diversas situaciones por las cuales el joven termina su vínculo con un amo. En la primera oportunidad, la separación tiene lugar cuando el muchacho se venga del ciego. Mucho se ha explayado la crítica acerca del episodio de la calabazada y la posterior y diferida acción de Lázaro ${ }^{149}$, cuando hace golpear al ciego contra un poste. Pero aquí lo que veremos es que, amén de la crueldad del amo, el criado expresa su individualidad y su decisión de no continuar soportando sus maltratos. Aquí se presentan dos cuestiones, por un lado, el mísero trato que le da su amo, y por otro la jerarquía que, a pesar de la pobreza de ambos, sigue existiendo. En este caso, el superior es otro pobre itinerante como Lázaro, de manera que esta relación de servicio encubre una unión de dos personas para deambular. A través de esta novela podemos observar un ambiente de miseria generalizada donde el niño es entregado por su madre a un hombre que no es menos pobre que ellos.

La separación de su segundo amo es consecuencia de los robos del criado que, al ser descubierto es castigado a palazos y expulsado. En el segundo tratado la crítica se centra en la conducta avara y glotona (anticristiana) del clérigo, que hambrea a Lazarillo. Este episodio, antes que mostrar el mal comportamiento del pícaro, nos

\footnotetext{
${ }^{146}$ Mateo Alemán, op cit, Primera Parte, p 460.

${ }^{147}$ Ibídem, Primera Parte, p 464.

148 Por ejemplo, Lazarillo abandona a su amo el alguacil, por considerar que desempeña un oficio peligroso: "Despedido del capellan, assenté por hombre de justicia con vn alguacil. Mas muy poco viui con él, por parescerme oficio peligroso. Mayormente, que vna noche nos corrieron a mi y a mi amo há pedradas y a palos vnos retraídos. Y a mi amo, que espero, trataron mal; mas a mi no me alcançaron. Con esto renegué del trato.” Anónimo, op cit, p 231.

${ }^{149}$ Ver Bronislaw Geremek, La estirpe... op cit, $\mathrm{p} 243$.
} 
informa sobre el trato cruel hacia los desprotegidos y cómo dicho comportamiento era legitimado socialmente.

El tercer amo de Lázaro, el escudero, no lo despide, sino que huye por sus deudas, dejando al niño solo y teniendo que responder por él ante quienes vienen a prenderlo, lo que muestra que el servicio no podía garantizar ni la estabilidad ni la retribución.

Una vez que el mozo ha superado el hambre, se suceden algunos episodios breves de los cuales se nos informa poco, pues la necesidad que guiaba las anteriores peripecias, desaparece de la narración ${ }^{150}$. En el séptimo tratado, Lázaro es empleado por un alguacil ${ }^{151}$, pero decide abandonar este trabajo por considerarlo peligroso, indicando la resistencia local a este tipo de agentes municipales ${ }^{152}$.

Lazarillo decide abandonar a su cuarto amo, el fraile mercedario, por sus abusos: "Este me dió los primeros çapatos, que rompi en mi vida; mas no me duraron ocho dias. Ni yo pude con su trote durar mas. Y por esto y por otras cosillas, que no digo, salí dél"153. Este episodio se anticipa cuando las costureras (quienes, se insinúa, son prostitutas) le presentan al clérigo, introducción que da cuenta de la conducta sospechosa del religioso ${ }^{154}$.

En el siguiente tratado, Lázaro abandona su trabajo como aguador. Entonces, el joven ha entrado en una lógica diferente. Ha atendido a la posibilidad de obtener ganancias, calculado y tenido una conducta que le ha permitido ahorrar dinero. Dicho capital es invertido en la compra de un ajuar, que él considera necesario para ascender social y económicamente. El cambio de ropa indica la nueva lógica del personaje, que decide contabilizar su ganancia, ahorrarla con el objetivo de adquirir el atuendo para, de este modo, poder aspirar a más ${ }^{155}$. Esto se vincula con las frecuentes simulaciones que

\footnotetext{
${ }^{150}$ Lazarillo también informa que se asentó con un maestro de pintar panderos para moler los colores, pero no otorga mayor detalle que haber padecido "mil males". Anónimo, op cit, p 229.

${ }^{151}$ Así, Lázaro, que sufrió la persecución de la justicia cuando era niño, ahora trabaja a su servicio. Ver Douglas Carey, op cit, p 38.

${ }^{152}$ Esto se puede observar en las ordenanzas locales: “Otrosí ordenamos y ponemos entre nos que ninguna persona sea osada de murmurar, ni maldecir ni injuriar a los regidores, repartidores de concejo, ni contra otros cualesquier oficiales de concejo que hayan jurado sus cargos u oficios, diciendo que no hacen lo que deben en sus oficios, so pena de tres reales de plata, a cada uno que lo contrario hiciere, para el concejo." Ordenanzas del concejo de Cabezón. Año de 1624, capítulo 47, en Juan Baró Pazos y Rogelio Pérez Bustamante, op cit, p 656.

${ }^{153}$ Anónimo, op cit, p 204.

154 “Al qual ellas le llamauan pariente.” Ibidem, p 203.

155 "Fueme tan bien en el officio, que al cabo de quatro años, que lo vsé, con poner en la ganancia buen recaudo, ahorré para me vestir muy honrradamente de la ropa vieja. De la qual compré vn jubon de fustan viejo y vn sayo raydo de manga trançada y puerta y vna capa, que auia sido frisada, y vna espada de las viejas primeras de Cuellar. Desque me vi en habito de hombre de bien, dixe a mi amo se tomasse su asno,
} 
los pícaros ejercían a través del vestuario, las cuales se corresponden con la cultura de apariencias de la época.

El final de la única relación de servicio en que se inscribe Pablos simboliza y legitima el abismo social entre el pícaro y su amo. Mientras el primero lee la carta en la cual su tío el verdugo narra cómo ahorcó a su padre como castigo por sus delitos, don Diego es instado a través de una carta de su padre a alejarse del pícaro por la mala fama que éste había cobrado. El joven lamenta tener que despedir a Pablos, a quien promete acomodar con un amigo suyo para que le sirva. Este episodio da cuenta del antagonismo social en las existencias de estos dos jóvenes a quienes diferencia su estamento, que aquí se muestra a través de las dos cartas y constituye el motivo de la separación. Sin embargo, el amo se encarga de dar seguridad y garantía a su antiguo subordinado ${ }^{156}$. Este episodio resalta un rasgo de humanidad del primero, así como la conciencia de su degradación por parte del último.

\section{Conclusión}

En el presente capítulo hemos examinado la representación de cómo se conjugan dos fenómenos sociales, uno correspondiente a la disciplina de los sectores integrados socialmente, y pertenecientes a la élite social principalmente, y otro referente al sometimiento de los hombres libres al trabajo asalariado. Respecto al primero, observamos la necesidad de ostentar la comitiva de criados domésticos por parte de los sectores poseedores, como una forma de capital simbólico. Paralelamente, en el marco de disciplinamiento de los sectores populares y de la mano de obra, se obligaba a los hombres a encuadrarse en la dependencia de un señor, quien sería su garante.

El servicio del marginal tiende a reproducir por un lado la economía y/o el status de quien lo emplee, pero también a sí mismo, pues logra de este modo la subsistencia, de manera que no es integrado ni eliminado. Es paradójico que los grupos sociales que los emplean demanden, para la reproducción de su capital simbólico, la contratación de individuos que no tienen status, tal como observamos precedentemente.

que no queria mas seguir aquel officio". Ibídem, p 230. Es irónica la descripción de la prosperidad del personaje, empleada en la compra de ropa gastada y miserable que, sin embargo, en el ambiente de miseria le daba respetabilidad.

${ }^{156}$ Pablos narra la relación sincera que mantiene con don Diego, a quien no puede engañar respecto a su procedencia y conductas, y la compasión de su joven amo: “... que a él, como a quien sabía quién yo soy, me pude descubrir sin vergüenza. Lastimóse mucho y preguntome que qué pensaba hacer". Francisco de Quevedo, op cit, p 94. 
Según la representación picaresca, algunos marginales que fueron obligados a hallar ocupación durante la temprana modernidad cumplieron ocasionalmente la función de criados dentro de las casas de la nobleza y de la burguesía urbana, en cuyo seno establecieron vínculos, tanto entre ellos, como con personas de otros estratos sociales. Este fenómeno contribuiría a la reproducción de las conductas desviadas de los miembros de ambos grupos, aunque sólo serían juzgados como tales los marginales, como consecuencia de la clasificación que se les había impuesto. Según los autores aquí repasados, el servicio, lejos de disciplinar a los pícaros, no hizo más que permitir la reproducción del grupo y sus conductas, en el marco de las casas en las cuales eran empleados. Lo que sugieren las novelas es que, por los motivos enunciados, dicha ocupación no devino en su integración social, sino que por el contrario pudo alimentar su progresiva marginación, pues una infracción podía conducir a otras mayores. Si el sistema económico-social generaba sectores marginales, a quienes en este período se intentaba domesticar de una $\mathrm{u}$ otra manera, la narrativa sugiere que este objetivo no sería alcanzado con las políticas instrumentadas al respecto.

Según la narrativa, los criados roban o traicionan a sus pares, dando cuenta de la falta de conciencia de grupo y de solidaridad, así como la imposibilidad de que dichas nociones y vínculos fueran generados por parte de los marginales. Las relaciones dentro de las casas de los señores refractan las que desarrollan fuera de ese espacio, en un sistema de lazos volátiles que cambian permanentemente, como consecuencia de la deslealtad y el delito. La casa puede presentarse como un espacio donde este grupo interactúa estableciendo relaciones de competencia y cooperación, pero la propia transitoriedad de la ocupación imposibilita los vínculos estables. Esta es una observación trascendente a la hora de analizar las contradicciones que se presentan en la estigmatización de este sector, pues si por un lado se describe su imposibilidad de vincularse con otros agentes y tener conciencia de sí, por el otro se los acusa de conformar bandas ocultas.

Los pícaros que entran como criados mantienen conductas marginales en su relación con el patrono, pues proyectan las que han experimentado en la sociedad que los rodea. Sin embargo, encontramos cuestiones ambiguas que implican el afecto que eventualmente pueden sentir amos y criados entre sí transgrediendo la geometría social, aunque las novelas denuncian una y otra vez el maltrato de muchos amos hacia los últimos. El vínculo que se establece entre ambos no sólo está teñido por las deficiencias 
para trabar relaciones por parte de los marginales, sino especialmente por la explotación en el marco de un proceso de cambio social.

Los miembros de la casa se envuelven en situaciones que implican conductas asociales (estafas o robos, por ejemplo), compartidas por todas las jerarquías sociales. Estas experiencias sirven a la formación del pícaro que, de esta manera adquiere las destrezas que desarrolla a lo largo del relato biográfico. En algunos casos se describe también a amos que son marginales o cuya condición linda con esta situación, pero en otros, aunque los patronos son personajes socialmente integrados, también tienen conductas desviadas que aparecen aprendidas y reproducidas por el pícaro. La consecuencia de dichas acciones difiere, según provengan del pícaro o del amo, en tanto no existe una misma ley para todos o bien porque el segundo posee recursos sociales de los cuales el criado no dispone.

Por otro lado, si en la documentación política se acusa a los hombres baldíos de resistirse al trabajo, tal como revisamos en el capítulo tercero, las novelas representan lo contrario, pues en cada encuentro con potenciales amos, los pícaros no tardan en ofrecerse y mostrar (o mentir acerca de) sus cualidades en pos de ser contratados. Al mismo tiempo, mientras exhiben su deseo de emplearse, también hacen una exposición acerca de la penuria en la que viven y la necesidad de un remedio para ella. Por otro lado, tampoco se trata, como vimos en las ordenanzas y resoluciones de las Cortes, de hombres que sólo se ofrecen para el servicio doméstico, improductivo desde el aspecto económico, sino que, como vimos, cuando se les oferta una posición en el marco del artesanado o la producción rural, también están dispuestos a ejercerla.

Estas observaciones contribuyen a la definición de los marginales como tales: constituyen un sector social fronterizo entre la exclusión y la integración y la narrativa ilustra su paso de limosneros a huéspedes de un señor, para desempeñarse luego como criados.

En el próximo capítulo examinaremos cómo estas características ambiguas de los marginales, en tanto que reproducen su propia condición, pero son funcionales a la comunidad donde se enmarcan, también se proyectan en la mendicidad, actividad que ejercen de manera temporal aunque frecuente. 
CAPÍTULO 5

ENTRE LA CARIDAD CRISTIANA Y LA

DELINCUENCIA: LA MENDICIDAD EN LA

LITERATURA PICARESCA 


\section{Introducción}

La mendicidad constituye un objeto de especial preocupación, tanto para los teólogos como para los juristas o los literatos tempranomodernos. En el capítulo tercero hemos revisado la procuración en Cortes y la abundante consideración de la escolástica en torno a este problema, discurso teórico que repasamos también aquí, vinculándolo con las ideas expresadas en los textos de carácter literario y legislativo. Aunque se ha atendido principalmente a la regulación del trabajo y su disciplinamiento, los historiadores también han observado otras formas de subsistencia entre los sectores pauperizados $^{1}$.

En el presente capítulo nos dedicaremos al análisis de la descripción de la mendicidad, tal como se presenta en las obras picarescas que venimos teniendo en consideración. Las novelas condenan -en mayor o menor medida- la rapacidad de los pícaros a través de dos mecanismos, por un lado la expresión de la postura del autor en el prólogo y, por el otro, la descripción de las conductas de los pícaros y la narración de los desengaños que sufren aquellas personas que los benefician.

Los autores se expresan en las palabras preliminares para manifestar su rechazo hacia ciertas conductas de los marginales y prevenir a los potenciales lectores de las ruindades con que los acechan: "Aquí hallarás en todo genero de Picardia (de que pie[n]so que los mas gustan) sutilezas, engaños, inuenciones, y modos, nacidos el ocio para viuir a la droga, y no poco fruto podras sacar del si tienes atención al escarmiento..."2. Los literatos pretenden demostrar que la animadversión que ellos expresan es una consecuencia ineludible de los comportamientos descriptos en las novelas. Sin embargo, las obras testifican la popularidad y generalidad de la limosna callejera, así como la piedad que siente la población integrada hacia los mendigos.

En este capítulo analizaremos la representación de la limosna callejera a través del examen de dos cuestiones: en primer lugar, la imagen que el autor pretende exponer ante su público lector, en tanto la literatura tiene una función de difusión de ideología; en segundo término veremos cómo, según este retrato, se efectuaba la demanda de limosnas y por qué motivo la sociedad era sensible hacia estos ruegos.

\footnotetext{
${ }^{1}$ Ver Mónica Bolufer Peruga, "Entre historia social e historia cultural: la historiografía sobre pobreza y caridad en la época moderna", en Historia Social. N ${ }^{\circ} 43$, Valencia, Universidad Nacional de Educación a Distancia, 2002, pp 105-127.

${ }^{2}$ Francisco de Quevedo, op cit, p 7.
} 
Existía una divergencia entre la realidad del pobre y su representación, mediante la cual se le atribuía constituir el agente de contagio de algún mal. La aristocracia no podía tener certezas respecto a la conducta de los marginales ${ }^{3}$, por eso, tal como vemos en las novelas, se presupone el ocultamiento de los mendigos: el de sus cuerpos, el de sus formas de vincularse y el de sus creencias.

La historia social ha reparado acerca de la variación en la percepción de los pobres como consecuencia del proceso de pauperización que tuvo lugar a partir del siglo XIV. Los indigentes fueron descriptos hasta el siglo XIII individualmente y luego como un fenómeno general, mientras se desdibujaba la imagen ideal del pobre que lo asimilaba a Cristo y se veía la miseria como fenómeno material ${ }^{4}$. Sin embargo, en la temprana modernidad, el desheredado volvió a ser retratado individualmente, pero no como figura digna de piedad, sino como delincuente o con probabilidades de llegar a serlo.

Así, la lucha contra la mendicidad tuvo lugar en el marco de las distintas formas de embate sobre la cultura de los sectores populares (tanto integrados como minorías y marginales $)^{5}$. Nos referimos a la persecución, criminalización o erradicación por medio de diferentes aparatos de poder (religioso o secular, aunque con una presencia cada vez mayor del segundo), de diferentes grupos que eran parte de los sectores subalternos de la sociedad, cuyas conductas eran tipificadas para convertirlas en delito durante un período de desarrollo del derecho ${ }^{6}$. En el caso que nos ocupa, la literatura promueve el hostigamiento a los mendigos, además de su vigilancia por parte de la sociedad.

La picaresca propone el prototipo del hombre joven y sano que recurre al fingimiento de deficiencias físicas para limosnear, actividad que combina con otras para sobrevivir, pues los pícaros ejercen diversas ocupaciones no especializadas que alternan con varias actividades ilícitas y otras éticamente cuestionables: una mendicidad

\footnotetext{
${ }^{3}$ Así sostenía Vives. Antonio Serrano González, op cit, p 167.

${ }^{4}$ Carmen López Alonso, op cit, p 267.

${ }^{5}$ Sobre el embate de la Iglesia contra las creencias populares, ver Carlo Ginzburg, El queso... op cit, especialmente $\mathrm{p} 89$.

${ }^{6}$ Iñaki Bazán Díaz sintetiza: "El crimen es, en definitiva, el marco de referencia, por antítesis, de la gramática de la conducta, y en la medida en que se produzca una mayor o menor reacción contra las actitudes criminales a través de la pena, sabremos 'la intensidad de los sentimientos colectivos que el crimen ofende'; es decir, podemos percibir cómo van surgiendo nuevos valores sociales a partir del conocimiento de la criminalización de las conductas, comportamientos y actitudes...”. Iñaki Bazán Díaz, "La historia social de las mentalidades y la criminalización de las conductas", en Barros, Carlos (ed.). Historia a debate. Tomo II: Retorno del sujeto. Santiago de Compostela, Historia a Debate, 1995, pp 85101, pp 95 y 96.
} 
condenada, estafas, juegos de azar, robos, etc. Se trata de hombres que, como eran físicamente aptos para trabajar, tenían prohibido limosnear. Por estos motivos, necesitaban disimularse mediante un atuendo de "pobres", constituido fundamentalmente por su vestimenta y la simulación de algún tipo de deficiencia o enfermedad. Por un lado, la apariencia de debilidad generaba piedad en los posibles benefactores; en segundo término, esa simulación era una estrategia ineludible porque la mendicidad de los hombres saludables era perseguida dado que podían trabajar, según un criterio que ignoraba el conflicto social, la falta de empleo y la dificultad de adaptación de los agentes pauperizados a las condiciones del trabajo asalariado.

\section{El teatro del mendigo}

En el marco de la cultura de la temprana modernidad, la representación visual era inherente a la percepción de la realidad. La picaresca demuestra la importancia de la dramatización, que es referida con mayor o menor frecuencia según cada autor: se trata de descripciones de las diversas pantomimas que ponen en marcha los personajes, provenientes de distintos sectores sociales y con variadas finalidades, que van desde la diversión hasta la supervivencia o el engaño malicioso. Encontramos muchos y variados personajes que son mentirosos ${ }^{7}$, sin embargo, la condena moral acerca de sus embustes varía según quién los ejecute. En este capítulo nos ocupamos del retrato de los engaños que realizan los limosneros cuando piden.

Cuando revisamos las novelas picarescas, encontramos que el mudar de vestimenta se vincula con la necesidad que tienen los mendigos de mostrarse ante la sociedad, según situaciones determinadas, recurso al cual apelan con mayor o menor intensidad los diversos autores ${ }^{8}$. Según estas imágenes, el cambio de atuendo es funcional a la rapacidad de los pícaros, que necesitan disimular su desvinculación social para estafar o vestirse de "pobres" para limosnear, aspecto que nos interesa en este apartado. Sin embargo, debemos observar que, en ambos casos, los personajes se están

\footnotetext{
${ }^{7}$ Cavillac ha desarrollado esta problemática, tal como se presenta en El Guzmán. Michel Cavillac, Pícaros y mercaderes... op cit, p 175.

${ }^{8}$ Así vemos, por ejemplo, en La hija de Celestina, un pasaje en el que se describe esta artimaña: "Él prosiguió su negocio y ella al suyo: que, alargando el paso, en breve tiempo llegó a la ropería, adonde, entrando en la casa más proveída, sin reparar en conciertos -porque entonces, por no detenerse y ganar tiempo, quería perder dinero- compró tres lutos que vistieron ella, su hermano y el pajecillo, sin atender a la curiosidad y aseo de que conformasen con los talles de las personas." Alonso J. de Salas Barbadillo, op cit, p 98.
} 
disfrazando intermitentemente para simular que pertenecen a uno $\mathrm{u}$ otro estrato, mientras ellos se hallan al margen de la sociedad, situación que les permite conocer e imitar diversas prácticas. La desvinculación del personaje habilita al autor a adjudicarle críticas que en realidad son suyas, acerca de variadas cuestiones sociales, pues el pícaro habla desde el punto de vista de alguien que conoce la comunidad pero no está totalmente integrado en ella. Esta óptica que es la de un observador marginal, ni integrado ni excluido de manera absoluta, porque puede testificar desde el propio seno de la sociedad. Es la misma mirada que le permite estudiar las apariencias e imitar los atuendos y las conductas correspondientes a otros sectores sociales ${ }^{9}$.

La apariencia de los pícaros refleja la fluctuación de su economía, que pasa por unos momentos de penuria y otros de un relativo "bienestar", tal como sucedía con los campesinos, que alternaban la bonanza del verano con la escasez del invierno. La vestimenta de los pícaros se adecua a su función como limosneros, pues además de ser un recurso para simular pobreza, sirve también para esconder un cuerpo sano y aparentar deficiencias físicas. Este juego teatral se vincula con la cultura barroca, que apelaba a la conmoción emocional y a la sensibilidad a partir del estímulo visual ${ }^{10}$.

Geremek propone que la mendicidad era entendida como un oficio. Si la limosna tenía un carácter de intercambio y contrato (relacionado con la lógica cristiana), el pordioseo constituía una profesión con sus propias técnicas. Por eso el aspecto exterior era un símbolo de status, pero también formaba parte del arte profesional. Esto explicaría que en la literatura los mendigos vendan sus ropas para comprar harapos ${ }^{11}$. Sin embargo, dichos intercambios están vinculados con el empobrecimiento de quienes intervienen en ellos, que consiguen dinero para sobrevivir mediante dicha transacción. Esta compra de harapos puede referir simbólicamente al "oficio", pero está relacionada objetivamente con la pobreza. Es importante tener en cuenta esta cuestión, pues la idea del disfraz de pobre que postulan las novelas ha sido retomada sin indagar la causa de la participación de los personajes en dichos intercambios ${ }^{12}$. Este aspecto de la existencia

\footnotetext{
${ }^{9}$ Juan Carlos González Hernández, op cit, p 151.

${ }^{10}$ José Luis Sánchez Lora, op cit, p 75.

${ }^{11}$ Bronislaw Geremek, La estirpe... op cit, pp 57 y 58.

${ }^{12}$ Por ejemplo: "Como el pedir me valía tan poco y lo compraba tan caro, tanto me acobardé, que propuse no pedirlo por estremo en que me viese. Fuime valiendo del vestidillo que llevaba puesto. Comencélo a desencuadernar, malogrando de una en otra prenda, unas vendidas, otras enajenadas y otras por empeño hasta la vuelta. De manera que cuando llegué a Madrid, entré hecho un gentil galeote, bien a la ligera, en calzas y en camisa: eso muy sucio, roto y viejo, porque para el gasto fue todo menester." Mateo Alemán, op cit, Primera Parte, p 275.
} 
de los pícaros los vincula con la figura de los vendedores ambulantes, también criminalizados.

Las novelas reproducen la sospecha, al parecer difundida en la sociedad y refractada a través de la óptica del autor, acerca de la existencia de los engaños practicados por los miembros del hampa ${ }^{13}$. El Buscón simula ser pobre en varias ocasiones, fingiendo ocasionalmente deficiencias corporales. Veamos la primera oportunidad en que Pablos decide "meterse a pobre" y la descripción de la imagen que desea presentar ante la sociedad. El pícaro cambia su ropa por otra en peores condiciones y luce un crucifijo y un rosario ${ }^{14}$. Estos dos objetos que el pícaro superpone remiten a la religión cristiana, que constituye la fundamentación teológica que justifica la caridad hacia el desheredado. En El Buscón se menciona en repetidas ocasiones que debajo del atuendo harapiento los mendigos esconden vestidos de mayor calidad y en mejor estado. Así lo hace una vieja embustera, "La qual se iba por las casas diciendo que era de una doncella pobre, y que se desacia del para comer. Y ya tenia para cada cosa su embuste, y su trapaza. Lloraba la vieja a cada paso; enclavijaba las manos, y suspiraba de lo amargo, llamaba hijos a todos. Traía encima de muy buena camisa jubon, ropa, saya y manteo, un saco de sayal roto de un amigo ermitaño..."15. Aquí se relata el ardid mediante la superposición de ropas, pero también la destreza verbal y argumentativa que posee la vieja (supuestamente pide para una doncella pobre, para evitar que caiga en el pecado, situación concebible y conmovedora para esa sociedad) y su lenguaje gestual. Los recursos verbales se combinan con la vestimenta adecuada para mendigar, consistente en harapos. El jubón prestado por el ermitaño refiere el vínculo entre los falsos religiosos y el mundo del hampa ${ }^{16}$, motivo que encontramos de manera más acabada en La Garduña de Sevilla ${ }^{17}$.

\footnotetext{
${ }^{13}$ Ver al respecto Bronislaw Geremek, La estirpe... op cit, passim.

${ }^{14}$ Así se describe al pícaro con su atuendo de falso mendigo: “... determiné salirme con dos muletas de la casa, y vender mi vestido, cuellos y jubones, que era todo muy bueno. Hícelo, y compré un jubonazo de estopa famoso, mi gabán de pobre, remendado y largo, mis polainas y zapatos grandes, la capilla del gabán en la cabeza; un Cristo de bronce traía colgando del cuello, y un rosario." en Francisco de Quevedo, op cit, $\mathrm{p} 249$.

${ }^{15}$ Ibídem, pp 191 y 192.

${ }^{16}$ Podría tratarse de una beata. Como las beatas no se sujetaban a monasterios o reglas, llegaron a tener por sí mismas mala fama, aunque no necesariamente eran falsarias y algunas atrajeron muchos prosélitos. Se trata de una figura característica de la primera modernidad que estaba especialmente mal vista por la Iglesia, en razón de su falta de sujeción a su dirección. Bartolomé Bennassar, Inquisición española: poder político y control social. Barcelona, Crítica, 1981, Capítulo 6 "La inquisición y la devaluación del verbo femenino", pp 171-207.

${ }^{17}$ En el capítulo XI de La garduña de Sevilla, Rufina castiga a un falso ermitaño que en realidad comanda una banda de delincuentes cuya base se localiza en su ermita. Alonso de Castillo Solórzano, "La garduña
} 
En la sociedad de Antiguo Régimen, la semiótica de la indumentaria era el primer indicio del status de las personas. De manera inversa, cuando los pícaros quieren simular una posición más elevada, superponen sus ropas -dañadas por el uso- para hacer visibles las partes sanas de cada una de ellas ${ }^{18}$. Esto se relaciona con su asidua intervención en el intercambio de textiles, que alternan según los objetivos que se propongan $^{19}$

La misoginia y la idea de la prostitución o al menos de la vida disoluta de las marginales está presente en todo este corpus. Si la novela tiene como protagonista a una mujer, se sugiere que utiliza su belleza para conseguir su subsistencia, si es joven, o es alcahueta, si es vieja. Pero la mujer que describe Pablos no presenta grandes diferencias en cuanto a su conducta y apariencia respecto a las representaciones referentes a los varones.

A pesar de que varios autores retratan la utilización de niños para estimular la caridad (nos referimos al ejemplo presente en la novela de Quevedo o la historia del Florentino en El Guzmán que veremos más adelante), esta estrategia no es mencionada en la representación de las mendigas. Lo mismo ocurre en las diatribas de los escolásticos, quienes mencionan la idea de que los limosneros tullen a los hijos en pos de estimular la caridad, pero no mencionan esta práctica por parte de las mujeres. Esto podría indicar que los autores no asociaban a las marginales más que con la vida disoluta. Estas mujeres se presentan como viejas delincuentes, celestinas y cuenteras, o como jóvenes aventureras y prostitutas, con protectores o no. Esto quizás nos pueda sugerir que, efectivamente, la presencia de mendigas era menor.

Mientras los tratados de los escolásticos defienden la caridad con los pobres vergonzantes $^{20}$ y las Cortes los omiten, el episodio de la vieja embustera citado

de Sevilla”, en Valbuena y Prat, Ángel (ed.), La novela picaresca española. Madrid, Aguilar, 1956, pp 1517-1618, pp 1591-1593.

${ }^{18}$ Así, un pícaro que finge vestir elegantemente y está prácticamente desnudo debajo de su capa: “...desde lejos vi venir un hidalgo de portante, con su capa puesta, espada ceñida, calzas atacadas y botas, y al parecer bien puesto, el cuello abierto, el sombrero de lado (...) al volver atrás, como hizo fuerza, se le cayeron las calzas, porque se le rompió una agujeta que traía (...) Yo que vi que, de la camisa, no se vía sino una ceja (...) por la parte de atrás, que cubría la capa, traía las cuchilladas con entretelas de nalga pura". Francisco de Quevedo, op cit, pp148-150. También hay otros ejemplos en pp 158 y ss y pp 164 y SS.

${ }^{19}$ En el Buscón vemos al protagonista dejar un depósito cuando adquiere la ropa de pobre “... deposité el dinero $\mathrm{y}$, en un instante, de la sotanilla me hicieron ropilla de luto de paño..."Ibídem, p 172. Más adelante, cuando quiere ostentar en la corte, "Di traza, con los que me ayudaron, de mudar de hábito, y ponerme calza de obra y vestido al uso, cuellos grandes..." Ibídem, p 220.

${ }^{20}$ Así, sostiene Soto: “... hay también muchos de buena sangre que están en pobreza, o porque perdieron sus haciendas, o porque son escuderos, los cuales no aprendieron oficio ni tienen arte de vivir, y estos no por eso son obligados a abatirse a oficios viles y trabajosos para mantenerse, sino que justamente pueden 
anteriormente se dirige no sólo contra los pobres fingidos, sino que aventuran que los vergonzantes también podrían ser falsos, atacando de este modo la práctica de la caridad hacia ellos ${ }^{21}$.

En La hija de Celestina, Elena recorre los hospitales junto a Mendez, sacando de estas instituciones cuanto pueden, haciéndose pasar por beatas ${ }^{22}$. La elección de este sector religioso tampoco es casual, pues en varios pasajes del corpus se vuelve a confundir a las marginales con aquéllas. Puesto que las beatas no querían o no podían profesar en un monasterio, eran religiosas sin dirección de un eclesiástico. Durante los siglos XVI y XVII muchas mujeres aspiraron a hacer oír su voz a través de la Iglesia, en general bajo dirección de esta institución, pero las que no lo hacían eran juzgadas por su doble condición de religiosas y mujeres sin tutela masculina. Por estos motivos y por su popularidad, fueron perseguidas ${ }^{23}$.

Amén de la existencia de algunos casos aislados como el anterior, la idea de los mendigos desarrollando una estafa colectiva y organizada a las instituciones no es la principal acusación en este corpus, donde la crítica principal recae sobre los que aparentan estar harapientos y llagados, diatriba que se basa en la idea de que la mayoría de ellos serían simuladores.

\section{La incapacidad física como premisa}

La imposibilidad de conseguir el sustento a través del trabajo manual sería la premisa que avalaría la mendicidad, pero sólo se consideraba la dificultad individual, no los factores sociales que podrían imposibilitar una ocupación que en la época se consideraba de designio divino. Mientras se negaban las condiciones objetivas, se suponía de manera generalizada que los mendigos simularían enfermedades para no ocuparse. Se aceptaba que los niños, ancianos, enfermos, tullidos y amputados estaban

pedir limosna, y se les debe hacer en mayor cantidad que a otros pobres de menor condición." en Félix Santolaria Sierra (ed.), El gran debate... op cit, p 85. Vives responde a Soto proponiendo que en la organización de la limosna se considere también el reparto a los vergonzantes. Ibídem, p 148.

${ }^{21}$ Así, el caso analizado en este capítulo sobre la simulación de Justina como pobre vergonzante. Francisco López de Úbeda, op cit, pp 335 y ss.

22 "Corrían Elena y Méndez en hombros de la misma fama: porque entre ambas vestidas en hábito de beatas y dándose el nombre la una de madre y la otra de hermana del bienaventurado, se ocupaban en visitar los hospitales, para cuyas camas hacían labor: ya sábanas, ya almohadas, y tal vez camisas, y en mucha cantidad, todo por su cuenta y a costa por entonces de sus bienes.” Alonso J. de Salas Barbadillo, op cit, $\mathrm{p} 140$.

${ }^{23}$ Sobre la persecución de las beatas, ver: Bartolomé Bennassar, Inquisición española ... op cit, pp 171207. 
imposibilitados de trabajar y eran legítimos destinatarios de la limosna, pero se temía que todos aquellos que aparentaban tales condiciones fueran en realidad falsarios.

En El Lazarillo volvemos a encontrar una excepcionalidad, pues el pícaro mendiga siempre solo y lo hace únicamente cuando su amo no le garantiza el alimento (con el escudero) o cuando se encuentra dañado físicamente (por los golpes que le propinó el clérigo):

Desta manera me fué forçado sacar fuerças de flaqueza y poco a poco, con ayuda de las buenas gentes, di comigo en esta insigne ciudad de Toledo, adonde con merced de Dios dende a quinze dias se me cerró la herida. Y mientras estaua malo, siempre me dauan alguna limosna; mas, despues que estuue sano, todos me dezian:

“Tu, vellaco y gallofero eres. Busca, busca vn buen amo a quien siruas" 24.

Al ser apaleado y expulsado por su segundo amo, Lazarillo limosnea. En este episodio observamos la reacción de la sociedad y su variación cuando el joven sana y ya no genera conmiseración, sino que a partir de entonces se lo instiga a trabajar.

Entre los mendigos falsarios, el estereotipo más acabado se concreta en el ciego (y quienes simulan serlo), tal como encontramos en varios pasajes de la picaresca. Es considerado como marginal en tanto su existencia transcurre en las fronteras de la sociedad, pero se trata de un sujeto que padece una afección física y por lo tanto minusválido, estado que lo conduce a la pobreza, aunque no sea condición necesaria. Los ciegos ejercían ciertos oficios característicos y las casas de corrección determinaban actividades para quienes tuvieran esta discapacidad, debido a lo relevante de su presencia $^{25}$. La narrativa los representa como los mendigos por antonomasia. Si bien en una primera etapa son vistos con compasión, luego producen rechazo y recelo, dada su condición de ambulantes ${ }^{26}$. Así existía también la idea de la corporación de mendigos ciegos que tendría la forma de una hermandad religiosa, socorro mutuo y monopolio del oficio, legitimando de este modo el papel del mendicante en la vida ciudadana y estructura de profesiones ${ }^{27}$, suposición que fue captada por el discurso literario.

\footnotetext{
${ }^{24}$ Anónimo, op cit, p 147.

${ }^{25}$ María Estela González de Fauve y Patricia De Forteza, "Reflexiones en torno al grupo marginal de los ciegos", en Fundación. N ${ }^{o}$ VIII. Buenos Aires, Fundación Para la Historia de España (Argentina), 20062007, pp 119-128, pp 121-123. Las autoras encuentran ciegos desempeñando diversas actividades como músicos, carpinteros, podadores de viñas, abogados, y una vez recluidos, seguir las reglas religiosas, rezar y actividades que pudieran desarrollar según cada caso.

${ }^{26}$ Ibidem, pp 119-125.

${ }^{27}$ Bronislaw Geremek, La Piedad... op cit, p 60.
} 
El primer amo de Lazarillo y encargado de su socialización cuando sale de su estructura familiar consigue la limosna a través de diversas artimañas vinculadas con la hechicería y la medicina popular. El narrador relata que el ciego maneja la alquimia así como la astrología y, debido a la eficacia de sus prácticas, es fielmente seguido por un público especialmente femenino ${ }^{28}$. A pesar de que este personaje es denostado a lo largo del texto, no se menciona que sus saberes fueran mentiras -aunque sí lo especule-, sino que es considerado por los demás como un sabio, apreciación que es compartida por el protagonista de la novela que, en una mezcla de astucia e ingenuidad infantil, describe un amo sagaz que sabe conducir la inocencia de los demás mediante el discurso.

El relato se detiene en las artes del ciego para rezar, la dicción y los gestos que utiliza para apelar a la piedad, con el objetivo de ser visto por otros fieles en la iglesia ${ }^{29}$, pues su devoción era recompensada porque se la entendía como una parte contractual de la limosna. El narrador quiere mostrar la maestría de su primer amo, comparándolo con otros de su género que realizaban la misma actividad sin contar con sus artificios.

Sin embargo, este ciego es un personaje cuya creencia está vinculada con la hechicería y su conducta, alejada de los valores cristianos. Su práctica dentro de la iglesia es sólo una dramatización ante los fieles/espectadores ("Tambien él abreuiaua el rezar y la mitad de la oración no acabaua" ${ }^{, 30}$ ). Se le imputa la trampa que denuncian los teólogos respecto a la oración interior: los religiosos y los fieles debían rezar en voz alta para saber si en lugar de ello se estaba pensando en otra cosa, aquí el ciego lo hace, pero no toda la súplica.

En el siglo XVI también se debatía cuál debía ser el rol de la institución eclesiástica en la supervivencia de los vagabundos. Este aspecto fue relevante para los escolásticos, cuyo debate incluía la secularización de la limosna, saliendo del amparo de la Iglesia que hasta entonces, de un modo u otro, era una institución importante en

\footnotetext{
${ }^{28}$ El ciego convencía a su público y sostenía “....saber oraciones para muchos y diuersos effectos (...) Echaua pronosticos (...) en caso de medizina, dezia que Galeno no supo la mitad que él para muela, desmayos, males de madre. Finalmente, nadie le dezia padecer alguna passion, que luego no le dezia: 'Hazed esto, hareys estotro, cosed tal yerua, tomad tal rayz'.

Con esto andauase todo el mundo tras él, especialmente mugeres, que quanto les dezia creyan". Anónimo, op cit, p 80. Para la época, las mujeres, más ignorantes que los hombres, son crédulas, por eso este pasaje constituye una crítica a las prácticas de las comadronas y los curanderos frente a la ciencia médica.

29 "En su officio era vn aguila. Ciento y tantas oraciones sabia de coro. Vn tono baxo, reposado y muy sonable, que hazia resonar la yglesia donde rezaua, vn rostro humilde y deuoto, que con muy buen continente ponia, quando rezaua, sin hazer gestos ni visajes con boca ni ojos, como otros suelen hazer". Ibídem, p 79. Todos eran recursos para atraer la atención -y la limosna- porque no podían ser insistentes en pedir.

${ }^{30}$ Ibidem, p 84.
} 
cuanto a su salvaguardia. El planteo de los escolásticos giraba en torno a cómo lograr la efectivización del estipendio que se debía dar por la gracia divina, cuestión que en ningún momento del debate es olvidada, sino por el contrario esgrimida ${ }^{31}$. El acto de la limosna y su relación con la religión no eran discutidos, sino la forma de ejercitarla para que fuera justa.

Según la representación picaresca y los tratados de los escolásticos, la práctica de la simulación constituía uno de los principales motivos que justificaba la sospecha que recaía sobre los mendigos ${ }^{32}$. El Buscón retrata la simulación de deficiencias físicas como una treta relativamente asequible para cualquier limosnero ${ }^{33}$. Según deducimos a partir de la lectura de esta obra, así como de otras contemporáneas y los tratados de los

\footnotetext{
${ }^{31}$ Así argumenta Soto: "Porque si somos obligados, según dice el Evangelio, a amar a nuestros prójimos como a nosotros mismos y, según dice San Juan, el que teniendo de los haberes del mundo sufre que su prójimo padezca necesidad, no está en caridad con su prójimo, síguese que el tal rico traspasa la ley del Evangelio y por el consiguiente está en pecado mortal, pues este pecado sólo puede ser causa por donde se pierda la caridad." en Félix Santolaria Sierra (ed.), El gran debate... op cit, p 79.

32 Encontramos incluso en el capítulo XIX del Memorial de Diversas Hazañas, en las Crónicas de los reyes de Castilla el siguiente ardid, en el que intervienen los poderosos del reino: "Y entre las otras maldades asentaron una no fecha semejante fasta entonces en el mundo, la qual fué que sepultaron al Príncipe Don Cárlos en forma de santo, y ficiéronle altar, y pusiéronle diadema, y buscaron hombres pobres á quien dieron gran suma de dineros tomando dellos estrecho juramento que jamas este secreto revelasen, de los quales unos se ficieron ciegos, otros tullidos, ó endemoniados, y otros de muy diversas enfermedades, que viniesen velar delante del Príncipe Don Carlos, y salidos de allí publicasen que salían sanos cada uno de la enfermedad que tenía; esto para enemistar al Rey y á la Reyna con todos los catalanes; y como á nuestro Señor place que las maldades algún tiempo prevalgan y no puedan para siempre permanecer ni queden sin pena los perpetrados de aquellas, quiso que un capitán de los que principalmente en esta maldad fueron llamados viniese por los campos de Urgel á la ciudad de Lérida con cierta gente, porque la ciudad más segura estuviese por los barceloneses, al qual el Ilustrísimo Rey de Aragón de aventura encontró y peleó con él y lo prendió á él y á muchos de los suyos, y los que escaparon subiéronse á una alta montaña, y pusiéronse en un castillo derribado que se llamaba el castillo de los Asnos; á los quales todos el Rey mandó tomar las armas y dexolos ir libres, y solamente detuvo al malvado capitán, el qual afirmaba en la ciudad de Tarragona el Príncipe Don Carlos haber fecho muy grandes milagros, sanando á coxos y dando vista á los ciegos, y salud á todos los enfermos que venían á visitar su sepultura; lo qual juraba todo ser verdad. Y como después de su vencimiento el Rey viniese á Tarragona y allí fuese traído el dicho capitán ligado en grandes prisiones, en público confesó por sentencia de Dios ser venido en el punto en que estaba por la falsedad que habia afirmado por el juramento de los milagros ya dichos, falsamente fabricados, con gran suma de dinero por la maldad de los barceloneses, en la qual él habia sido compañero y uno de los principales fabricadores de aquella; por la qual confisión espontánea el Rey lo mandó enforcar, y sin duda los barceloneses no quedaron sin pena de la maldad así por ellos falsamente fabricada, á los quales el Rey fizo contino cruel guerra por espacio de trece años, en el qual tiempo el Rey ovo dellos muy grandes vitorias, y fueron infinitos muertos de los catalanes, y finalmente la ciudad de Barcelona fué tomada por el Rey, y toda la provincia de Cataluña fué puesta so la obediencia de su cetro Real, y despues la ciudad de Barcelona se le dió, como adelante se dirá, con perpétua infamia y daños irreparables de los barceloneses; los quales, de muy ricos y poderosos que antes eran, por su maldad fueron tornados pobres, flacos y menguados, y en vano demandaron ayuda del Rey Don Enrique, al qual desde el comienzo desta rebelión habian enviado por embaxador á Mosen Capones, hombre muy astuto, malicioso, y sin vergüenza y gran elocuente." Cayetano Rosell (ed.), Crónicas de los reyes de Castilla. Desde Alfonso el Sabio, hasta los Católicos Don Fernando y Doña Isabel. Madrid, Manuel Rivadaneyra, 1878, Tomo tercero, p 23. Capítulo XIX "De la embaxada de los aragoneses y valencianos, y de la guerra de Navarra y de la muerte del Príncipe Don Carlos y de la muerte del Rey Don Carlos de Francia".

${ }^{33}$ Por ejemplo Pablos "Llebaba metidas entrambas piernas en vna bolsa de cuero, y liadas, y mis dos muletas". Francisco de Quevedo, op cit, p 251.
} 
escolásticos, esta práctica constituía uno de los principales motivos para explicar la sospecha que recaía sobre los mendigos tullidos. El Buscón es la novela en la cual se atiende más enfáticamente a la representación de esta treta, postulándola como una forma de estafa, porque el falso pobre sería suficientemente válido y no merecería asistencia cuando podría subsistir a través de un trabajo. Quien otorgaba la limosna suponía entregarla a un hombre incapacitado para trabajar y, mediante esta buena acción, compraba el perdón divino, dentro de una cosmovisión dominada por la religión católica, que plantea la salvación eterna como una relación de don y contradón: la limosna que se entrega al pobre se retribuye ultraterrenalmente con la promesa de la salvación eterna.

\section{El pordioseo y la creencia cristiana}

El análisis de las novelas nos muestra que ciertas formas de la práctica de la caridad estaban siendo cuestionadas por parte del conjunto de la sociedad, que quería denunciar algunos aspectos de su nocividad a partir de la sospecha sobre los mendigos, e infundir el rechazo hacia ellos. Consideramos que se trataba de un momento de crisis de la caridad como sistema de distribución hacia los pobres que no poseyeran vínculos, mientras tenía lugar su proletarización.

La manera más efectiva de generar un conflicto frente a la caridad radica en causar desconfianza respecto a los mendigos, tal como hacen las novelas, pues la reciprocidad descansa en último término en la confianza, que no sólo se sitúa en el plano personal, sino que involucra al conjunto del grupo ${ }^{34}$. Quienes entregaban limosnas suponían la necesidad de aquellos que las recibían, aspecto fundamental para que resultaran en un acto de bien que los redimiera, mientras ganar el cielo motivaba esta forma de altruismo. Sin embargo, en el período que estudiamos, vemos que diversos discursos -las analizadas peticiones de Cortes en el plano político, los tratados de los escolásticos, también repasados, y las novelas que aquí examinamos- apuntaban a la pérdida de dicho crédito a través de la representación de mendigos en quienes no se debía confiar, pues su falta de piedad hacía de ellos malos intercesores con la divinidad.

\footnotetext{
${ }^{34}$ La caridad puede ser encuadrada dentro de la reciprocidad generalizada, consistente en actos de donaciones altruistas, donde el aspecto social de la relación supera al material y lo encubre. Miguel Bahamondes Parrao, "Contradicciones del concepto 'capital social'. La antropología de las alianzas y subjetividad campesina", en AAVV Encuentro de la Asociación de Estudios Latinoamericanos, Washington D. C., LASA, 2001, pp 1-23, p 7.
} 
M. Mauss en su ya clásico Ensayo sobre el don, repasó la caridad en diversas culturas $^{35}$, vinculándola con el don, la fortuna y el sacrificio. El antropólogo sostiene que, al ser entendida la caridad como la obligación que tienen los hombres de deshacerse de su riqueza, se convierte en un principio de justicia, según la moral del $\operatorname{don}^{36}$.

Bourdieu indica que el intercambio de dones supone el desconocimiento de la verdad del "mecanismo" objetivo de la transacción ${ }^{37}$. Así el dar, recibir y restituir generan un tejido denso de relaciones "que pone en tensión a toda la sociedad en sus múltiples manifestaciones, social, religiosa, económica, política" ${ }^{38}$. No se trataba sólo de un intercambio entre dos particulares, sino que a través de estos dones se ponían en juego las concepciones y expectativas sociales, que se tensaban en cada una de las decisiones de los individuos que conformaban las redes de relaciones que eran el entramado de la sociedad tradicional.

A. Guerreau-Jalabert no encuentra en la limosna un acto de justicia distributiva porque no se detiene en el mérito de quien la recibe, según su interpretación de los textos cristianos ${ }^{39}$. Así, según la lectura que la autora hace de San Agustín, el don no tiene otro principio que el amor que profesamos a nuestro prójimo y que conduce a la búsqueda de su bien, por sí mismo y por Dios, pero no por nosotros ${ }^{40}$, pues la gratuidad y libertad constituirían dos propiedades esenciales del Don, cuya necesaria conformidad

\footnotetext{
${ }^{35}$ Por ejemplo, el antropólogo refiere que los dones a los niños y a los pobres agradan a los dioses entre los hausa de Sudán, mientras entre los brahmanes la cosa dada es devuelta en la otra vida, pero aumentada. Marcel Mauss, Ensayo sobre el don. Buenos Aires, Katz, 2009, pp 102-103.

36 "La limosna es el fruto de una noción moral del don y de la fortuna, por un lado, y de una noción del sacrificio, por el otro. La liberalidad es obligatoria, porque la Némesis venga a los pobres y a los dioses del exceso de dicha y de riqueza de algunos hombres que deben deshacerse de ellas: es la vieja moral del don convertida en principio de justicia." Ibídem, p 103.

${ }^{37}$ Pierre Bourdieu, Campo de poder y reproducción social. Elementos para un análisis de la dinámica de las clases. Córdoba, Ferreyra Editor, 2006, p 168.

${ }^{38}$ Miguel Bahamondes Parrao, op cit, $\mathrm{p} 7$.

${ }^{39}$ Anita Guerreau-Jalabert, "Caritas y don en la sociedad medieval occidental", en Hispania. Vol. LX/1, $\mathrm{N}^{\mathrm{o}}$ 204, Madrid, Consejo Superior de Investigaciones Científicas, 2000, pp 27-62, p 50. Guerreau-Jalabert analizó las asociaciones léxicas de los términos caritas, pax, amor y amicitia, básicos en la doctrina cristiana, que en la representación literaria son utilizados subversivamente. La historiadora considera que a partir de la lectura de los Padres de la Iglesia, la caridad se ubica en el centro de lo divino, pues en el sistema de equivalencias transitivas que caracteriza a la teología cristiana, las propiedades de la perfección divina también lo son de la caridad. Ésta constituiría un elemento para medir la calidad de los cristianos, de modo que actuar contra ella equivaldría a hacerlo contra Dios. La autora sostiene que en este contexto el vínculo que une a la divinidad con los hombres ocupa un lugar central en la teología cristiana, pues se trata de un amor perfecto, por lo tanto gratuito, pues no es dado en espera de una contrapartida y no tiene otro motivo que su propia esencia, de modo que la caridad se fundamentaría en que el amor a Dios es inseparable del que se profesa por el prójimo. En este sentido, la doctrina de los méritos sostiene que sólo la misericordia divina es capaz de salvar al hombre, quien lo único que puede hacer para tratar de redimir sus pecados es manifestar su amor a Dios mediante la práctica de la limosna. Ibídem, pp 30-56.

${ }^{40}$ Ibídem, op cit, p 49.
} 
respecto al espíritu de caridad implica que sea hecho sin espera de contradón ${ }^{41}$. La caridad se distingue de la justicia, que en el pensamiento teológico es inferior, pues la última tiene su fundamento en una equivalencia del Don y su devolución (que debe producirse en un momento determinado), mientras la caridad representa un ideal espiritual de libertad del Don del amor y de lo que de él deriva ${ }^{42}$.

Las novelas se esfuerzan por mostrar que los mendigos no son verdaderamente necesitados por cuanto se niegan al trabajo que debía sustentarlos y, por lo tanto, falsean la caridad de la cual son depositarios. Guzmán plantea esto en términos de una "economía de la salvación", que presenta a Dios como garante del pobre, falseando el significado cristiano de la limosna: "Rico amigo, ¿no estás harto, cansado y ensordecido de oír las voces que te han dicho que lo que hicieres por cualquier pobre, que te lo pide por Dios, lo haces por el mismo Dios y Él mismo te queda obligado a la paga, haciendo deuda ajena suya propria?"43. Si quien recibía la limosna no era en realidad un verdadero pobre incapacitado para el trabajo, el benefactor estaba cooperando con la propagación del vagabundeo. En este sentido, los escolásticos plantearon que la buena voluntad de quien se desprendiera de sus riquezas -aunque inocentemente errado- no resultaría suficiente para acercarlo al paraíso ${ }^{44}$. Mediante este mecanismo se cuestionaba el ocultamiento del pícaro como un acto mucho más grave que quitar el pan al verdaderamente necesitado -físicamente incapacitado-, ya que con su accionar también estaba robando a su benefactor la posibilidad de la redención. Este aspecto fue planteado por Alemán en la voz del pícaro arrepentido, quien reflexiona sobre el robo de la limosna que corresponde al verdadero pobre: “...considerando que todas mis trazas y modos de engañar era engañarme a mí mesmo, robando al verdaderamente necesitado y pobre, lisiado, impedido del trabajo, a quien aquella limosna pertenecía, y que el pobre nunca engaña ni puede, aunque su fin es ése; porque quien da no mira al que lo da..."45. Aquí se identifican incapacidad física, pobreza e inocencia, como antinomia del hombre saludable pero malintencionado y vicioso. El narrador plantea que el robo no se

\footnotetext{
${ }^{41}$ Ibídem, op cit, p 50.

42 Ibidem, pp 50 y 51.

${ }^{43}$ Mateo Alemán, op cit, Primera Parte, p 420. Las cursivas son nuestras.

${ }^{44}$ Así sostiene Soto: “... que cuando hiciéramos bien, catemos a quién, que hagamos bien al justo, como Dios que aborrece a los pecadores y ha misericordia de los arrepentidos, y así nosotros demos al misericordioso y no recibamos al pecador, demos al bueno y no al malo. (...) Dice San Agustín, que todo se compadece, si al pecador no le hagamos bien por respecto de su pecado ni para favorecerle en el mal, sino para librarle de su necesidad. Y así, la intención del Eclesiástico es que cuando de la abundancia de las limosnas el pobre toma asa y favor para sus vicios, entonces es caridad quitarle la yesca de sus pasiones, dejándole de hacer limosna”. Félix Santolaria Sierra (ed.), El gran debate... op cit, p 91.

${ }^{45}$ Mateo Alemán, op cit, Primera Parte, p 420.
} 
realiza sólo contra su benefactor, sino que también recae en otra persona que podría haber hecho buen uso del don apropiado, pero problematiza la imposibilidad que encuentra quien da la limosna para seleccionar correctamente al destinatario. Este conflicto surgió a partir de la propagación de la pobreza urbana y el aumento de la mendicidad callejera y anónima a fines de la Edad Media.

En el marco del miedo a la potencialidad sediciosa de estos marginales, se temía especialmente que el acto de caridad que se practicaba con los mendigos acabara convirtiéndose en un gesto indigno como consecuencia de que, a partir del engaño del pordiosero, se permitiese sostener a un hombre cargado de pecados y vicios, colaborando con su vagancia, en lugar de socorrer a un necesitado ${ }^{46}$. Esto dio lugar a la radicalización de la discriminación respecto a los pobres, mientras la degradación de la tipología de la pobreza provocó un incremento del miedo a hacer el bien, en reacción a la supuesta ausencia de temor en el vagabundo ${ }^{47}$.

La forma de representación del mendigo y su falsedad está en estrecha relación con la condena que el autor imprima acerca de los personajes que representa. Las novelas más críticas respecto a sus desarrapados personajes son también aquéllas en las que se describe obsesivamente la mentira del pordiosero, demostrando que este era un aspecto clave a la hora de criminalizarlos. Así, en La hija de Celestina, Montúfar apela también a la creencia cristiana. Vemos que las imploraciones del rufián son también escandalosas, además de repetitivas:

...con una campanilla en las manos salió por las calles diciendo en altas voces, una y muchas veces: 'Loado sea el Santísimo Sacramento', instituyendo en los muchachos de la ciudad esta buena costumbre, enseñándoles el camino de la Doctrina Cristiana.

Hacía esto el galeote con tanta arte, acompañando así el rostro como todas sus acciones de cuidados modestia, que en pocos días se alzó con las voluntades de la ciudad... ${ }^{48}$

Este fragmento contiene varios argumentos para la criminalización de los marginales. La calificación de galeote, que se debe a que lo fue y sobrevivió, acentúa la idea de dureza y encallecimiento en el crimen por parte del personaje y alude a que se trata de un delincuente (por tanto pecador). También observamos la virtud que utiliza

\footnotetext{
${ }^{46}$ Raúl Susín Betrán, op cit, pp 108 y 110.

${ }^{47}$ Antonio Serrano González, op cit, pp 36 y 40.

${ }^{48}$ Alonso J. de Salas Barbadillo, op cit, p 140.
} 
para la estafa colectiva, y su elaborado carisma, que explica su éxito. Entretanto, Elena y Méndez hacen su parte: muestran su falsa piedad en los hospitales, instituciones para el alojamiento de los pobres, también relacionadas con el acto de misericordia ${ }^{49}$. Esta imagen de los mendigos como personas viciosas y disolutas que esconden una vida libertina detrás de su piedad es parte del estereotipo del pícaro.

En El Lazarillo, las concepciones religiosas son reconocidas por el pícaro entre el resto de la población y utilizadas con fines prácticos e individuales, cuando intenta sobrevivir mediante la limosna: "Con baxa y enferma voz e inclinadas mis manos en los senos, puesto Dios ante mis ojos y la lengua en su nombre, comienço a pedir pan por las puertas y casas mas grandes, que me parecia” ${ }^{, 50}$. El uso de la semántica cristiana para la súplica de limosnas está vinculado con el hecho de que se trata de una religión de la salvación eterna que remite a la lógica reciprocitaria a la que hemos aludido ${ }^{51}$. El protagonista sale a pedir limosnas utilizando algunos gestos que son constitutivos del estereotipo del mendigo: una posición semejante a la de la imploración a la divinidad y la demanda en nombre de Dios. También reconoce y pone en práctica diversas artimañas propicias a la obtención de dádivas: los gestos adecuados casi ritualizados, la apelación verbal a imágenes religiosas, la imitación de la posición de vírgenes y santas y la elección de los espacios adecuados, prácticas que son aprendidas como parte de la formación del mendigo.

La descripción de la imagen que Pablos como falso pobre presenta a la sociedad reúne varias características de los falsos mendigos ${ }^{52}$. Este retrato es confirmado mediante su discurso "fiado en mi buena prosa",53, recurso que constituye uno de los más importantes entre los usados por los pícaros. El personaje se refiere a la supuesta causa de su penuria: “... dalde una limosna al pobre tullido y lastimado de la mano del

\footnotetext{
${ }^{49}$ Respecto a este episodio, ver la nota 22 de este capítulo. Allí se indica que fingen ser beatas. Era una forma de religiosidad femenina independiente, cumplida por quienes no tenían capacidad económica para entrar a un monasterio o no querían hacerlo, porque su devoción no era patrocinada, sino combatida por la Iglesia en razón de que no seguían la dirección de sacerdotes y hasta se atrevían a predicar.

${ }^{50}$ Anónimo, op cit, pp 167 y 168. Lazarillo se refiere a la alimentación que consigue gratuitamente y por la propia voluntad de los benefactores como aquella que se le otorga "por Dios" o "por amor de Dios" Así, encontramos los panes "de los de por Dios" Ibídem, p 154. También la referencia que hace el escudero respecto a la limosna: "Que mas vale pedillo por Dios, que no hurtallo" Ibídem, p 169. “... quanto el peccadorcico se llega aqui a nuestra casa y le damos de comer lo que podemos por amor de Dios..." Ibídem, pp 199 y 200.

${ }^{51}$ Sobre el uso desviado de la religión ver Pilar García Mouton, "Religiosidad popular en la picaresca", en AAVV, La Religiosidad popular. Tomo II: Vida y muerte: la marginación religiosa. Barcelona, Anthropos, 1989, pp 146-153, p 149.

${ }_{53}^{52}$ Respecto a esta descripción, ver la nota 14 de este capítulo.

${ }^{53}$ Francisco de Quevedo, op cit, pp 249 y 250.
} 
señor! (...) trabajando en una viña, me trabó mis miembros, que me vi sano, como se ven y se vean, loado sea el Señor!" ${ }^{54}$. Debemos observar aquí la posición que adoptan los mendigos a la hora de pedir limosnas: reclinados, remitiendo a la posición de los fieles en la iglesia, extienden su brazo y muestran, para recibir el dinero, la mano, que remite al trabajo físico que en este caso no se ejerce y se reemplaza por el pedido en nombre de Dios ${ }^{55}$. En el marco del conflicto ideológico al que hemos aludido, el protagonista sostiene haber sido herido cuando trabajaba, noción que potencia la legitimidad de su condición, en un mecanismo que apela a todos los medios para estimular a quien posee riquezas a desprenderse de ellas en favor del inválido.

Pablos pide por Dios a través de diversas estrategias discursivas vinculadas a la devoción cristiana para mover a la caridad. Él y sus pares estudian minuciosamente a sus benefactores para lograr una mayor efectividad en sus plegarias, que adecuan a cada uno de ellos, mostrando la individualización de la limosna, no sólo por parte de quien la recibe, sino también de quien la otorga. Si quien entrega la limosna elige individualmente al beneficiario, aquel que la demanda encuentra formas particulares de pedirla a los diversos transeúntes ${ }^{56}$. Este fenómeno halla su explicación en una novedad que habían traído la urbanización y la monetarización, pues entre las diversas formas de la limosna, existía ahora la posibilidad de ejercerla de manera individual y entre desconocidos $^{57}$, así vemos en El Lazarillo que las plegarias del ciego son remuneradas por parte de quienes las reconocen ${ }^{58}$.

La estructura de las descripciones sobre la forma que adopta la mendicidad se repite a lo largo de varios pasajes de El Buscón. En primer lugar Quevedo hace referencia a la apariencia del pícaro y luego al discurso que utiliza para pedir; posteriormente se muestra su efectividad. Veamos como ejemplo la descripción de un pícaro de la corte: Polanco. La apariencia de este personaje es construida a través de cuatro elementos: "su saco pardo, cruz grande, barba larga postiza, y campanilla". La

\footnotetext{
${ }^{54}$ Ibídem, p 250.

55 Carmen López Alonso, op cit, p 56.

${ }^{56}$ Así, otro mendigo “...decía:-'¿Miren la pobreza y regalo que hace el Señor al cristiano!'. Si pasaba mujer, decía:-'¡Ah, señora hermosa, sea Dios en su ánima!'; y las más, porque las llamase así, le daban limosna, y pasaben por allí aunque no fuese camino para sus visitas. Si pasaba un soldadico:-'Ah, señor capitán’, decía; y si otro hombre cualquiera: -‘¡Ah, señor caballero!'. Si iba uno en coche, luego le llamaba señoría, y si clérigo en mula, señor arcediano. En fin, él adulaba terriblemente.” Francisco de Quevedo, op cit, pp 251 y 252.

${ }^{57}$ Carmen López Alonso, op cit, pp 285 y 287.

${ }^{58}$ En la iglesia, el ciego trata con los demás fieles, quienes “... quando le mandauan rezar y le dauan blancas”. Anónimo, op cit, p 83. Según Geremek, a cambio de la limosna el mendicante ofrece la oración, dando utilidad y valor a su ocupación, contrato con el cual debe cumplir. Bronislaw Geremek, La piedad... op cit, p 57.
} 
indumentaria refiere a la pobreza, dada la calidad, y estado de la prenda. También el color, porque como en el caso de los monjes, se trata de prendas de lana sin teñir. La cruz refiere al cristianismo y, en este sentido, apela visual y emotivamente a sus valores. Entretanto la barba remite al artificio de su imagen, ya que no es auténtica, pero también evoca la imposibilidad de cortarla. Por último, la campanilla se asocia a los leprosos, grupo cuya enfermedad inspiraba piedad y horror. El falso mendigo, portando esta batería de símbolos visuales, pide diciendo "Acordaos de la muerte, y hazed bien por las animas..."59, apelando al motivo de la salvación ultraterrena por haber hecho bien al desheredado. Inmediatamente se alude al éxito de este reclamo o se introduce el robo como vía alternativa: "y entrábase en las casas que veía abiertas; si no había testigos ni estorbo, robaba cuanto había... ${ }^{60}$. Este pasaje homologa la mendicidad y el robo, mientras representa en un mismo agente al limosnero y al ladrón, avalando la criminalización de los pordioseros, que alternarían diversas prácticas delictivas.

Los falsos pobres se caracterizan por la impostura de la voz y la alusión a las imágenes cristianas, así como a las cicatrices y mutilaciones que ostentan y hacen visibles. De esta manera, Guzmán “... pedía la voz levantada, el tono extravagante (...) ¡Dame, noble cristiano, amigo de Jesucristo! ¡Ten misericordia deste pecador afligido y llagado, impedido de sus miembros! ¡Mira mis tristes años! ¡Amancíllate deste pecador!"61. El mendigo emplea una retórica imperativa, en lugar de humilde y quejumbrosa, pero suplica también por piedad entre los hombres. Alude a la deshonra y humillación (¡Amancíllate!) y a la nobleza de quienes participan de la religión cristiana y su vínculo con Cristo, la misericordia y la condición de pecadores compartida por todos los hombres. Finalmente, describe la penuria física que expone. Con este pedido el protagonista muestra su interiorización de la lógica de reciprocidad contenida en el acto de la limosna, que consiste en un don inmediato y un contradón a largo plazo, noción clave de una religión de salvación eterna.

La literatura sólo nos informa sobre una de las interpretaciones, que desde la representación hasta la trama es una construcción para afirmar y difundir la criminalidad de los mendigos. La narración en primera persona remite a la idea de una confesión por parte de un delincuente.

\footnotetext{
${ }^{59}$ Francisco de Quevedo, op cit, p 191.

${ }^{60}$ Ibidem, p 191.

${ }^{61}$ Mateo Alemán, op cit, Primera Parte, p 423.
} 
En las novelas, la figura del falso pobre se asocia directamente con el engaño vinculado a las prácticas religiosas, motivo que se presenta en diversos grados que van desde el pordioseo eventual en nombre de Dios hasta la descripción de delincuentes que se encubren detrás de una supuesta vida devota, como vimos en La hija de Celestina. Si bien las novelas son críticas respecto a los pícaros y su uso de la creencia ajena con el fin de demandar una limosna que, según los autores, es ilegítima, por otro lado retratan una particular "religiosidad marginal", nutrida de valores o ideales que no son acordes a los predicados por la Iglesia ${ }^{62}$.

El mendigo no pide en su propio nombre sino en el de Dios y en esa incorporación de conceptos, imágenes y semántica de la Iglesia, los personajes exponen el marco social urbano de religiosidad, lo cual sugiere el grado en que se había difundido un cristianismo elemental entre el pueblo, imposibilitando el cumplimiento de la norma que apuntaba a abandonar la limosna y denunciar al mendigo falso. Pero señalaría también un desfase porque sería una persistencia de la concepción del pobre de Dios. Esto explicaría por qué los limosneros podían sobrevivir gracias a que la sociedad, que era convocada a denunciarlos o a tomarlos en servicio, no adoptaba estas medidas. A pesar de que se sostenía que esta clase de pobres se había convertido en una plaga, el arraigo de la práctica inducía a la caridad hacia los mendigos.

Con el proceso de mercantilización de la salvación, el pobre sufrió una cosificación redentora para el paso al paraíso, siendo sólo un medio para ejercer la caridad. La obligación de la limosna encuentra su explicación en la idea de que la riqueza y la pobreza existen porque tienen funciones complementarias, pues si el desposeído necesita la limosna para poder sobrevivir, quien la entrega concibe que debe usar parte de lo que tiene para actos piadosos en pos de ser redimido luego de su muerte. Pero en el contexto que estudiamos se cuestionó quiénes merecían la limosna, pues se sostenía que el mendigo no era pobre en caso de que fuera físicamente capaz de trabajar $^{63}$.

Las iglesias son descriptas como espacios de socialización y contacto de los vagabundos entre sí, pero sobre todo con el resto de la sociedad. En esta representación, el marginal utiliza estos lugares para limosnear, participar de las sopas públicas que se otorgan fuera de ellas y relacionarse con mujeres y hombres vanidosos a los que

\footnotetext{
${ }^{62}$ Pilar García Mouton, op cit, passim.

${ }^{63}$ Sobre quienes reciben la limosna: Carmen López Alonso, op cit, pp 266 y ss. Sobre la entrega de limosna por su salvación ver Ibídem, pp 500 y ss.
} 
pretende estafar. Los pícaros asisten a las sopas de los conventos sólo cuando no consiguen comer mediante otras formas de rapiña ("Cuando esto nos falta, ya tenemos sopa de algun convento aplazada; no la tomamos en público, sino a lo escondido, haciendo creer a los frailes, que es mas devoción que necesidad.") ${ }^{64}$. La crítica de la concurrencia al convento por parte de estos hombres es recurrente en el género, que exhibe a la Iglesia y a sus representantes como parte del circuito necesario para que ellos pudieran desarrollar sus actividades, en las cuales aprovechan subversivamente la cosmovisión de la sociedad cristiana. Si las novelas evocan el poco respeto hacia la Iglesia profesado por los pícaros (e incluso su anticlericalismo), no siempre refieren la falta de religiosidad, sino una devoción que se manifiesta en signos y ritos externos que ejecutan con cuidado.

La noción de los pobres escandalosos en la iglesia fue esgrimida en el debate que mantuvieron los escolásticos ${ }^{65}$. En el marco de la acusación hacia los mendigos que se guarecían en aquéllos templos, se sostiene la importancia de la visión, el oído y el olfato para su percepción ${ }^{66}$. El estereotipo de los miserables ruidosos sugiere la competencia entre los mendigos por las limosnas, pero también la invisibilización del pobre y su necesidad de apelar a diversas estrategias para llamar la atención en el espacio público ${ }^{67}$. Justina comienza a pordiosear a partir de la observación de una mujer que apela a los transeúntes estimulando su atención a la distancia y por un tiempo más prolongado, para que la súplica fuera más efectiva ${ }^{68}$. El pedido escandaloso a los transeúntes indica que, a pesar de que los autores quieren insistir en que la plaga de la

\footnotetext{
${ }^{64}$ Francisco de Quevedo, op cit, pp 156 y 157.

${ }^{65}$ Así, Juan de Robles sostiene en relación a la Semana Santa, que daba lugar a procesiones y misas continuas que permitían la acumulación de los mendigos en las grandes ciudades: "Cuán mejor parece la Semana Santa hacerse los oficios divinos con quietud y silencio que con el ruido que hasta aquí, de gente que ni miraban al tiempo ni al oficio ni a dejar tener atención a los ministerios de aquella Santa Semana, sino solamente a cómo sacaría el dinero de aquellos a quien pedían. Cuánto mejor parece que, en reverencia de la Pasión de Cristo, estén aquel tiempo los pobres proveídos y remediados que no que estén tendidos a las puertas de las iglesias gritando...” en Félix Santolaria Sierra (ed.), El gran debate... op cit, p 177.

${ }^{66}$ Antonio Serrano González, op cit, p 38.

${ }^{67}$ Así, tal como sintetiza J. Bravo Lozano, “... esta banalización perjudica a los pobres porque los estanca en su pobreza al restarles novedad e impacto, de lo que se deriva una pérdida de eficacia en sus demandas. Aumenta la pobreza, disminuyen las limosnas. En consecuencia, los pobres van a reaccionar intensificando y diversificando su 'oferta' de pobreza provocando una respuesta en todos los niveles, individual, institucional, etc." Jesús Bravo Lozano, "Mendicidad y cultura de la pauperización”, en Torre de los Lujanes. N ${ }^{o}$ 51, Madrid, Real Sociedad Económica Matritense de Amigos del País, 2003 pp 73-86, p 73.

${ }^{68}$ Así se describe a la mendiga, relacionando la práctica de Justina con la de los minusválidos: “...aquella mujer pedía limosna con aquellas tabletas, y para pedir de lejos, de modo que, cuando allí lleguen los caminantes, traigan desatacada la bolsa y no se detengan en madurar la gana de dar (...) que esto se hace para que puedan pedir todos los pobres que aquí se curan, aunque sean gangosos y mudos". Francisco López de Ubeda, op cit, p 262.
} 
pobreza era tan visible en las ciudades, los mendigos aun necesitaban hacer este tipo de apelaciones para poder interpelar a los transeúntes, pues el menesteroso modesto y silencioso queda fuera del campo de observación ${ }^{69}$. De este modo también se insinúa que el "verdadero pobre" puede ser el que menos llame la atención y el vocerío corresponde a una competencia entre numerosos falsarios que luchan por el interés de quienes pueden proveerles limosna. La observación del pícaro-narrador media las suposiciones del hombre integrado, el escritor, quien indica, a partir de la imitación mutua entre los mendigos, la falsedad de estos personajes cuya práctica se reproduce de esta manera.

Según la narrativa, la religión no es la única explicación para el ejercicio de la caridad. La entrega de limosna es también un gesto indicador del status de quien la otorga $^{70}$, pues la ostentación de liberalidad con los bienes sirve como medio de legitimación social ${ }^{71}$. Vimos también en la representación de Quevedo, cómo sus personajes pueden dar la limosna a cambio de las adulaciones del mendigo ${ }^{72}$. Desde las filas de la nobleza, el autor critica la movilidad social, pues quienes ascendieran necesitarían permanentemente esa construcción de su nuevo estado. Para ello se valdrían de los marginales, con quienes establecerían una relación que los beneficiaría mutuamente (el mendigo recibiría limosna y quien la otorgara, ostentaría su estado con ello) y que implica una contradicción porque la legitimación del status tiene lugar a través de un marginal.

\section{EI mendigo, el delincuente}

\footnotetext{
${ }^{69}$ Antonio Serrano González, op cit, p 39.

${ }^{70}$ Carmen López Alonso, op cit, p 497.

${ }^{71}$ Así hace Guzmán, en un momento en el que ha salido de la pobreza pero, envilecido, no ha abandonado sus prácticas marginales: “¡Cuántas veces también, cuando tuve prosperidad y trataba de mi acrecentamiento -por sólo acreditarme, por sola vanagloria, no por Dios, que no me acordaba ni en otra cosa pensaba que solamente parecer bien al mundo y llevarlo tras de mí, que, teniéndome por caritativo y limosnero, viniesen a inferir que tendría conciencia, que miraba por mi alma y hiciesen de mí más confianza-, hacía juntar a mi puerta cada mañana una cáfila de pobres y, teniéndolos allí dos o tres horas por que fuesen bien vistos de los que pasasen, les daba después una flaca limosna y, con aquella nonada que de mí recebían, ganaba reputación para después mejor alzarme con haciendas ajenas!. ¡Cuántas veces de mi pan partí el medio, no quedando hambriento, sino muy harto, y con aquella sobra, como se había de perder o darlo a los perros, lo repartí en pedazos y lo di a pobres, no donde sabía padecerse más necesidad, sino donde creí que sería mi obra más bien pregonada!" Mateo Alemán, op cit, Segunda Parte, p 475. Esta recriminación que se hace Guzmán también es una amonestación social.

${ }^{72}$ Respecto a esta representación, ver la nota 56 de este capítulo.
} 
La representación de los mendigos como simuladores domina la literatura picaresca. Este estereotipo se impone de modo tal que en algunas novelas donde se describe la limosna callejera, no se menciona ni un solo pordiosero que sea una persona físicamente inválida para el trabajo. Así, se presume desde el comienzo el carácter engañoso de aquellos minusválidos que mendigaban en las calles ${ }^{73}$. Esta presuposición alcanza otros aspectos de su conducta, pues se sospecha que el mendigo válido alterna esta práctica con el hurto o la estafa.

El marginal aparece fluctuando entre la mendicidad y el robo, pero ¿pedir limosnas siendo un hombre sano no constituye una forma de fraude contra quien la entrega y contra quien "verdaderamente" la necesita? Las novelas estigmatizan a los marginales como mendigos/ladrones, incitando la aversión hacia ellos por parte de los lectores. Existía la suposición generalizada según la cual algunos limosneros inválidos eran en realidad hombres que habían acumulado cierta riqueza con su actividad, a quienes la avaricia los conducía a simular enfermedades y a cometer atrocidades como deformar a sus hijos para incentivar la caridad mediante la conmiseración ${ }^{74}$. Esta idea está en relación con otra acusación que se suele hacer contra el pobre: se trataría de un sujeto ambicioso porque no acepta el estado que le corresponde y no se somete al trabajo manual ${ }^{75}$. Para Soto, esta particularidad se vinculaba a la ociosidad, la adulación, la codicia y la delincuencia ${ }^{76}$ y sería una falta moral, religiosa y contra el orden social y la naturaleza porque podría conducir a tullir al descendiente, cometer un acto contra la caridad, desvergonzarse y no someterse al orden natural de ocuparse (y ganar el pan con el sudor de la frente) ${ }^{77}$, construyendo de este modo una radicalización de la figura antitética de lo social. Diversos sectores estigmatizados han sido acusados de prácticas

\footnotetext{
${ }^{73}$ Bronislaw Geremek, La piedad... op cit, p 61.

${ }^{74}$ Lo que sí podemos recordar es la mutilación de los castrati que resultaba rentable a sus familias.

${ }^{75}$ Carmen López Alonso, op cit, pp 143 y 144.

${ }^{76}$ Así sostiene Soto: “... como dice aquel proverbio del Sabio: mucha maldad engendra la ociosidad. Y la causa da en otro proverbio, do dice que el ocioso siempre está preñado de deseos, y por eso no puede sino parir maldades.

Lo primero, a la costumbre de pedir es luego anexo el vicio de la adulación. Y lo segundo, el perdimiento de la vergüenza, que es el freno que a los hombres detiene de hacer el mal.

Y lo tercero, el vicio de la deshonestidad, que como dijo aquel poeta: ocia si tollas pariere cupidinis arcus. Quita la ociosidad, y quebraste la flecha de la carne. Y lo cuarto, quien siendo sano es enseñado a pedir, fácilmente aprende a hurtar." Félix Santolaria Sierra (ed.), El gran debate... op cit, p 59. Aquí aparece el debate honra-vergüenza, que podemos repasar en Giovanni Ricci. Povertà, vergogna, superbia. Il declassati fra Medioevo e Età moderna. Bolonia, Il Mulino, 1996.

${ }^{77}$ Por ejemplo, el éxito de Justina en la adquisición de limosnas, la conduce a ambición de dinero que podría adquirir de este modo. Por ello, la joven comienza a pedir más de lo que necesita para su subsistencia, volcándose a esta actividad “... porque, cada cuarto que me echaban era aceite en el fuego de mi codicia y clavo que me cosía de nuevo con el asiento donde estaba." Francisco López de Úbeda, op cit, p 341 .
} 
despiadadas contra los niños (así, se supone que las brujas los someten en sus aquelarres o que los judíos atentan contra ellos) ${ }^{78}$. En El Guzmán encontramos la narración intercalada que refiere a un mendigo florentino que mutila a su hijo para pedir limosnas y de este modo recaudar una enorme riqueza. La entelequia acerca del mendigo rico surge a partir de que puede vivir sin someterse al trabajo manual al que estaba obligado por su origen. Tal personaje no gastaría dicha fortuna, sino que la escondería. De aquí se infiere otra crítica, que radica en su mezquindad, mientras la generosidad y la propensión por el derroche eran consideradas como virtudes en los grupos poderosos ${ }^{79}$. La historia del Florentino llega a oídos de Guzmán como un mito del grupo, de acuerdo con el arquetipo sobre los limosneros que alquilarían niños o los secuestrarían, que se repite obsesivamente no sólo en la picaresca sino también en otros discursos que corresponden a otras formaciones sociales $^{80}$. Si el mendigo puede convertirse en delincuente como consecuencia de su codicia -indicativa de que es pecador-, la picaresca también alerta acerca de la situación inversa, la del delincuente que se esconde bajo el disfraz de mendigo ${ }^{81}$.

El pobre además debe tener vergüenza ${ }^{82}$ de su condición porque se percibe la limosna como una situación humillante ${ }^{83}$. Así leemos en La pícara Justina:

\footnotetext{
${ }^{78}$ Ver por ejemplo "Aquelarre", obra de Francisco de Goya conservada en el Museo Lázaro Galdiano (1797-1798). También, respecto a la reproducción del antisemitismo en España en la Baja Edad Media, debemos mencionar la leyenda del Santo Niño de La Guardia, en la cual se acusa falsamente a los judíos y conversos de un asesinato ritual que habrían llevado a cabo en Toledo, y por el cual fueron procesados y quemados varios conversos y judíos en 1491. Dicha acusación contribuyó a alimentar el odio a los judíos, que serían expulsados un año más tarde.

${ }^{79}$ Mateo Alemán, op cit, Primera Parte, pp 412 y ss.

${ }^{80}$ Jean Delumeau, op cit, p 300 . En este caso es sobre vagabundos "ladrones, pícaros, impostores".

${ }^{81}$ Así, por ejemplo, Marcos de Obregón, al escapar luego de cometer un delito, aparenta ser un mendigo. Tras esta simulación basada nuevamente en los harapos e instalarse en la puerta de la iglesia entre otros pobres, continúa con su huida, lo cual pretende demostrar que en tanto los menesterosos no estuvieran regulados, darían lugar al desorden, en el cual se pueden mezclar personas de diversas condiciones y por lo tanto ser funcional a la propagación del caos social. La novela describe la confusión de mendigos y criminales en el marco de la iglesia, bajo el amparo del eclesiástico. Aquí vemos la mención del retraído, aquel que se acoge a una iglesia. El sacristán sospecha que se asilan en la iglesia porque temen ser perseguidos por delitos cometidos. "Llegó muy furioso a buscarme en la iglesia; el sacristán cerró la iglesia antes que llegase, y juró -y con verdad- que no había en toda ella retraído ni otra gente sino aquellos pobres que a nadie dejaban oír misa, y que si quería sacar algún retraído, él se lo daría en las manos, echándolos de allí. Luego él comenzó a echallos, diciéndoles: 'Vosotros algunos delincuentes debéis de ser"'. Vicente Espinel, "Vida del escudero Marcos de Obregón", en Valbuena y Prat, Ángel (ed.). La novela picaresca española. Madrid, Aguilar, 1956, pp 921-1087, p 1008.

${ }^{82}$ Covarrubias tiene una apartado interesante:

"Latine verecundia, pudor, modestia, ingenuitas; su contrario se dize desvergüenza, y desvergonçado el descompuesto y de poco respeto; como vergonçoso el que de qualquiera cosa que a su parecer no aya hecho con la decencia devida se pone colorado y le llamamos vergonçoso, indicio de virtud y de modestia. De quanta importancia sea la desvergënça del hombre, lo podrás ver con mucha particularidad en la ley 16 , tit $13, \mathrm{p} 2$.

Vergüenças: (...) 'más vale vergüença en cara que mancilla en coraçón'; hay algunos desvergonçados que con mucha libertad piden lo que se les antoja a los hombres honrados y vergonçosos, los cuales, muchas
} 
Y como la gente de la romería viese a la puerta de la iglesia, cosa allí pocas veces usada, una mujer de buen talle, compadecíanse de mí, y decían:

- ¡Ah, triste de tí, que te hace la pobreza ser niña grande echada en la arca de la misericordia! ${ }^{84}$

Si bien puede ser que le tengan lástima, la idea de ser niña grande ${ }^{85}$ asociaría la mendicidad a la debilidad infantil por no poder sustentarse mediante su trabajo. Son otros personajes quienes observan a la protagonista y presuponen su situación vergonzosa ${ }^{86}$, aunque a la marginal se le imputa no compartir ese sentimiento porque elige pedir sin adecuarse a la condición de trabajadora o someterse a la potestad masculina.

Esta observación sobre los marginales como ladrones o humillados tiene lugar en un período en que se amplifica la acusación de quienes no se adaptan a su situación heredada, dinámica que se vio acentuada por la coyuntura de miedo e inquietud que atravesaba la sociedad. Desde los siglos XIV y XV la xenofobia se hacía más sistemática y la herejía ya no era considerada sólo como una ruptura religiosa sino también como una secesión social y un crimen de lesa majestad ${ }^{87}$. En este contexto, el pordioseo por parte de los hombres sanos es evaluado como una mentira y una traición religiosa.

\section{La propagación de los mendigos y su sociabilidad}

La presunta contrasociedad que conformarían los falsos mendigos fue objeto de la preocupación de los literatos, así como un motivo de temor por parte de la sociedad. Los textos referentes a ello han sido leídos de manera acrítica por algunos historiadores

veces no osan negar lo que estos tales les piden; y es lo mesmo que salir a saltear a un camino, porque aunque lo pidan prestado no tienen ánimo de bolverlo. A éste se consigue otro, que dize: 'Quien vergüença no tiene, toda la villa es suya'. Avergonçarse en valde, quando han respondido a estos tales pidiendo alguna cosa, nescitis quid petatis. Proverbio: 'A poca barba, poca vergüença'. 'Al moço vergonçoso, el diablo le llevó a palacio’.” Sebastián de Covarrubias, op cit, p 1003.

${ }^{83}$ Carmen López Alonso, op cit, pp 99, 100 y 331; Bronislaw Geremek, La piedad... op cit, p 37.

${ }^{84}$ Francisco López de Úbeda, op cit, p 339.

${ }^{85}$ Sebastián de Covarrubias, op cit, p 829. "Niño: (...) hay algunos muchachos tan regalones que con ser grandes no saben desasirse del regaço de sus madres; salen éstos grandes tontos o grandes bellacos viciosos".

${ }^{86}$ El don proporciona superioridad a quien da sobre quien recibe. Mauss sostiene que "la caridad aún es hiriente para quien la acepta y todo el esfuerzo de nuestra moral tiende a suprimir el patronazgo inconsciente e injurioso del rico 'limosnero'". Marcel Mauss, op cit, p 229.

${ }^{87}$ Hervé Martin, op cit, pp 427 y 428. 
que no han hallado y explicado correctamente todas las posibilidades que aquellos presentan y que han sostenido, a partir de lo encontrado en las fuentes literarias, la existencia de bandas estables de mendigos/delincuentes. Sin embargo, antes de hacer esta clase de afirmaciones es necesario reflexionar acerca de la soledad de estos menesterosos, indicativa de que es probable que se mantuvieran sin lazos estables y sin formar un grupo solidario ${ }^{88}$.

Las novelas apuntan a que el mayor peligro es la secesión de los miembros de la sociedad, que podría tener lugar si cada uno de sus agentes se negara a aceptar la posición heredada y cumplir con el rol que se esperaba de él en dicha condición. Este argumento era importante para imponer el control en un período de crecimiento de las ciudades, donde era necesario reforzarlo y cambiar la técnica para ejercerlo, pues en las pequeñas villas, la vecindad podía realizar esta tarea ${ }^{89}$.

En varias novelas se relata cómo los mendigos se enseñan mutuamente las destrezas verbales para pedir, clave en la reproducción cultural del grupo, que contiene a su vez un aspecto decisivo de su reproducción social. Este fenómeno es presentado como una epidemia, pues estos hombres se propagarían de manera invisible, peligrosa y temible. Si bien el conocimiento y reproducción de los hábitos del hampa están presentes en varias novelas, dos de ellas (El Guzmán y El Buscón, las más importantes e indiscutidas del género) describen la asociación de los mendigos.

En El Guzmán encontramos una agrupación de limosneros que normaliza su actividad para una mayor efectividad de todos todos sus miembros. Guzmán aprende las "Ordenanzas mendicativas", que manejan los limosneros romanos cuando entra en el "gremio". Se trata de un discurso formalmente similar al de las normativas locales pero cuyo contenido radica principalmente en la regulación del arte de la simulación en pos de garantizar la efectividad de todos los mendigos ${ }^{90}$. El autor está reflejando en la contracultura marginal las mismas estructuras organizativas que él conoce y que imagina como las únicas posibles.

El aprendizaje dentro del ámbito marginal es un tópico en la picaresca funcional a su objetivo didáctico vinculado con la estigmatización de los pobres y mendigos, a

\footnotetext{
${ }^{88}$ Claudio Guillén, "Sobre la soledad del pícaro", en Exemplaria. № 5, Huelva, Universidad de Huelva, 2001, pp 121-128. En este artículo C. Guillén explora la formación del pícaro a partir de su soledad.

89 Jean Delumeau, op cit, pp 298 y 299. El autor rastrea en el marco del miedo a los mendigos por la posibilidad de que armaran bandas, un fenómeno de temor generalizado en 1523 por una supuesta "conmoción" de mendigos, que comenzó con la sospecha de que querían pervertir la ciudad.

${ }^{90}$ Mateo Alemán, op cit, Primera Parte, pp 388 y ss. Examinaremos las “Ordenanzas mendicativas" en el próximo capítulo.
} 
quienes se supone agrupados en un mundo paralelo y oculto que se imagina antagónico a las normas sociales, donde se enseñan las prácticas delictivas. El aprendizaje de las diversas "artes" (usando el modelo gremial) indica la propagación de este mal social. La novela ilustra cómo el pícaro subvierte la caridad para usar una dádiva que debería servir para la asistencia a un verdadero pobre, quitándosela en su propio provecho. La falta de control sobre la caridad favorece a los falsos mendigos, quienes conforman una contracultura con su propia cosmovisión y su sistema de valores particular ${ }^{91}$. Alemán muestra un proceso de aprendizaje de la mendicidad que consiste en encontrar la manera adecuada de pedir:

\begin{abstract}
Guiábame otro mozuelo de la tierra, diestro en ella, de quien comencé a tomar liciones. Este me enseñó a los principios cómo había de pedir a los unos y a los otros; que no a todos ha de ser con un tono ni con una arenga. Los hombres no quieren plagas, sino una demanda llana, por amor de Dios; las mujeres tienen devoción de la Virgen María, a Nuestra Señora del Rosario (...) 'Dios encamine sus cosas en su santo servicio y las libre de pecado mortal, de falso testimonio, de poder de traidores y de malas lenguas!' Esto les arranca el dinero de cuajo, bien pronunciado y con vehemencia de palabras recitado. Enseñóme cómo había de compadecer a los ricos, lastimar a los comunes y obligar a los devotos. Dime tan buena maña, que ganaba largo de comer en breve tiempo. ${ }^{92}$
\end{abstract}

El autor se esfuerza en presentar la idea del rendimiento del esfuerzo, pues el personaje se jacta de su artificio, que le permite alimentarse sin trabajar y en un tiempo breve. En esta cita se pretende mostrar la riqueza de los limosneros, que consiste en la posibilidad de sobrevivir sin someterse al trabajo manual. La súplica debe ser selectivamente dirigida al potencial benefactor, que será una persona que, por una incitación emotiva y religiosa, actuará con misericordia y dará algo al pobre. Cada grupo de personas es movilizado por estímulos diferentes, asociados a las variaciones que cada tipo social imprime en su creencia, pues la religiosidad popular es heterogénea. Por otra parte aquí se aprovecha para introducir la crítica hacia las mujeres, a quienes se supone temerosas de las malas lenguas o del castigo por el pecado, porque secretamente pueden ser culpables. Sin embargo, el final de este pasaje

\footnotetext{
${ }^{91}$ Así, admiran a los mejores farsantes. "Después di en acompañarme con otros ancianos en la facultad, que tenían primores en ella, para saber gobernarme. Íbame con ellos a limosnas conocidas, que algunos por su devoción repartían por las mañanas en casas particulares"Ibídem, Primera Parte, p 387.

${ }_{92}$ Ibídem, Primera Parte, p 386.
} 
también indica el limitado horizonte real de las aspiraciones de los mendigos -comer todos los días-.

En El Buscón, la relación competitiva entre los hombres que se disputan la beneficencia es descripta en un episodio en el que un pícaro trata de apropiarse de la limosna por sobre sus pares. Cuando uno de ellos quiere sobrepasar la cantidad estipulada para cada uno se produce una reacción corporativa, de acuerdo con la lógica gremial de repartición de la demanda de la ciudad, lo cual demuestra que el autor probablemente estaría remedando la actuación de los gremios artesanos. La sanción de la competencia desleal que, si beneficia a uno, daña a los otros que cuentan con una porción menor en la distribución, es característica de dichas corporaciones. Se trata de asociaciones que regulan la competencia y la cooperación, así como las artes y técnicas que pueden desarrollar sus miembros para garantizar un ejercicio justo por parte de cada uno en el marco de dicha comunidad y la posición del grupo en la sociedad a la que ofrece su trabajo. De este modo, si uno de ellos contraviene lo estipulado por el conjunto, lo daña porque se apropia de algo que podría ser compartido, además de que también puede perjudicar la fama del colectivo $\mathrm{y}$, por lo tanto, a cada uno de los artesanos. La novela quiere mostrar que los mendigos ejercían reglas similares a las de los gremios para el beneficio de su grupo, que controlaría sus prácticas mediante sistemas de disciplinamiento interno, con el objetivo de garantizar la subsistencia del conjunto $^{93}$.

La cooperación entre los pícaros también se expresa en la enseñanza de las diversas "artes" del gremio. Pablos aprende rápidamente de los falsos mendigos distintas formas de hurtar, o lo que es lo mismo, conseguir una limosna que no le corresponde $^{94}$. De esta manera se instala la idea de la propagación veloz de este mal social, a partir de la oculta -y en tanto que oculta, incontrolable- socialización de estos pícaros. Quevedo describe la sabiduría de aquel mendigo que "Estaba riquísimo, y era como nuestro retor; ganaba más que todos; tenía una potra muy grande, y atábase con un cordel el brazo por arriba, y parecía que tenía hinchada la mano y manca, y

\footnotetext{
${ }^{93}$ Así se describe en la novela de Quevedo la competencia entre los mendigos por la caridad, mientras se hace referencia a la mentira, la gula y la avaricia: "Entro luego mi compañero desechas las narices, y toda la cabeza entrapajada, lleno de sangre, y muy sucio. Preguntámosle la causa, y dijo que había ido a la sopa de San Jerónimo y que pidió porción doblada, diciendo que era para unas personas honradas y pobres. Quitaronselo a los otros mendigos para dárselo, y ellos, con el enojo, siguiéronle, y vieron que, en un rincón detrás de la puerta, estaba sorbiendo con gran valor. Y sobre si era bien hecho engañar por engullir y quitar a los otros para sí, se levantaron voces, y tras ellas palos..." Francisco de Quevedo, op cit, pp 185 y 186.

${ }^{94}$ Ibidem, pp 191 y 192.
} 
calentura, todo junto. Poníase echado boca arriba en su puesto, y con la potra defuera, tan grande como una bola de puente..."95. El cuadro mostraría que este personaje atraía la atención por la curiosidad malsana, pues se ataba el brazo por arriba y exhibía su deformidad $^{96}$, imagen que sugiere además la infamia que implica la enfermedad sexual. El mendigo se enriquece (idea que, como observamos, se desprende de la posibilidad de subsistir sin trabajar) gracias a la simulación de una deficiencia física y la posición adecuada para hacerse visible. Este éxito que da lugar a su preminencia pero implica desvergüenza e indecencia por su exhibición pública, que engaña a los incautos.

Lo más destacado de los mendigos en las novelas es su destreza discursiva, principal recurso de Pablos. Dentro del grupo de pícaros, aquellos con más habilidades consiguen cierto poder, pues la admiración y respeto de sus pares les otorga un liderazgo carismático. El vínculo que establecen estos personajes fluctúa entre la competencia y la cooperación y ambas relaciones conducen a la dispersión de sus conductas. La relación competitiva implicaría la necesidad de perfeccionar las estrategias que pondrían en práctica para sobrevivir a través de la creatividad o la imitación. Pablos aprende a partir de la observación e imitación de “... un mocetón mal encarado, manco de los brazos y con una pierna menos, que me rondaba las mismas calles en un carreton..." ${ }^{, 97}$, cuya efectividad reside en su forma de rogar aludiendo a las imágenes cristianas: “...decía con voz ronca rematando en chillido: - ‘¡Acordáos, siervos de Jesucristo, del castigado del Señor por sus peccados! ¡Dalde al pobre lo que Dios reciba!' Y añadía: ‘Por el buen Jesú!’; y ganaba que era un juicio. Yo advertí, y no dije más Jesús, sino quitábale la s. y movía a más devoción"98. Esta representación contiene todos los artificios del limosnero, que incluyen la exhibición de sus lesiones, la voz algo enferma e insoportable y la referencia al pecado y la bondad divina. Sin embargo, el narrador considera como clave de su éxito la ausencia de la $\mathrm{S}$, que tiene que ver con un habla regional de Andalucía, estereotipo que se debe a que los pobres andaluces eran más numerosos porque migraban de su territorio como consecuencia de su pauperización.

El grupo de mendigos tendría otras características comunes con los gremios. Cuando ingresa en el "colegio buscón", Pablos entrega su dinero, que pasa a ser

\footnotetext{
${ }^{95}$ Ibídem, p 251.

${ }^{96}$ En Covarrubias, Potra: "Quasi putrida, es cierta enfermedad que se cría en los testículos y en la bolsa dellos. Cerca de los médicos tiene diferentes nombres, por la diversidad de especies de esta enfermedad, como es hernia y cirro, etc.” Sebastián de Covarrubias, op cit, p 879.

${ }^{97}$ Francisco de Quevedo, op cit, p 250.

${ }^{98}$ Ibídem, p 251.
} 
administrado de manera colectiva (como los bienes personales de los monjes pasan a ser comunes en algunas órdenes religiosas), y se le otorgan ropas adecuadas a su trabajo (harapos de pobre). Los mendigos se dividirían la ciudad en diócesis (imitando nuevamente la organización eclesiástica) para proceder de manera ordenada y así no superponerse, consiguiendo un mayor beneficio por esta buena administración ${ }^{99}$, idea que encontramos sólo en la novela de Quevedo, quien hace una correlación tácita entre la caridad recibida por la Iglesia y la que obtienen los pobres.

La iniciación y la prueba del novato consisten en pedir en soledad en una "diócesis" de la ciudad -según la categorización de la cofradía-, para que "él solo busque y apolille" $" 100$. Diversos aspectos de la dinámica grupal tienen características similares al de las organizaciones de la sociedad corporativa que enmarca las obras, porque los literatos no podían imaginar nada que estuviese fuera de su experiencia.

Varios autores han interpretado las descripciones que representan al mundo marginal como una contracultura organizada, sin inquirir sobre el grado de verosimilitud que se les puede atribuir, aunque resulte cuestionable la posibilidad de que existieran realmente dichos grupos tal como fueron delineados. En este sentido debemos reflexionar sobre dos aspectos: en primer lugar, es dudosa la veracidad de las referencias a estas asociaciones, cuyas características idénticas son imaginadas por la literatura en tiempos y lugares remotos; en segundo término, los marginales establecen con el resto de la sociedad una relación de engaño y traición permanentes, trato que refracta los vínculos que establecen entre pares, imposibilitando los lazos estables entre ellos. La existencia solitaria del pícaro hace que encuentre compañeros ocasionales con quienes no establece relaciones duraderas, sino que en ellas preponderan la traición y la deslealtad $^{101}$.

Veremos detenidamente en el capítulo sexto el vínculo entre nomadismo, socialización y construcción del enemigo al que se supone enmarcado en un complot, por lo tanto aquí avanzaremos sobre la representación de los castigos a los mendigos, considerados insuficientes por parte de los literatos.

\section{La persecución y el castigo}

\footnotetext{
${ }^{99}$ Ibidem, pp 171 y 172.

${ }^{100}$ Ibídem, op cit, p 172.

${ }^{101}$ José Antonio Maravall, La literatura picaresca... op cit, p 317.
} 
En el capítulo tercero consideramos las medidas ensayadas para el control de los marginales; parte de cuyos esfuerzos se dirigían contra los mendigos. La literatura describe cómo los castigos públicos podrían amedrentar al limosnero, quien no cambiaría su forma de vida sino que buscaría alternativas de manera momentánea. Así, El Lazarillo testifica la solución local al problema cuando narra la persecución de los pobres durante un año de miseria ${ }^{102}$. Allí observamos el terror que inspira al muchacho ver la procesión y la posible punición, pero él tiene sus propios lazos, también marginales (se trata de dos mujeres solas que complementan su ocupación como costureras con la prostitución), que le permiten sustentarse por un tiempo ${ }^{103}$. De esta manera, la novela describe el miedo por la represión violenta, único recurso pedagógico desde el poder, pero también las posibilidades que su flexibilidad y capacidad de adaptación le otorgan al pícaro.

Cuanto más enfatizan las novelas sobre la criminalidad de los marginales, mayores son las referencias a la condena de los mendigos. En La hija de Celestina, la estafa realizada por la banda de Montúfar acaba con la pena de la vieja y de los criados, ella es sometida a cuatrocientos azotes -muriendo unos días más tarde- y los mozos a doscientos y desterrados. Sin embargo, la novela narra la persecución de los otros dos pícaros (Elena y el rufián) hasta que consiguen huir de la ciudad porque son más hábiles que la justicia que los acosa ${ }^{104}$. Por otra parte, no sólo son asediados por agentes locales sino que el descubrimiento de la estafa a la caridad desata la ira popular y su acecho por parte de diversos sectores sociales ${ }^{105}$. Los pícaros consiguen escapar gracias a la

\footnotetext{
${ }^{102}$ El narrador adulto recuerda la procesión que presenció siendo niño y que lo alejó de la mendicidad, pero no de otras formas marginales de supervivencia: "Y fue, como el año en esta tierra fuesse esteril de pan, acordaron el ayuntamiento que todos los pobres extrangeros se fuessen de la ciudad, con pregon que el que de alli adelante topassen fuesse punido con açotes. Y assí, executando la ley, desde a quatro dias, que el pregon se dió, vi lleuar una procession de pobres açotando por las quatro calles. Lo cual me puso tan gran espanto, que nunca osé desmandarme a demandar." Anónimo, op cit, p 179.

103 "A mi dieronme la vida vnas mugercillas hilanderas de algodón, que hazian bonetes y viuian par de nosotros, con las quales yo tuue vezindad y conocimiento. Que de la lazeria, que les trayan, me dauan alguna cosilla, con la qual muy passado me passaua." Ibídem, p 180.

${ }^{104}$ En La hija de Celestina se describe la huida de la pícara y su amante, quienes reciben la ayuda de otros personajes: "Más pudo la prevención de Elena que la mucha diligencia de la Justicia. Buscábanla dentro y fuera de la ciudad, no había parte adonde no la cercasen con asechanzas, y ella, como cuerda, estábase en la mira, encerrada en una casa de confianza y seguridad, hasta que pasasen los rayos." Alonso J. de Salas Barbadillo, op cit, $\mathrm{p} 147$.

105 "Corrióse el vulgo de haber sido engañado, y volviendo el devoto respeto en insolente venganza, si mucho habían cantado sus loores, más dijeron afeando sus vicios. Los muchachos, que en todos los casos públicos tienen parte, y no la menor, les hicieron coplas de aquel modo que saben, donde, por lo menos, dicen lo que quieren, y muchas veces con tan buena gracia que los hombres cuerdos y de cuyo parecer se hace siempre caso, no se admiran poco. Pero la variedad de los sucesos, que trayendo unos olvida otros, dio de mano a esta novedad y tanto, que se puso silencio en ella como si nunca hubiera sucedido". Ibídem, p 147.
} 
protección de otras personas, lo cual podría constituir también una denuncia por parte del autor, demostrando la posibilidad de contar con complicidades temporales. La persecución por parte de la población se activa por un período de tiempo muy breve y sirve como ejemplo para criticar todas estas prácticas.

La novela de Quevedo ejemplifica minuciosamente la criminalidad de estos sujetos y su relación con los comerciantes en el episodio que lleva a Pablos y su grupo a la cárcel. En el intento de vender objetos robados, uno de ellos es descubierto y delata a la banda, revelando sus prácticas y conductas. El autor enfatiza en la inclinación a la delación y traición de los marginales, poniendo en cuestión que pudieran formar grupos solidarios $^{106}$.

Teniendo en cuenta el vínculo entre estas novelas y el intento de regulación de la mendicidad, primero en el marco de la corte, para luego extenderse al resto del reino, la narrativa acompaña este proceso y critica el funcionamiento de este sistema, que los pícaros violan fácilmente. En El Buscón, encontramos a un pícaro en la corte que esgrime "... una carta, con la cual, diciendo que era licencia para pedir para una pobre..." ${ }^{\prime 107}$, secuencia que muestra la ineficacia de la autoridad para regular la mendicidad con el sistema de cédulas.

Los verdugos que deberían ejecutar los castigos son también marginales y su oficio es uno de los más degradados en la sociedad del Antiguo Régimen porque está marcado por el tabú de la sangre. En una ocasión en que Pablos está en lo de su tío, que tiene dicha ocupación, entra a la casa un falso pobre ("uno de los que piden para las ánimas") ${ }^{108}$ que había sido azotado como consecuencia de su práctica, y menciona cierta negociación: "cuatro ducados di yo a Flechilla, verdugo de Ocaña (...) por que no llevase la penca de tres suelas, cuando me palmearon"109. Los azotes no pueden ser efectuados en la forma prescripta debido a la negligencia de sus ejecutores, quienes tampoco temen ser penados por ello, lo que sugiere la persistencia de los mendigos gracias a la complicidad de los oficiales municipales. En el caso de los verdugos, se relata un episodio de colaboración consciente y decidida con los pícaros, relación que pone en tensión la idea de un rechazo generalizado, además de desdibujar la frontera del hampa. Si la intención del autor es demostrar la segregación de los marginales, consideramos que a lo largo de la obra se trasluce la posibilidad de supervivencia del

\footnotetext{
${ }^{106}$ Francisco de Quevedo, op cit, p 192.

${ }^{107}$ Ibidem, p 164.

${ }^{108}$ Ibídem, p 136.

${ }^{109}$ Ibídem, p 137.
} 
pícaro a través de su inserción en la sociedad de manera individual, tal como corroboramos en otras novelas.

Finalmente, los autores identifican a los falsos pobres sobre todo con el fenómeno urbano, pues eligen representar la mendicidad en ciudades como Toledo, Sevilla o Roma, donde eran más difíciles de controlar, mientras en los pequeños poblados la comunidad regularía a los pobres propios.

\section{Las pícaras y la mendicidad}

Habiendo reparado en diversos aspectos acerca de la estigmatización de los mendigos a través de la novela picaresca, nos referiremos brevemente a la forma particular en que las mujeres fueron caracterizadas como mendigas en esta narrativa. Aquí también encontramos diferencias en cuanto a la representación de las formas de dramatización que ponen en juego estos personajes para pedir limosnas. Cuando la protagonista es una marginal, se trata de una joven bella, a diferencia de las mujeres segregadas que son personajes secundarios en las novelas cuyos protagonistas son pícaros, pues en estos casos no cuentan con aquella cualidad.

Las pícaras recurren menos a la simulación de la enfermedad y eligen, en cambio, otros mecanismos pecaminosos como la exhibición de la belleza. Hay una cierta ambigüedad, piedad y preocupación por su situación expuesta a la prostitución, y la sospecha de que ya ha caído en ella o de que está dispuesta a caer. Cuando Justina mendiga en la puerta de una iglesia, se oculta para no ser reconocida y realiza una simulación diferente a la de sus pares masculinos: ella no esconde su cuerpo sano ni pretende horrorizar con la miseria de sus harapos, sino que se muestra como pobre vergonzante. Elige representar a una mujer con cierto status pero empobrecida por su viude $z^{110}$. Es una tipología de pobreza que aparece diferenciada de la de los mendigos inválidos que también tenían derecho a pedir mas por una causa diferente, pues la legitimidad de los vergonzantes no se debía a su debilidad física pero a no estar obligados al trabajo manual, sino constreñidos por su status a no ejercerlo. Además la

\footnotetext{
${ }^{110}$ En la descripción de Justina como vergonzante encontramos el ocultamiento del personaje real mientras se construye el de la viuda que pediría limosnas: “... me puse mi manto, que era largo y me cubría todos mis ribetes y cortapisas, y puesta ansí, que el diablo no me conociera, me tapé como condesa viuda, (...) me senté a la puerta de la iglesia como pobre envergonzante; puse sobre mis rodillas un pañuelo blanco para que los que me hubiesen de tirar limosna diesen en el blanco y para señuelo de que pedía y no para los mártires." Francisco López de Úbeda, op cit, p 339.
} 
pícara utiliza una seña para atraer la atención (que evidentemente de otro modo no recibiría), que sirve como herramienta para obtener las dádivas, demostrando que los pobres no eran tan visibles como sostienen las novelas y los tratados.

En La hija de Celestina no sólo se acusa a los mendigos de mentir en nombre de Dios de modo ocasional y no premeditado, sino que se aventura que se trata de una forma de vida que cuenta con un sistema de simulaciones acerca de la creencia religiosa. Así retoman la semántica de la Iglesia e, imprimiendo su carisma y procedencia popular, consiguen tener éxito en la demanda de limosnas, tal como vemos en el suceso que generan Montúfar, Méndez y Elena cuando llegan a Sevilla, donde emprenden una forma de vida basada en un doble comportamiento, mostrando públicamente una conducta que no se condice con su vida privada ${ }^{111}$. Pero a través de su lectura comprobamos la intencionalidad y la conspiración para el engaño: no se trata de una salida ante una situación adversa para poder sobrevivir, pues habían madurado la idea en el camino a Sevilla. Los simuladores mantienen una imagen miserable a partir del atuendo y, a pesar de practicar este truco por primera vez, conocen las triquiñuelas que deben poner en práctica para estimular la caridad. En la novela de Salas Barbadillo vemos el funcionamiento de una banda que disimula su rapacidad fingiendo fe y devoción, mientras el relato se encarga de demostrar que se trata sólo de una apariencia que, cuando se descubre la verdad, acaba en el castigo de Méndez y los criados (pues los otros dos cómplices consiguen huir). El texto fluctúa permanentemente entre el relato de lo que ocurre en el ámbito privado y lo que se muestra ante la sociedad, como dos polos contrapuestos.

En las novelas sobre pícaras además de la misoginia que se constata en todo el género se acentúa la idea del terror hacia la belleza femenina ${ }^{112}$ (la belleza del diablo, arma ante la cual los hombres sólo pueden sucumbir) aunque la narrativa sobre pícaros representa una realidad diferente en este sentido, cuestiones respecto a la construcción del miedo que retomaremos en el próximo capítulo.

\footnotetext{
${ }^{111}$ La descripción da cuenta de la premeditación en la treta mediante la cual Elena, Méndez y Montúfar sobreviven un tiempo en Sevilla. El relato combina además la exhibición visual del delincuente (entonces un pobre fingido) y su discurso que apela a la religión: "Al día siguiente alquiló Montúfar una casilla pobre, y aderezándola honestamente -porque así convenía para poner en ejecución el modo de vida que entre los tres venía concertado- se pasaron a ella, donde, vistiéndose él de buriel pardo, ferreruelo largo y sotana que llegaba hasta la media pierna, y poniéndose calzas groseras de lo mismo y zapato de vaqueta, con una campanilla en las manos salió por las calles diciendo en altas voces, una y muchas veces: 'Loado sea el Santísimo Sacramento..."' Alonso J. de Salas Barbadillo, op cit, pp 139-140.

112 Jean Delumeau, op cit, pp 471 y ss.
} 


\section{Conclusión}

El supuesto que encontramos en las novelas se basa en la idea de que la totalidad de los mendigos son aptos para el trabajo corporal. A partir de esta noción se especula sobre diversas simulaciones que ellos pondrían en práctica para engañar a quienes pudieran otorgarles dádivas. Estas estrategias se basan fundamentalmente en la construcción de una imagen estereotipada de los limosneros, retrato compuesto por su atuendo y las diversas deficiencias físicas que simulan. Los pícaros refuerzan esta apariencia a través de su expresión verbal, imitando la prédica evangélica con la cual piden por amor a Dios, la Virgen o los santos, así como aludiendo a su pasado como trabajadores y a su incapacidad para seguir viviendo como tales en el momento en que requieren dádivas. La manipulación del discurso religioso y la apelación malintencionada a la devoción ajena en pos de vivir disolutamente, convierte su simulacro especulativo en un crimen aun más grave, pues además de estafar, profanan los valores cristianos para arribar a fines antagónicos a los que la institución eclesiástica profesa, causando así daño al reino y la cristiandad, tanto en este mundo como en el otro. Se trataría de una asimilación de la ideología dominante para reutilizarla con fines distintos a los originarios; señalando una manipulación que pueden ejercer porque están en contacto con la sociedad, aunque ese vínculo está alterado porque provienen de los márgenes. De este modo, las novelas pretenden exponer cómo estos hombres consiguen evadir todo tipo de control y cómo su supervivencia constituye una carga para las personas socialmente integradas, mientras se hace alusión a la peligrosidad de los mendigos, dada la imposibilidad de efectivizar el control sobre ellos y sobre la difusión de sus prácticas.

Estas obras buscan predisponer a los lectores contra los limosneros, mostrando que detrás de su aspecto desamparado y piadoso simulado esconden un submundo extremadamente nocivo para el reino. Aquí hemos explorado la posibilidad de pensar que se trata una literatura que promueve la segregación y persecución de los vagabundos, que apela al miedo para construir la estigmatización de un sector que funciona como chivo expiatorio, haciéndolo encarnación de los problemas de la sociedad, mediante la referencia a su peligrosidad ${ }^{113}$.

\footnotetext{
${ }^{113}$ Sobre la comparación de las descripciones en otras literaturas de Europa ver Bronislaw Geremek, La estirpe... op cit. Sobre la similitud de las imágenes construidas acerca de otros grupos marginados -judíos y leprosos- en comunidades espacial y temporalmente distantes ver Carlo Ginzburg, Historia nocturna. Barcelona, Muchnik, 1991, pp 58 y ss.
} 
Varias suposiciones sobre este tipo de marginales poseen cierto paralelismo en las sospechas que recaen sobre otros grupos segregados durante la modernidad europea $^{114}$. La novela picaresca pone en guardia a los lectores sobre la peligrosidad de los mendigos a través del minucioso retrato individual: son caracterizados como estafadores, burladores de mujeres, ladrones y acusados de embaucar a quienes les otorgan las limosnas.

La pintura atemorizadora se construye también a partir de la idea de un grupo oculto en cuyo seno se inventan, organizan y comunican los distintos artificios que los pícaros utilizan contra el resto de la población cuando abandonan este espacio y están diseminados en la sociedad. Justamente su inserción epidérmica en el cuerpo social les permite actuar, ya que no son excluidos absolutos. Este retrato se asienta en la elaboración de un modelo de conducta que está en contradicción con los valores aceptados socialmente. Se los supone enfermizamente ambiciosos y mezquinos, sujetos que pueden vivir holgadamente a partir de la limosna y otras actividades rapaces, sin dejar de practicarlas a pesar de ello, imputándoseles conductas aberrantes como lastimar sus cuerpos y los de sus hijos u otros niños para generar compasión ${ }^{115}$. La desconfianza hacia los limosneros nos conduce a la presunción de culpabilidad del mendigo de ser un falso pobre a priori.

Esta imagen se reitera en las novelas picarescas, cuyos autores recurren a este tipo de retratos que pretenden atemorizar a la sociedad frente al accionar organizado y oculto de un grupo que podría atentar contra cualquiera debido a su carácter secreto. La misma imagen es reproducida por otro tipo de textos literarios, como los "avisos", cuyos casos presentan historias muy similares a las de la picaresca ${ }^{116}$. Por su parte, los escolásticos imputaban a los mendigos algunas de estas prácticas y vicios ${ }^{117}$.

Es necesario deslindar qué descripciones corresponderían a la realidad, cuáles son determinadas por los recursos literarios y qué observaciones dependerían de la subjetividad del autor -que responde asimismo a la demanda de un público lector y/o al interés de un mecenas. Si consideramos que la imagen se repite no sólo en la narrativa sino también en otro tipo de escritos, en primera instancia podemos creer que aquello

\footnotetext{
${ }^{114}$ Sobre otros grupos como judíos y supuestos demonólatras, ver Jean Delumeau, op cit, pp 445 y ss y pp 545 y ss.

115 Ver imaginaciones similares sobre otros grupos estigmatizados en Carlo Ginzburg, Historia nocturna... op cit, pp 58 y ss.

${ }_{116}^{116}$ Antonio Liñán y Verdugo, op cit, passim.

${ }^{117}$ Aunque asume las faltas que puedan tener los pobres, Soto sostiene que hay maldad en todos los grupos sociales, pero distinta justicia respecto a ellos. Félix Santolaria Sierra (ed.), El gran debate... op cit, $\mathrm{p} 86$.
} 
que leemos corresponde fielmente a la realidad. Pero la similitud de estas imaginaciones, no sólo en las fuentes españolas sino también en las europeas, avala su cuestionamiento. Sospechamos que éstas pueden haber sido creadas por los propios acusadores, aunque basadas en parte en prácticas reales -porque la descripción debía ser verosímil- pero que resulta difícil calificar de habitual por su imposible cuantificación. La tipologización del mendigo -vale decir, la construcción de la imagen de un modelo de enemigo del orden social- resultaba necesaria para estigmatizar a este sector de la población cuando se convirtió en un problema por las dimensiones que había adquirido y por la imposibilidad de erradicarlo ${ }^{118}$.

La mendicidad por parte de un hombre que podría trabajar constituía un acto contra la caridad, de allí que fuera considerada una falta hacia Dios y el orden social. A partir de allí se edifica la idea conspirativa que la picaresca recoge, reproduce y exacerba $^{119}$. Si la construcción monárquica implica la definición de la disidencia y su vigilancia coercitiva ${ }^{120}$, podemos considerar entonces que los retratos que repasamos aquí sobre los mendigos encuentran también su explicación en este fenómeno.

En el siguiente capítulo atenderemos a la relación entre la mendicidad y otros problemas que presenta el análisis de la picaresca, relacionados con el nomadismo y la dificultad para formar lazos estables, en abierta contradicción con la suposición acerca de la existencia de bandas ocultas. Atenderemos a estas cuestiones en relación con la criminalización de los marginales y su descripción como enemigos de la sociedad.

\footnotetext{
${ }^{118}$ Encontramos aquí el vínculo entre chivo expiatorio y situaciones de "crisis social". Al respecto, es interesante la relación establecida por R. Po-Chia-Hsia respecto a las brujas. Ver también en relación con la crisis social: Ronnie Po-Chia-Hsia, Social Discipline in the Reformation: Central Europe, 1550-1750. Londres, Routledge, 1992, Capítulo 8 "Confessionalism and people", pp 143-175, p 160.

${ }^{119}$ Los leprosos también constituyeron un grupo temido. Se suponía que la enfermedad era un castigo por sus perversiones, pero que como se sabían condenados y marginados, trataban de difundirla de manera vengativa. En el siglo XIX se decía esto mismo de los tuberculosos. Ver sobre el reemplazo de la marginación de los judíos por la de los mendigos: Carlo Ginzburg, Historia nocturna ... op cit, p 65.

${ }^{120}$ Brian Levack, Witch Hunting in Scotland: Law, Politics, and Religion. Londres, Routledge, 2008, Capítulo 6 "Absolutism, Statebuilding, and Witchcraft”, pp 98-114, p 100.
} 


\section{CAPÍTULO 6}

SUBSISTENCIA, SOCIALIZACIÓN Y NOMADISMO EN

LA REPRESENTACIÓN PICARESCA 


\section{Introducción}

A lo largo de esta tesis hemos observado la estigmatización de los marginales que llevaban una vida vagabunda y eran criminalizados por su forma de vida. En el presente capítulo observaremos algunas cuestiones referentes a su posibilidad de supervivencia y reproducción, considerando su existencia vagabunda, con el objetivo de saldar cuestiones referentes a la representación de su socialización, así como acerca de la definición de su grupo, su reproducción y estigmatización.

En los capítulos anteriores pudimos hacer referencia a otras cuestiones como los vínculos que tienden los marginales y su estigmatización, asuntos que observaremos específicamente en este acápite. Aquí nos dedicaremos a profundizar en cuestiones inherentes a la marginalidad que estuvieron presentes en los capítulos anteriores, como el lenguaje y la jerga, el nomadismo, los vínculos y la reproducción del sector y, por último, las imágenes que se desprendían de estos elementos y fraguaban en un estereotipo.

\section{El lenguaje}

El habla es un aspecto constitutivo de la identidad de la subcultura marginal que implica una delimitación positiva por parte de los miembros del sector y otra negativa, percibida por quienes no comparten dicho lenguaje ${ }^{1}$. Por eso, su encuadramiento puede realizarse a partir de la consideración de su lenguaje, que constituye una pieza fundamental para la conformación de la comunidad y que fue percibido por parte de los observadores externos, quienes lo consideraron hermético para el resto de la sociedad. Además, lo evaluaban como sospechoso en sí mismo porque habría sido ideado para facilitar la comunicación entre delincuentes con fines criminales.

Partimos del planteo de R. Williams, quien sostiene que el lenguaje es constitutivo y constituyente de una conciencia práctica, en tanto actividad social que configura el sistema de relaciones. Así, el habla no resulta un mero reflejo de la realidad material sino que ésta es captada a través del lenguaje que se desarrolla en el seno de

\footnotetext{
${ }^{1}$ Podemos mencionar el relevamiento apuntado por Geremek en su obra acerca de la literatura moderna referente a la marginalidad. El autor sostiene que las poesías y baladas en jerga (mayoritariamente anónimas) presentaban un ajuste lingüístico en el que se cuenta la vida criminal en su propia lengua. Bronislaw Geremek, La estirpe... op cit, pp 236 y 237.
} 
una sociedad y cuya dinámica compone ${ }^{2}$. De esta manera, el idioma es usado de modo diferenciado por cada grupo social, que adapta particularidades del habla según sus necesidades de comunicación, pero también para distinguirse respecto de los demás sectores ${ }^{3}$.

Si el lenguaje es funcional para moldear la idea del otro también lo es para delimitar al propio grupo mediante la utilización de una lengua propia y particular, la jerga. El habla de estos sectores no fue registrada sistemáticamente, impidiendo el acceso directo a ella y obstaculizando la localización de fronteras precisas entre los grupos que pudieron utilizarla. Geremek plantea la dificultad para establecer el límite entre la terminología popular y la especializada de los marginales, dado que el modo de vida de estos últimos -vagabundo e inestable- provocaba que el léxico propio de cada uno de ellos confluyera en un habla común ${ }^{4}$. De la misma manera, se inventaban nuevas palabras con el fin de definir prácticas criminalizadas, conductas desviadas, espacios de delito o referencias a los agentes de la justicia ${ }^{5}$, convirtiendo a la lengua de esta subcultura en una parte constitutiva de la evasión a la norma.

La jerga reutiliza conceptos que componen el lenguaje de la sociedad donde se desarrolla la subcultura que la maneja (en nuestro caso la marginal) pero adaptándolos a sus propias necesidades. Así, no constituye un sistema de comunicación autosuficiente, sino que manipula elementos y estructuras de la lengua de aquélla en la cual se desarrolla $^{6}$. La novela picaresca tiene pasajes reveladores en referencia a la jerga, descripta por un sujeto que está distanciado del mundo marginal, pero que detalla su forma de imaginarlo, suponiendo que su habla constituiría un medio de reproducción,

\footnotetext{
${ }^{2}$ Raymond Williams, Marxismo y literatura. Barcelona, Península, 1980, pp 49-51.

3 Ibídem, p 153. Aquí enmarcamos la crítica de Bourdieu al estructuralismo, al que tacha de "intelectualismo" basado en la ficción de atribuir a los individuos determinadas ideas que el científico social tiene acerca de ellos, sin anclaje en la objetividad. Ver Pierre Bourdieu, El sentido... op cit, p 54.

Según C. Valentine, "Las subsociedades regionales, de clase y generacionales se diferencian a menudo por las variantes lingüísticas que integran sus subculturas y que a veces se consideran dialectos. Las diferencias entre las subculturas pertenecientes a un modo de vida general pueden asimilarse a los contrastes en los modismos, las pequeñas diferencias de vocabulario o de acento por los cuales se distinguen los dialectos. Todos los dialectos de una misma lengua comparten principios estructurales y elementos de forma y contenido que los vuelve reconocibles como pertenecientes a aquélla. De manera análoga, las subculturas tienen en común, presumiblemente, ciertos elementos temáticos, pautas y configuraciones que las señalan como partes de una cultura. Estos elementos y principios comunes permiten, por lo regular, a las subsociedades coexistir en una interacción orgánica o en relaciones predecibles basadas en las pautas subculturales, del mismo modo como dialectos distintos suelen ser más o menos inteligibles mutuamente". Charles Valentine, La cultura de la pobreza. Buenos Aires, Amorrortu, 1972, pp 114 y 115.

${ }^{4}$ Bronislaw Geremek, La estirpe... op cit, pp 216-220.

${ }^{5}$ Geremek da ejemplos de esta práctica en su estudio sobre los marginales parisinos. Bronislaw Geremek, Les Marginaux... op cit, pp 129 y ss.

${ }^{6}$ César Hernández Alonso y Beatriz Sanz Alonso, op cit, p 42.
} 
un rasgo identitario y una delimitación del grupo. Quevedo ilustra el manejo del habla entre los vagabundos en la corte cuando Pablos se dirige al lector para explicarle la semántica referente a los juegos prohibidos:

No quiero darte luz de más cosas; éstas bastan para saber que has de vivir con cautela, pues es cierto que son infinitas las maulas que te callo. 'Dar muerte' llaman quitar el dinero, y con propiedad; 'revesa' llaman la treta contra el amigo, que de puro revesada no la entiende; 'dobles' son los que acarrean sencillos para que los desuellen estos rastreros de bolsas; 'blanco' llaman al sano de malicia y bueno como el pan, y 'negro' al que deja en blanco sus diligencias ${ }^{7}$.

Este fragmento ilustra el manejo de la lengua entre el grupo de pícaros, en pos de reutilizar vocablos para indicar fenómenos diferentes al significado que tienen para el resto de los hablantes. Retomando las propuestas de Williams, el signo tiene un efectivo núcleo de significado, aunque en la práctica posee una esfera de acción variable en correspondencia con la diversidad de situaciones en las que es utilizado, adquiriendo relaciones nuevas y cambiantes ${ }^{8}$.

El pasaje citado también indica la relativa permeabilidad de la jerga, cuyos secretos son revelados por el narrador. Pablos se dirige al narratario para explicarle los significados de estas expresiones que tienen como objetivo embaucar a la sociedad, mientras destaca que también está callando otras tantas. De esta manera traiciona al grupo porque la jerga no debería ser revelada para mantener su efectividad. Sin embargo no completa esta acción, pues el narrador se reserva una parte, recordando al lector su hermetismo. De esta manera el habla delinea la frontera entre Pablos, que pertenece al mundo marginal y el lector, que no lo integra y por lo tanto no podría compartirla.

Una de las características más importantes de la jerga reside en que resulta una delimitación de la microsociedad que conforman los marginales, con sus propios códigos, valores de conducta y ética específica. Tal como indica Williams, el habla no sólo es inherente a la comunicación, sino que también es constitutiva de la práctica social $^{9}$.

En las novelas que nos ocupan, los pícaros aprenden simultáneamente las conductas y el lenguaje en que se expresan cuando entran en la nueva forma de

\footnotetext{
${ }^{7}$ Francisco de Quevedo, op cit, p 274.

${ }^{8}$ Raymond Williams, op cit, p 53.

${ }^{9}$ Raymond Williams, op cit, pp 49-51.
} 
sociabilidad. Su subcultura no comparte los valores de la sociedad que la enmarca y en cuyo seno está funcionando como una parte residual. Se trata de un grupo que se instala sólo de manera epidérmica en la sociedad, de la cual no está separado territorialmente, convivencia que conduce a la necesidad de generar códigos crípticos que resultarían innecesarios si ambas culturas estuvieran separadas. Tal como observa Geremek, el lenguaje funciona como una definición territorial, pues la soberanía de esta subcultura no habría estado delimitada en el espacio, sino por medio del habla, que actuaba como frontera cultural ${ }^{10}$.

En El Lazarillo se introduce la enseñanza de la jerga de manera inmediata al comienzo del periplo marginal, mientras el momento iniciático del viaje con el ciego se sanciona con el ardid de la calabazada, truco que el viejo utiliza para explicar al joven que ante todo debe ser astuto. La conclusión del muchacho gira en torno a la soledad ("Verdad dize éste, que me cumple abiuar el ojo y auisar; pues solo soy, y pensar cómo me sepa valer. Començamos nuestro camino y en muy pocos dias me mostró jerigonça" ${ }^{\prime 1}$ ). El muchacho recibe la instrucción necesaria para la existencia que está comenzando, basada en la desconfianza incluso respecto a su compañero, que puede traicionarlo o engañarlo. Mientras interioriza esta idea, empieza la peregrinación de ciudad en ciudad -deambular intrínseco a la condición y forma de vida de estos personajes- y aprende la lengua de la subcultura en la cual se está integrando, en un episodio que contiene todos los rasgos de la nueva socialización.

En consonancia con la idea de que el aprendizaje primario implica hablar la lengua y pensar en ella al mismo tiempo ${ }^{12}$, la del grupo se enseña junto con las prácticas, pues Lázaro, al presente de la narración entiende que “... despues de Dios, este [el ciego] me dió la vida y, siendo ciego, me alumbró y adestró en la carrera de viuir" ${ }^{\prime 3}$. El primer amo del pícaro es considerado como determinante en su enseñanza, instrucción que resulta un reflejo de aquella que recibían los aprendices. Sin embargo, otras obras acentúan menos la idea de un mentor, dejando la función educativa a la comunidad de vagabundos, que en esta obra está ausente.

Los cambios en el lenguaje con el objetivo de evadir las normas eran percibidos por quienes las emitían, teniendo que renovar las disposiciones para garantizar su

\footnotetext{
${ }^{10}$ Bronislaw Geremek, La estirpe... op cit, p 180.

${ }^{11}$ Anónimo, op cit, p 78. Lazarillo describe en este episodio el comienzo de su viaje con el ciego, en cuyo transcurso aprende, a partir de la observación de las prácticas del viejo, distintas estrategias del mendigo.

${ }^{12}$ Pierre Bourdieu, El sentido... op cit, p 109.

${ }^{13}$ Anónimo, op cit, p 78.
} 
vigencia. En la Novísima Recopilación de las Leyes de España vemos este reparo en la penalización de los juegos:

Mandamos, que todo lo dispuesto por las leyes de estos nuestros Reynos cerca del juego de los dados, ansí quanto á las penas y aplicación dellas, como al modo de proceder en ellas ordenado, haya lugar, y se practique y execute en el juego de los naipes que llaman los bueltos, bien así, y de la misma forma y manera que si real y verdaderamente el juego de los bueltos fuera juego de dados: y se entienda, y extienda y execute en los juegos que dicen de bolillo y trompico, palo ó instrumentos, asi de hueso como de madera o qualquier metal, ni de otra materia alguna que tenga encuentros, ó azares ó reparos, y en qualquiera manera que en la forma y modo del jugar, y usar de él, pareciere ó semejare á los dichos juegos de dados, bueltos y carteta, aunque le pongan y transformen de otro nombre... ${ }^{14}$.

La normativa, tal como observamos en esta recopilación, recoge el cambio de nombres de los juegos en relación a la necesidad de atender a dicha práctica para poder perseguirla. El juego, la jerga y el nomadismo se vinculan en la representación picaresca en tanto constituyen un medio para sobrevivir en el camino, lo cual conforma rasgos recurrentes en el género. Pablos subsiste mediante los juegos de azar en su viaje de Toledo a Sevilla, las dos capitales de esta novelística. Este episodio es narrado en la jerga que se utiliza para indicar las trampas que le permiten hacerse de dinero ${ }^{15}$.

La idea de un grupo que fuera antagónico a las pautas generales y peligroso para los demás habitantes (que serían víctimas de robos, estafas y otros delitos) constituye la concepción de este enemigo interno, tanto más peligroso por la noción de infiltración que conlleva. El carácter críptico del lenguaje definiría la peligrosidad de este sector, cuyos agentes podrían comunicarse con el resto de la sociedad, mientras mantendrían los códigos particulares herméticamente dentro del grupo.

En cuanto a la reutilización del lenguaje con fines diferentes a aquellos que la mayoría de los hablantes comparte y que son los aceptados por el discurso oficial,

\footnotetext{
${ }^{14}$ Título XXIII "De los juegos prohibidos", Ley XIII Según la Pragmática del 20 de febrero de 1586, "Lo dispuesto por las leyes acerca del juego de los dados y sus penas se extiende á los de bueltos, bolillo, trompico, palo y otros." En Julián Viana Razola (ed.), op cit, Tomo V, p 407.

15 "Pasé el camino de Toledo a Sevilla prósperamente, porque, como yo tenía ya mis principios de fullero, y llevaba dados cargados con nueva pasta de mayor y de menor, y tenía la mano derecha encubridora de un dado -pues preñada de cuatro, paría tres-, llevaba gran provisión de cartones de lo ancho y de lo largo para hacer garrotes de morros y ballestilla; y así, no se me escapaba dinero". Luego sintetiza la manera en que solventó su viaje: "Yo, pues, con este lenguaje [la jerga] y estas flores, llegué a Sevilla; con el dinero de las camaradas, gané el alquiler de las mulas, y la comida y dineros a los huéspedes de las posadas". Francisco de Quevedo, op cit, pp 272 y 274.
} 
encontramos otra característica que no refiere a la modificación interna del sentido de las palabras, sino que pretende conectar a la sociedad global con sus agentes marginales para que los últimos puedan subsistir en el seno de la primera: si los vagabundos sobreviven a partir de la rapiña que ejercen sobre el resto de la comunidad (mediante robos, estafas o limosnas, por ejemplo), no sólo necesitan comunicarse entre ellos sino también con aquellas personas que no pertenecen a su subcultura y de quienes obtienen sus medios de vida.

El lenguaje inherente a la socialización de estos hombres se vincula con la vida pícara en la corte, prototipo también recurrente en el género. La existencia de un número elevado de marginales en este ámbito conduce a la suposición de la posibilidad de que se agruparan en una cofradía, pues varios aspectos de la representación de una dinámica grupal tienen características similares a este tipo de organizaciones de la sociedad corporativa que enmarca a las obras. Nuevamente la novela de Quevedo da cuenta de la funcionalidad que cumple la jerga como frontera en el mencionado espacio: “... entró por la puerta una estantigua vestida de bayeta hasta los pies, más raída que su vergüenza. Habláronse los dos en germanía, de lo cual resultó darme un abrazo y ofrecérseme. Hablamos un rato, y sacó un guante con diez y seis reales, y una carta, cuan la cual, diciendo que era licencia para pedir para una pobre, los había allegado" ${ }^{\text {. }}$ El contenido de esa comunicación no es revelado y, mediante este mecanismo, el escritor y el lector quedan alejados del mundo marginal porque el secreto de la jerga no es compartido con ellos. Pero entendemos que se está tratando acerca de la membresía de Pablos a la comunidad, pues luego de ese intercambio el falso mendigo (de quien da sobrada cuenta la descripción de su atuendo así como la homologación entre esta proyección visual y su complexión moral) muestra su treta, indicando que la jerga es funcional al ocultamiento y al mantenimiento de la frontera grupal.

La existencia de un lenguaje propio del grupo indica que se trataría de una subcultura específica que poseía su lengua específica para expresar su cosmovisión, que sería particular, dado que, aunque compartirían algunas creencias con otros sectores populares, sería construida a partir de las prácticas marginales. Además, utilizarían la jerga para comunicarse las técnicas y los secretos como en un gremio ${ }^{17}$, tal como leemos en las "Ordenanzas mendicativas", donde la reglamentación de diversas artes de

\footnotetext{
${ }^{16}$ Ibídem, p 164.

${ }^{17}$ Ver en Altenberg la mención de la mendicidad como un oficio: Tilmann Altenberg, op cit, p 364.
} 
los limosneros romanos apela a la germanía ${ }^{18}$.

Los marginales tienen códigos propios para representar su visión del mundo y comunicarla de manera secreta, otorgando sentido de pertenencia a los miembros de esta contracultura, en la cual la funcionalidad de la jerga reside en su carácter críptico, sólo comprensible para sus hablantes, quienes no deben revelarla. Este lenguaje presupone un aspecto aun más peligroso, ya que es indicativo de la consolidación del sector como una subcultura particular que tiene potencialidad para conspirar contra la sociedad $^{19}$. Se imaginaba que estos códigos serían utilizados para organizar y comunicar los distintos artificios que los miembros del grupo accionarían contra el resto de la población cuando estuvieran diseminados en la sociedad. La representación del lenguaje de los pícaros informa acerca de la percepción por parte de una sociedad que los segregaba.

El problema de la marginalidad y su representación se enmarca en el de la construcción y reproducción de una ideología. Van Dijk sostiene que ésta caracteriza la dimensión "mental" de la sociedad, tratándose de una "mente social" en su "contexto social", constituyendo la "base de las representaciones sociales compartidas por los miembros de un grupo" e influyendo sobre lo que se evalúa como verdadero o falso ${ }^{20}$. Los objetivos, los intereses y los valores del propio conjunto son inherentes a la construcción de prejuicios acerca de $\operatorname{otros}^{21}$, pues se evalúa de manera negativa a todos los sujetos que puedan alterarlo, contradecirlo o perjudicarlo. Quienes son sospechosos de ello, son prejuzgados y evaluadas a partir de atributos que se consideran disfuncionales para la sociedad.

Siguiendo a Van Dijk, en la edificación deslegitimadora del otro se utilizan muchos detalles "vívidos", "visuales" de las acciones realizadas por dicho agente, como hemos constatado a través de la lectura de la narrativa que nos ocupa, cuando se narran las tretas realizadas por los pícaros ${ }^{22}$. Existe una elección explícita de tópicos negativos para despreciar a los otros, involucrando la proyección de modelos de acontecimiento ideológicamente tendenciosos sobre temas de la conversación y del texto, tal como

\footnotetext{
${ }^{18}$ Mateo Alemán, op cit, Primera Parte, pp 388-393.

${ }^{19}$ Por ejemplo, podemos observar el valor del secreto como parte de la religiosidad en el caso de los marranos estudiado minuciosamente por N. Wachtel. El autor apunta también al carácter secreto como un factor constitutivo del marranismo. Nathan Wachtel, La foi du souvenir. Labyrinthes marranes. París, Éditions du Seuil, 2001, p 339.

${ }^{20}$ Teun Van Dijk, op cit, pp 19 y 21.

${ }^{21}$ Ibidem, p 85.

${ }^{22}$ Ibídem, p 335.
} 
observamos a lo largo de nuestro examen, pues la picaresca se esfuerza en representar las prácticas de los marginales que resultan perjudiciales para el resto de la sociedad ${ }^{23}$.

La ineficacia en el control social por parte de las autoridades implicaba la necesidad de que fuera llevado a cabo por la comunidad, a cuyos agentes era necesario convencer mediante la estigmatización de los marginales. La efectivización de dicho procedimiento implicaba instalar diversos discursos y representaciones, de manera que se ejerciera la condena o reprobación generalizadas de un tipo social definido por su pobreza y modo de vida errante. Se trataba de una crítica que descalificaba a una parte de la población, para lo cual se necesitaba designarla (calificarla) previamente, mediante "la formulación literaria o administrativa de tipologías de amplio espectro, o bien sencillamente a través de un proceso de designación semántica, en principio difuso pero con virtualidad discriminante", tal como sintetiza Serrano González ${ }^{24}$. La procuración hablaba de los "vagamundos" y "hombres baldíos", lo cual era retomado por el debate escolástico para agregarle la noción de la falsa pobreza. Finalmente, encontramos el estereotipo literario del marginal presente en la picaresca.

Estas construcciones tienen anclaje en la realidad: la existencia de personas segregadas por su modo de vida itinerante, los vagabundos, cuyo deambular era una contravención ${ }^{25}$.

\section{La movilidad}

El vagabundo es una figura fundamental en la narrativa picaresca, donde encarna un personaje altamente sospechoso debido a la imposibilidad de erradicarlo, inviabilidad que produce a su vez la magnificación de su potencialidad conflictiva. ${ }^{26}$. Su deambular significa no sólo una salida de la estructura social estable sino también, en

\footnotetext{
${ }^{23}$ Esto ha sido analizado en el capítulo quinto de esta tesis, especialmente en el apartado "El teatro del mendigo". Tal como sostiene T. Eagleton, "Parece pues que, por lo menos, algo de lo que llamamos discurso ideológico es verdadero en un nivel pero no en otro: verdadero en su contenido empírico pero engañoso en su fuerza, o verdadero en su significado externo pero falso en las suposiciones que subyacen.” Terry Eagleton. Ideología. Una introducción. Barcelona, Paidós, 1997, p 38.

${ }^{24}$ Antonio Serrano González, op cit, p 52.

${ }^{25}$ La norma se instala en las construcciones mentales de los miembros de una sociedad y su violación marca lo desviado Lotman sostiene que la memoria cultural está organizada de dos maneras: fija las reglas (las estructuras) y las violaciones de las normas (los acontecimientos). Las primeras son abstractas, mientras las segundas son concretas. Iuri Lotman, op cit, Tomo II, p 216.

26 Serrano González sostiene que entre la autoridad y la figura colectiva del vagabundo se estableció un juego violento y espectacular de acción y reacción, caracterizado por la incapacidad objetiva de ser resuelto definitivamente. Antonio Serrano González, op cit, p 43.
} 
palabras de Geremek, la entrada en un "modelo de socialización asocial", pues los pícaros perderían vínculos locales y se someterían dificultosamente a las nuevas condiciones de socialización ${ }^{27}$.

El hombre errante y sin trabajo era tratado como un criminal presunto, pues el camino para convertirse en tal estaba legalmente iniciado: en tanto proviniese de un estamento obligado a la actividad manual, ya hemos visto que evadirla constituía un delito. En un contexto de cambio progresivo de la sociedad rural, muchas personas eran expulsadas de la tierra a los caminos, donde se encontraban sin los lazos comunitarios de origen. La mutación de la tradicional forma de vida de una sociedad que basaba sus relaciones en la costumbre condujo al temor y conmoción, que se expresaron en descontento y resistencia por parte de la élite respecto a la potencialidad sediciosa de algunos sectores populares, dando lugar a la necesidad de denominarlos y estigmatizarlos para reprimirlos, así como a la urgencia de evitar que su potencial rebeldía se expandiera. La ineficacia de las medidas tomadas se vincula con la necesidad de persuadir al resto de la sociedad de que los vagabundos estaban dispuestos a todas las traiciones y a las peores subversiones ${ }^{28}$. La estigmatización de los mendigos se relaciona con la que recaía sobre otros sectores segregados. En el capítulo tercero vimos cómo las acusaciones que tenían por objeto a estos hombres y mujeres se relacionaban con las de otros sectores del hampa y con los pequeños comerciantes, mientras que también observamos las caracterizaciones que se atribuían a otras minorías como los gitanos, con quienes llegaban a confundirse.

Los potenciales trabajadores eran en realidad hombres sin amo que no se encuadraban en las nuevas condiciones laborales, quienes también eran presuntos criminales. Se consideraba que los hombres baldíos podrían ser ociosos, posibles herejes, transmisores de la peste, libertinos disolutos al margen de toda norma, irracionales, además de envidiosos secretos, lo cual los conduciría a la blasfemia y el hurto, de modo que, debido a lo último, constituían una amenaza a la propiedad ${ }^{29}$.

En el caso de los marginales que aquí nos ocupan, tenemos que tener en cuenta que, si bien la procedencia podía ser rural, estos sectores fermentaban en lugares con una fuerte desorganización social ${ }^{30}$. Es necesario considerar la proliferación de esta clase de personajes en la corte y en ciudades portuarias, donde se sumaba además la

\footnotetext{
${ }^{27}$ Bronislaw Geremek, La estirpe... op cit, p 289.

${ }^{28}$ Jean Delumeau, op cit, p 304.

${ }^{29}$ Bronislaw Geremek, La piedad... op cit, pp 38 y ss.

${ }^{30}$ Bronislaw Geremek, Les marginaux... op cit, $\mathrm{p} 103$.
} 
circulación de riqueza, en la cual tenían esperanzas de participar.

El poder político intentaba regular la vida y las conductas de estos indigentes, pero esta voluntad resultaba contrariada ya que su existencia encarnaba una lógica diferente de aquella a partir de la cual se maduraban las normas y se pretendía la efectivización del control por medio de la fijación espacial. El razonamiento de los procuradores y la monarquía se basaba en la suposición de una sociedad sedentaria y corporativa, pero estos postulados eran contrariados por la vida errante de los marginales que aquí nos ocupan ${ }^{31}$. El pícaro se vincula, tal como observamos en la definición de Covarrubias, con el extranjero, el extraño permanentemente sospechado. En este marco, Soto consideraba a los vagabundos no sólo como aquellos que circulaban, sino que lo hacían "sin necesidad ni utilidad", en tanto no tenían oficio ${ }^{32}$, diferenciando a estos sujetos errabundos de otros sectores emergentes de la dinámica social que también eran móviles. El negociante compartía características del errabundo sometido a la incertidumbre (en este caso la de su ganancia), pues también deambulaba persiguiendo un posible provecho que dependía de la confianza del prójimo ${ }^{33}$. Sin embargo, mientras teólogos y moralistas alababan la fecunda movilidad del "verdadero mercader", afrentaban la del vagabundo, que constituía un factor de perturbación para la sociedad, dado que la economía requería la sedentarización del mendigo (paralela a su conversión en asalariado). Pero tendía a instaurarse el fenómeno opuesto, pues el comerciante, convertido en financista, se instalaba, mientras que los miserables se volcaban crecientemente al vagabundaje. Cavillac localiza en esa desviación la emergencia de la narrativa picaresca, que constituiría la "novela de la movilidad estéril”,34, pues el dinamismo geográfico presente en este género refleja la crisis

\footnotetext{
${ }^{31}$ Se evaluaba como ociosos a los mendigos válidos, pero también a los hombres armados que no estaban en un cuerpo regular. En la documentación encontramos a los soldados inmovilizados y a los desertores ejerciendo la rapiña en las comunidades a través de la violencia física, medio de vida al que se habían adaptado previamente. Vida y hechos de Estebanillo González da cuenta de diversos conflictos en torno a la circulación de soldados cuando no se combatía. Este pícaro circula al son de los conflictos diplomáticos europeos, lo cual da cuenta de la amplitud admisible en el estereotipo.

32 Soto define a los vagabundos: “... aunque el nombre de vagabundo no parece, suena más de hombre que no tiene propia casa ni habitación señalada, sino que anda vagando por el mundo (...) empero la propiedad de este nombre añade que anden por el mundo sin necesidad ni utilidad. Porque vagar no sólo quiere decir no tener casa, empero no tener oficio ni legítima causa o necesidad de discurrir. Que de otra manera no sería este nombre infame como lo es, ni sonaría mal como suena, porque significa ociosidad. Y así, en castellano se llaman baldíos, como ganado sin dueño. Por lo cual, el que por razón de su trato o su oficio, o su necesidad, anda por el mundo, ni es digno de reprensión ni se puede, por ende, juzgar vagabundo." Félix Santolaria Sierra (ed.), El gran debate... op cit, p 57.

${ }_{33}^{33}$ Michel Cavillac, Pícaros y mercaderes... op cit, $\mathrm{p} 420$.

${ }^{34}$ Ibídem, p 421. "A lo largo de la biografía urbana del Pícaro se entrecruzan así dos problemáticas (desarrolladas conjuntamente por la literatura mercantilista): la del 'mendigo fingido', rebelde a toda actividad sedentaria, y la del 'mercader fingido', traidor a su vocación itinerante; dos figuras homólogas
} 
española ${ }^{35}$.

Este deambular tiene lugar en los caminos, donde se arman grupos o parejas de pícaros, se encuentran antiguos camaradas, se cuentan sus historias y se cruzan información, pero que ante todo constituyen el medio para huir de la pobreza o la justicia. Los caminos son lugares peligrosos donde se corre el riesgo de ser asaltado, dada la índole de las personas que es posible encontrar allí, lo cual implica que quienes estén en este espacio serán etiquetados como anómalos y poco confiables (esto ocurre con los venteros cuyo estereotipo ya hemos observado). De esta manera, la ruta es, además del medio de conexión entre ciudades, un espacio donde todos son de alguna manera forasteros ${ }^{36}$.

F. Moretti ha estudiado acertadamente la geografía de la literatura europea, que él evalúa como un aspecto decisivo para entender el desarrollo de la narrativa, en tanto cuestiona de qué manera la dimensión espacial propicia el desarrollo de la novela en Europa durante la modernidad. El espacio sería correlativo del argumento, completando una tríada junto a las figuras ${ }^{37}$. Gran parte del relato picaresco tiene lugar en el camino, en el confín entre un lugar y otro, como un espacio abierto. Estas rutas castellanas del siglo XVI se recorrían con el uso de mulas, presentes en las descripciones de estos viajes que propician el paso por las ventas, donde los pícaros aprenden a estafar, por ejemplo a través del manejo de las cantidades de alimento que se da a los animales, lo cual constituye parte de su experiencia formativa marginal. El pícaro se convierte en tal en la ruta, pues allí tiene lugar el aprendizaje de sus técnicas delictivas. Así leemos en El Guzmán: "Viéndome perdido, comencé a tratar el oficio de la florida picardía. La vergüenza que tuve de volverme perdíla por los caminos, que como vine a pie y pesaba tanto, no pude traerla o quizá me la llevaron en la capilla de la capa"38. El camino, la picardía y la falta de vergüenza son representados como un solo y mismo fenómeno,

cuya interferencia dialéctica permite a Alemán globalizar el debate nacional sobre el pauperismo.” Ibídem, p 422. En este aspecto, sigue la noción de Braudel sobre la traición de la burguesía a la propia clase.

${ }^{35}$ Pues el vagabundeo también era, según el autor "el destino de todos los náufragos de las clases medias desarticuladas por el fracaso de los valores burgueses y la degeneración del ethos nobiliario". Ibídem, p 422.

${ }^{36}$ Exceptuamos sin embargo a los peregrinos, cuya aceptación oficial en su deambular los exime de la etiqueta estigmatizadora.

${ }^{37}$ Franco Moretti, Atlas de la novela europea. 1800-1900. México, Siglo XXI, 1999, p 49. Según M. Bachtin, en este tipo de novelas, "El mundo es la contigüidad espacial de diferencias y contrastes; y la vida representa una alternancia de distintas situaciones contrastantes: buena o mala suerte, felicidad o desdicha, triunfos o derrotas, etcétera." Michail Bachtin, Estética de la creación verbal. México, Siglo XXI, 1995, p 201.

${ }^{38}$ Mateo Alemán, op cit, Primera Parte, p 275. 
pues todos se vinculan con la condición del forastero, que no sólo es sospechoso, sino también víctima de otros de similar condición. Si las rutas constituyen el lugar donde se despliega la existencia de los marginales, la segregación de estos hombres está relacionada con su circulación por aquéllas, por eso el nomadismo de los pícaros constituye un motivo suficiente para que sean considerados poco confiables.

Las novelas que nos ocupan en esta tesis tienen itinerarios precisos, a través de cuyo análisis podemos observar cuáles eran los lugares concebidos como caldo de cultivo de la vida vagabunda, cuáles serían los sitios de paso de los pícaros y dónde se asentarían con el objetivo de medrar. Lazarillo inicia su vida en la aldea de Tejares, de donde pasa a Salamanca con su madre, con el objetivo de sobrevivir en un mesón donde sirve a los estudiantes ${ }^{39}$. Allí Lazarillo se separa de la pauperizada familia y comienza su vagabundeo yendo a Toledo (pasando por Almorox) con el ciego: “Quando salimos de Salamanca, su motiuo fué venir a tierra de Toledo. Porque dezia ser la gente más rica; aunque no muy limosnera. Arrimauase a este refrán: Mas da el duro que el desnudo. E venimos a este camino por los mejores lugares. Donde hallaua buena acogida e ganançia, deteniamonos; donde nó, a tercero dia haziamos Sant Juan"40 ${ }^{\text {. La }}$ partida de Lazarillo está subordinada al interés del amo, que conoce los mejores lugares para obtener la limosna. La apreciación de la poca inclinación de los toledanos hacia ella se puede relacionar con la existencia de una nobleza antigua pero no muy rica, o también con la presencia de judíos -de avaricia proverbial- denunciada en El Guzmán, que deja la ciudad por este motivo. También sostiene haber ido por los mejores lugares, esto es, donde es más propicio sobrevivir a partir de las dádivas, posibilidad que determina el itinerario. La partida de ciertas ciudades puede vincularse con que no se aceptaba por más tiempo a los pobres forasteros, por eso la movilidad es inherente a la existencia de este tipo de marginales. Cuando se separa de su patrono pasa a Torrijos, pero como no lo considera un lugar seguro, quizás debido al permanente acecho que se cernía sobre los vagabundos, parte hacia a Maqueda, donde se asienta con el clérigo avaro. Cuando termina esta relación se va "poco a poco, con ayuda de las buenas gentes" ${ }^{\prime 41}$ (gracias a la mendicidad) a Toledo, donde se pone al servicio de diversos amos y lo encontramos en el presente de la narración.

\footnotetext{
${ }^{39}$ Veremos esta necesidad de la mujer de arrimarse a quienes pudieran demandar sus servicios luego de perder su sustento con base en la aldea.

${ }^{40}$ Anónimo, op cit, p 91.

${ }^{41}$ Ibídem, p 147.
} 
En esta obra, la ruta es el ámbito de aprendizaje con el ciego, pero luego del primer tratado, el camino pierde importancia y el relato se centra en los momentos en que Lazarillo está asentado en la ciudad, especialmente en Toledo, permitiendo visualizar dos situaciones muy diferentes; por un lado, el año estéril en que los mendigos son flagelados, pero también cuando "el victorioso emperador de esta insigne ciudad de Toledo entró y tuuo en ella cortes y se hizieron grandes regozijos, como vuestra merced aurá oydo" 42 .

La ciudad portuaria es un escenario recurrente en la narrativa picaresca. Guzmán comienza su itinerario como criado en Sevilla, punto de partida para los mercaderes. Cavillac interpreta la geografía de El Guzmán como la del capitalismo financiero en la Península ${ }^{43}$. El primer viaje conduce al protagonista hacia Cantillana, cuando para en una venta donde atraviesa su experiencia iniciática en el episodio de los huevos empollados. De allí parte con un arriero hacia Cazalla de la Sierra y luego a otra venta, donde se asienta temporalmente.

En un corto trayecto experimenta las diversas experiencias formativas del pícaro: además de los intercambios con los camaradas de ruta, va preso temporalmente, pasa por dos ventas (en una es estafado con los huevos y en la otra aprende todo tipo de artimañas que le son enseñadas por su amo), se detiene en un mesón donde nuevamente lo engañan dándole de comer mula por ternera -además de robarle la capa- $\mathrm{y}$, primordialmente, aquí conoce también el hambre y la caridad (que es ejercida por parte de dos frailes).

Esta experiencia lo impulsa a ir a Madrid, a donde llega "hecho pícaro", indicando que se ha formado en el camino. En la corte desarrolla varias actividades: sirve a un cocinero, mendiga, luego roba a un especiero, suceso que da lugar a su huida. El forzado abandono de la ciudad se vincula a nivel narrativo con la evasión de los agentes de la justicia, pero también con la soledad inherente al pícaro, que solo cuenta con sus harapos ${ }^{44}$, en un episodio que relaciona la pobreza, la movilidad y la

\footnotetext{
${ }^{42}$ Ibídem, pp 241 y 242. D. Carey interpreta acertadamente la novela como una descripción por oposición a la utopía, pues se trataría de "A confessional work presenting a negative utopia par excellence, the Lazarillo de Tormes paints society as disorganized and anti-Christian; it portrays not the Augustinian City of God but the cities of man, from Salamanca to Toledo". Douglas Carey, op cit, p 38.

${ }^{43}$ Michel Cavillac, Pícaros y mercaderes... op cit, pp 427-428. Por eso considera a Sevilla como una ciudad que constituye la clave de un espacio urbano regido por la presencia de financistas.

${ }^{44}$ Así se sintetiza la situación de Guzmán en su huida: "Desta manera me entretuve en tanto que desmentí las espías y cuadrilleros que sin duda debieron de ir tras de mí. Así se perdió el rastro. Y pareciéndome que todo estaría seguro para poder mudar el rancho y marchar, hice un pequeñuelo lío de los forros viejos que del sayuelo me quedaron, donde metí envuelta la sangre de mi corazón. Quedóme sólo el viejo lienzo
} 
criminalidad del personaje y de sus semejantes. Antes de partir, Guzmán se esconde efímeramente y se va en la noche, evitando el camino real para no ser descubierto ${ }^{45}$, secuencia que informa acerca de las diversas posibilidades de estos personajes, así como de su conocimiento para hacer uso de ellas.

Tan pronto como llega a Toledo intenta un buen atuendo y busca infructuosamente una compañía de soldados. Para evitar ser reconocido no duerme más de tres noches en cada posada, mientras toma un paje y ostenta su aparente prosperidad en las iglesias. Luego de huir miserablemente de Madrid, el pícaro se presenta con un aspecto absolutamente diferente en Toledo, lo que indica que la circulación abre paso al engaño en torno a la fama y el status, justificando la desconfianza respecto al forastero. Sin embargo, tal como señala la novela el pícaro está obligado al movimiento permanente, pues aún en un nuevo lugar no puede estar totalmente seguro de verse libre de sus perseguidores ${ }^{46}$.

El pícaro busca medios para el nuevo viaje en la plaza, como se estipulaba que debería hacerlo para encontrar un empleador, según postulaban las reglamentaciones sobre el trabajo. El marginal sostiene abandonar Toledo como consecuencia del malestar que siente ante la presencia de judíos, indicando la diferencia entre su segregación y la de la minoría religiosa ${ }^{47}$. Es frecuente la representación de la discriminación por parte de los protagonistas marginales de esta narrativa respecto a otros sectores estigmatizados, como vemos en El Lazarillo respecto al negro Zaide o en La hija de Celestina en torno a su madre esclava. Mediante estos recursos los autores indican la ausencia de identidad y de solidaridad en una sociedad jerarquizada entre agentes segregados por diversos motivos, de acuerdo con la heterogeneidad de los marginales.

Luego de salir de Toledo pasa dos noches en el camino (una en Orgaz y otra en

de los calzones, un juboncillo desarrapado y una rota camisa...”. Mateo Alemán, op cit, Primera Parte, p 337.

45 "Ya cansado y harto de estar hecho conejo en aquel vivero, temeroso que una guarda o cualquiera que allí me viera residir de asiento no tomase de mí mala sospecha, comencé a caminar de noche a escuras por lugares apartados del camino real, tomando atraviesas, trochas y sendas por medio de la Sagra de Toledo...”. Ibidem, Primera Parte, p 338.

${ }^{46}$ Así encontramos a Guzmán en Toledo: "Estaba desesperado y, para consuelo de mis trabajos, a la noche, cuando fui a la posada, hallé un alguacil forastero preguntando por no sé qué persona. Ya ves lo que pude sentir. Díjele a mi criado que me esperase hasta la mañana. Salí por la puerta del Cambrón, donde pensando y paseando pasé casi hasta el día, haciendo mis discursos, qué podía querer o buscar aquel alguacil; mas como amaneciese, parecióme hora segura para ir a casa y mudar de vestido y posada. Aseguré mi congoja, porque no era yo a quien buscaba, según me dijeron". Ibídem, Primera Parte, pp 351-352.

47 "Salí a la plaza de Zocodover. Pregonaban allí dos mulas para Almagro. Más tardé en oírlo que en concertarme y salir de Toledo. Porque allí todo me parecía tener olor de esparto y suela de zapato." Los zapateros eran frecuentemente conversos y el olor a esparto remite a la soga del ahorcado. Ibídem, Primera Parte, p 352. 
Malagón), donde se nos informa acerca de la peligrosidad de esta ciudad, incluso para el pícaro ${ }^{48}$. Cuando llega a Almagro entra en una compañía de soldados, con quienes va a la costa a esperar las galeras (por tres meses) para ir a Italia. Este tiempo propiciaba los vínculos y los comportamientos marginales entre quienes allí acudían y permanecían por un lapso indeterminado. La segunda sección del periplo comienza en Génova, donde conoce a sus familiares, que nuevamente lo engañan, aspecto analizado minuciosamente por Cavillac ${ }^{49}$. Así como no poseen amigos, en las novelas los picaros tienen vínculos familiares traicioneros y deshonrosos.

Desde Génova, siempre pobre, viaja a Roma donde la miseria lo hace "estudiar el arte bribiática; llevóme por esos caminos, hoy en un lugar, mañana en otro, pidiendo limosna en todos" ${ }^{20}$. Esta referencia indica el vínculo entre el nomadismo y el pordioseo, pues los personajes pueden (y deben) trasladarse mientras sobreviven a través de la mendicidad. En Roma se dedica a limosnear ${ }^{51}$, de donde pasa brevemente a Gaeta de la misma manera, antes de volver a la Ciudad Eterna, donde es hallado por el cardenal y vive de diversas ocupaciones de servicio hasta el final de la primera parte de la obra ${ }^{52}$.

La primera parte de El Guzmán amerita haber sido tratada por la crítica como el gran ejemplar de la picaresca y modelo del género, dada la densidad de los estereotipos de esta literatura representados en sus páginas: el servicio para diversos amos, la mendicidad, el vagabundeo y la vida pícara en la corte, tal como hemos examinado hasta aquí.

El Buscón inicia su camino en Segovia al servicio de Diego Coronel, con quien va a estudiar a Alcalá de Henares, ciudad en que tiene lugar la etapa estudiantil de los muchachos. En este primer trayecto también encontramos la parada en lo de un ventero, cuya estigmatización se completa con las cualidades de "morisco y ladrón" "53, donde se narra una primera experiencia con un grupo de rufianes. Separado de Don Diego, sale hacia Segovia a conocer a sus parientes, en quienes tiene esperanzas de ayuda. La

\footnotetext{
48 "Aquella noche tuve en Orgaz, y en Malagón la siguiente. Pero con el sobresalto, de que las noches antes no había podido reposar, llegué tan dormido que a pedazos me caía, como dicen...”. Ibídem, Primera Parte, $\mathrm{p} 352$.

${ }^{49}$ Allí, el pícaro busca un sustituto de la figura paterna en su tío, que es evaluado por Cavillac como "Arquetipo de la concupiscencia, el Genovés anónimo es la cara militante del pecado económico cuyo reverso ocioso es presentado a través de la ambivalencia de la imago paterna." Michel Cavillac, Pícaros y mercaderes... op cit, $\mathrm{p} 436$.

${ }^{50}$ Mateo Alemán, op cit, Primera Parte, $\mathrm{p} 385$.

${ }^{51}$ Ver este episodio en el precedente capítulo (p 201).

${ }_{53}^{52}$ Hemos dado cuenta de estas ocupaciones en el capítulo cuarto.

${ }^{53}$ Francisco de Quevedo, op cit, p 51.
} 
partida, a diferencia de lo que describe habitualmente la picaresca, tiene aún rasgos de apego, pues esta primera etapa ha sido hecha en un relativo marco de integración junto a su joven patrono, pero a partir de este momento se deshace de sus vínculos y de sus míseras posesiones, para convertirse, a lo largo de su futuro trayecto, en pícaro ${ }^{54}$. Si bien cuenta con dos compañeros sucesivos a quienes conoce en el viaje, uno que lo acompaña hasta Torrejón y otro con quien va a Rejas, la soledad es inherente a su experiencia formativa, en cuyo proceso reflexiona y reconoce su condición como individuo. El pícaro debe ser ignoto en el nuevo lugar y allí crear una nueva biografía, totalmente diferente, para evitar ser reconocido, consiguiendo el anonimato que le permitiría medrar $^{55}$. En la ruta topa con un poeta loco, con quien llega a Madrid y para en una posada, pero luego Pablos parte hacia el puerto, en cuyo camino se relaciona con un soldado que lo introduce en las prácticas picarescas en el marco de la corte. El equipo de vagabundos suma a un ermitaño con quien llega a Cercedilla, donde se apean en una posada y juegan con naipes. Este primer grupo se desarma nuevamente cuando parten Pablos y el soldado, para sumar en el trayecto a un genovés, hasta llegar a Segovia. Este periplo muestra la variedad de personajes posibles del mundo de la picaresca y da cuenta de los lazos efímeros que se tendían en las rutas, donde los marginales compartían información y prácticas. Ilustra también algunos estereotipos, como el del soldado cuando no está en la guerra, el forastero (asociado al comercio) o el ermitaño (dudoso), que se reiteran en diversas novelas.

Pablos parte hacia Madrid, donde nadie lo conoce, y en su camino topa con un pícaro en atuendo de hidalgo que le enseña las técnicas picarescas que debe poner en práctica una vez instalado en la corte. La descripción varía en torno al desarrapado personaje. La primera representación acerca de él pinta un hidalgo, pero a medida que continúa, la observación del narrador devela un pícaro andrajoso, indicando la falsificación de las apariencias, que terminan por ser descubiertas. En Madrid tienen lugar diversos episodios picarescos del "colegio buscón", que hemos observado en el capítulo anterior y otros que abordaremos más adelante, pero por lo pronto diremos que la persecución por sus delitos obligan la huida de nuestro héroe, que parte hacia Toledo,

\footnotetext{
54 "Llegó el día de apartarme de la mejor vida que hallo haber pasado. Dios sabe lo que sentí el dejar tantos amigos y apasionados, que eran sin número. Vendí lo poco que tenía, de secreto, para el camino, y, con ayuda de unos embustes, hice hasta seiscientos reales. Alquilé una mula y salíme de la posada, adonde ya no tenía que sacar más de mi sombra”. Ibídem, p 97.

55 "Con esto, caminé más de una legua que no topé persona. Iba yo entre mí pensando en las muchas dificultades que tenía para profesar honra y virtud, pues había menester tapar primero la poca de mis padres, y luego tener tanta, que me desconociesen por ella. Y parecíanme a mí tan bien estos pensamientos honrados, que yo me los agradecía a mí mismo". Ibídem, pp 108-109.
} 
donde es desconocido. En pos de preparar su viaje, asiste a diversos mesones donde puede conseguir medios para la partida, indicando que el pícaro ha sido bien instruido acerca de las estrategias para circular. La planificación de dicho movimiento señala que no sería necesariamente un acto espontáneo frente a una situación adversa o una buena oportunidad. Pablos encuentra a un antiguo compañero de estudios que trabaja en una compañía de comediantes, con quienes parte rumbo a Toledo, pues la ruta es un espacio de reencuentro con viejos camaradas. El último tramo de la novela (de Toledo a Sevilla) lo sobrelleva gracias al juego (o a la trampa) ${ }^{56}$. Finalmente termina esta primera parte de su vida (la que nos es narrada) en Sevilla, de donde pasa a Indias, último viaje que es el corolario de su vida pecaminosa y cuyo infeliz destino se adelanta mientras el protagonista es condenado por parte del autor ${ }^{57}$.

El Bachiller Trapaza comienza en Zamarramala, donde nuestro héroe nace y se cría hasta los cuatro años, cuando su madre y abuelo se mudan a Segovia para que él estudie. Este pícaro, como veremos más adelante, procede de un ámbito de relativa integración social, por lo tanto su marginalidad no es consecuencia -como en El Lazarillo, El Buscón o La hija de Celestina- de la pobreza heredada y el posterior desarraigo, sino que se deriva de sucesivos desvíos del protagonista cuando comienza su etapa estudiantil.

El joven viaja a Salamanca, periplo que da lugar a sus conductas marginales, cuando falsifica su identidad, se inclina al juego y olvida los consejos familiares ${ }^{58}$. Todos estos aspectos se relacionan con su nueva condición de forastero, sus prácticas condenadas y el deseo de medrar que las moviliza. El relato señala los antecedentes familiares para la conducta de Trapaza, nombrando la hipocresía de su madre cuando lo aconseja antes de partir, testimonio del rechazo a los sectores populares y de la misoginia que caracterizan a la narrativa picaresca.

\footnotetext{
${ }^{56}$ Ver este episodio en la nota 15 de este capítulo.

57 "La justicia no se descuidaba de buscarnos; rondábanos la puerta, pero, con todo, de media noche abajo, rondábamos disfrazados. Yo que vi que duraba mucho este negocio, y más la fortuna en perseguirme, no de escarmentado -que no soy tan cuerdo-, sino de cansado, como obstinado pecador, determiné, consultándolo primero con la Grajal, de pasarme a Indias con ella, a ver si, mudando mundo y tierra, mejoraría mi suerte. Y fueme peor, como v. m. verá en la segunda parte, pues nunca mejora su estado quien muda solamente de lugar, y no de vida y costumbres." Francisco de Quevedo, op cit, p 280.

58 “... partió Hernando de la Trampa de Segovia, mudando el apellido de su padre por malsonante y olvidando el de la madre por lo mismo. Y así tomando el de Quiñones, sin licencia de la casa de los condes de Luna, se vistió deste apellido, y en una buena mula caminó a Salamanca". Alonso de Castillo Solórzano, Aventuras del Bachiller... op cit, p 69. "La madre no quiso dejar de dar su donativo a su hijo; y así, de lo que tenía ahuchado le dio cincuenta escudos, y consejos de madre, que valen mucho y cuestan poco. Si nuestro licenciado los siguiera, juntamente con la instrucción del agüelo, mucho le valieran para sus estudios; pero al mismo paso que se iba alejando de su patria, se le alejó la memoria desto, y la juventud y mala inclinación del juego hicieron su oficio". Ibídem, p 70.
} 
La primera parada de Trapaza es en Villoria, donde lo encontramos apostando en un mesón, cuya ganancia invertirá en mudar de hábito. Así decide entrar en Salamanca, comprando primero todo el nuevo atuendo en Valladolid, agregándose el Don, cambiando su dicción y tomando criado. El pícaro no comunica sus intenciones a su mozo de mulas para evitar que se divulgara su propósito ${ }^{59}$, situación que evidencia cómo los criados podían difundir información, porque eran parte de la trama comunitaria.

Luego del período salmantino, el pícaro perseguido huye a Sevilla junto a Estefanía y Varguillas, sus nuevos compañeros, compartiendo el carro con un médico y dos hombres de Valladolid. En este marco se habla de este transporte como el navío terrestre, indicando cómo el mar dio lugar a los caminos como vía de comunicación reconocida por la literatura, tal como señala Moretti ${ }^{60}$.

En el viaje de Sevilla a Valladolid se introduce una novelita contada por el médico. Los caminos son propicios para las historias personales o también aquellas cuyo único fin es la diversión y, al nivel de la narración, permiten a los autores insertar este tipo de digresiones. Los relatos entre los compañeros de camino pueden dar lugar a las novelas intercaladas, siendo la más reconocida en el género la de Ozmín y Daraja en El Guzmán, que permite a Alemán insertar la reflexión moral.

El grupo se detiene en un mesón en Trujillo, donde Trapaza termina preso mientras Estefanía y Varguillas huyen. La moza consigue escapar gracias a que un mesonero les facilita la mula y el contacto con familiares en una aldea cercana, donde se queda hasta que Trapaza es liberado, mientras el comerciante se garantiza la nueva

\footnotetext{
59 "Era vano y muy quimerista, y parecióle que debía de entrar en Salamanca con otro porte del que pensaba tener, pues la fortuna le había sido tan favorable. Y, mudando de camino, volvióse atrás, yéndose a la noble Valladolid, adonde hizo hacer dos vestidos muy galanes de camino y compró también una vuelta de cadena; tomó un criado y con nuevos bríos no quiso pasar plaza de Hernando de Quiñones, sino que añadió a esto un don, que no le tenía de costa más que el ponérsele, y dijo ser un caballero de la casa de los Quiñones de León, si bien nacido en Canaria, donde tenía a su padre. Para desconocerse más, se puso antojos y comenzó a cecear un poco. Desto no dio parte al mozo de mulas, porque en Segovia no lo publicase; mas, despedido dél y pagado en Salamanca, comenzó en este porte a tratarse”. Ibídem, p 73. Quienes hacían fortuna en Indias, lograban ser reconocidos hidalgos en Canarias.

${ }^{60}$ Así leemos en El Bachiller Trapaza: "Para esto se valieron del bagaje de un carro, bergantín terrestre que anda en corso siempre aquellos pantanosos caminos de invierno y aquellos páramos desiertos en verano." Ibídem, p 105. Así, señala F. Moretti: "La mula, podríamos decir, derrota a la nave (y al corcel del caballero); la sublimidad del mar abierto, con sus maravillosas aventuras y sus acontecimientos asombrosos, es sustituida por un avance lento y regular, cotidiano, polvoriento, al borde de lo trivial. Pero ése es precisamente el secreto de la novela moderna (del "realismo" si se quiere): episodios modestos, de valor narrativo limitado, aunque nunca carecen totalmente de valor narrativo." Franco Moretti, op cit, pp 51 y 53
} 
amante sin levantar sospechas en la ciudad donde reside ${ }^{61}$. Este episodio indica la relación entre la movilidad de los personajes, la falta de lealtad y los vínculos laxos, además de la nueva aparición de un mesonero, cuyo estereotipo se relaciona con todos estos aspectos. Reunidos con Trapaza, dejan Trujillo "en una noche algo obscura, que en esto les fue favorable, para que no les viese nadie" ${ }^{22}$; al llegar a Córdoba paran en una venta, donde nuevamente se separan y Trapaza sigue camino a Sevilla, tramo en el cual se inserta otra novela y se introduce un nuevo compañero, Pernia. Trapaza decide rápidamente llevar a cabo una treta para obtener algo de dinero, impulsado por sus necesidades, que lo obligan a desarrollar nuevas invenciones permanentemente. El pícaro se vale del buen aspecto de su nuevo compañero, ilustrando la necesidad ocasional de cooperación entre los vagabundos ${ }^{63}$. La propuesta de Trapaza da cuenta del reducido calibre de las estafas realizadas por los pícaros, pues cuando incita a Pernia a asociarse, aclara sus limitadas expectativas: "Yo tengo pensado un arbitrio que, si nos sale bien, pienso que por lo menos comeremos" ${ }^{\prime 64}$. En este breve fragmento vemos las posibilidades algo más certeras de cooperación y asociación efímeras entre marginales, con un objetivo determinado y vinculado siempre a su subsistencia.

La llegada de los forasteros causa gran impacto en la población, que los ve pasar por la plaza. Este espacio, donde los hombres sin amo deberían emplearse, es representado por la literatura como un lugar que recibe múltiples usos por parte de los marginales, como la limosna o la atención de las mulas para moverse, señalando un control de baja intensidad por parte de las autoridades y del resto de la población, que engañada o de buen grado colabora con ellos. Sin embargo, en el episodio que nos ocupa, el alcalde sospecha inmediatamente la delincuencia del forastero que llega a la plaza, situación que indica la desconfianza respecto a quien no perteneciera a la

\footnotetext{
61 "Luego que la justicia salió del mesón con los presos, Estefanía y Vargas, pareciéndoles que no les estaba bien asistir allí, se salieron aquella noche de Trujillo, yendo Estefanía en un jumento del mesonero que se le prestó y Vargas a pie. Caminaron tres leguas aquella noche, llegando a una pequeña aldea, adonde iban dirigidos por orden del mesonero, que se aficionó a la moza, para que en ella una tía suya, mujer anciana, los albergase y tuviese en su casa hasta que las cosas de Trapaza parasen en bien. Esto hizo el mesonero, con fin de tener por cuenta suya a Estefanía ausente de los ojos de su mujer y ir a verla de cuando en cuando". Alonso de Castillo Solórzano, Aventuras del Bachiller... op cit, pp 128-129.

${ }^{62}$ Ibídem, p 135.

63 "Viéndose, pues, sin blanca, como la necesidad aviva el ingenio, dio Trapaza en un capricho para tener dineros, que les remedió por entonces aquella necesidad. Diole motivo para él ver la disposición de cara y talle de su compañero, el cual era lampiño, sin pelo de barba, por ser muchacho. Estaba bien aliñado con un vestido de color, adornado de lucidos cabos, sombrero grande, su espada y daga. No era muy alto de cuerpo, todo a propósito para lo que Trapaza tenía pensado...” Ibídem, p 172.

${ }^{64}$ Ibídem, p 173.
} 
comunidad $^{65}$.

Luego de asentarse con Don Tomé en Sevilla, debe huir como consecuencia de la violencia entre señores, que se expresa a través del ataque de la clientela, en la cual se inscribe temporalmente el marginal. Trapaza sale hacia Jaén con un estudiante y un mozo de mulas, con la intención de ir de allí a Granada, pero desde aquella ciudad se marcha hacia Madrid con una compañía de comediantes. Previo a la partida, se informa de lo que sucede en la corte, tal como hacen Pablos y Guzmán, poniendo una vez más de manifiesto el estereotipo de los pícaros -y la forma de reproducción de su grupo- que intercambian información sobre lo que sucede en la corte -y cómo sobrevivir allícuando se encuentran en diversas rutas. Los compañeros ocasionales pueden indicar el camino a seguir, ya sea mediante planes compartidos o sugerencias sobre las distintas ciudades por donde transitan los marginales. Este episodio se encadena también con otras acciones picarescas ${ }^{66}$. Los compañeros viajan con el único objetivo de robarle, pues contaban con la información de que Trapaza tenía dinero. El robo es posible gracias al vínculo que tienen con él, a quien traicionan en una venta. Entretanto, la precariedad de los bienes sustraídos da cuenta de su nivel de pobreza, en un episodio que condensa la relación entre marginalidad, nomadismo, vínculos laxos, imposibilidad de tender relaciones sólidas, delito y miseria.

El viaje es el eje estructural del relato en La hija de Celestina. A diferencia de las otras novelas que analizamos, ésta comienza durante el periplo de nuestra heroína, a quien encontramos llegando a Toledo, de donde debe escapar tras engañar a un galán. La descripción de la huida es retomada por el autor para informarnos diversas cuestiones sobre los marginales, vinculando el nomadismo con las conductas condenadas $^{67}$. Pero más aún, indica la prevención del entramado comunitario respecto a

\footnotetext{
${ }^{65}$ Así se describe su llegada, la sospecha que recae sobre ellos y la incompetencia del alcalde: "Con esto llegaron a Tocina, seis leguas de Sevilla, lugar de quinientos vecinos. Era día de fiesta, acababa la gente de salir de misa de una iglesia que está en la plaza, por donde pasaron los dos. Venía Pernia instruido por Trapaza que, en viendo gente, se embozase. Hízolo así, cosa que causó novedad en cuantos lo miraron, y en particular al alcalde del pueblo, que era un buen viejo, porque otro que había, su compañero, estaba en Sevilla, en un pleito. Siguió este alcalde los forasteros, presumiendo que el que se embozaba era algún delincuente y que lo hacía por no ser visto y conocido". Ibídem, p 174.

66 "Llegó la hora en que el licenciado tenía tratado con el mozo de mulas irse y fue a tiempo que Trapaza estaba sepultado en blando sueño: eso era lo que el escolar requería, porque agarrando de sus vestidos y maleta, cargó con todo y dejóle in puribus, como dicen. Esto hizo, porque traía soplo desde Sevilla que venía con dinero; y así, entre él y el mozo de mulas, se concertaron y tomaron aquel viaje para sólo robarle; lográronlo, como se ve, porque dejando durmiendo al descuidado Trapaza y cerrado por de fuera, se pusieron en sus mulas, hecha cuenta con el huésped, y marcharon a Sevilla”. Ibídem, pp 212 y 213.

67 "Poníale el miedo alas a Elena y sus compañeros, y al cochero cierta cantidad con que le untaron las manos dándole a entender que para negocio de mucha importancia les convenía pasar a Madrid; y así, más parecían aves por el viento que caminantes por la tierra. El que mal vive no tiene casa ni ciudad
} 
ellos, pues el engaño a un miembro de la vecindad es sentido por el común, que se encarga de la justicia de manera colectiva. Esto se reitera en el último viaje de la obra, cuando Elena y Montúfar deben huir como consecuencia de la reacción comunitaria, que se activa ante una situación de injusticia hacia la colectividad o alguno de sus miembros, actuando el cuerpo como garante de los vecinos.

La narración de la huida ilustra la falta de temor hacia la justicia divina y a la terrena -valor que convierte al pícaro en un sujeto peligroso-, motivo que explica sus actos y que constituye una de las principales acusaciones en su contra, dado que correlaciona su falta de respeto por la jerarquía celestial y terrenal. Entretanto, el episodio informa acerca de cuestiones técnicas, como las maneras en que los pícaros podrían moverse, en este caso pagando una cantidad extra al cochero. A su vez informa acerca del miedo que experimentan los personajes cuando huyen, insuficiente para que cambien el rumbo de su vida ${ }^{68}$. Lo que quiere representar el autor es el punto de compromiso al que han llegado, porque ya no hay retorno a partir del primer paso en el sentido equivocado. Durante esta travesía Elena relata su vida y explica cómo se ha convertido en pícara, aspecto que diferencia a esta novela de las otras, en las cuales la formación del protagonista es narrada al principio ${ }^{69}$.

La imposibilidad de construir vínculos estables entre los marginales es señalada en la relación que Elena establece con Montúfar. En una primera oportunidad ella y Méndez lo abandonan enfermo y parten hacia Burgos, en cuyo camino son encontradas y castigadas por él, quien se vale de la confianza que le tienen las mujeres. Las aparta del camino real y las conduce a un monte menos transitado, lugar peligroso por antonomasia para los viajeros de la época ${ }^{70}$. Luego el grupo se reunifica y continúa

permaneciente, porque antes de volver las espaldas, ganando, con uno a quien ofende, a todos por enemigos porque, como se recelan justamente de igual daño, reciben la ofensa por común; y aunque sea criatura tan desamparada del socorro del cielo que nunca tenga pesar del mal que hace, por lo menos jamás le falta temor, considerando cuán graves castigos le están guardados si da en las manos de la Justicia.” Alonso J. de Salas Barbadillo, op cit, p 105.

68 "Ellos caminaban, y aunque la hora de la noche pedía sueño, el temor no consentía, porque es cama muy dura: sobre ella nadie descansa. Al más perezoso inquieta y desvela...” Ibídem, p 106.

${ }^{69}$ Analizaremos en el apartado pertinente el contenido de esta narración.

${ }^{70}$ El rufián engaña a las dos mujeres para llevarlas al monte. La narración combina la familiaridad entre los personajes, la fragilidad de estos vínculos y la violencia entre ellos: “... él, con rostro alegre, mostró no estar ofendido: antes procuró con mucha industria asegurarlas, y haciéndolas entender que llevaban errado el viaje, las apartó del camino real y guiándolas por un monte espeso -parte adonde él sabía que nadie jamás llegaba- ya que estuvo en lo más escondido y retirado de aquella desconversable soledad, despojando una daga de la vaina, a quien siempre ellas miraban con mucha reverencia y devoción (...) las dijo que entregasen todo el oro y joyas que llevaban, so pena de la vida". Ibidem, pp 129 y 130. 
hacia Sevilla ${ }^{71}$. El miedo de los fugitivos que quieren llegar velozmente a destino impregna este trayecto y los conduce a no cometer faltas. El camino es por un lado un medio para escapar, pero para aquellos que vagan sin un destino cierto o sin apuro, también un espacio de socialización y delincuencia ${ }^{72}$.

A través de este periplo podemos constatar la estancia reiterada de los pícaros en algunas urbes: Sevilla en primer lugar, pero también Madrid, Valladolid y Toledo. La presencia de estos marginales en Sevilla se debe a su condición de ciudad portuaria donde encontrarían diferentes posibilidades en ocupaciones no especializadas, además de que la circulación de dinero y el anonimato que propicia la urbe les permitiría eventualmente medrar de otra manera ${ }^{73}$. Significaba también una gran clientela para las prostitutas y, finalmente, un punto de partida hacia otros destinos (Italia para Guzmán y las Indias para Pablos, por ejemplo) ${ }^{74}$.

Las otras dos ciudades, Madrid y Valladolid, son elegidas porque allí reside temporalmente la corte y el pícaro puede sobrevivir en parte en torno a las posibilidades que encuentra gracias a la gran circulación de personas. Cuando Guzmán decide ir a Madrid lo hace porque sabe que allí puede encontrar a muchos de su misma condición, pero también a titulados a costa de quienes pretende medrar ${ }^{75}$.

La instrucción que Trapaza recibe acerca de la corte vincula la importancia

\footnotetext{
${ }^{71}$ Este destino se presenta nuevamente como el más seguro para los pícaros, quienes, además, deben evitar ser reconocidos en otras ciudades donde ya han delinquido o engañado y podrían ser perseguidos y ajusticiados: "Hiciéronse amigos los tres y juraron olvidar las injurias: diéronse abrazos estrechos para más seguridad y decretaron no pasar a Burgos, recelosos de encontrar en aquella ciudad al caballero toledano; con este pensamiento se conformaron, eligiendo a Sevilla por verdadero centro y último reposo de su jornada". Ibídem, p 138.

72 Así se describe la posibilidad de evadir el castigo a través de la huida a nuevas ciudades donde no fueran conocidos: "En todo el camino no les sucedió cosa que sea digna de repetirse, porque como iban huyendo, temerosos siempre de que el castigo les venía a los alcances, no trataron por entonces de acrecentar culpas, sino de darse prisa hasta llegar a tierra más segura, donde, empezando libro nuevo, se diesen a conocer por diferente estilo". Ibídem, p 139.

Hemos analizado en el capítulo quinto de esta tesis la estafa que realizan en Sevilla y la posterior huida a Madrid, donde Elena muere miserablemente, por lo que no nos detendremos en ello nuevamente.

${ }^{73}$ Así, J. I. Carmona García identifica en su estudio sobre la pobreza en Sevilla, la elevada cantidad de pobres que procedían de otras regiones e incluso extranjeros. Ver José Ignacio Carmona García, El extenso mundo de la pobreza: la otra cara de la Sevilla imperial. Ayuntamiento de Sevilla, Servicio de Publicaciones, 1993, pp 55 y 56.

${ }^{74}$ Ruth Pike, Aristócratas y comerciantes. La sociedad sevillana en el siglo XVI. Barcelona, Ariel, 1978, "El hampa", pp 200-227, donde cita novelas picarescas.

${ }^{75}$ Guzmán describe su idea sobre la corte y su motivación para viajar hasta allí, vinculada con la esperanza de medrar: “... estaba allí la corte, donde todo florecía, con muchos del tusón, muchos grandes, muchos titulados, muchos prelados, muchos caballeros, gente principal y, sobre todo, rey mozo recién casado. Parecióme que por mi persona y talle todos me favorecieran y allá llegado anduvieran a las puñadas haciendo diligencia sobre quién me llevara consigo". Mateo Alemán, op cit, Primera Parte, pp 266-267.
} 
política de la ciudad con la magnificencia edilicia ${ }^{76}$. La descripción identifica distintas categorías entre los nobles, negociantes y oficiales reales. El narrador observa la presencia de quienes buscan medrar para llegar a más, a través de la exposición pública en diversas actividades o la ostentación de sus ropas y arreglos a la moda ${ }^{77}$. La narración identifica los diversos lugares donde las personas se muestran, donde se mezclan los sitios públicos principales con otros marginales, pero frecuentados por miembros de diversos sectores sociales.

Según vemos en la Guía y avisos de forasteros que vienen a la Corte de A. Liñán y Verdugo ${ }^{78}$, el contacto con el hampa puede conducir a la degeneración moral de una persona. Esta obra, compuesta por "avisos" intercalados con "novelas y escarmientos" que ejemplifican a través de breves historias aquello que se pretende prevenir, da cuenta de los artilugios que ponen en práctica diversos delincuentes en el ámbito de la corte, explicando la existencia de variadas prohibiciones de permanecer allí por parte de quienes no iban a tramitar nada. El objetivo supuesto de esta literatura es alertar a las personas honradas, pero es clara en ella la intención de estigmatizar a los marginales que circulan en este espacio, que podrían, potencialmente, engañar a toda la población, que quedaría indefensa al caer en sus trampas y, peor aún, impedida de volver a su estado anterior ${ }^{79}$.

\footnotetext{
76 "Madrid, insigne Corte del cuarto Filipo, monarca invicto de las Españas, es una villa de santísimo temple, de subtiles aires y regalados mantenimientos; sus edificios son suntuosos: edifican en esta insigne villa los más títulos y señores de España casas suntuosísimas en que vivir. Aunque Madrid es antigua villa y tiene por naturales suyos muchos calificados caballeros, sus patriotas, el concurso de la gente forastera que asisten a ella, o sus negocios y pretensiones, o a sus ganancias, como son los oficiales, o a vivir en la Corte, la hacen más populosa, y así viene a ser una patria común". Alonso J. de Castillo Solórzano, op cit, p 265.

${ }^{77} \mathrm{La}$ novela clasifica diversos personajes en la corte, donde identifica su procedencia social, sus inclinaciones, prácticas (más o menos respetables), sus atuendos y los espacios donde se relacionan: “... que hay en Madrid mucha cantidad de caballeros que, portándose lucidamente se comunican familiares con títulos y grandes con quien andan. Déstos se dividen conforme a las edades e inclinaciones: unos se inclinan a los ejercicios bélicos, y tratando de la destreza de las armas, de torear, de justar y torneos; otros, más pacíficos, tratan de oír comedias, acudir a la calle Mayor a su cotidiano paseo, no olvidando el del Prado, galantear y servir damas; otros acuden a casas de juego, donde, siendo perpetuo tahúres, no dejan alhaja que no jueguen, y hoy se ven prósperos, y mañana sin qué gastar (...) Hay cierto género de gente, que llaman hijos de vecinos. Estos andan tan al uso que no perdonan al estío, primavera ni invierno. Son los que primero estrenan los trajes y con desproporción usan dellos; los que inventaron en cimentar los mostachos con cabello de las mejillas, los que subieron las ligas a las rodillas, ajustaron las mangas, acortaron las faldillas de las ropillas. Éstos pecan los más valientes y hablan grueso". Ibídem, p 266.

${ }^{78}$ Antonio Liñán y Verdugo, op cit.

${ }^{79}$ Algunos "avisos" narran cómo las mujeres pueden ser engañadas por los pícaros sin poder reintegrarse posteriormente a su entorno social. Comentaremos brevemente el caso narrado en la novela y escarmiento catorce. Ésta refiere cómo una joven que vivía con su familia en una casa principal de Madrid se pierde como consecuencia de su romance con un "hombre de los ociosos y sobrados en Corte" (Ibídem, p 250). Ella "convirtióse tan en otra mujer, que arrojó las disciplinas, dejó las contemplaciones (...) se moría por mirar y ser vista" (Ibidem, p 252). La idea de embrujamiento y de la curiosidad femenina vinculada a la
} 
Una de las particularidades de la socialización de los marginales radica en la permanente circulación que, en una sociedad sedentaria, los convertía en sujetos sospechosos, impulsándolos a su vez a moverse por las amenazas de la justicia o de la expulsión. Esta característica daba lugar a que mantuvieran vínculos laxos con otros hombres que compartían su condición, dificultando aun más su inserción permanente en las redes de las aldeas, por eso los vemos circulando por las urbes populosas.

\section{Los vínculos y la reproducción del sector marginal}

Analizaremos aquí la representación picaresca de los vínculos y reproducción de la masa marginal, cuyo incremento durante la temprana modernidad la convirtió en un conflicto que alarmaba a diversos campos de la élite. Los motivos de dicho crecimiento podían ser diversos, así como los destinos de los agentes que atravesaban esta condición.

El marginal se constituye como tal a lo largo de su existencia. Los vínculos que adquiere en el marco del hampa propician los intercambios y, por tanto, su reproducción. La narrativa propone en variados casos el aprendizaje en el seno de la familia. Tal como las existencias heroicas de los libros de caballerías se inician con la ascendencia ejemplar de los protagonistas, nuestros desarrapados personajes también comienzan con la descripción de su estirpe, que se caracteriza por su origen bajo ${ }^{80}$. Generalmente se trata de criados domésticos díscolos, delincuentes, hechiceras o prostitutas, todos ellos miserables, artificio que ayudaría a los autores a sugerir que existe una inclinación hereditaria de la sangre, además de una mala educación y peores influencias entre el vulgo. Pero también podemos encontrar que la familia provenía de

transgresión de las normas se evidencia cuando la muchacha comenta a su criada -quien la estimula en su elección amorosa-, "no sé qué me trajiste en este libro y en esta cinta, que muero por saber quién es ese hombre" (Ibídem, p 253). Este pícaro, entretanto, también había enamorado a otra mujer, que "falta de juicio y paciencia", se lamenta porque "una mujer tan rica, tan hermosa, tan principal y tan muchacha, ha puesto los ojos en un pícaro sin camisa, de la más vil gente del mundo, que si yo no le sustentara y vistiera, pidiera limosna" (Ibídem, p 255). Ella decide delatar a la muchacha, a quien le "descubrió el demonio un camino arrojadísimo", ante su padre (Ibídem, p 256). El hombre, al enterarse, sospecha que se trata de "alguna ilusión del demonio". A partir de esto, la muchacha huye de su casa junto a su criada. Si bien en el final del relato la protagonista consigue un feliz casamiento, el narrador reflexiona: "Mirad lo que pasa en la vida de Corte, y cuán á peligro se crían de perderse los hijos é hijas en ella, y porque de camino, si no son demasiado buenas las inclinaciones, hay quien los distraiga" (Ibídem, p 264). Esta breve historia representa y quiere convencer acerca del peligro que suponen -según el autor- los marginales que, silenciosamente, pueden desviar hasta a las personas más honradas.

${ }^{80}$ Gustavo Correa, "El héroe de la picaresca y su influencia en la novela moderna española e hispanoamericana", en Pérez Patiño, Rubén (ed.). Thesaurus. Boletín del instituto Caro y Cuervo. Muestra antológica 1945-1985. Santafé de Bogotá, Tomo II, pp 713-732, p 719. 
un ámbito integrado como Trapaza o, más aún, Guzmán, pero cuya desviación moral anticipa la que se exacerbará en el pícaro.

La narrativa presenta la reproducción intergeneracional de la marginalidad, que puede tener lugar como consecuencia de la caída en la pobreza de la familia (como en el caso de El Lazarillo) o bien por la reproducción de una célula que ya es marginal (siguiendo la descripción de El Buscón). Consideramos esta descripción como la representación de un caso en que se dan dos pasos sucesivos en la marginalidad de la familia. Sin embargo, esto contraría la norma, pues la masa de pobres de la ciudad aumentaba principalmente por inmigración. Además, la descripción de Quevedo tampoco coincide con la de la documentación política, que sólo nos habla de la expansión de este problema por “imitación”. Los escolásticos mencionan la reproducción intergeneracional de los vagabundos cuando sostienen que, a fin de acrecentar las limosnas, estimulan a sus hijos en su actividad (e incluso pueden tullirlos para generar compasión), noción retomada en El Guzmán en la historia del mendigo florentino y en las Ordenanzas mendicativas ${ }^{81}$. Sin embargo, debido a la repetición de este estereotipo (que llega hasta nuestros días en numerosos mitos urbanos), la realidad de este aspecto también es discutible, pues se trata del modelo de un mendigo que se basa en la contradicción de reglas éticas fundamentales para la reproducción de la sociedad como el amor a los niños y su cuidado, ideas que se repiten acerca de diversos grupos segregados a lo largo de la historia.

La picaresca muestra un modelo antiejemplar, que no se proyecta sólo en el protagonista y sus eventuales compañeros, sino que describe existencias semejantes en la ascendencia del pícaro, pero no de igual manera o en el mismo grado. Sin embargo encontramos el elemento común de algún tipo de desviación moral en los padres convirtiendo a las genealogías de los pícaros en parodias de la ascendencia noble en las altas jerarquías de la sociedad ${ }^{82}$. Los pícaros son previamente juzgados al exhibir su ascendencia. La novela picaresca localiza al protagonista en un determinismo hereditario, perteneciendo a una "clase moral" de la cual no tiene salida ${ }^{83}$. La importancia de la genealogía en el género picaresco se entiende si observamos cómo la jerarquía social era presentada por la oligarquía, que rechazaba la movilidad social ${ }^{84}$.

\footnotetext{
${ }^{81}$ Ver Félix Santolaria Sierra (ed.), El gran debate... op cit, p 86.

${ }^{82}$ Gustavo Correa, El héroe... op cit, p 719.

${ }^{83}$ Américo Castro. Hacia Cervantes. Madrid, Taurus, 1957, p 89.

${ }^{84}$ Javier Herrero, "Renaissance Poverty and Lazarillo's Family: The Birth of the Picaresque Genre", en PMLA. Vol. 94, N5, Nueva York, Modern Language Association, 1979, pp 876-886, p 882.
} 
En varias novelas, los padres de los protagonistas no son marginales en el grado en que esta condición se presenta en los pícaros, de manera que la potencialidad de la marginalidad se heredaba, conformando la idea de una sociedad estamental en la cual el vulgo estaba predeterminado, justificando las propuestas para su represión, a fin de evitar que se desviara.

Además de la herencia plebeya, el fracaso económico de la familia condiciona la marginalidad del pícaro, cuya ambición consiste, según Cavillac, en recobrar la fortuna humilde (Lázaro) o brillante (Guzmán) de su infancia ${ }^{85}$, de ahí la condena por no someterse a su destino. Sin embargo, consideramos que van aún más lejos al querer medrar, como Pablos, que trata de ascender, o pueden también continuar con la desviación heredada (Elena). Revisaremos las genealogías de los pícaros que nos ocupan (que pueden llegar hasta tres generaciones) pero sin detenernos en la de Guzmán, que fue minuciosamente analizada por Cavillac ${ }^{86}$.

El primer tratado del Lazarillo relata la marginalización del protagonista como consecuencia de la separación compulsiva del cabeza de familia (castigado por robar). Los conflictos subsiguientes son superados mediante los cambios en la estrategia de subsistencia puestos en práctica por la madre del protagonista, hasta que la acumulación de las falencias en la economía familiar la obliga a desarticular esta unidad, llevando a Lázaro al periplo que es narrado en el texto ${ }^{87}$.

Estos conflictos pueden ser leídos en relación con la estructura del cuento popular planteada por V. Propp, pues en El Lazarillo podemos constatar el nacimiento en el río; el padre molinero, figura sospechosa y tópicamente rapaz dentro de la comunidad aldeana $^{88}$; la función "ausencia" cuando éste es ajusticiado y el infortunio y la carestía que derivan de esta separación y de la insuficiencia de los medios de

\footnotetext{
${ }^{85}$ Michel Cavillac, Pícaros y mercaderes... op cit, pp 432-433.

${ }^{86}$ Cavillac analiza la genealogía del bastardo Guzmán considerando la doble influencia del pícaro, por un lado su padre Genovés (cuya procedencia representa la burguesía financiera, los malos manejos y la avaricia) y por el otro al marido (engañado) de su madre, un caballero sevillano, representante de la decadente aristocracia española. En este marco, también analiza, a partir de la doble paternidad, el problema del adulterio (pecado cometido por la madre y no sólo una "transgresión del orden divino", sino también puesto en cuestión de manera casi coetánea a la novela durante el Concilio de Trento. Ibídem, pp 102 y ss.

${ }^{87}$ Así L. Villamía analiza la formación del pícaro como consecuencia de los progresivos desgarramientos que vive desde su niñez, que transita en una familia ya deteriorada. De esta manera, el autor aborda este problema a partir de la noción de infancia. Luis Villamía, "Sobre la historiografía del género picaresco: pliegues modernos de la literatura del pobre", en Hipertexto. $\mathrm{N}^{\circ} 13$, Texas, The University of Texas-Pan American: Department of Modern Languages and Literature, invierno 2011, pp 42-58.

${ }^{88}$ Ver acerca del tema Edward Thompson, Costumbres en común. Barcelona, Crítica, 1995, pp 249 y 250.
} 
existencia $^{89}$.

El padre de Lázaro es molinero, oficio que era marginal en la aldea a pesar del valor económico que tenía esta ocupación. Se trataba de una figura controvertida dentro de los grupos campesinos dado el poder que podía ejercer sobre la comunidad rural ${ }^{90}$. El molinero tenía a cargo el manejo del grano y, con ello, existía la posibilidad de robar una cantidad en la trituración, pero también de ser acusado de sustracciones cuando existiera animadversión hacia él. Así, en El Lazarillo “... siendo yo niño de ocho años, achacaron a mi padre ciertas sangrias malhechas en los costales de los que alli a moler venian, por lo qual fué preso y confessó e no negó y padesció persecución por justicia." 91.

La represión de un robo podía llevar al desclasamiento social, tal como constatamos con el padre de Lázaro, quien es acusado de sustraer parte del grano. El molinero es desterrado, forma de segregación que significaba la degradación y muerte civil, pues este castigo en una villa llevaba a la proscripción en otras, condenando al ajusticiado al vagabundeo, porque pocos podían tener luego oportunidad de una vida integrada a las redes de un nuevo lugar ${ }^{92}$. Ésta era una forma de exclusión de una persona que era considerada nociva para la sociedad y que resultaba expulsada por ésta. Más tarde, el padre de Lázaro brinda servicios como mulero a un caballero en la guerra, muriendo en la expedición a los Gelves ${ }^{93}$.

El primer marginado de la familia es el padre de Lázaro. El protagonista tiene luego la misma suerte, pero existen diferencias entre la segregación de ambos personajes. La primera de ellas consiste en que el padre es expulsado por la comunidad rural y no por la familia, como le sucede al hijo. La segunda radica en que el hombre es separado por la intervención de la justicia y el joven por motivos económicos.

La crisis es superada por la familia mediante un cambio en la estrategia de

\footnotetext{
89 Podemos localizar estos elementos en Vladimir Propp, Morfología del cuento. Madrid, Editorial fundamentos, 2006, pp 38, 48, 101, 112, 113, 135 y ss. Según K. Niemeyer, la vinculación de los personajes con estereotipos folklóricos garantiza verosimilitud. Katharina. Niemeyer, El ser de ... op cit, p 103.

${ }^{90}$ Ver Carlo Ginzburg, El queso... op cit, passim; Jean Calude Schmitt, L'histoire... op cit, p 350. Ver también sobre el molino como un espacio de prostitución que facilita el propio molinero: Ordenanzas de Lon y Brez de 1602, Capítulo 8, en Juan Baró Pazos y Rogelio Pérez Bustamante, op cit, p 181.

91 Anónimo, op cit, p 66.

${ }^{92}$ Bronislaw Geremek, Les marginaux... op cit, pp 120 y 121. El autor polaco agrega que dichos hurtos podían tener un carácter accidental como la "instigación diabólica" o estar ligados a una necesidad momentánea (recordemos que las dificultades que atravesaba la sociedad que él estudia multiplicaban dichas circunstancias), elementos que se presentan como atenuantes cuando son juzgados.

${ }^{93}$ Anónimo, op cit, pp 67 y 68. Se menciona la muerte del padre en Gelves en la página 75.
} 
subsistencia llevado a cabo por la madre ${ }^{94}$, a través de la emigración a la ciudad, en coincidencia con la información que brinda la historiografía de este período, que sostiene que las mujeres eran las que tenían que formular tácticas para sobrevivir en los períodos de escasez. En este contexto, la huida hacia centros urbanos resultaba una reacción habitual de los campesinos pobres cuando se perdía el amparo de la antigua colectividad, llegando a constituirse en un flujo constante que alimentaba demográficamente a las ciudades ${ }^{95}$, mientras los municipios elaboraban instrumentos jurídicos para evitar el asentamiento permanente de pobres sin ocupación o amo conocido $^{96}$.

La mujer comienza a servir a los estudiantes y caballeros ${ }^{97}$, tal como hace Lázaro más adelante. Aquí se constata el aprendizaje de diversas actividades por parte del futuro pícaro, quien además ha comenzado su emigración, aunque todavía en el marco familiar. En este ámbito la mujer se amanceba con un esclavo negro ${ }^{98}$, cuidador de los animales de los caballeros, corroborando que la marginalidad producía lazos familiares no formales entre distintos tipos de segregados, que reforzaban la marginalidad $^{99}$, fenómeno que se debía a la carencia de medios para radicarse y cuyas consecuencias eran la falta de pertenencia a una comunidad, que a su vez podía implicar la ausencia de medios estables de subsistencia y la imposibilidad de estrechar vínculos sólidos y permanentes. Todos estos aspectos se implicaban mutuamente y conducían a la deslegitimación y segregación, explicando la dificultad que se imponía a estas personas

\footnotetext{
${ }^{94}$ Sobre las viudas como grupos de pobres ver Carmen López Alonso, op cit, pp 45 y ss. La viuda es caracterizada como un pobre arquetípico, aunque objetivamente no lo sea en el caso de los sectores propietarios. Pero entre aquellos en los que una eventualidad puede llevar a la carencia material, la pobreza objetiva es incrementada cuando se trata de una mujer.

${ }^{95}$ Sobre la emigración de los pobres rurales: José Antonio Maravall, "Pobres y pobreza del medioevo a la primera modernidad", en Cuadernos hispanoamericanos. Madrid, Agencia Española de Cooperación Internacional para el Desarrollo, 1981, pp 189-242, p 228.

${ }^{96}$ Así, por ejemplo, en el séptimo de los "Capítulos de buen gobierno de Lon y Brez" de 1594, se ordena que "...los dichos regidores que son o fueren no consientan andar ningún pobre forastero, ni que sea (a)limentado en él, antes le echen luego de (é)l, y sólo dejen a los pobres naturales. Y si los forasteros no quisieren ir, den noticia a la justicia de la dicha villa para que los castiguen, y no hagan lo contrario, con apercibimiento que serán castigados por todo rigor." Juan Baró Pazos y Rogelio Pérez Bustamante, op cit, pp 172 y 173 .

${ }^{97}$ P. Vilar habla de la propagación de estos trabajos en España a partir de la cantidad de excedente proveniente del botín, que no es utilizado para producir sino para dilapidar en servicios diversos, generando “...un clima económico en el que el rico podía fácilmente ser generoso, y en el que el pobre tenía más interés en vivir al azar que en percibir un salario poco estimulante frente a los precios y frente a las promesas de la aventura". Pierre Vilar, op cit, p 343. Este argumento respecto del pobre viene a reforzar lo que creen los redactores de las ordenanzas y lo que creen los escritores acerca de los pícaros.

${ }^{98}$ Sobre este interesante personaje ver el estudio de Baltasar Fra Molinero, "El negro Zaide: marginación social y textual en el Lazarillo", en Hispania. Vol. 76, № 1, Madrid, Consejo Superior de Investigaciones Científicas, 1993, pp 20-29. La situación de la madre era la de una necesidad desesperada de ayuda, pues Zaide es el extremo de la marginalidad por pobre y negro.

${ }^{99}$ Bronislaw Geremek, Les marginaux... op cit, p 333.
} 
para integrarse.

La unidad doméstica pierde al segundo hombre por motivos similares a los que producen la separación del primero ${ }^{100}$. El padre roba parte de la molienda que tiene a cargo; mientras Zaide hurta diversos artículos de las caballerizas donde trabaja, para sustentar a la familia ${ }^{101}$. Sin embargo, aquí terminan los parecidos, pues si bien el molinero resulta relativamente estigmatizado por la comunidad, también detenta cierto poder (motivo del rechazo popular hacia él), además de ser blanco y cristiano. Pero Zaide no sólo no tiene ningún tipo de poder, sino que además es invisibilizado en su condición de esclavo negro, lo cual también explica la mayor severidad en su castigo. Los artículos robados indican la precariedad de la vida de este grupo, en contradicción con la noción de que los marginales delinquían con el objetivo de medrar. Mientras algunos de dichos elementos son consumidos, otros son vendidos por los niños para obtener comida ${ }^{102}$, aprendiendo así las conductas marginales en el seno de la familia.

La madre, sola y pobre, es azotada públicamente y expulsada. Además de esta sanción oficial de su exclusión, es marginada por la comunidad por su relación con el esclavo ladrón, quien muere en la horca -castigo ejemplar, pues la comunidad tenía que presenciar la pena del delincuente con fines preventivos-. La mujer vuelve a desplazarse (acentuando la idea del paria condenado al nomadismo) y comienza a trabajar brindando servicios junto a su hijo mayor -al que no abandona- en un mesón ${ }^{103}$. Lazarillo aprende a realizar diversos recados y es inmerso en la socialización de dicho espacio, que se vincula con la circulación de distintos tipos de marginales.

Así llegamos al último episodio de la vida familiar del personaje, quien, a partir de aquí, comienza su existencia errabunda poniéndose al servicio de diversos amos. El presente de la narración biográfica nos muestra un Lázaro adulto que no ha podido vivir en el marco de integración social, pues si bien está instalado con una mujer en una

\footnotetext{
${ }^{100}$ La franja marginal se alimentaba de un aporte constante de clases inferiores. La infracción es señal del desclasamiento. Ibidem, p 343.

${ }^{101}$ Así describe el narrador los artículos robados por Zaide, dando cuenta de la precariedad de la familia: “...hecha pesquisa, hallose que la mitad por medio de la ceuada, que para las bestias le dauan, hurtaua, y saluados, leña, almohaças, mandiles, y las mantas y sauanas de los cauallos hazia perdidas, y, quando otra cosa no tenia, las bestias desherraua, y con todo esto acudia a mi madre para criar a mi hermanico." Anónimo, op cit, p 72.

${ }^{102}$ Así describe Lázaro, en el presente de la narración, su formación en un medio marginal, retomando la óptica de un niño: "Porque a mí con amenazas me preguntauan e como niño respondia e descubria quanto sabia con miedo, hasta ciertas herraduras, que por mandado de mi madre a vn herrero vendi." (Las cursivas son nuestras.). Ibidem, p 73.

${ }^{103}$ Así describe Lazarillo la vida en el mesón, donde continúa su formación: "E allí, padesciendo mil importunidades, se acabó de criar mi hermanico, hasta que supo andar e a mi hasta ser buen moçuelo, que yua a los huespedes por vino e candelas y por lo demás, que me mandauan.” Ibídem, pp 74 y 75.
} 
comunidad y tiene trabajo, su vinculación depende de un clérigo, con quien ella está amancebada. Esta situación, condenada pero ampliamente difundida entre los eclesiásticos, vuelve sobre la necesidad que tenían aquellos que estaban integrados en la sociedad de la existencia de los marginales, relacionando a ambos sectores.

Vemos, por otro lado, cómo el aparato coercitivo puede conducir a la escisión de todo un grupo a partir de su intervención. En la sociedad corporativa, cada persona siempre está inmersa en un colectivo (familia, gremio, etc.), por eso, si el cabeza de familia es condenado, el conjunto entero sufre las consecuencias morales y prácticas. La no integración en un grupo implica una total falta de protección para el individuo. El Lazarillo se destaca en el género por la relativa benevolencia por parte de su anónimo autor respecto a su criatura, que es claramente una víctima de las circunstancias sociales, políticas y económicas, mientras se denuncia la injusticia hacia los grupos desheredados "No nos marauillemos de vn clérigo ni frayle, porque el vno hurta de los pobres y el otro de casa para sus deuotas y para ayuda de otro tanto, quando a vn pobre esclauo el amor le animaua a esto" ${ }^{104}$. Se censura al pícaro, pero como fondo también se critica a la sociedad entera, plagada de otros ejemplos de corrupción.

La novela de Quevedo nos introduce en una óptica diametralmente diferente a la que imprimió el autor del Lazarillo. Su criatura proviene de una familia cuya marginalidad tiene relación con la desviación, lo cual entra en consonancia con la virulenta expresión del autor en cuanto a los sectores bajos en el resto de su obra. Se trataría, según esta novela, de sujetos cuya marginalidad se vincularía con todo tipo de actividades condenadas socialmente, condición que se acentuaría intergeneracionalmente.

El padre del pícaro es un barbero alcohólico y ladrón, que cuenta con la ayuda de su hijo menor en los pequeños robos, introduciendo de este modo a los niños en la delincuencia $^{105}$, mostrando, una vez más, la predestinación del pícaro. Como consecuencia de sus actos, es ahorcado públicamente. La descripción del ajusticiamiento de este personaje también funciona como una parodia de la caballería, mostrando la manera heroica en que se dispone a enfrentar su destino, que no atemoriza a su hijo. El verdugo es un pariente suyo, cuya corrupción moral nos brinda aún más

\footnotetext{
${ }^{104}$ Ibidem, pp 72 y 73 .

105 “...porque las malas lenguas daban en decir que mi padre metía el dos de bastos para sacar el as de oros. Probósele que, a todos los que hacía la barba a navaja, mientras les daba con el agua, levantándoles la cara para el lavatorio, un mi hermanico de siete años les sacaba muy a salvo los tuétanos de las faldriqueras. Murió el angélico de unos azotes que le dieron en la cárcel. Sintiólo mucho mi padre, por ser tal que robaba a todos las voluntades." Francisco de Quevedo, op cit, p 16.
} 
indicaciones acerca de la familia, pues recordemos que dicho oficio era uno de los más degradados ${ }^{106}$.

La madre de Pablos contiene todos los motivos para la estigmatización: prostituta, hechicera y conversa ${ }^{107}$, lo cual explica su captura por parte de la inquisición. Esta figura es un estereotipo de todo lo que una mujer marginal puede ser. El pícaro entonces hereda por la vía de la sangre no sólo su carácter vulgar, sino también judío (y todo lo que se atribuía a este grupo segregado), además de la educación que una familia desviada le había dado. Sin embargo, esto constituye sólo una parte de las incriminaciones de Quevedo hacia su criatura, cuyo principal acto de rebeldía es tener altas aspiraciones $^{108}$.

Recordemos que Pablos es, entre todos los pícaros, el más agraviado por parte de su creador, cuyo punto de vista respecto a la realidad y dinámica de cambio del período explica la construcción de esta criatura. La crítica comienza con la de sus padres y otros personajes de su familia, que él pretende evadir, pero no por la vía de la subordinación y aceptación de su condición sino mediante la educación e inserción en medios sociales más elevados. Ante el fracaso de su primera estrategia, incurre en el pecado de soberbia al formar parte del mundo de la delincuencia. La novela propone que su marginalidad se reproduce de todos los modos posibles, mediante la procreación, la imitación y la voluntad de quienes se encuentran en esta condición, en consonancia con la virulencia de las consideraciones del autor respecto a los sectores populares y su potencialidad sediciosa.

Con el objetivo de plantear un tercer caso con una genealogía similar a la que encontramos en varias obras menores del género, revisaremos la estirpe de La hija de Celestina. El retrato de Elena, tal como el de Quevedo, no guarda ninguna conmiseración con la protagonista que además es uno de los pocos de la picaresca

\footnotetext{
106 "Dios sabe cuál estaba de ver la infamia de mi tío..." Ibídem, p 136. Respecto a la mala fama y segregación del verdugo: "Tenía mi buen tío su alojamiento junto al matadero, en casa de un aguador." Ibídem, $\mathrm{p}$ 135. El peor lugar para vivir y que normalmente era frecuentado por gente brutal y cruel.

107 "Sospechábase en el pueblo que no era cristiana vieja, aunque ella, por los nombres y sobrenombres de sus pasados, quiso forzar que era descendiente de la letania. Tuvo muy buen parecer, y fue tan celebrada, que, en el tiempo que ella vivió, casi todos los copleros de España hacían cosas sobre ella.” Ibídem, p 16. "Hubo fama que redificaba doncellas, resucitaba cabellos encubriendo canas. Unos la llamaban zurcidora de gustos; otros, algebrista de voluntades desconcertadas, y por mal nombre alcagüeta." Ibídem, pp 17 y 18. "Tenía su aposento -donde sola ella entraba y algunas veces yo, que, como era chico, podía-, todo rodeado de calaveras que ella decía eran para memorias de la muerte, y otros, por vituperarla, que para voluntades de la vida." Ibídem, p 18.

${ }^{108}$ Así se describe, con ironía, la reproducción de los marginales, en una representación que combina la mala educación y la falta de sumisión: “... hubo grandes diferencias entre mis padres sobre quién había de imitar en el oficio, mas yo, que siempre tuve pensamientos de caballero desde chiquito, nunca me apliqué a uno ni a otro." Ibídem, p 18.
} 
ajusticiado con la pena capital, sin redención. La historia de su familia no coincide en la narración con el principio del relato, sino que es introducida una vez que conocemos las aventuras de la protagonista. Comienza su biografía con la de sus padres, un lacayo madrileño alcohólico y una esclava ladrona que trabaja en una casa de la nobleza ${ }^{109}$. Elena sostiene el alto status de los amos, en coincidencia con la posesión de un gran número de sirvientes. Sin embargo, observamos la vergüenza que se imputa a la pícara para asumir la esclavitud de su madre (al igual que vemos en El Lazarillo respecto al negro Zaide). El énfasis en la condición de los amos de la madre da cuenta de la forma en que se enmarca simbólicamente el personal dentro de la clientela nobiliar ${ }^{110}$.

Los padres de Elena se conocen en los ámbitos de socialización de las comunidades de sirvientes. Son varias las novelas que presentan la noción de los criados como precursores de nuestros héroes, así como la socialización en el río con las lavanderas. Se trataba de un personal doméstico cuya funcionalidad era la reproducción del status de los amos, pero vemos que, si los últimos convalidaban su honra por la posesión de una caterva de dependientes, también reproducían el estrato de la marginalidad, cuya principal característica es la ausencia de status.

La esclava es liberada al morir su ama en agradecimiento por ser nodriza de su hija, a quien amamanta, capacidad que se vincula con su prostitución y sus relaciones con los no cristianos ${ }^{111}$. Esto es indicativo de la necesidad para su reproducción por parte de los dos sectores, el de los amos y el de esta clase de domésticos.

Libre, la madre de Elena continúa con la misma labor que la ocupaba como esclava. Pero además, y a pesar de que sus padres habían muerto en manos de la inquisición, se ocupa como alcahueta y gana la fama que introduce este título en el macrotexto del género junto a La Celestina ${ }^{112}$. La madre también aplica sus artes a Elena, a quien vende tres veces por virgen. En el peligro de ser descubiertas, ambas deben huir a Sevilla (destino recurrente en la picaresca), donde la mujer muere y Elena continúa sola su derrotero marginal ${ }^{113}$. Este relato contiene varios estereotipos, como la

\footnotetext{
${ }^{109}$ Alonso J. de Salas Barbadillo, op cit, pp 106 y 107.

110 Entretanto, Elena se enorgullece al confesar que su madre ha sido pretendida por hombres distinguidos, tratando la narradora, mediante este mecanismo, de hacerla partícipe de dicha posición.

111 "Túvola tanta [diligencia] en agradar a su ama, que cuando murió la dejó libre en agradecimiento de que le acabó de criar una criatura con mucha salud. Después de haber andado en manos de infinitas amas enferma, y tanto que los médicos desesperaron de su vida, púdolo hacer ella muy fácilmente, porque los más años, imitando a la buena tierra, daba fruto; que de algo la había de servir la conversación de tanto moro caballero con quien solía emboscarse por aquel soto y quitarse todos los malos deseos." Ibídem, p 108.

${ }_{112}^{112}$ Ibidem, pp 109 y 110.

${ }^{113}$ Ibidem, p 113.
} 
utilización de los hijos en las prácticas marginales para sobrevivir (que de este modo las aprenden y reproducen) y el nomadismo como consecuencia de la transgresión de las normas.

El Bachiller Trapaza presenta particularidades aun más interesantes ya que, si bien su familia procede de sectores populares, no es marginal sino que se encuentra integrada en la trama comunitaria, atribuyéndose al protagonista su marginalidad, que deviene de conductas desviadas. Sin embargo, dicho destino está en la potencialidad que implica su clase. Su padre, Pedro de la Trampa (este nombre nos anticipa la intención del autor) es un oficial artesano que va a Segovia a ocuparse en el labrado del paño, es un buen trabajador que llega a capataz de un mercader. La madre, Olalla Tramoya (nombre que completa la genealogía del embustero) es una labradora cristiana vieja procedente de una aldea vecina a Segovia, adonde se dirige para vender parte de la producción familiar $^{114}$.

La inserción de la familia en las redes comunitarias se constata a través de los vínculos del abuelo de Trapaza, que es amigo del mercader para quien trabaja de la Trampa y a quien pide que case al joven con su hija, requerimiento que el tratante logra, amenazando al oficial con que, de no hacerlo, lo llevaría ante la justicia, e insiste ofreciéndole "de su parte no faltarle jamás mientras viviese y, demás desto, ayudarle para su casamiento en todo cuanto pudiese por la afición grande que le había cobrado" $"$. Estos aspectos de los vínculos entre los personajes dan cuenta de una marcada integración y cohesión social, tanto en la relación de amistad como en la de dependencia o en la trama familiar ${ }^{116}$. Tras la negativa del muchacho, el viejo debe insistir al mercader para que busque otra solución ("Vuesa merced vea el modo que se debe tener para no trapacearme el honor") ${ }^{117}$, ilustrando cómo el patrono debe responder por el joven, pero también la manera en que la falta de la hija afecta al honor del padre, ya que no es atribuida solamente a ella, porque se entiende que el padre es culpable de

\footnotetext{
${ }^{114}$ Alonso de Castillo Solórzano, Aventuras del Bachiller ... op cit, p 60.

115 Ibidem, p 63.

${ }^{116}$ P. Rosanvallon analiza la discusión, en 1789, en torno a la inclusión política de los domésticos, porque "simbolizaban la dependencia de un tercero". Sieyès sostuvo que son "aquellos a quienes una dependencia servil mantiene atados, no a un trabajo cualquiera, sino a las voluntades arbitrarias de un amo", mientras Condorcet rechazó su voto porque sólo duplicaría el de su amo, pues "la relación amocriado es una relación de tipo natural, que no consiste en una relación contractual o en un encuentro entre dos individuos igualmente autónomos". Así, “el doméstico es un ser entre dos mundos. Se encuentra entre la antigua servidumbre y el asalariado moderno, en la intersección de la relación familiar y la relación social." Pierre Rosanvallon, op cit, pp 112 y 114.

${ }^{117}$ Alonso de Castillo Solórzano, Aventuras del Bachiller... op cit, p 63.
} 
no haberla impedido ${ }^{118}$.

Las novelas se detienen más o menos extensamente en la descripción de la historia de los padres del protagonista. La forma y el grado de su inserción social están en consonancia con el conocimiento que tiene el autor acerca de los personajes a los que retrata. Ninguno de ellos procede del ámbito de la baja nobleza, y el único que proviene de la burguesía es la criatura de Alemán ${ }^{119}$. Todos comparten el origen vulgar, que sería una precondición para la desviación.

Algunas novelas muestran pequeñas desviaciones por parte de la familia del protagonista, que bien pueden ser educativas -dando lugar a que el pícaro aprenda en dicho ámbito las conductas desviadas- o determinantes de la existencia marginal que constituye el argumento del texto. Pero en otros casos, un infortunio (la muerte o la acusación de un robo, por ejemplo) es el desencadenante de la marginalidad de los personajes, pues se trata de episodios que hacen que una familia que se encuentra integrada en la comunidad, deje de estarlo. Sin embargo, la mayoría de los padres de los pícaros están relativamente integrados de diversas formas, y sólo en el caso de la novela de Quevedo, aquéllos son totalmente estigmatizados. Su participación social puede serlo en tanto están instalados en una comunidad, o en cuanto son pícaros insertos en diversas clientelas, si se trata de criados que tienen a sus señores como garantes sociales.

La exposición de estas genealogías apunta a señalar cuáles son los vicios que, según sospechan los autores, conducen a la emergencia de personajes que son considerados nocivos para el cuerpo social. Tanto los documentos normativos como la picaresca indican el proceso de desestructuración de las familias como corolario de la

\footnotetext{
${ }^{118}$ Finalmente, el oficial es puesto en la cárcel y sentenciado a galeras que debería padecer de no casarse, lo cual finalmente acepta, pero muere rápidamente, quedando la crianza de Trapaza en manos de su madre y de su abuelo. Ibídem, pp 65 y 66.

La falta de la joven implica el des honor de su padre, es una afrenta a él, que no pudo impedirla. Debemos tener en cuenta la concepción del honor en la sociedad antiguorregimental. Así, nos indica T. Mantecón Movellán: "El honor y la posición social que públicamente se reconocía como efecto de una determinada ubicación personal y corporativa dentro de la escala de honor y estima social pasaban a primer plano del debate cotidiano en la vida de los vecindarios urbanos y, sobre todo, en las comunidades rurales. En ambos espacios y en la Castilla interior se expresaba también un honor corporativo a través de instituciones sociales que componían una suerte de parentelas artificiales, como eran las cofradías religiosas postridentinas y aquellas otras más relacionadas con la noción de cofradía-gremio (...) [el parentesco] Era, más que nada, cuestión de valores, actitudes y voluntades de la gente. En el plano de los valores cobraba protagonismo una estructura de poder arraigada en la casa y la autoridad paterna. También en esta esfera intervenían el honor y la honra." Tomás Mantecón Movellán, "Sobre linajes y peleas de perros: parentelas y pendencias en la Castilla Moderna", en Chacón Giménez, Francisco, Hernández Franco, Juan y García González, Francisco (eds.). Familia y organización social en Europa y América, siglos XV-XX. Murcia, Ediciones de la Universidad de Murcia, 2007, pp 151-183, p 159.

${ }^{119}$ Esta composición fue explicada en sus particularidades por Cavillac. Michel Cavillac, Pícaros y mercaderes... op cit, passim.
} 
dinámica social. El marginal que se desprende de ella se forma a través de las actividades en las que se inscribe, pero también mediante el vagabundeo y sus nuevas relaciones. Así lo explica Guzmán, quien llegando a la corte se reúne con otras personas de su misma condición, estableciendo una relación de cooperación y aprendizaje. El relato describe el proceso de adquisición de la maestría a partir de la colaboración con quienes conocen el mundo del hampa de Madrid $^{120}$. A partir de este tipo de supuestos la narrativa propone la existencia de una red compacta de marginales. Sin embargo, la forma descripta por los autores de relacionarse entre ellos no avala esta posibilidad. Cuando Trapaza realiza una treta junto a Pernia, actuando de manera cooperativa, el vínculo se disuelve rápidamente debido a que el muchacho considera a nuestro pícaro poco conveniente, como consecuencia de su adicción al juego ${ }^{121}$. Además de la imposibilidad de tener lazos estables, el episodio informa que los pícaros están en el nivel de la subsistencia, pese a bonanzas ocasionales.

\section{La construcción del vagabundo}

Tal como hemos observado a lo largo de esta tesis, hay visiones que reprueban más o menos a los marginales. La normativa los condena sin remisión y tiene la intención de obligarlos a trabajar. La teología aborda el fenómeno con mayor complejidad: hay verdaderos y falsos pobres, los últimos son enemigos de Dios o al menos rebeldes a su mandato al no ajustarse al plan divino sobre el trabajo que ha determinado el pecado original. Pero algunos teólogos reconocen que todos cumplen el mandato superior de la conservación de la vida, por ello, el problema es el de identificar a los verdaderos y obligar a los falsos a ocuparse. Por último, la narrativa fluctúa desde

\footnotetext{
${ }^{120}$ Guzmán narra su iniciación, en la cual se describe la imitación y el aprendizaje de diversas prácticas de rapiña: "Juntéme con otros torzuelos de mi tamaño, diestros en la presa. Hacía como ellos lo que podía; mas como no sabía los acontecimientos, ayudábales a trabajar, seguía sus pasos, andaba sus estaciones, con que allegaba mis blanquillas. Fuime así dando bordos y sondando la tierra. Acomodéme a la sopa, que la tenía cierta; pero había de andar muy concertado relojero, que faltando a la hora prescribía, quedándome a escuras. Aprendí a ser buen huésped, esperar y no ser esperado". Mateo Alemán, op cit, Primera Parte, pp 275-276.

121“Pero duróles muy poco, porque una noche en la posada, habiendo juego, quiso Trapaza probar la mano y de manera se picó que perdió todo el dinero que traía, hasta la espada, hallándose tan apurado que ese otro día hubo de venderla para comer él y Pernia.

Sintió tiernamente el compañero que hubiese Trapaza dado tan mala cuenta del caudal ganado por su persona, y así se lo dio a entender; de lo cual Trapaza, le dijo algunas razones pesadas de que se ofendió Pernia; y así, se vinieron a desvenir aquel día, de modo que cada uno buscó su vida, apartándose uno del otro.” Alonso de Castillo Solórzano, Aventuras del Bachiller... op cit, pp 178 y 179.
} 
una cierta piedad, como en El Lazarillo, hasta posiciones cuya condena es más acabada, como la de Quevedo o Salas Barbadillo. Encontramos diversos matices en la representación del marginal como producto de una sociedad sobre la cual todos los autores tienen una visión crítica. Sin embargo, aunque el pícaro no sea el único corrupto, se trata de un individuo que no tiene frenos morales interiorizados. Si bien dichas representaciones destacan sus aspectos antisociales, se retratan también actitudes hacia ellos por parte del resto de la sociedad que podrían demostrar que no eran rechazados de manera unánime.

Creemos que la imagen que censura a los vagabundos no se modeló positivamente - por la observación de sus propias acciones- sino negativamente, a partir del contraste de las conductas consideradas socialmente correctas, esto es, en términos de lo que no eran ${ }^{122}$. El examen de su universo podría implicar el reflejo de lo que se esperaba que fuera la estructura social ${ }^{123}$.

Tal como hemos adelantado, se suponía que los vagabundos se congregaban en una comunidad paralela y oculta que se imaginaba antagónica a las normas sociales y donde se enseñaban las prácticas delictivas, lo cual conduciría a la propagación de este mal social, a partir de su oculta $-\mathrm{y}$, por lo tanto, incontrolable- socialización. Sin embargo, en contradicción con esta idea, vimos también a los amos enseñando trampas a sus propios criados y dependientes.

La noción de una subcultura contrapuesta a la sociedad dominante en cuyo seno se desarrolla es imaginada por los literatos como perfectamente antagónica a lo que la sociedad debía ser, pues no se presenta como el caos, sino que se le imputa tener el mismo orden que la comunidad que la enmarca (aunque la representación asume que ésta contiene algunos personajes que son tan tramposos como los marginales) pero con fines y jerarquías opuestos. Esta cultura es pensada como un espejo, se trata de una construcción mental que muestra el reflejo negativo de lo que se quiere que sea la

\footnotetext{
${ }^{122} \mathrm{~S}$. Clark sostiene que los hombres construyen verdades a través de su expresión en un sistema de lenguaje, cuyos signos describen una determinada realidad, tal como es pensada por el sistema de hablantes, que la creen correcta. Stuart Clark, op cit, p 9. El autor refiere particularmente al caso de las brujas. Consideramos que algunas de sus afirmaciones son válidas para el análisis de otros tipos de marginalidad como la de los vagabundos, que aquí abordamos. Si bien las situaciones no son idénticas, sí son similares en algunos aspectos. El autor revisa la historiografía al respecto y encuentra dos modelos interpretativos: mientras los realistas asumen que las verdades se encuentran en el mundo y luego son observadas y representadas por el lenguaje, los anti-realistas sostienen que la realidad esta conformada por el uso del lenguaje. Así, la brujería no se construye de manera positiva, sino negativamente, por contraste en relación a los significados de otras acciones. Presentada como una realidad inmutable y natural, el demonismo se volvió tan dependiente de estrategias lingüísticas particulares que pasó a ser visto como un producto de su propio lenguaje. Ibídem, pp 7 y 9.

${ }^{123}$ Ibídem, p 181.
} 
sociedad, de manera que esta representación imputa todo lo malo a ese opuesto, que funciona por un lado como chivo expiatorio y por otro como un espacio donde las personas integradas socialmente no deberían mezclarse pero lo hacen, instigándolas de esta manera a diferenciarse tanto como fuera posible.

En El Guzmán encontramos un buen ejemplo de la estructura del mundo invertida en la idea de la existencia de ordenanzas que regirían a los mendigos en Roma. Cuando Guzmán llega a la ciudad, desconociendo la existencia del grupo y sus reglas, mendiga sin considerar el arte del oficio, ni cómo los errores en su práctica pueden perjudicar a los demás limosneros, evaluando su necesidad individual pero no los principios de la corporación, que interviene uniéndolo al grupo y adoctrinándolo ${ }^{124}$. Quien se propone disciplinarlo procede en primer lugar a un interrogatorio acerca de su vida, "como si fuera protopobre", comparación que indica el reconocimiento inmediato de los escalafones identificables del mundo oficial ${ }^{125}$.

Las prácticas aceptadas entre los mendigos no sólo circulan de manera oral, sino que también están plasmadas en las "Ordenanzas mendicativas", que guardan de manera impecable el lenguaje jurídico en que suelen redactarse, para darles mayor verosimilitud $^{126}$. Comienzan distinguiendo las formas de pedir en las diversas regiones europeas, a las cuales los mendigos se deberían adaptar en cada caso, diferenciando variados estereotipos de limosneros. A partir de esto, también se delimita el grupo, separándolo de (y prohibiendo el trato con) otros agentes que tienen prácticas ilícitas. Esta apreciación entra en contradicción con la propia descripción de la novela acerca de esta clase de marginales, pues también se indica que un mismo sujeto hace uso de variadas estrategias rapaces (como el robo, la estafa o la mendicidad) no sólo a lo largo de su vida, sino simultáneamente ${ }^{127}$. Una vez trazadas las distintas fronteras del grupo comienzan las diversas reglas, que delimitan en primer lugar la posición y lugares que pueden (y deben) tener los ancianos de la profesión, a quienes se otorga una escala de

\footnotetext{
124 “-Este rapaz español que agora pide en Roma, nuevo es en ella, sabe poquito y nos destruye, por lo que he visto, que habiendo una vez comido, en las más partes que llega, si le dan vianda no la recibe. Destrúyenos el arte, dando muestras que los pobres andamos muy sobrados; a nosotros hace mal y a sí proprio no sabe aprovecharse." Mateo Alemán, op cit, Primera Parte, p 387. Debemos tomar nota también de la ironía en la localización de este grupo en la ciudad santa del catolicismo.

125 "Lo primero que hizo, como si fuera protopobre, examinó mi vida, sabiendo de dónde era, cómo me llamaba, cuándo y a qué había venido. Díjome las obligaciones que los pobres tienen a guardarse el decoro, darse avisos, ayudarse, aunarse como hermanos de mesta, advirtiéndome de secretos curiosos y primores que no sabía...". Ibídem, Primera Parte, p 388.

${ }^{126}$ Ibídem, Primera Parte, pp 388-393.

${ }^{127}$ En el capítulo II de la Primera Parte de la obra, cuando Guzmán deja al ventero, viaja a Madrid y pasa su primer tiempo allí, se relatan la mendicidad, la venta de su vestimenta, el robo, la asistencia las sopas públicas y el juego. Ibídem, Primera Parte, pp 274-279.
} 
status más elevado en el marco del grupo, concluyendo de esta manera la noción de pertenencia y legitimidad. Esta descripción da cuenta de la cosmovisión del autor, que sólo puede pensar a la sociedad (la que lo enmarca o su reflejo exactamente opuesto) en términos tradicionales.

La reglamentación del atuendo ocupa una atención preponderante respecto a otros aspectos (seis ítems dedicados a la indumentaria, herramientas y armas), confirmando que éste era la base de la caracterización que se hacía acerca de los mendigos. Esto implica, por un lado, la evaluación de la imagen del mendigo como una de las herramientas de su arte (para obtener más éxito al limosnear), pero por otro, la imposibilidad real (que aquí se omite) de que efectivamente pudiera acceder a otro tipo de vestuario.

Las ordenanzas atienden también a la distribución de la ciudad por áreas, para evitar la competencia entre los mendigos de acuerdo con los principios de cualquier gremio. Los enfermos o lisiados pueden andar juntos, pero deben partir lo que reciben, indicando, por un lado, la profesión diferenciada de estos pordioseros, pero por otro se está asumiendo la existencia de personas efectivamente incapaces de trabajar, que en la picaresca suele ser descontada, pues representa a la enorme mayoría de los mendigos como falsos pobres.

Otro ítem se detiene en que los mendigos no pueden revelar los misterios del grupo, como los integrantes de los gremios tienen prohibida la difusión de los secretos técnicos de su oficio. La obligación de comunicar entre ellos las nuevas tretas ideadas, así como de socializar el conocimiento de diversos espacios donde se entregan limosnas, se corresponde con la tradición de los antiguos oficios, que implicaba la protección del saber y la técnica y la solidaridad entre sus conocedores. Tal como sostiene G. Balandier, esto sirve para transmitir el arte y sus instrumentos y, al asociarles sistemas simbólicos, mitos, misterios y ritos, conduce a que los artesanos (y en nuestro caso los mendigos) conformen una comunidad particular en el seno de la sociedad que los enmarca. Como sintetiza el sociólogo francés, la tradición consiste en la acumulación de dichos saberes, acontecimientos y principios fundadores de la colectividad y expresa una visión del mundo y una forma específica de presencia en él ${ }^{128}$.

\footnotetext{
${ }^{128}$ Esto va de la mano del esoterismo, que requiere un pequeño número de poseedores de claves. Pero este conocimiento también puede ser visto como una herejía, que representa una amenaza más poderosa cuanto más secreta para el orden oficial, perspectiva desde la cual es una imagen invertida para ser
} 
Las ordenanzas vuelven sobre la idea de la utilización de los niños para generar compasión, estableciendo las edades y las formas de llevarlos, pero también que se los emplee o sean propios, pues los hijos de los mendigos deben pedir por sus padres "enfermos", recayendo nuevamente en el estereotipo de los falsos pobres y su reproducción, pues serían educados para ser vagabundos. Se compele a los mendigos a que eviten que sus hijos aprendan oficios, pues "...ganando poco, trabajan mucho y

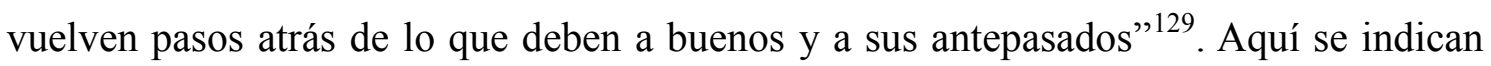
los míseros salarios de los trabajadores, pero también la presuposición de que la mendicidad sería una elección que podía resultar muy redituable. La necesidad de conformación del grupo y sus redes, que debe consolidarse a través de varias generaciones, informa acerca de la experiencia del gremio que tenía Alemán al escribir estas pautas.

También se estipulan los horarios, pues se reglamenta "Que en el invierno a las siete ni el verano a las cinco de la mañana ninguno esté en la cama ni en su posada; sino que al sol salir o antes media hora vayan al trabajo y otra media en antes que anochezca se recoja y encierre en todo tiempo, salvo en los casos reservados que de Nós tienen licencia" ${ }^{130}$. Estos horarios son los mismos que los que debían cumplir los trabajadores. Esta similitud con los ordenamientos de labores da cuenta de que se está copiando aquellos que estipulaban los tiempos de trabajo. Por otro lado, en el plano de la realidad, es posible que muchos de los mismos personajes que componían las filas de la mendicidad fuesen quienes se empleaban como asalariados por temporadas, siempre que su salud lo permitiese. Las Ordenanzas mendicativas entienden al pordioseo como un trabajo libre, en tanto quienes lo realizan eligen hacerlo, manual y redituable. Por último, la noción de un "Nós" refuerza la idea del poder corporativo que se imputa a los limosneros.

También se establecen las comidas y sus horarios, lo cual está en relación con el arte del oficio en tanto que, si simulan hambre, no deben oler a comida, imputando a quienes demandan alimento que su necesidad es también fingida. Aquellos que no cumplieran con esta regla, serían "tenidos por inhábiles e incapaces"131 en el marco de la profesión. Según esta idea, era necesaria la maestría -tal como exigían los gremios-

transformada en una representación del caos. George Balandier, El desorden. La teoría del caos y las ciencias sociales. Barcelona, Gedisa, 2003, p 89 - 91.

${ }^{129}$ Mateo Alemán, op cit, Primera Parte, p 392. Aquí vemos además una parodia del discurso nobiliario del honor y de la honra.

${ }_{130}$ Ibídem, Primera Parte, pp 392 y 393.

${ }^{131}$ Ibidem, Primera Parte, p 393. 
para el ejercicio de la mendicidad, que deja de ser considerada una ocupación no especializada y eventual.

Por otro lado, los limosneros tienen prohibido robar "pena que será excluido de nuestra Hermandad y Cofradía y relajado al brazo seglar"132, diferenciando así a los mendigos de los ladrones, y amenazando con la expulsión de la comunidad. Esta práctica refracta la de los gremios que podían quitar la membresía a la comunidad, cuya pertenencia, en este caso, garantizaría la seguridad, pues de ser abandonado por parte del grupo, éste no garantizaría la protección respecto a la imposición de las penas públicas. Esta última indicación sugiere vínculos entre los sectores marginales y los agentes de la justicia. Finalmente, se establece el tiempo de formación, pues luego de tres años de ejercicio como aprendiz "habiéndolos cursado legal y dignamente en el

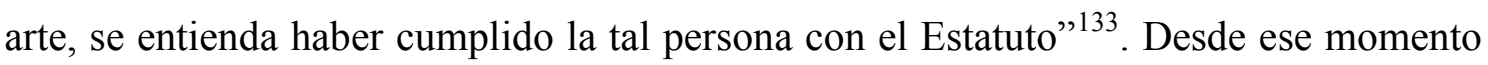
gozan de los derechos, pero también deben cumplir con las obligaciones del grupo, pues las ordenanzas establecen que esta persona "sea tenida por profesa, haya y goce las libertades y exempciones por Nós concedidas, con que de allí adelante no pueda dejar ni deje nuestro servicio y obediencia, guardando nuestras ordenanzas y so las penas dellas”" ${ }^{234}$. Esta última apreciación vuelve sobre la idea corporativa y los lazos sólidos y permanentes a los que se ven obligados los miembros de un grupo compacto de pertenencia.

Este mundo paralelo es construido a partir de datos de la realidad que luego se amplifican, deforman y convierten en estereotipos. Lo que sostenemos no es que los mendigos tullidos eran una invención del discurso, ni siquiera los que pudieran haberse causado dicho daño adrede, sino que a partir de casos puntuales, se amplificó tanto esta imagen, que, por ejemplo, en la novela de Quevedo no hay ni un limosnero que no sea un falso pobre.

La marginalización y la condena basadas en la suposición de un complot oculto con fines maliciosos tienen puntos de contacto con la persecución de las brujas durante la temprana modernidad, pues se trataba de personas que eran acusadas también de aparentar algo diferente de lo que realmente eran con el objetivo de hacer el mal, guiadas por el diablo. Asimismo podemos trazar un paralelo con las ideas sobre el

\footnotetext{
${ }^{132}$ Ibídem, Primera Parte, p 393. Relajar el brazo seglar era lo que hacia la inquisición con quienes hallaba judaizantes o herejes, por otro lado, esta misma expresión se encuentra en las ordenanzas de los gremios.

${ }_{133}$ Ibídem, Primera Parte, p 393.

${ }^{134}$ Ibidem, Primera Parte, p 393.
} 
complot de los judíos para envenenar aguas. En el primer caso, la maldad escapa a la voluntad del ejecutor, que es guiado por una fuerza superior (el demonio); en el segundo, el motivo de la marginación es religioso (una característica heredada genéticamente, relacionada con la sangre), pero a partir de eso se supone la conspiración, con el fin de culparlo del crimen y así despertar el miedo en el resto de la población ${ }^{135}$. Según Balandier, lo encubierto se revela indirectamente bajo el aspecto de un "trabajo oculto" movilizado por una intención destructora, cuyo agente "se sitúa en el espacio de lo nefasto, manipula el desorden, trastoca las convenciones sociales y las conductas", por lo que constituye al enemigo interno enmascarado (conformado por los irreductibles, ya lo sean por condición o por elección y convicción) ${ }^{136}$.

Los autores de las novelas que nos ocupan, a excepción del anónimo del Lazarillo, fundamentan la que suponen una justificada segregación de los marginales, pero a lo largo de las obras se trasluce que la supervivencia de estos hombres dependía de su "inserción" en la sociedad de manera individual y episódica y que la sociedad en la que lograban dicha inserción no guardaba el orden perfecto que se pretendía. Esta existencia que fluctúa entre la exclusión y la inclusión sólo puede ser explicada por la confianza transitoria o la complicidad que depositan en el pícaro los diversos amos y camaradas que según la literatura lo benefician, a quienes de una u otra manera aquél traiciona o por ellos es traicionado. Las novelas ilustran la suposición de que hay un lado oculto en la existencia de estos hombres, que están imbricados en la comunidad pero que, con su forma de vida, atentan contra el orden vigente. Estos postulados coinciden con la suposición de que los vagabundos no trabajaban porque no deseaban hacerlo ya que preferían esa vida ociosa.

El delincuente debe serlo de manera integral: haragán, ladrón, inmoral ${ }^{137}$. Aquí hay un problema de límites del concepto de pobre peligroso, pues lo que se teme es la subversión de las condiciones en tanto el pobre no acepta su estado como destino, pues el conflicto no son todos los pobres, sino los que cambian (o pretenden hacerlo) de condición. Esta idea se vincula con dos cuestiones, por un lado, el problema de la subversión en el status en tanto las personas no se sometieran a las obligaciones impuestas a su estrato, tal como hemos analizado en el primer capítulo; en segundo

\footnotetext{
${ }^{135}$ Carlo Ginzburg, Historia nocturna... op cit, pp 58 y ss.

${ }^{136}$ George Balandier, El desorden... op cit, $\mathrm{p} 91$.

${ }^{137}$ Cuando en los juicios hallamos los párrafos en que los procuradores de una parte tratan de desvalorizar a los testigos de la otra parte, se observa que, si bien no se los criminaliza porque no están acusados de nada, casi se lo hace para desautorizar su testimonio. Por otra parte, a los acusados se les atribuye vicios y delitos más allá de aquel del cual se los acusa.
} 
término, es un argumento en contra de los mendigos, que no ejercerían esta actividad como consecuencia de su pobreza (entendida como la incapacidad de sobrevivir mediante la actividad manual), sino porque buscarían "medrar" a través de ella. En consecuencia, se sospecha que la codicia o su ambición los conduce a la criminalidad, cuestión que tiene su aspecto más macabro cuando se supone que llegan al secuestro y deformación de niños con el objetivo de conseguir limosnas.

El principal motivo de temor hacia estos hombres radica en su capacidad para ocultarse y engañar a otras personas, gracias a la cual pueden ser victimarios de cualquiera que ignore la situación real. Así, la causa del rechazo respecto a estos sujetos no radica en lo que se sabe de ellos a través de la percepción directa, sino especialmente en lo oculto.

Balandier encuentra que el desorden y el caos no están solamente situados, sino también representados, pues de manera imaginaria y simbólica se asocia un conjunto de figuras que manifiesta su acción en el interior del espacio civilizado. Se trata de sujetos presentes en la sociedad -como nuestros mendigos- pero lo hacen en una situación de ambivalencia por lo que se dice de ellos y lo que designan: "son lo otro, complementario y subordinado, objeto de desconfianza y temor a causa de su diferencia

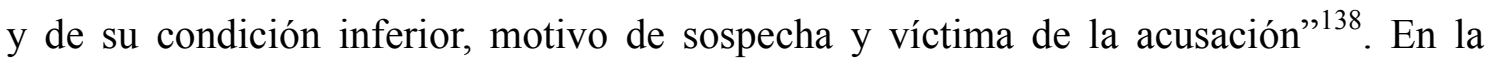
literatura que nos ocupa, se representa cómo el desorden puede generar también que alguien que no posee honor sea antepuesto a otro que sí lo tiene.

Por último, en el caso de los textos que analizamos, constatamos el vínculo que se establece con la disidencia religiosa. Esto se verifica de dos maneras: por un lado, las novelas ponen en juego mecanismos similares a los utilizados para la estigmatización de los réprobos o de la brujería; por otra parte, entre las acusaciones que recaen sobre estos personajes también se encuentra la hechicería o la dudosa genealogía cristiana ${ }^{139}$. Siguiendo a Balandier, y en coincidencia con la intención didáctica de la narrativa, el temor que inspira el ser sospechado de brujería mantiene una autocensura que reduce las tentaciones de cometer transgresiones y corrige las conductas en pos de evitar las desviaciones causantes de desorganización ${ }^{140}$.

\footnotetext{
${ }^{138}$ George Balandier, El desorden ... op cit, p 96.

${ }^{139}$ Thomas y Macfarlane explican la caza de brujas mediante la idea de que en un mundo rural en vías de mutación, la polarización en la aldea y el individualismo dan lugar a que cada vez haya más negativas a la ayuda en dinero y en especie a personas en apuros que, a partir de esta situación podrían querer vengarse; detrás de esto encontramos que los que negaban ayuda sentían culpa por su propia actitud, sentimiento que transformaban en resentimiento contra los demandantes de limosna. Jean Delumeau, op cit, p 579.

${ }^{140}$ George Balandier, El desorden... op cit, pp 107 y 108.
} 


\section{Conclusión}

En las páginas anteriores hemos visto problemas referentes a la situación del desclasado itinerante que tenía una vida nómade en las fronteras de la sociedad, movilidad inherente a su supervivencia, ya que de ese modo podía cambiar de ocupaciones velozmente, pero también evadir las reglas, completando el análisis realizado en los capítulos precedentes, donde observamos la representación literaria de dos de esas estrategias, así como el intento de la procuración de domiciliar a los hombres e insertarlos en el trabajo.

Los marginales que nos ocupan en esta tesis presentan la particularidad de llevar una vida itinerante en el plano geográfico. La circulación les garantizaba su posibilidad de sobrevivir en los poros de la sociedad, pues circularían en busca de distintas opciones y según la oferta de cada localidad. En el marco de la España Imperial, las ciudades portuarias serían lugares atractivos por varios motivos. En primer lugar, la circulación de riquezas facilitaba la subsistencia a través de diversos mecanismos como los trabajos no especializados o la limosna. Entre los primeros, el puerto ofrecía diversas oportunidades que iban desde la posibilidad de embarcarse hasta el comercio en pequeña escala. En torno a la segunda estrategia, la mayor circulación de personas y convivencia entre ricos y pobres favorecería la limosna callejera. Además, la gran ciudad resultaría un espacio propicio para los pícaros porque el conocimiento entre las personas (y la importancia de dicho intercambio) sería menor que en las pequeñas comunidades. Por estos motivos, Sevilla se convierte en una de las capitales de la picaresca, por donde circulan sus protagonistas como lugar de tránsito (para ir a Indias, como en El Buscón, o a Italia, en El Guzmán), pero también como un destino relativamente seguro para los pícaros, que podrían escabullirse de los controles con mayor facilidad.

La corte es el otro espacio de refugio que se repite en las novelas permanentemente porque también resulta atractivo debido a la concentración de hombres en ella. Por este motivo se intentó evitar la presencia de personas desocupadas y sin necesidad de realizar gestiones allí. Además, tanto las Cortes como la literatura señalan el problema que generaba la gran cantidad de criados que llevaban los caballeros y también el conflicto ideológico que tenía lugar en torno a la confusión de 
estados en un lugar donde resultaba dificultosa la certificación de la procedencia de los concurrentes.

En el plano de la representación, la picaresca es una narrativa de caminos, los marginales allí retratados se encuentran circulando permanentemente entre distintos pueblos y ciudades. En estos trayectos es donde tienen lugar muchos aspectos que son característicos en el género. En primer lugar, propicia la socialización, pues los pícaros conocen a otros personajes de su misma condición en el marco de la circulación entre diversos puntos, allí establecen vínculos, se enseñan habilidades, acuerdan actividades o consiguen información. El camino también es considerado peligroso porque allí transitan forasteros y la narrativa advierte diversos actos violentos que tienen lugar en estas rutas.

La frontera debía instalarse por el lenguaje, que no sólo definía al grupo por sus usuarios, sino que se convertía en un medio de comunicación entre ellos. Sin embargo, éste también era fluctuante y no del todo definido, en tanto compartía sus aristas con el dialecto popular. La jerga delimitaría la pertenencia de los marginales, además de permitirles una comunicación efectiva sin que pudiera ser entendida por las demás personas de la misma sociedad. Su habla constituiría también una fuente de temor entre quienes no la compartieran, pues su sola existencia sería demostrativa de la consolidación del sector.

El miedo hacia los marginales tenía su origen en el aumento de este grupo durante la Baja Edad Media, pero a partir de este dato objetivo se les atribuía las más diversas atrocidades, así como una forma de reproducción que los convertiría en una "plaga". El temor incrementaba las imputaciones que recaían sobre ellos, como la formación de organizaciones similares a las que regían a la sociedad. Esta noción indica que al otro se lo puede construir sólo a partir de las nociones conocidas, lo cual explica los reglamentos y escalafones entre marginales, en correspondencia con la sociedad corporativa que rodeaba a los autores y lectores. 


\section{CONCLUSIONES GENERALES}

Los pícaros que protagonizaron la narrativa española en la segunda mitad del siglo XVI y la primera del XVII no fueron personajes construidos como un mero reflejo de lo que se observaba en la sociedad que rodeaba a esta producción literaria. Ni resultaron totalmente de una invención de la narrativa, tal como los evaluó la corriente antirrealista en el marco de los estudios literarios. Tampoco los consideramos un retrato de los pobres o de los desviados, ni de un sector que haya surgido de manera anómala como producto de la circulación de la plata americana, de acuerdo con el planteo de varios historiadores y críticos.

Esta tesis nos ha permitido arribar a una idea diferente respecto de los pícaros y la relación que existe entre los marginales y su representación literaria. Esta pintura guarda ciertas particularidades que deben ser consideradas si se pretende hacer un examen aproximado de estos hombres y que se vinculan con el proceso de criminalización y persecución de los hombres sin amo durante la primera modernidad.

Hemos indagado acerca de la marginalidad para categorizar al pícaro literario, que constituiría una refracción y un estereotipo construido a partir de la observación del vagabundo, cuya proyección en la narrativa contribuía a su estigmatización. No se trata de un mero reflejo de la realidad ni de una invención literaria, sino que en una formación social cuyo funcionamiento daba lugar a la ampliación progresiva de la franja menos vinculada socialmente, tenía lugar la creación de los literatos, cuyas representaciones sociales condicionaban la forma de retratar dicho fenómeno.

A lo largo de nuestro estudio encontramos que esta narrativa fue utilizada de modo ilustrativo y a veces testimonial por muchos historiadores, sin examinar las múltiples lecturas que amerita. Nosotros hemos indagado acerca de la posibilidad de pensar al pícaro a partir de la noción de su marginalidad.

Para ello consideramos, junto a la lectura monográfica, los testimonios documentales acerca de los marginales. Su historia constituye una materia difícilmente aprehensible dado que las fuentes muestran refracciones de su existencia, casi siempre con el fin de encuadrarlos en el orden, perseguirlos o estigmatizarlos.

Encontramos un amplio abanico de propuestas para la definición del marginal. En principio consideramos la necesidad de distinguirlos de las minorías, los pobres que formaban parte, como tales, de la comunidad local y los excluidos absolutos. Adherimos 
a la idea de que se trata del sector que tiene como común denominador el nomadismo que resulta de la pobreza y es aducido como elemento determinante para su persecución. $\mathrm{Su}$ vagabundeo implica la desvinculación desde varios aspectos (como la falta de residencia, de familia o de lazos estables), lo cual conduce a su evaluación como asociales y, finalmente, a su condena moral.

La historia de los marginales es confundida con la de la pobreza, la de su persecución o la de los cómputos de las instituciones de beneficencia, por eso es necesario pensar acerca de la brecha que existe entre ambas instancias. Como estos integrantes de un grupo hostigado no dejaron sus propios registros, debimos tratar de detectarlos a través de la literatura y la procuración en las Cortes, que tenía la intención de operar sobre la dinámica social. Aquí hemos considerado las coincidencias y las contradicciones, así como la insistencia o la permanencia en el tiempo de algunos tópicos. A partir de este análisis, podemos tener una idea sobre cuáles son los estereotipos, qué aspectos pueden corresponder a testimonios más cercanos a la realidad y cuáles a la proyección de temores -y construcciones intelectuales a partir de ellos- que se tenían respecto a este fragmento social.

La procuración imputa al hombre baldío las condiciones de ocioso y ladrón y, por lo tanto, el carácter electivo de su situación. La escolástica agrega el juicio moral acerca de él y retrata determinadas conductas reprobables en el ámbito público. Sin embargo, hay autores que, aunque no niegan dichas características, entienden los motivos de su pobreza y la desigualdad en el juicio respecto a él, justificando sus prácticas como una forma de supervivencia. Pero la literatura realiza una caracterización minuciosa de este personaje en la cual el autor puede ser más o menos piadoso. Los recursos de la narrativa habilitan extensas descripciones en las pseudoautobiografías de estos marginales, cargadas de episodios donde el pícaro lleva a cabo actividades condenables y acciones que dañan a las personas integradas en el cuerpo social, además de la desviación, la ociosidad y el envilecimiento como consecuencia de sus decisiones. Si bien existían personas con algunas de las características y conductas que contiene la figura literaria, a medida que se fue desarrollando esta narrativa determinados elementos fueron seleccionados (se recortaron algunos datos acerca de ellos), amplificados, generalizados y difundidos con el objetivo de estigmatizar a los hombres sin amo, errantes, quienes incurrían eventualmente en la delincuencia, los trabajos no especializados y la mendicidad.

La intención de los escritores es señalar de manera humillante las prácticas de 
los marginales y el carácter delictivo de estos hombres y mujeres, opinión que esperaban que fuese compartida por su público. Sin embargo, variadas apreciaciones indican que todos estos actores se vinculaban en una realidad mucho más dinámica de lo que los contemporáneos asumían en sus representaciones mentales. Las novelas testimonian la permanente interacción entre los pícaros y el resto de la sociedad, desde sectores populares rurales y urbanos hasta la burguesía y la baja nobleza. Se trata de relaciones fluidas y constantes entre las personas integradas en la sociedad y otras más desvinculadas que, según la posición de los autores, deberían ser segregadas y temidas. Además de la explicación económica de la necesidad de contar con una franja marginal, la literatura ilustra el impacto cultural de su existencia, así como la interacción individual entre los marginales y el resto de la sociedad.

Quienes se encontraban integrados socialmente necesitaban a quienes no lo estaban de una u otra manera, ya fuera en el ámbito doméstico, con la realización de numerosas tareas no especializadas o incluso para la satisfacción de diversas demandas o resolución de conflictos que, debido a que el propio status limitaba ciertas conductas, los requerían. La narrativa permite la extensa descripción de una relación que también se constata en la documentación política, pues en las Cortes se promueve instigar o tentar a diversos sectores a perseguirlos o emplearlos y anular la posibilidad de otras formas de supervivencia desvinculada.

Estas posibilidades tenían lugar gracias a los lazos más o menos efímeros que los marginales podían tender en el marco de la comunidad, de la cual no estaban separados físicamente. Dicha relación permitía la supervivencia individual de cada uno de ellos pero también del sector que conformaban, que se reproducía gracias a los contactos con los otros estratos. Se les permitía subsistir por cuanto se los necesitaba desde tres puntos de vista: como mano de obra de reserva para el trabajo temporal, como depositarios de la caridad y como chivo expiatorio.

La sociedad era proclive a la caridad necesaria para que estos sujetos sobrevivieran magramente, sin salir de su situación precaria. La embestida contra la mendicidad, bajo diversas excusas y a través de distintos medios, era consecuencia de la necesidad de que los desposeídos se vieran obligados a trabajar en las condiciones que se les impusieran, explicando la emisión de los discursos que hemos observado aquí, dado que ya no estaban dominados permanentemente por un amo, que se encargaría de su control y sometimiento al trabajo. Pero también la tendencia a la disgregación de ciertos grupos corporativos, como los gremios, o las aldeas y la acumulación de 
desocupados en las ciudades, cuya situación no podía ser solucionada por los poderes y tampoco por iniciativa individual, conducían al desprestigio de la filantropía.

En la temprana modernidad se intentó combatir la limosna, aduciendo que quienes la demandaban en los espacios públicos eran hombres capaces de trabajar pero que elegían esta forma de vida, considerada pecaminosa porque se vinculaba con la ociosidad. Mientras el poder político buscaba impedir la caridad no institucional, la literatura denunciaba el fraude en esta práctica. Si se distinguía entre los pobres "verdaderos" (impedidos de trabajar por condiciones objetivas) y los "falsos", la narrativa se ocupa especialmente de los últimos y hace de ellos las más detalladas imágenes. Además, el relato en primera persona le permitía imputar a los limosneros cuestiones que serían invisibles al resto de la población, convirtiéndolos en estafadores.

La percepción que se tenía acerca del pobre había cambiado desde la Baja Edad Media, explicando la emergencia de la picaresca algunos siglos más tarde. Los pasajes que describen las conductas condenadas de los personajes bajos representados en esta narrativa suelen estar acompañados por una reflexión moralizante o educativa, señalando la intención del escritor y la funcionalidad de la obra. En estas intervenciones se inmiscuye la voz del autor, quien confirma el vínculo con el lector, a quien se supone también distanciado socialmente de los personajes retratados.

Consideramos que esta literatura no sólo hace una crítica social, sino que promueve la persecución de los hombres sin amo y la extinción de algunas de sus bases de subsistencia, no sólo para que se sometieran al poder de otra persona (pues también ilustra la deficiencia al intentar encuadrarlos en las clientelas), sino además al trabajo asalariado -pues se trata de una diatriba contra la ociosidad-, aunque ambas esferas se confundieran.

Entre las posibles ocupaciones de los marginales, podían servir para alimentar las clientelas, colocándose en diversos quehaceres domésticos cuya función era la de acrecentar el status y capital social de quien detentaba el patronazgo de la caterva. Esta situación muestra la dualidad del marginal, quien se inserta temporalmente en las estructuras que lo marginan y las reproduce a cambio de una supervivencia temporal que lo deja, luego de su paso, en el mismo punto de origen en el que se encontraba antes de su ingreso.

La necesidad de conducir a estos hombres al trabajo y la diatriba contra la "ociosidad" de los sectores pauperizados no indica necesariamente que se trate de una literatura burguesa, porque sus puntos de vista eran compartidos por las oligarquías de 
los concejos, la aristocracia y la monarquía, pues la actividad de aquéllos también sería en beneficio de estos sectores sociales, que los emplearían o extraerían renta a partir de su trabajo de manera indirecta. La actividad de los desclasados a cambio de un salario era rentable para todos los sectores propietarios y comerciantes. Entre los marginales que estudiamos aquí, su falta de especialización, medios y disciplina para otras ocupaciones, así como la persecución de las prácticas de rapiña, los obligarían a esta forma de trabajo, gracias a un mecanismo político que buscaba garantizar la disponibilidad de mano de obra barata para los eventuales empleadores (miembros de los mismos sectores dominantes involucrados en la procuración). La determinación de la ocupación obligatoria y la posibilidad de que un vecino tomara a cualquier hombre baldío tenían la intención de garantizar su empleo mientras los mecanismos de mercado no podían hacerlo.

La picaresca se detiene en la dificultad de los marginales que retrata para ocuparse. La principal crítica en este sentido se dirige a la indolencia con que se relacionaban con el trabajo. Si bien las novelas acusan su ociosidad, el problema descripto en ellas radica especialmente en la dificultad para someterlos al trabajo y las normas que lo regulaban, dado que la trama comunitaria garantizaba la disciplina laboral de quienes estaban inscriptos en ella, pero la subordinación de quienes no pertenecían a dicha red era más difícil. Las novelas ilustran que en los períodos en que los pícaros son empleados, los amos responden por los criados frente a la vecindad, pero luego los disciplinan ellos mismos, haciéndolos castigar (posibilidad ante la cual huyen) o despidiéndolos. Por eso vuelven, luego de estos más o menos efímeros ciclos de integración relativa, al vagabundeo.

Por otro lado, las novelas informan acerca del temor a la adaptabilidad del marginal y su capacidad de movimiento permanente, debido a que, objetivamente, dificultaba su persecución, pero también los convertía en anómalos en una sociedad que pretendía que sus miembros (enmarcados en diversos cuerpos) estuvieran fijos en el plano social y en el geográfico. Su movilidad los convertía en peligrosos porque las estructuras disciplinantes no estaban preparadas para responder al fenómeno que su presencia significaba. La posibilidad de entrar y salir de las redes comunitarias indica también que dichos entramados permitían que esto sucediera. Por un lado se arengaba la expulsión de los pobres forasteros de las aldeas, pero por otro su empleo en ocupaciones que, finalizaban por diversos motivos, lo cual conducía a que recomenzaran nuevamente en otro lugar. Si en las pequeñas comunidades eran los vecinos quienes vigilaban el 
cumplimiento de este tipo de normas, el control era más difícil en las urbes, haciendo de ellas un destino posible y más fácil para estos hombres. La falta de lazos y obligaciones avalan que la novela ilustre a un pícaro que está permanentemente eligiendo su porvenir. Sin embargo, consideramos que dicha libertad de decisión que pretenden mostrar los autores no es tal, pues viven huyendo de la ley o del hambre.

Los escritores pudieron tener vínculos con estos marginales, por eso conocerían algunos de los aspectos que describieron. Sin embargo, la picaresca representa también un mundo oculto donde se sospecha la existencia de grupos organizados, permanentes y compactos de desheredados. Consideramos que las narraciones que a ellos se refieren fueron construidas sobre la base de la imaginación colectiva y ellos mismos, convertidos en estereotipos que fueron reproducidos.

Los marginales tendrían un contacto esporádico y epidérmico con otros miembros de la sociedad, que conocerían su parte "visible", pero los literatos les imputan una contracultura compacta y organizada que, suponen, permanecería oculta para el resto de la comunidad.

Dicha imagen no era una invención total, sino que se basaba en datos de la realidad, como la existencia objetiva de los marginales, sus prácticas delictivas o condenadas, sus vínculos y la apariencia andrajosa, que se suponía fingida, de quienes se dedicaban a la mendicidad, pero a partir de ello se desplegó una conjetura que magnificaba algunos datos, los generalizaba y a partir de allí imputaba nuevos atributos $\mathrm{y}$ acciones a todos los vagabundos. Si bien las novelas por un lado ilustran lo variopinto del mundo marginal, por otro homologan a todos sus miembros, invisibilizándolos pero también naturalizándolos dentro del espectro social, lo cual hace presumir que su presencia no era ni tan extraordinaria ni tan peligrosa.

De esta manera, parte de los desheredados (aquellos que se convirtieron en vagabundos) fueron doblemente marginados, incrementando su persecución, que involucraría a diversas esferas del tejido social para efectivizar el control. La picaresca individualiza y describe minuciosamente a estos personajes, mediante retratos heterogéneos que van de la pobre vergonzante a la vieja alcahueta o al criado fugado, e indica el carácter delictivo de todos ellos. Por esto sostenemos que esta narrativa no se detiene en invenciones absolutas ni en un reflejo de la realidad, sino que se trata de una construcción mucho más compleja que se sitúa entre la objetividad y la imagen mediada por las intenciones políticas de los autores, su procedencia, sus eventuales financistas y el público. 
Si bien el clásico libro de Maravall presenta un examen exhaustivo de la relación de esta narrativa con su contexto social, nos resultó acuciante reconsiderarla a la luz de la noción de marginalidad. Maravall examina la desviación de los protagonistas, también su pobreza y diversas características que los colocan en la situación de segregados sociales. Sin embargo, quedaba abierta la pregunta acerca de la relación entre esta literatura, la persecución de los hombres baldíos que aparece en las normas que tienen su origen en Cortes y la necesidad de domesticación de la fuerza de trabajo. Al considerar al pícaro a partir de la marginalidad inherente a la dinámica social y funcional al desarrollo de relaciones capitalistas en su seno, podemos entender el tipo social representado y la relación con el fenómeno de su persecución, de acuerdo con la necesidad de subordinarlo al trabajo asalariado.

Las representaciones contienen contradicciones dado que los autores persiguen sus propios intereses y perspectivas y eligen un recorte particular de la realidad para pintar un determinado retrato. La construcción del marginal demanda diversas características que se relacionan con la apreciación que tenían el autor y la comunidad respecto a él. La primera es una imagen relacionada con la percepción sensorial: el vagabundo era harapiento, maloliente, eventualmente tullido. A esto se sumaban datos que provenían de historias particulares en las que se daba cuenta del vínculo que ellos podían establecer con otras personas: la forma de pedir limosna, de contratarlos, de encontrarlos eventualmente en un mesón. La segunda noción era una construcción que derivaba del temor a la potencialidad sediciosa de los marginales, idea edificada a partir de su concepción como otros internos al cuerpo social de manera epidérmica y su consideración como enemigos en el seno de la comunidad.

A partir de estas percepciones eran pensados los vínculos entre los marginales, opacos al resto de la sociedad, cuyas descripciones literarias guardan características muy similares a otras relaciones sociales conocidas por los escritores y su forma de organización, aunque están en contradicción con las otras particularidades que se imputan a estos hombres, como sus vínculos laxos, su falta de compromiso o su insubordinación a las estructuras y jerarquías. Creemos que esta contradicción se debe a que la única forma en que los sectores dominantes podrían imaginar una comunidad era por similitud u oposición a la propia, pero no distinta.

Además de la vigilancia por parte de diversos agentes sociales, estaba el castigo. La picaresca presenta situaciones en las que el protagonista llega a ser penado por la justicia local o se describe la flagelación de los mendigos forasteros. Pero encontramos 
de manera más frecuente la representación de su necesidad de escapar porque se les atribuyen robos y estafas o se descubren tretas que van desde hacerse pasar por más hasta simular su invalidez, por lo cual hubieran sido penados o la comunidad, con su justicia informal, los castigaría. A ello hay que agregar los casos en que las represalias están en manos de los propios amos o aquellos otros en que prefieren despedirlos a escarmentarlos o entregarlos a la justicia.

Por último, la represión de los baldíos está presente en todas las novelas, pues el derrotero de sus personajes, su modo de mendigar, su flexibilidad para ocuparse en las más diversas actividades, su jerga y la manera de vincularse con otros marginales están signados por la necesidad de prevenir ser ajusticiados, en consonancia con las diversas formas de evasión de la pena. Entonces, por un lado, el control era ineficiente por cuanto permitía este tipo de existencias, pero por el otro determinaba su forma de vida. Geremek sostiene que a partir de un paso en falso, una persona en una relativa situación de integración podía ser segregada como consecuencia de su proscripción (fenómeno que constatamos en la representación literaria), pero agregamos que, una vez en dicha situación, la persecución conducía a que se persistiera en esta forma de vida y se acentuaran sus rasgos asociales, pues sería la única forma de evadir las penas que podrían llegar hasta marcar el cuerpo de quien sería etiquetado como delincuente y por lo tanto perdería las posibilidades de entrar, al menos temporalmente, en las redes comunitarias.

En los análisis que hemos realizado en esta tesis, la lectura de fuentes de diverso origen contribuyó a esclarecer problemas en torno a la conceptualización de los marginales, la forma en que estos actores se imbricaban en la sociedad española tempranomoderna, las representaciones que de ellos se hicieron y la brecha que existiría entre sus retratos y la dinámica social objetiva. Aunque hemos saldado los interrogantes que movilizaron esta investigación, en este recorrido también hemos encontrado otros que merecen ser examinados y que, esperamos, den lugar a nuevas propuestas y discusiones. Creemos que es necesario iluminar la historia de los marginales, cuya opacidad reproduce, en el discurso de las ciencias sociales, la suerte que han tenido a lo largo de su existencia. 


\section{BIBLIOGRAFÍA}

AAVV. Marginados y minorías sociales en la España Moderna. Y otros estudios sobre Extremadura. VI Jornadas de Historia en Llerena. Llerena, Sociedad Extremeña de Historia, 2005.

AAVV. Edad de Oro. N ${ }^{\circ}$ 20, Madrid, Ediciones de la Universidad Autónoma de Madrid, 2001.

Abrams, Fred. “¿Fue Lope de Rueda autor del Lazarillo de Tormes?”, en Hispania. Vol. 47, №2, Madrid, Consejo Superior de Investigaciones Científicas, 1964, pp 258-267.

Acebo Ibáñez, Enrique del y Brie, Roberto. Diccionario de sociología. Buenos Aires, Claridad, 2001.

Aguiar e Silva, Víctor. Teoría de la literatura. Madrid, Gredos, 1982.

Altenberg, Tilman. "Francisco de Quevedo, Historia de la vida del Buscón”, en Meyer-Minnemann, Klaus y Schlickers, Sabine (eds.). La novela picaresca. Concepto genérico y evolución del género (siglos XVI y XVII). Madrid, Iberoamericana Verbuert, 2008, pp 353-390.

Alvar, Alfredo. "La pobreza y sus remedios: teoría y práctica (siglos XVI al XVIII)", en Torre de los Lujanes. N ${ }^{0}$ 51, Madrid, Real Sociedad Económica Matritense de Amigos del País, 2003, pp 11-13.

Álvarez Santaló, León Carlos. "La construcción social de mundos mentales: un bricolage psicológico", en Carlos Barros (ed.). Historia a Debate. Tomo II: Retorno del sujeto. Santiago de Compostela, Historia a Debate, 1995, pp 9-23.

- "Hagiografía y marginación: Una propuesta de prudencias de uso", en Carrillo, Santiago (et al.). Disidentes, heterodoxos y marginados en la Historia. Salamanca, Ediciones Universidad de Salamanca, 1998, pp 119-144.

Amelang, James S.. El vuelo de Ícaro. La autobiografía popular en la Europa moderna. Madrid, Siglo XXI, 2003.

Ariés, Philippe. El niño y la vida familiar en el Antiguo Régimen. Madrid, Taurus, 1987, Capítulo 2 "El descubrimiento de la infancia".

Arranz Lago, David Felipe. "La afirmación identitaria de Quevedo y el discurso social del siglo XVII”, en Dicenda. Cuadernos de Filología Hispánica. Vol. 27, Madrid, Publicaciones Universidad Complutense de Madrid, 2009, pp 5-18. 
Asensio, Manuel. "La intención religiosa del Lazarillo de Tormes y Juan de Valdés", en Hispanic Review. Joseph E. Guillet Memorial Volume, Part I, Vol. 27, №1, Filadelfia, University of Pennsylvania Press, 1959, pp 78-102.

Astarita, Carlos. Desarrollo desigual en los orígenes del capitalismo. El intercambio asimétrico en la primera Transición del feudalismo al capitalismo. Mercado feudal y mercado protocapitalista. Castilla, siglos XIII a XVI. Buenos Aires, Tesis 11 Grupo Editor, 1992.

-“Dinámica del sistema feudal, marginalidad y transición al capitalismo", en Carrillo, Santiago (et al.). Disidentes, heterodoxos y marginados en la Historia. Salamanca, Ediciones Universidad de Salamanca, 1998, pp 21-49.

-“Classe sociale, statut et pouvoir de la 'caballería villana' de Castille. Une révision”, en Le moyen age. Revue d'histoire et de philologie. № 2, Tomo CV, Bruselas, De Boeck, 1999, pp 415-437.

Auerbach, Erich. Mímesis. La representación de la realidad en la literatura occidental. México, Fondo de Cultura Económica, 1950.

Bachtin, Michail. La cultura popular en la Edad Media y el Renacimiento. El contexto de François Rabelais. Madrid, Alianza, 1989.

-Estética de la creación verbal. México, Siglo XXI, 1995.

Bahamondes Parrao, Miguel. "Contradicciones del concepto 'capital social'. La antropología de las alianzas y subjetividad campesina", en AAVV Encuentro de la Asociación de Estudios Latinoamericanos, Washington D. C., LASA, 2001, pp 1-23.

Balandier, George. El poder en escenas. Barcelona, Paidós, 1994.

- El desorden. La teoría del caos y las ciencias sociales. Barcelona, Gedisa, 2003.

Barthes, Roland. Lo obvio y lo obtuso. Imágenes, gestos, voces. Barcelona, Paidós, 1986.

Bataillon, Marcel. Novedad y fecundidad del Lazarillo de Tormes. Salamanca, Anaya, 1968.

Bazán Díaz, Iñaki. "La historia social de las mentalidades y la criminalización de las conductas", en Carlos Barros (ed.). Historia a debate. Tomo II: Retorno del sujeto. Santiago de Compostela, Historia a Debate, 1995, pp 85-101.

Becker, Howard. Outsiders. Etudes de sociologie de la deviance. París, A.-M. Métailié, 1985.

Bennassar, Bartolomé. Inquisición española: poder político y control social. 
Barcelona, Crítica, 1981.

-La España del Siglo de Oro. Barcelona, Crítica, 1983.

Bennholdt-Thomsen, Veronika. "Marginalidad en América Latina. Una crítica de la teoría", en Revista mexicana de sociología. Vol. 43, № 4, México, Universidad Nacional Autónoma de México, 1981, pp 1505-1545.

Benítez Claros, Rafael. Visión de la literatura española. Madrid, Rialp, 1963.

Betrán Moya, José Luis. "Pobreza y marginación en la Barcelona de los siglos XVI y XVII", en Historia Social. Nº 8, Valencia, Universidad Nacional de Educación a Distancia, 1990, pp 101-121.

Bianchi, Diana. La ilustración española y la pobreza. Montevideo, Facultad de Humanidades y Ciencias de la Educación, 2001.

Bodin, Louis. Los intelectuales. Buenos Aires, Eudeba, 1965.

Bogani, Esteban. "De marginales y desocupados", en Nueva Sociedad. № 197, Buenos Aires, Fundación Friedrich Ebert, 2005, pp 41-53.

Bjornson, Richard. "The Picaresque Novel in France, England, and Germany", en Comparative Literature. Vol. 29, N², Eugene, University of Oregon, 1977, pp 124147.

Bolufer Peruga, Mónica. "Entre historia social e historia cultural: la historiografía sobre pobreza y caridad en la época moderna", en Historia Social. № 43, Valencia, Universidad Nacional de Educación a Distancia, 2002, pp 105-127.

Bourdieu, Pierre. "Campo intelectual y proyecto creador", en AAVV. Problemas del estructuralismo. México, Siglo XXI, 1969.

- Critique social du jugement. París, Les editions du minuit, 1979.

- Las reglas del arte. Génesis y estructura del campo literario. Barcelona, Anagrama, 1995.

- ¿Qué significa hablar? Economía de los intercambios lingüísticos. Madrid, Akal, 1999.

- Las estructuras sociales de la economía. Buenos Aires, Manantial, 2002.

- Argelia 60. Estructuras económicas y estructuras temporales. Avellaneda, Siglo XXI, 2006.

- Campo de poder y reproducción social. Elementos para un análisis de la dinámica de las clases. Córdoba, Ferreyra Editor, 2006.

- El sentido práctico. Villa Ballester, Siglo XXI, 2007.

Braudel, Fernand. Civilización material, economía y capitalismo. Siglos XV- 
XVII. Tomo 2. Los juegos del intercambio. Madrid, Alianza Editorial, 1984.

Bravo Lozano, Jesús. "Mendicidad y cultura de la pauperización”, en Torre de los Lujanes. $N^{\mathrm{o}}$ 51, Madrid, Real Sociedad Económica Matritense de Amigos del País, 2003, pp 73-86.

Buchbinder, Pablo. Maestros y aprendices. Estudio de una relación social de producción (España, siglos XV-XVII). Buenos Aires, Biblos, 1991.

Burke, Peter. Hablar y callar: funciones sociales del lenguaje a través de la historia. Barcelona, Gedisa, 1996.

- Popular culture in early modern Europe. Aldershot, Ashgate, 2002.

Cabo Aseguinolaza, Fernando. El concepto de género y la literatura picaresca. Santiago de Compostela, Universidad de Santiago de Compostela, 1992.

Cabrera, Emilio. "Sobre la violencia en Andalucía durante el siglo XV", en La Península Ibérica en la era de los descubrimientos 1391-1492. Actas de III Jornadas Hispano-Portuguesas de Historia Medieval. Sevilla, 1997, pp 1063-1079.

Campuzano, Elizabeth. "Ciertos aspectos de la novela picaresca", en Hispania. Vol. 32, N², Madrid, Consejo Superior de Investigaciones Científicas, 1949, pp 190197.

Carasa Soto, Pedro. Historia de la beneficencia en Castilla y León. Valladolid, Secretariado de Publicaciones Universidad de Valladolid, 1991.

- "La historia y los pobres: de las bienaventuranzas a la marginación", en Historia Social. N ${ }^{0}$ 13, Valencia, Universidad Nacional de Educación a Distancia, 1992, pp 77-99.

Carbonell Esteller, Montserrat. "Las mujeres pobres en el setecientos", en Historia Social. N ${ }^{0}$ 8, Valencia, Universidad Nacional de Educación a Distancia, 1990, pp 123-134.

Carey, Douglas. "Lazarillo de Tormes and the Quest of Authority", en PMLA. Vol. 94, Nº1, Nueva York, Modern Language Association, 1979, pp 36-46.

Carilla, Emilio. Quevedo. Tucumán, Universidad Nacional de Tucumán. Instituto de Lengua y Literatura Española, 1949.

Carlé, María del Carmen. "La sociedad castellana en el siglo XV: los criados", en Cuadernos de Historia de España. N ${ }^{\circ}$ LXIX, Buenos Aires, Universidad de Buenos Aires, 1987, pp 109-121.

Carmona García, José Ignacio. El extenso mundo de la pobreza: la otra cara de la Sevilla imperial. Ayuntamiento de Sevilla, Servicio de Publicaciones, 1993. 
Carretero Zamora, Juan Manuel. Cortes, monarquía, ciudades: las Cortes de Castilla a comienzos de la época moderna. Madrid, Siglo XXI de España Editores, 1988.

Carrillo, Santiago. "Disidentes, heterodoxos y marginados de la Historia", en Carrillo, Santiago (et al.). Disidentes, heterodoxos y marginados en la Historia. Salamanca, Ediciones Universidad de Salamanca, 1998, pp 13-19.

Caselli, Elsa. "La España de fines del siglo XVI en la mirada de un abogado de la Inquisición: Martín González de Cellorigo", en Prohistoria. N ${ }^{\mathrm{o}}$ 6, Rosario, Prohistoria Ediciones, 2002, pp 49-78.

Castel, Robert. "La dinámica de los procesos de Marginalización”, en Topía. Año I, Nº II, Buenos Aires, Editorial Topía, 1991, pp 18-27.

- "Las trampas de la exclusión”, en CEIL (comp.). Pobres, pobreza y exclusión social. Buenos Aires, CEIL, 1995, pp 247-262.

Cavallo, Guglielmo y Chartier, Roger (eds.). Historia de la lectura en el mundo occidental. Madrid, Taurus, 1998.

Castro, Américo. Hacia Cervantes. Madrid, Taurus, 1957.

Cavillac, Michel. Pícaros y mercaderes en el Guzmán de Alfarache. Granada, Universidad de Granada, 1994.

- "Pícaros y pobreza en tiempos del Guzmán de Alfarache: Cristóbal Pérez de Herrera y Mateo Alemán (1594-1604)”, en Torre de los Lujanes. №51, Madrid, Real Sociedad Económica Matritense de Amigos del País, 2003, pp 15-30.

Chartier, Roger. Libros, lecturas y lectores en la Edad Moderna. Madrid, Alianza, 1993.

-"La construcción estética de la realidad. Vagabundos y pícaros en la edad moderna", en Tiempos modernos. Revista electrónica de historia moderna. Vol. 3, No 7 , 2002, pp 1-15.

Cid, Jesús-Antonio. "Gallegos, hidalgos y pícaros en la España del siglo XVII. Estebanillo González y Salvatierra de Miño”, en Cuadernos de Estudios Gallegos. Tomo XL (105), Galicia, Consejo Superior de Investigaciones Científicas, 1992, pp 259-287.

Clark, Stuart. Thinking with Demons: the idea of witchcraft in Early Modern Europe. Oxford, Oxford University Press, 1997.

Collantes de Terán Sánchez, Antonio. "Actitudes ante la marginación social: malhechores y rufianes en Sevilla", en Actas del III Coloquio de Historia Medieval 
Andaluza. La sociedad medieval andaluza: grupos no privilegiados. Jaén, 1984, pp 293302.

Córdoba de la Llave, Ricardo. "Marginación social y criminalización de las conductas", en Medievalismo. Año 14, № 13-14, Murcia, Ediciones de la Universidad de Murcia, 2004, pp 293-322.

Correa, Gustavo. "Naturaleza, Religión y Honra en La Celestina", en PMLA. Vol. 77, Nº1, Nueva York, Modern Language Association, 1962, pp 8- 17.

-"El héroe de la picaresca y su influencia en la novela moderna española e hispanoamericana", en Pérez Patiño, Rubén (ed.). Thesaurus. Boletín del instituto Caro y Cuervo. Muestra antológica 1945-1985. Santafé de Bogotá, Tomo II, pp 713-732.

Cortés, Fernando. "Consideraciones sobre la marginalidad. Marginalidad económica y exclusión social”, en Papeles de población. № 47, Toluca, Universidad Autónoma del Estado de México, 2006, pp 71-84.

Cros, Edmond. Literatura, ideología y sociedad. Madrid, Gredos, 1986.

- "La noción de la novela picaresca como género desde la perspectiva sociocrítica”, en Edad de Oro. N $\mathrm{N}^{\mathrm{o}}$ 20, Madrid, Ediciones de la Universidad Autónoma de Madrid, 2001, pp 85-94.

Da Graca, Laura. Poder político y dinámica feudal. Procesos de diferenciación social en distintas formas señoriales (siglos XIV y XVI). Valladolid, Universidad de Valladolid, 2009.

David, Nicholas. "Child and adolescent labour in the late medieval city: a flamish model in regional perspective", en The English Historical Review. Vol. 110, ${ }^{\circ}$ 439, Oxford, Oxford University press, 1995, pp 11031131.

De las Heras Santos, José Luis. "Los galeotes de los Austrias: la penalidad al servicio de la armada", en Historia Social. N6, Valencia, Universidad Nacional de Educación a Distancia, 1990, pp 127-140.

Deleito y Piñuela, J. La mala vida en la España de Felipe IV. Madrid, Alianza, 1994.

Delumeau, Jean. El miedo en Occidente. Madrid, Taurus, 1989.

Di Camillo, Ottavio. "Interpretations of the Renaissances in Spanish Historical Thought: The Last Thirty Years", en Renaissance Quarterly. Vol. 49, №2, Chicago, The University of Chicago Press, 1996, pp 360-383.

Díaz Rodríguez, Antonio. "Las casas del deán Don Juan de Córdoba: lujo y clientela en torno a un capitular del renacimiento", en Hispania Sacra. N ${ }^{\circ}$ LXI, Madrid, 
Consejo Superior de Investigaciones Científicas, 2009, pp 77-104.

Diez Rodríguez, Fernando. "Estructura social y sistema benéfico-asistencial en la ciudad preindustrial", en Historia Social. Nº13, Valencia, Universidad Nacional de Educación a Distancia, 1992, pp 101-122.

Dubert, Isidro. "Criados, estructura económica y social y mercado de trabajo en la Galicia rural a finales del antiguo Régimen”, en Historia Agraria. No 35, Murcia, Universidad de Murcia, 2005, pp 9-26.

Duby, Georges. Los tres órdenes o lo imaginario del feudalismo. Barcelona, Argot, 1983.

Durán Villa, Francisco y Santos Solla, Xavier Manuel (eds.). Semata. No 16, Marginados y Excluidos. Un enfoque interdisciplinar. Santiago de Compostela, Universidad de Santiago de Compostela, 2005.

Dyer, Christopher. Niveles de vida en la Baja Edad Media. Barcelona, Crítica, 1991.

Eagleton, Terry. Ideología. Una introducción. Buenos Aires, Paidós, 1997.

Ettinghausen, Henry. “Quevedo’s Converso Pícaro”, en MLN. Hispanic Issue. Vol. 102, N², Baltimore, Johns Hopkins University Press, 1987, pp 241-254.

Fortea Pérez, José Ignacio. Las Cortes de Castilla y León bajo los Austrias. Una Interpretación. Valladolid, Junta de Castilla y León. Consejería de Cultura y Turismo, 2008

- "En torno a la historia social en la España Moderna: la atomización de un problema historiográfico", Ponencia dentro del Seminario Metodológico de Historia Moderna en la Universidad de Cantabria, 2012, pp 1-34.

Foucault, Michel. Dits et écrits. Gallimard, París, 1994.

- El orden del discurso. Buenos Aires, Tusquets, 2005.

Fra Molinero, Baltasar. "El negro Zaide: marginación social y textual en el Lazarillo", en Hispania. Vol. 76, N 1, Madrid, Consejo Superior de Investigaciones Científicas, 1993, pp 20-29.

Francis, Alan. Picaresca, decadencia, historia. Madrid, Gredos, 1978.

Elliot, John Huxtable. Poder y sociedad en la España de los Austrias. Barcelona, Crítica, 1982.

- La España Imperial. 1469-1716. Barcelona, Vicens Vives, 1993.

García Cárcel, Ricardo. "La identidad de los escritores del Siglo de Oro", en Stvdia Histórica. Historia Moderna. Vol. VI, Tomo II, Salamanca, Ediciones de la 
Universidad de Salamanca, 1998, pp 327-337.

García Gibert, Javier. La humanitas hispana. Sobre el humanismo literario en los Siglos de Oro. Salamanca, Ediciones Universidad de Salamanca, 2010.

García Mouton, Pilar. "Religiosidad popular en la picaresca", en AAVV, La Religiosidad popular. Tomo II: Vida y muerte: la marginación religiosa. Barcelona, Anthropos, 1989, pp 146-153.

García Oliver, Ferrán. "Elusiva cultura marginal”, en AAVV, Cultura y culturas en la historia. Salamanca, Ediciones Universidad de Salamanca, 1995, pp 19-38.

García Pardo, Manuela. "Marginados en el mundo medieval y moderno", Almería 5 a 7 de noviembre de 1998. Almería, Instituto de estudios almerienses, Diputación de Almería, 2000, pp 13-24.

García Sánchez, Miguel Ángel. "La pobreza como construcción social en el antiguo régimen", en Torre de los Lujanes. N 51, Madrid, Real Sociedad Económica Matritense de Amigos del País, 2003, pp 97-124.

García Varela, Jesús. "Factores constitutivos del discurso del marginado en la literatura del siglo de Oro", en Thesaurus. Tomo XLIX, №2, Santafé de Bogotá, Instituto Caro y Cuervo de Colombia, 1994, pp 275-292.

Geremek, Bronislaw. La piedad y la horca. Historia de la miseria y la caridad en Europa. Madrid, Alianza, 1989.

- Les marginaux parisiens aux XIV et XV siècles. Saint Amand, Flammarion, 1990.

- La estirpe de Caín. Madrid, Mondadori, 1991.

Germani, Gino. El concepto de marginalidad. Buenos Aires, Edición Nueva visión, 1973.

Gilman, Stephen. "The Death of Lazarillo de Tormes", en PMLA. Vol. LXXXI, №3, Nueva York, Modern Language Association, 1966, pp 149-166.

Giménez, Gilberto. "Materiales para una teoría de las identidades sociales". México, Instituto de Investigaciones Sociales, UNAM, 1997, mimeo.

Ginzburg, Carlo. Historia nocturna. Barcelona, Muchnik, 1991.

-El queso y los gusanos. Barcelona, Muchnik, 1994.

Goedelier, Maurice. “Acerca de las cosas que se dan, de las cosas que se venden y de las que no hay que vender ni dar sino que hay que guardar. Una reevaluación crítica del ensayo sobre el don de Marcel Mauss", en Hispania. Vol. LX/L, No 204, Madrid, Consejo Superior de Investigaciones Científicas, 2000, pp 11-26. 
Gómez Camacho, Francisco. Economía y filosofía moral: la formación del pensamiento económico europeo en la escolástica española. Madrid, Síntesis, 1998.

González de Fauve, María Estela y De Forteza, Patricia. "Reflexiones en torno al grupo marginal de los ciegos", en Fundación. N ${ }^{0}$ VIII. Buenos Aires, Fundación Para la Historia de España (Argentina), 2006-2007, pp 119-128.

González Hernandez, Juan Carlos. "Marginación y picaresca en el proceso de cambio de la sociedad tradicional", en AAVV, Homenaje a José Antonio Maravall 19111986. Valencia, Monografías del Consell de Valencia de Cultura, 1988, pp 151-165.

Gramsci, Antonio. Literatura y vida nacional. México, Juan Pablos Editor, 1975.

-Los intelectuales y la organización de la cultura. Buenos Aires, Ediciones Nueva Visión, 2006.

Green, Otis. "On the Attitude Toward the Vulgo in the Spanish Siglo de Oro", en Studies in the Renaissance. Vol. 4, Chicago, The University of Chicago Press, 1957, pp 190-200.

Guerreau-Jalabert, Anita. "Caritas y don en la sociedad medieval occidental", en Hispania. Vol. LX/1, No 204, Madrid, Consejo Superior de Investigaciones Científicas, 2000, pp 27-62.

Guha, Ranahit. Voces de la historia. Crítica, Barcelona, 2002.

Guillén, Claudio. "Sobre la soledad del pícaro", en Exemplaria. № 5, Huelva, Universidad de Huelva, 2001, pp 121-128.

Gurievich, Aaron. Las categorías de la cultura medieval. Madrid, Taurus, 1990.

Hanrahan, Thomas. "Lazarillo de Tormes: Erasmian satire or protestan reform?" en Hispania. Vol. 66, №3, Madrid, Consejo Superior de Investigaciones Científicas, 1983, pp 333-339.

Hernández Alonso, César y Sanz Alonso, Beatriz. Germanía y sociedad en los Siglos de Oro la cárcel de Sevilla. Valladolid, Universidad de Valladolid, 1999.

Herrán Martínez de San Vicente, Ainara. "El mecenazgo de los jerarcas eclesiásticos en la época de los Reyes Católicos”, en Salvador Miguel, Nicasio y Moya García, Cristina (eds.). La literatura en la época de los Reyes Católicos. Madrid, Iberoamericana Verbuert, 2008, pp 79-101.

Herrero, Javier. "Renaissance Poverty and Lazarillo's Family: The Birth of the Picaresque Genre", en PMLA. Vol. 94, No5, Nueva York, Modern Language Association, 1979, pp 876-886.

Hill, Christopher. El mundo trastornado. El ideario popular extremista en la 
Revolución Inglesa del siglo XVII. Madrid, Siglo XXI de España, 1983, pp 28-46.

Hobsbawm, Eric. Bandidos. Barcelona, Ariel, 1976.

Hollingsworth, Thomas Henry. Demografia Histórica. Cómo utilizar las fuentes de la historia para construirla. México, Fondo de Cultura Económica, 1983.

Ife, Barry W. Lectura y ficción en el Siglo de Oro: las razones de la picaresca. Barcelona, Crítica, 1992.

Imízcoz, José María. "Las redes sociales de las élites. Conceptos, fuentes y aplicaciones”, en Soria Mesa, Enrique; Bravo Caro, Juan Jesús y Delgado Barrado, José Miguel (eds.). Las élites en la época moderna: la monarquía española. Vol. I Nuevas Perspectivas, Servicio de Publicaciones de la Universidad de Córdoba, Córdoba, 2006, pp 77-111.

Isambert, François. "Religion populaire, sociologie, histoire et folklore", en Arch. Sc. Soc des Rel. No 43/2, París, EHESS, 1977, pp 161-181.

Izquierdo Benito, Ricardo. Un espacio desordenado: Toledo a fines de la Edad Media. Madrid, Universidad de Castilla, 1996.

Jaume, Fernando. "El concepto de marginalidad", en II Congreso Argentino de Antropología Social, Buenos Aires, 1986, pp 1-27.

Kamen, Henry. "Toleration and Dissent in Sixteenth-Century Spain: The Alternative Tradition", en Sixteenth Century Journal. Vol. 19, Nº1, Kirksville, The Sixteenth Century Journal, 1988, pp 3-23.

Ladero Quesada, Miguel Ángel. “Aristócratas y marginales: aspectos de la sociedad castellana en La Celestina", en Espacio, Tiempo y Forma. Serie III, Historia Medieval, No 3, Madrid, Universidad Nacional de Educación a Distancia, 1990, pp 95120.

Laslett, Peter. El mundo que hemos perdido, explorado de nuevo. Madrid, Alianza, 1987.

Lázaro Carreter, Fernando. Lazarillo de Tormes en la picaresca. Barcelona, Ariel, 1972.

Le Goff, Jacques. "Los marginados en el Occidente Medieval”, en Le Goff, Jacques. Lo maravilloso y lo cotidiano en el Occidente Medieval. Barcelona, Gedisa, 1985, Capítulo IX, pp 129-135.

- Una larga edad media. Barcelona, Paidós, 2008.

Levack, Brian. Witch Hunting in Scotland: Law, Politics, and Religion. Londres, Routledge, 2008, Capítulo 6 “Absolutism, Statebuilding, and Witchcraft”, pp 98-114. 
Lewis, Oscar. "La cultura de la pobreza", en Vendrell Ferré, Joan (comp.). Teoría social e historia. La perspectiva de la antropología social. México, Instituto Mora, 2005, pp 321-337.

Lis, Hugo y Soly, Catharina. Pobreza y capitalismo en la Europa preindustrial (1350-1850). Madrid, Akal, 1985.

López Alonso, Carmen. La pobreza en la España Medieval. Estudio histórico social. Madrid, Ministerio de Trabajo y Seguridad Social, 1986.

López Álvarez, Alejandro. "Coches, carrozas y sillas de mano en la monarquía de los Austrias entre 1600 y 1700: evolución de la legislación”, en Hispania. Vol. LXVI, № 224, Madrid, Consejo Superior de Investigaciones Científicas, 2006, pp 883-908.

López de Goicochea Zabala, Javier. "De Subventione Pauperum: Los tratados sobre la pobreza en los orígenes del Estado Moderno", en Saberes, revista de estudios jurídicos, económicos y sociales. Vol. I, Villanueva de la Cañada, Universidad Alfonso X el Sabio, 2003, pp 1-26.

Lotman, Iuri. La semiósfera. Semiótica de la cultura y del texto. Madrid, Cátedra, 1996.

Luchía, Corina. La dinámica de la propiedad comunal y las condiciones de desarrollo transicional del feudalismo al capitalismo en el área concejil de realengo castellana. Siglos XIV al XVI. Buenos Aires, Universidad de Buenos Aires, 2008, mimeo.

Mantecón Movellán, Tomás. "Sobre linajes y peleas de perros: parentelas y pendencias en la Castilla Moderna", en Chacón Giménez, Francisco, Hernández Franco, Juan y García González, Francisco (eds.). Familia y organización social en Europa y América, siglos $X V$ - $X X$. Murcia, Ediciones de la Universidad de Murcia, 2007, pp 151183.

Maravall, José Antonio. "Pobres y pobreza del medioevo a la primera modernidad", en Cuadernos hispanoamericanos. Madrid, Agencia Española de Cooperación Internacional para el Desarrollo, 1981, pp 189-242.

-Utopía y reformismo en la España de los Austrias. Madrid, Siglo XXI de España, 1982.

- Estado Moderno y mentalidad social. Madrid, Alianza, 1986.

- La literatura picaresca desde la historia social. Madrid, Taurus, 1987.

- La cultura del Barroco. Barcelona, Ariel, 1990.

- Estudios de historia del pensamiento español. Madrid, Ediciones Cultura 
Hispánica, 2001.

- "La época del renacimiento", en Rico, Francisco (dir.). Historia y crítica de la literatura española. Tomo II. Siglos de Oro: Renacimiento, edición a cargo de López Estrada, Francisco. Barcelona, Crítica, 1980-2004, pp 44-53.

Marco Fabre, Miguel. "Consideraciones en torno al concepto de exclusión”, en Acciones e investigaciones sociales. No 11, Zaragoza, Universidad de Zaragoza, 2000, pp 10-21.

Marcos Martín, Alberto. "Iglesia y beneficencia en Castilla durante el antiguo régimen”, en Torre de los Lujanes. N ${ }^{\circ}$ 51, Madrid, Real Sociedad Económica Matritense de Amigos del País, 2003, pp 87-96.

- "Movilidad social ascendente y movilidad social descendente en la Castilla Moderna”, en Gómez González, Inés y López-Guadalupe Muñoz, Miguel Luis (coord.), La movilidad social en la España del Antiguo Régimen. Granada, Comares, 2007, pp $19-47$.

Martin, Hervé. Nouvelle Clio, L'histoire et ses problèmes. Mentalités Médiévales. XIe - Xve siècles. París, Presses Universitaires de France, 1996, Capítulo XIII "Les mentalités au négatif".

Martínez García, Luis. "Pobres, pobreza y asistencia en la Edad Media Hispana. Balances y perspectivas", en Medievalismo. № 18, Murcia, Ediciones de la Universidad de Murcia, 2008, pp 67-107.

Marx, Karl. El capital. México, Fondo de Cultura Económica, 1984.

Mauss, Marcel. Ensayo sobre el don. Buenos Aires, Katz, 2009.

Mendoza Garrido, Juan Miguel. Delincuencia y represión en la Castilla Bajomedieval (Los territorios castellano-manchegos). Granada, Casa de Castilla-La Mancha, 1999.

Menjot, Denis. "Prostitutas y rufianes en las ciudades castellanas a fines de la Edad Media", en Temas medievales. N4, Buenos Aires, Consejo Nacional de Investigaciones Científicas y Técnicas, 1994, pp 189-204.

Meyer-Minnemann, Klaus. "El género de la novela picaresca", en MeyerMinnemann, Klaus y Schlickers, Sabine (eds.). La novela picaresca. Concepto genérico y evolución del género (siglos XVI y XVII). Madrid, Iberoamericana Verbuert, 2008, pp $13-40$.

Meyer-Minnemann, Klaus y Schlickers, Sabine. “Es el Lazarillo de Tormes una novela picaresca? Genericidad y evolución del género en las versiones, continuaciones y 
transformaciones de La vida de Lazarillo de Tormes desde las ediciones de 1554 hasta la refundición de 1620 por Juan de Luna", en Meyer-Minnemann, Klaus y Schlickers, Sabine (eds.). La novela picaresca. Concepto genérico y evolución del género (siglos XVI y XVII). Madrid, Iberoamericana Verbuert, 2008, pp 41-75.

Mitre Fernández, Emilio. Fronterizos de Clio (marginados disidentes y desplazados en la Edad Media). Granada, Universidad de Granada, 2003.

Molho, Maurice. "El pícaro de nuevo", en MLN. Hispanic Issue. Vol. 100, No2, Baltimore, The John Hopkins University Press, 1985, pp 199-222.

Mollat, Michel. Pobres y miserables en la Edad Media. México. Fondo de Cultura Económica, 1988.

Monreal Requena, Pilar. "¿Sirve para algo el concepto de cultura de la pobreza?", en Revista de Occidente. № 215, Madrid, Fundación Ortega y Gasset, 1999, pp 75-88.

Moore, Robert Ian. La formación de una sociedad represora. Crítica, Barcelona, 1989.

Moretti, Franco. Atlas de la novela europea. 1800-1900. México, Siglo XXI, 1999.

Mullet, Michael. La cultura popular en la Baja Edad Media. Barcelona, Crítica, 1990.

Nalle, Sara. "Inquisitors, Priests, and the people During the Catholic Reformation in Spain", en The Sixteenth Century Journal. Vol. 18, N4, Kirksville, The Sixteenth Century Journal, 1987, pp 557-587.

- "Literacy and culture in early modern Castile", en Past and Present. № 125, Oxford, Oxford University Press, 1989, pp 65-96.

Nathan Bravo, Elia. “Ordenes mendicantes: integración de elementos marginales a la Iglesia", en Gónzález, Aurelio, y Walde Moheno, Lilian von der (eds.). Edad Media: marginalidad y oficialidad. México, Universidad Nacional Autónoma de México, 1998, pp 183-205.

Niemeyer, Katharina. ““... El ser de un pícaro el sujeto deste libro’. La Primera parte de Guzmán de Alfarache (Madrid, 1599)", en Meyer-Minnemann, Klaus y Schlickers, Sabine (eds.). La novela picaresca. Concepto genérico y evolución del género (siglos XVI y XVII). Madrid, Iberoamericana Verbuert, 2008, pp 77-116. 
- “'¿Quién creerá que no he de decir más mentiras que letras?' El libro de entretenimiento de la Pícara Justina, de Francisco López de Úbeda (Medina del Campo, 1605), en Meyer-Minnemann, Klaus y Schlickers, Sabine (eds.). La novela picaresca. Concepto genérico y evolución del género (siglos XVI y XVII). Madrid, Iberoamericana Verbuert, 2008, pp 193-221.

-Niemeyer, Katharina y Meyer-Minnemann, Klaus. "Cervantes y la picaresca", en Meyer-Minnemann, Klaus y Schlickers, Sabine (eds.). La novela picaresca. Concepto genérico y evolución del género (siglos XVI y XVII). Madrid, Iberoamericana Verbuert, 2008, op cit, p 223-262.

Nun, José. Marginalidad y exclusión social. Buenos Aires, Fondo de Cultura Económica, 2003.

Núñez Bespalova, Marina. "El mecenazgo nobiliario en la literatura de la época de los Reyes Católicos", en Salvador Miguel, Nicasio y Moya García, Cristina (eds.). La literatura en la época de los Reyes Católicos. Madrid, Iberoamericana Verbuert, 2008, pp 167-188.

Parker, Alexander. Los picaros en la literatura. La novela picaresca en España y en Europa (1599- 1753). Madrid, Gredos, 1975.

Parsons, Talcott. El sistema social. Madrid, Ediciones de la Revista de Occidente, 1966.

Paugam, Serge. "La exclusión en la sociedad francesa: Usos sociales y aporte de la investigación", en Sociedad. N ${ }^{\circ}$ 16, Buenos Aires, Facultad de Ciencias Sociales (UBA), 2000, pp 29-48.

Peirce, Charles Sanders. Escritos lógicos. Madrid, Alianza, 1968.

Pelorson, Jean-Marc. La frustración de un Imperio (1476-1714), Madrid, Labor, 1982.

Peña Díaz, Manuel. "Libro e inquisición: conflictos y actitudes sociales en Barcelona en el siglo XVI", en Historia Social. No 14, Valencia, Universidad Nacional de Educación a Distancia, 1992, pp 85-95.

Pérez, Joseph. Historia, literatura, sociedad. Granada, Editorial Universidad de Granada, 2010.

Perry, Mary Elizabeth. "Deviant Insiders: Legalized Prostitutes and Consciousness of Women in Early Modern Seville", en Comparative Studies in Society and History. Vol. 27, № 1, Cambridge, Cambridge University Press, 1985, pp 138-158. 
Peters, Michaela. "Estructuras de poder y percepción de la autoridad en la novela picaresca del Siglo de Oro", en Arellano, Ignacio; Strosetski, Christoph y Williamson, Edwin (eds.). Autoridad y poder en el Siglo de Oro. Madrid, Iberoamericana Verbuert, 2009, pp 101-116.

Pike, Ruth. Aristócratas y comerciantes. La sociedad sevillana en el siglo XVI. Barcelona, Ariel, 1978.

Piñero, Pedro M., "Lazarillo de Tormes", en Rico, Francisco (ed.). Historia y crítica de la literatura española. Tomo 2. Siglos de Oro: Renacimiento, edición a cargo de López Estrada, Francisco. Barcelona, Crítica, 1980-2004, pp 340-351.

Po-Chia Hsia, Ronnie. Social Discipline in the Reformation: Central Europe, 1550-1750. Londres, Routledge, 1992, Capítulo 8 "Confessionalism and people”, pp 143-175.

Price, R. M.. "On Religious Parody in the Buscón”, en MLN. Hispanic Issue. Vol. 86, N², Baltimore, The John Hopkins University Press, 1971, pp 273-279.

Propp, Vladimir. Morfología del cuento. Madrid, Editorial fundamentos, 2006.

Rey, Alfonso. "La novela picaresca y el narrador fidedigno", en Hispanic Review. Reichenberg Memorial Issue. Vol. 47, $\mathrm{N}^{\mathrm{o}} 1$, Filadelfia, University of Pennsylvania Press, 1979, pp 55-75.

Rey Hazas, Antonio. Deslindes de la novela picaresca. Málaga, Servicio de Publicaciones de la Universidad de Málaga, 2003.

Rial García, Serrana. "Solas y pobres: las mujeres de las ciudades de Galicia ante la marginalidad y la prostitución”, en Durán Villa, Francisco y Santos Solla, Xavier Manuel, (eds.). Semata. No 16, Marginados y Excluidos. Un enfoque interdisciplinar. Santiago de Compostela, Universidad de Santiago de Compostela, 2005, pp 301-331.

Ricci, Giovanni. Povertà, vergogna, superbia. Il declassati fra Medioevo e Età moderna. Bolonia, Il Mulino, 1996.

Rico, Francisco. "Estructuras y reflejos de estructuras en el Guzmán de Alfarache", en MLN. Hispanic Issue. Vol. 82, N², Baltimore, The John Hopkins University Press, 1967, pp 171-184.

-La novela picaresca y el punto de vista. Barcelona, Seix Barral, 1970.

Robert, Philippe y Lévy, René. "Historia y cuestión penal”, en Historia Social. No 6, Valencia, Universidad Nacional de Educación a Distancia, 1990, pp 47-88.

Roca Fabregat, Pere. “¿Quién trabajaba en las masías? Criados y criadas en la agricultura catalana (1670-1870)", en Historia Agraria. № 35, Murcia, Universidad de 
Murcia, 2005, pp 49-92.

Rodríguez Bernal, Núria. "Marginados de hoy y de ayer en la obra de Antonio Domínguez Ortiz", en Historia Social. No 47, Valencia, Universidad Nacional de Educación a Distancia, 2003, pp 113-125.

Rodríguez Giles, Ana Inés. "La representación y penalización del vagabundeo en Castilla en los siglos XIV - XVI. Análisis de las Cortes", en IACOBVS. Revista de estudios jacobeos y medievales. № 27, Sahagún (León), Centro de estudios del camino de Santiago, 2010, pp 95-117.

-"La estigmatización de los mendigos en el siglo de Oro. Análisis de Guzmán de Alfarache (1599)", en Anales de Historia Antigua, Medieval y Moderna. № 43, Bsuenos Aires, Universidad de Buenos Aires, 2010, pp 191-210.

-"Problemas en torno a la definición de la marginalidad", en Trabajos y Comunicaciones (2da época). № 37, La Plata, Universidad Nacional de La Plata, 2012, pp 203-220.

Rodríguez Mansilla, Fernando. "Émulo de Guzmán de Alfarache y tan agudo y gracioso como Don Quijote. El lugar del Buscón en la picaresca", en Etiópicas. № 1 , Huelva, Universidad de Huelva, 2004-2005, pp 144-160.

Rodríguez Molina, José. “La pobreza como marginación y delito”, en Gazeta de antropología. No 19, Granada, Universidad de Granada, 2003, pp 1-38.

Rodríguez Sánchez, Ángel. "Pobreza y marginación social en la España Moderna", en Norba. Revista de Arte, Geografia e Historia. №2, Badajoz, Universidad de Extremadura, 1981, pp 233-244.

-“La historia de la violencia: espacios y formas en los siglos XVI y XVII", en Barros, Carlos (ed.) Historia a debate. Tomo II: Retorno del sujeto. Santiago de Compostela, Historia a Debate, 1995, pp 117-127.

Rosanvallon, Pierre. La consagración del ciudadano: historia del sufragio universal en Francia. México, Instituto Mora, 1999.

Rozas, Juan Manuel. "'Siglo de Oro': Historia y mito", en Rico, Francisco (ed.), Historia y crítica de la literatura española. Tomo 3. Siglos de Oro: Barroco, edición a cargo de Wardropper, Bruce. Crítica, Barcelona, 1980-2004, pp 64-68.

Ruiz Gálvez, Ángel María. “Guardar las apariencias. Formas de representación de los poderes locales en el medio rural cordobés en la Época Moderna", en Historia y Genealogía. N I, Córdoba, Universidad de Córdoba, 2011, pp 167-188.

Ruiz Ibáñez, José Javier y Vincent, Bernard. Los siglos XVI y XVII. Política y 
sociedad. Madrid, Síntesis, 2007.

Sabat de Rivers, Georgina. "La moral que Lázaro nos propone", en $M L N$. Hispanic Issue. Vol. 95, №2, Baltimore, Johns Hopkins University Press, 1980, pp 233251.

Salillas, Rafael. El delincuente español. El lenguaje: (estudio filológico, psicológico y sociológico): con dos vocabularios jergales. Alicante, Biblioteca Virtual Miguel de Cervantes, 2000. Edición digital basada en la edición de Madrid, Librería de Victoriano Suárez, 1896. http://www.cervantesvirtual.com/obra-visor/el-delincuenteespanol-el-lenguaje-estudio-filologico-psicologico-y-sociologico-con-dos-vocabulariosjergales--0/html/

Salvia, Agustín. "Consideraciones sobre la transición a la modernidad, la exclusión social y la marginalidad económica”, en Salvia, Agustín y Chávez Molina, Eduardo (comp.). Sombras de una marginalidad fragmentada. Aproximaciones a la metamorfosis de los sectores populares de la Argentina. Buenos Aires, Miño Dávila, 2007, pp 25-42.

Salomon, Noël. "Algunos problemas de sociología de las literaturas de lengua española" en Botrel, Jean François y Salaün, Serge. (coord.). Creación y público en la literatura española. Barcelona, Castalia, 1974, pp 15-39.

- La vida rural castellana en tiempos de Felipe II. Barcelona, Ariel, 1982.

Samuel, Raphael. Historia popular y teoría socialista. Barcelona, Crítica, 1984.

Sánchez Lora, José Luis. "Barroco y simulación: Cultura de ojos y apariencias, desengaño de ojos y apariencias, en AAVV. Cultura y culturas en la historia. Salamanca, Ediciones Universidad de Salamanca, 1995, pp 75-86.

Sánchez Ortega, María Helena. "La 'pecadora' como disidente social”, en Carrillo, Santiago, (et al.). Disidentes, heterodoxos y marginados en la Historia. Salamanca, Ediciones Universidad de Salamanca, 1998, pp 145-179.

Santana Pérez, Juan Manuel. "Sobre el encierro de los pobres en los tiempos modernos", en Espacio, Tiempo y Forma. Serie IV, Historia moderna, Tomo 9, Madrid, Universidad Nacional de Educación a Distancia, 1996, pp 339-357.

- "Castigo y control de los marginales", en AAVV. Fontanta. Historia i projecte social. Reconeixement a una trajectoria. Crítica, Barcelona, 2004, Vol. I, pp 315-325.

- "Enfermedad y marginalidad en Canarias durante el siglo XVIII y primer tercio del XIX”, en Boletín Millares Carlo. № 28, Las Palmas de Gran Canaria, Centro Asociado Universidad Nacional de Educación a Distancia, 2009. 
Santolaria Sierra, Félix. “¿Dar limosna o enseñar un oficio? El debate sobre la caridad en el Siglo de Oro", en Torre de los Lujanes. No 51, Madrid, Real Sociedad Económica Matritense de Amigos del País, 2003, pp 31-54.

Saraví, Gonzalo. "Pobres y pobrezas de ayer y de hoy. Hacia un enfoque centrado en la acumulación de desventajas”, en Cuestiones de Sociología. № 2, La Plata, Ediciones al Margen, 2004, pp 151-173.

-"Nuevas realidades y nuevos enfoques: exclusión social en América Latina", En Saraví, Gonzalo (ed.). De la pobreza a la exclusión: continuidades y rupturas de la cuestión social en América Latina, México, CIESAS, 2007, Capítulo 1, pp 19-52.

Sartre, Jean Paul y Beauvoir, Simone de (coord.). ¿Para qué sirve la literatura? Buenos Aires, Proteo, 1970.

Saussure, Ferdinand de. Curso de Lingüistica General. Madrid, Alianza, 1983.

- Saussure y los fundamentos de la lingüística. Buenos Aires, Centro Editor de América Latina, 1985. Introducción de José Sazbón.

Schlickers, Sabine. "Segunda parte de la vida del pícaro Guzmán de Alfarache. Compuesta por Mateo Luján de Sayavedra, natural vecino de Sevilla (Valencia, 1602"), en Meyer-Minnemann, Klaus y Schlickers, Sabine (eds.). La novela picaresca. Concepto genérico y evolución del género (siglos XVI y XVII). Madrid, Iberoamericana Verbuert, 2008, pp 117-144.

- "Segunda parte de la vida de Guzmán de Alfarache. Atalaya de la vida humana, por Mateo Alemán, su verdadero autor (Lisboa 1604), en Meyer-Minnemann, Klaus y Schlickers, Sabine (eds.). La novela picaresca. Concepto genérico y evolución del género (siglos XVI y XVII). Madrid, Iberoamericana Verbuert, 2008, pp 145-175.

Schmitt, Jean Claude. "'Religion populaire' et culture folklorique”, en Annales. Histoire, Sciences Sociales. Vol. 37, No 5, París, EHESS, 1976, pp 941-953.

- "L'histoire des marginaux", en Le Goff, Jacques (dir.). La nouvelle histoire. París, CEPL, 1978, pp 344-369.

- "Les traditions folkloriques dans la culture mèdiévale", en Archives de Sciences Scoailes des Religions. No 52/1, París, EHESS, 1981, pp 5-20.

Scholberg, Kenneth. "Minorities in medieval castilian literature", en Hispania. Vol. 37, No2, Madrid, Consejo Superior de Investigaciones Científicas, 1954, pp 203209.

Seccombe, Wally. A millenium of family change. San Francisco, Verso, 1995.

Sentaurens, Jean. "Les comediens espagnols au siecle d'or: une 'societe 
fermee'?", en AAVV. Les sociétés fermées dans le monde iberique (XVIe-XVIIIe siècles). Définitions et problématique. París, C.N.R.S, 1986, pp 237-255.

Serrano González, Antonio. Como lobo entre ovejas. Soberanos y marginados en Bodin, Shakespeare, Vives. Madrid, Centro de Estudios Constitucionales, 1992.

Soria Mesa, Enrique. "La imagen del poder. Un acercamiento a las prácticas de visualización del poder en la España moderna", en Historia y Genealogía. № I, Córdoba, Universidad de Córdoba, 2011, pp 5-10.

Spadaccini, Nicholas. "Estebanillo González and the Nature of Picaresque 'lives"', en Comparative Literature. Vol. 30, N³, Eugene, University of Oregon, 1978, pp. 209-222.

Susín Betrán, Raúl. "Los discursos sobre la pobreza. Siglos XVI-XVIII”, en Brocar. No 24, La Rioja, Universidad de La Rioja, 2000, pp 105-135.

Thompson, Edward. Costumbres en común. Barcelona, Crítica, 1995.

Thompson, Irving. "Cortes y ciudades: tipología de los procuradores (extracción social, representatividad)", en AAVV. Las Cortes de Castilla y León en la Edad Moderna. Valladolid, Junta de Castilla y León, 1989, pp 191-248.

Toivo, Raisa María. "The Witch-craze as holocaust: the Rise of Persecuting Societies" en Barry, Johnathan y Owen, Davies (eds.). Padgrave Advances in Witchcraft Historiography. Hampshire, Palgrave Macmillan, 2007, pp 90-107.

Torres Corominas, Eduardo. "Gonzalo Pérez, Francisco de los Cobos y El Lazarillo de Tormes", en Libros de la Corte. №4, Año 4, Madrid, Universidad Autónoma de Madrid, 2012, pp 74-104.

Valbuena y Prat, Ángel. La novela picaresca española. Madrid, Aguilar, 1956.

Valdeón Baruque, Julio. "Problemática para un estudio de los pobres y de la pobreza en Castilla a fines de la edad media”, en Actas de las Primeras Jornadas lusoespañolas de historia medieval. Lisboa, Instituto de Alta Cultura, 1973, Tomo II, pp 879-918.

Valentine, Charles. La cultura de la pobreza. Buenos Aires, Amorrortu, 1972. Introducción "Usos y abusos de la idea de cultura", pp 13-28 y Capítulo 5 "El estudio antropológico de las sociedades complejas. Métodos y perspectivas para una mejor comprensión", pp 107-146.

Van Dijk, Teun. Ideología. Una aproximación multidisciplinaria. Barcelona, Gedisa, 1999.

Vaquero Iglesias, Julio Antonio. "Mentalidades e ideologías”, en Barros, Carlos 
(ed.). Historia a Debate II: Retorno del sujeto. Santiago de Compostela, Historia a debate, 1995, pp 25-35.

Velázquez Martínez, Matías. Desigualdad, indigencia y marginación social en la España Ilustrada. Murcia, Universidad de Murcia, 1991.

Vian Herrero, Ana. "El mundo social y La Celestina", en Cuadernos hispanoamericanos. $\quad \mathrm{N}^{\mathrm{o}}$ 477-78, Madrid, Agencia Española de Cooperación Internacional para el Desarrollo, 1990, pp 261-274.

Vilar, Pierre. Crecimiento y desarrollo. Barcelona, Ariel, 1983.

Villalba Pérez, Enrique. "Delincuencia, marginación y control del orden público en el Madrid del siglo XVII", en Morán, Miguel y García, Bernardo. El Madrid de Velázquez y Calderón. Villa y Corte en el siglo XVII. Madrid, Ayuntamiento de Madrid, 2000, pp 169-180.

Villamía, Luis. "Sobre la historiografía del género picaresco: pliegues modernos de la literatura del pobre", en Hipertexto. $\mathrm{N}^{\mathrm{o}} 13$, Texas, The University of Texas-Pan American: Department of Modern Languages and Literature, invierno 2011, pp 42-58.

Villarreal, Juan. La exclusión social. Buenos Aires, Editorial Norma, 1996.

Vincent, Bernard. "Ciudades y marginalidad”, en Fortea Pérez, José Ignacio (ed.). Imágenes de la diversidad. El mundo urbano en la Corona de Castilla (Siglos XVI-XVIII). Cantabria, Universidad de Cantabria, 1997, pp 347-361.

- "La sociedad española en la época del Quijote", en Feros, Antonio y Gelabert, Juan (eds.). España en tiempos del Quijote. Madrid, Taurus, 2004, Capítulo 9, pp 279408.

Volóshinov, Valentín Nikoláievich. El marxismo y la filosofía del lenguaje. Buenos Aires, Ediciones Godot, 2009.

Wachtel, Nathan. La foi du souvenir. Labyrinthes marranes. París, Éditions du Seuil, 2001.

Wacquant, Loïc. Los condenados de la ciudad. Guetos, periferia y Estado. Avellaneda, Siglo XXI, 2007.

-Parias urbanos. Marginalidad en la ciudad a comienzos del milenio. Buenos Aires, Manantial, 2001.

White, Hayden. El contenido de la forma. Barcelona, Paidós, 1992.

Whittle, Jane. The development of agrarian capitalism. Land and labour in Norfolk (1440-1580), Oxford, Oxford University Press, 2000, Capítulo 5, pp 225-275.

Williams, Raymond. Marxismo y literatura. Barcelona, Península, 1980. 
Woolf Stuart. Los pobres en la Europa moderna. Barcelona, Crítica, 1989.

-"Pauperismo en el mundo moderno. Estamento, clase y pobreza urbana", en Historia Social. Nº, Valencia, Universidad Nacional de Educación a Distancia, 1990, pp 89-100.

Yundráin, Domingo. "El renacimiento de Lázaro", en Hispania. Vol. 75, №3, Madrid, Consejo Superior de Investigaciones Científicas, 1992, pp 474-483.

Zafra, Ketty. "El mundo de la prostitución en La hija de Celestina: el castigo del desorden", en Actas del 40 Congreso de la ACH. Winnipeg, Universidad de Manitoba, 2004, http://fis.ucalgary.ca/ACH/Congreso_abierto/2004/Ketty_Zafra.htm

Zecevic, Patricia. 'La pícara Justina a la luz de la 'teoría' de parler-femme de Leuce Irigaray", en Actas del XII Congreso de la Asociación Internacional de Hispanistas, Birmingham, 1995, pp 282-291.

Zumthor, Paul. La mesure du monde. París, Seuil, 1993.

Fuentes:

Alcalá Yañez y Rivera, Jerónimo de. "El donado hablador Alonso", en Valbuena y Prat, Ángel (ed.). La novela picaresca española. Madrid, Aguilar, 1956, pp 11981339.

Alemán, Mateo. Guzmán de Alfarache. Madrid, Cátedra, 2006. Edición a cargo de José María Micó.

Anónimo. La vida de Lazarillo de Tormes. Madrid, Espasa-Calpe, 1969. Edición a cargo de Julio Cejador y Frauca.

Baró Pazos, Juan y Pérez Bustamante, Rogelio (eds.). El gobierno y la administración de los pueblos de Cantabria. Tomo I Liébana. Santander, Institución Cultural de Cantabria, 1988.

Canto de la Fuente, Carlos del y Carbajo Martín, Victoriano Antonio (eds.). Ordenanzas municipales de Zamora. Siglos XV y XVI. Zamora, Diputación de Zamora, 1991.

Carreira, Antonio y Cid, Jesús Antonio (eds.). Vida y hechos de Estebanillo González. Barcelona, Cátedra, 1990.

Castillo Solórzano, Alonso de. "La niña de los embustes, Teresa de Manzanares (natural de Madrid)", en Valbuena y Prat, Ángel (ed.). La novela picaresca española. Madrid, Aguilar, 1956, pp 1342-1424. 
- Aventuras del bachiller Trapaza. Madrid, Cátedra, 1986. Edición a cargo de Jacques Joset.

-“La garduña de Sevilla", en Valbuena y Prat, Ángel (ed.). La novela picaresca española. Madrid, Aguilar, 1956, pp 1527-1618.

Cervantes Saavedra, Miguel de. Novelas ejemplares. Madrid, Castalia, 1985.

Congreso de los Diputados. Actas de las Cortes de Castilla. Madrid, Establecimiento Tipográfico "Sucesores de Rivadaneyra”, 1887, Tomos XII y XIII.

Covarrubias, Sebastián de. Tesoro de la lengua castellana o española. Barcelona, Horta, 1943.

Enríquez, Antonio. El siglo pitagórico y Vida de Don Gregorio Guadaña. Madrid, Cátedra, 1991. Edición a cargo de Teresa de Santos.

Espinel, Vicente. "Vida de Marcos de Obregón”, en Valbuena y Prat, Ángel (ed.). La novela picaresca española. Madrid, Aguilar, 1956, pp 921-1087.

Franco Silva, Alfonso. "Pedraza de la Sierra. El proceso de formación de unas Ordenanzas de Villa y Tierra en los siglos XIV y XV", en Historia. Instituciones. Documentos. No 18, Sevilla, Universidad de Sevilla, 1991.

García, Carlos. "La desordenada codicia de los bienes ajenos", en Valbuena y Prat, Ángel (ed.). La novela picaresca española. Madrid, Aguilar, 1956, pp 1156-1195.

García Fitz, Francisco y Kirschberg Schenck Débora. "Las ordenanzas del Concejo de Sevilla de 1492", en Historia. Instituciones. Documentos N ${ }^{\circ} 18$, Sevilla, Universidad de Sevilla, 1991.

Giginta, Miguel de. Tratado de remedio de pobres. Barcelona, Ariel, 2000. Edición a cargo de Félix Santolaria Sierra.

Liñán y Verdugo, Antonio. Guía y avisos de forasteros que vienen a la Corte. Madrid, Editorial Nacional, 1980.

López de Úbeda, Francisco. La pícara Justina. Madrid, Cátedra, 1991. Edición a cargo de José Miguel Oltra.

Luna, Juan de. Segunda parte del Lazarillo. Madrid, Cátedra, 1988. Edición a cargo de Pedro Piñero.

Pérez de Herrera, Cristóbal. Amparo de pobres. Madrid, Espasa-Calpe, 1975. Edición a cargo de Michel Cavillac.

Quevedo, Francisco de. La vida del Buscón llamado Don Pablos. Salamanca, Acta Salmanticensia, 1965. Edición a cargo de Fernando Lázaro Carreter.

Real Academia de la Historia. Cortes de los Antiguos Reinos de León y de 
Castilla. Madrid, Establecimiento Tipográfico "Sucesores de Rivadaneyra", 18631903.

Rojas, Fernando de. La Celestina. Barcelona, Atalaya, 1995. Edición a cargo de Dorothy Severin.

Rosell, Cayetano (ed.). Crónicas de los reyes de Castilla. Desde Alfonso el Sabio, hasta los Católicos Don Fernando y Doña Isabel. Madrid, Manuel Rivadaneyra, 1878, Tomo tercero.

Salas Barbadillo, Alonso J. de. La hija de Celestina. Madrid, Cátedra, 2008. Edición a cargo de Enrique García Santo Tomás.

Santa Rosa de Viterbo, Joaquim de. Elucidario das palavras, termos e frases que em Portugal antegamente se usaram e que hoje regularmente se ignoram. Lisboa, Livraria Civilização, 1966.

Santolaria Sierra Félix (ed.). El gran debate sobre los pobres en el siglo XVI. Domingo de Soto y Juan de Robles 1545. Barcelona, Ariel, 2003.

Velez de Guevara, Luis. "El diablo cojuelo", en Valbuena y Prat, Ángel (ed.). La novela picaresca española. Madrid, Aguilar, 1956, pp 1638-1675.

Viana Razola, Julián (ed.). Novísima Recopilación de las Leyes de España. Madrid, Julián Viana Razola, 1805-1829.

Zayas, María de. "Castigo de la miseria”, en Valbuena y Prat, Ángel (ed.). La novela picaresca española. Madrid, Aguilar, 1956, pp 1620-1635.

Manuscrito: Archivo General de Simancas. CCA, DIV, 43, DOC. 10. 